\title{
COMMUNITY PARTICIPATION IN URBAN DESIGN \\ A Masterplan for Shelly Bay
}





\section{COMMUNITY PARTICIPATION IN URBAN DESIGN}

A Masterplan for Shelly Bay

Jay Tony Short

A 120 - point thesis submitted to the Victoria University of Wellington in partial fulfilment of the requirements for the degree of Masters of Architecture (Professional)

Victoria University of Wellington

School of Architecture

2019 


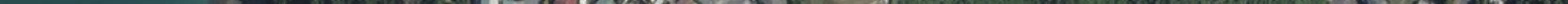




\section{Acknowledgements}

A big thank you goes out to my friends and family who have supported me over the past five years. Special mentions go to my mum (Debra), dad (Tony) and brother (Sam) who constantly push me to be my best and are always there for me if I need anything.

To everyone who battled through the long nights with me over the years - cheers - I couldn't have done it without you.

To my supervisor, Regan, thank you for your guidance over the past year. Your wise words of advice always settled my worries when I thought I had bitten off more than I could chew.

To everyone who shared their vision for Shelly Bay - this is for you. I hope it is something you can all be proud of.

Finally, this research would not have been possible without the support from Mary and everyone from MBID; as well as, Vanessa and the team at the Chocolate Fish Cafe. Your willingness to support my research went far beyond what I could have ever hoped for - and for that, I am grateful. 
"AS MUCH AS I APPRECIATED THE SALARY I EARNED AT TRADITIONAL DESIGN FIRMS, THE WORK ITSELF WAS NOT VERY SATISFYING. IT TOOK ME TO INTERESTING PLACES AND PUT ME IN TOUCH WITH IMPORTANT PEOPLE, BUT IT HAD LITTLE RELEVANCE TO MY OWN PARTICULAR DESIGN INTEREST - THAT OF CREATING BETIER PRODUCTS AND ENVIRONMENTS FOR CONSUMERS THROUGHOUT THEIR LIFE SPAN."

- PATRICIA MOORE (1984)

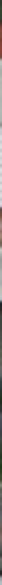




\section{Abstract}

This research examines the role of community participation in urban design. It looks at developing more efficient methods of facilitating participation so that it can become more feasible for developers and designers.

A literature review and analysis of case studies found that community participation in urban design, in the developed world, is almost non-existent. In impoverished countries, however, it is more common - recognising that the commercial and political pressures of Western societies make participation in urban design difficult to justify.

The research then moves to its major case study - Shelly Bay. This area is facing a large development which has been highly protested by members of the local and wider community. One of the more significant reasons for the protest was the lack of transparency in the development planning stages.

So why does the public not have a say on the future of Shelly Bay? This thesis researches ways which developers, architects and urban designers can involve local community groups in the design of the environments they live, work and play in.
The research consists of two stages; Stage One uses traditional methods of consultation (surveying and interviewing) while Stage Two uses less conventional methods - presented as a workbook. The results from these participatory experiments have been used to produce a community masterplan proposal for Shelly Bay - 'Shelly Bay 2030'.

This research concludes by stressing the importance of communicating and working with those who are most affected by the decisions made by urban developers. It recognises the challenges of reaching a level of collaboration but believes that the traditional surveying and interviewing methods should be standard in urban design. It also finds that a tool as simple as a workbook can be extremely effective in gathering public feedback.

Shelly Bay 2030, is strikingly different to the current development plans - showing the disconnect between the community and the developer. This research argues that if they were able to work together, it would be possible to create something which benefits everyone involved. 


\section{Table of Contents}

V Acknowledgements

VII Abstract

VIII Table of Contents

\section{Chapter 1: Introduction}

2 Introduction

$4 \quad$ Research Scope \& Questions

5 Thesis Structure

7 The Process

9 Research Methodology

\section{Chapter 2: Literature Review \& Case Studies}

12 Literature Review

What is Participatory Design?

Participatory Design - A Brief History

The Importance of Community Participation in Placemaking

Creating Community Participation

Levels of Participation

$21 \quad$ Case Studies

Participatory Chinatown

Asili

Community Arts Centers

\section{Chapter 3: Major Case Study - Shelly Bay}

28

\section{Background}

Port Nicholson Block Settlement Trust

The Wellington Company Ltd.

The Deal

Housing Accords and Special Housing Areas Act 2013

Enterprise Miramar Peninsula Inc.

Mau Whenua

The Legal Battles

33 The Timeline

35 Te Motu Kairangi - Miramar Peninsula

37 The 1999 Shelly Bay Design Guide

41 The Taikuru Proposal 
Chapter 4: Stage One - Shelly Bay, Your Way

48 Introduction

49 The Survey

51 Data Interpretation

54 The Interview Process

55 The Interviews

Susan Macaulay - Public Opinion

Mary Anderson - Public Opinion + MBID/EMPI Member

Tim Alexander - Public Opinion + Weta Digital

Other Consultations

63 Conclusion

\section{Chapter 5: Stage One - Concept Design}

66 Background

67 Concept One - Residential

69 Concept Two - Tourism \& Recreation

71 Concept Three - Community Hub

\section{Chapter 6: Stage Two - Shelly Bay, Our Way}

74 Background

75 Consultation Context

77 'Shelly Bay, Our Way' Booklet

Identification of Objectives \&

Components

Masterplan Gameboard

Written Vision \& Identification of

Design Principles

Drawn Vision

83 Consultation Results \& Analysis

Objectives \& Components Identified

Masterplan Gameboards

Design Principles

Vision Statements

93 'Shelly Bay, Our Way' Conclusion
Chapter 7: Stage Two - Shelly Bay 2030

96 Background

97 Data Weighting \& Interpretation

99 The Brief - Shelly Bay 2030

Project Scope

Project Objectives

Design Objectives \& Components

101 Design Process

112 Final Masterplan - Shelly Bay 2030

North Bay

Wharf Area

South Bay

\section{Chapter 8: Reflection}

128 Reflection of Participatory Process

129 Reflection of Participatory Design Tools

131 Reflection of Final Design Outcome

135 Research Findings \& Applications

137 A Final Word

\section{List of Figures}

139 List of Figures

\section{References}

143 References

\section{Appendices}

145 Appendix A - Survey Results

155 Appendix B - Interview Guide

157 Appendix C - Workbook 


\section{THE HYPOTHESIS.}

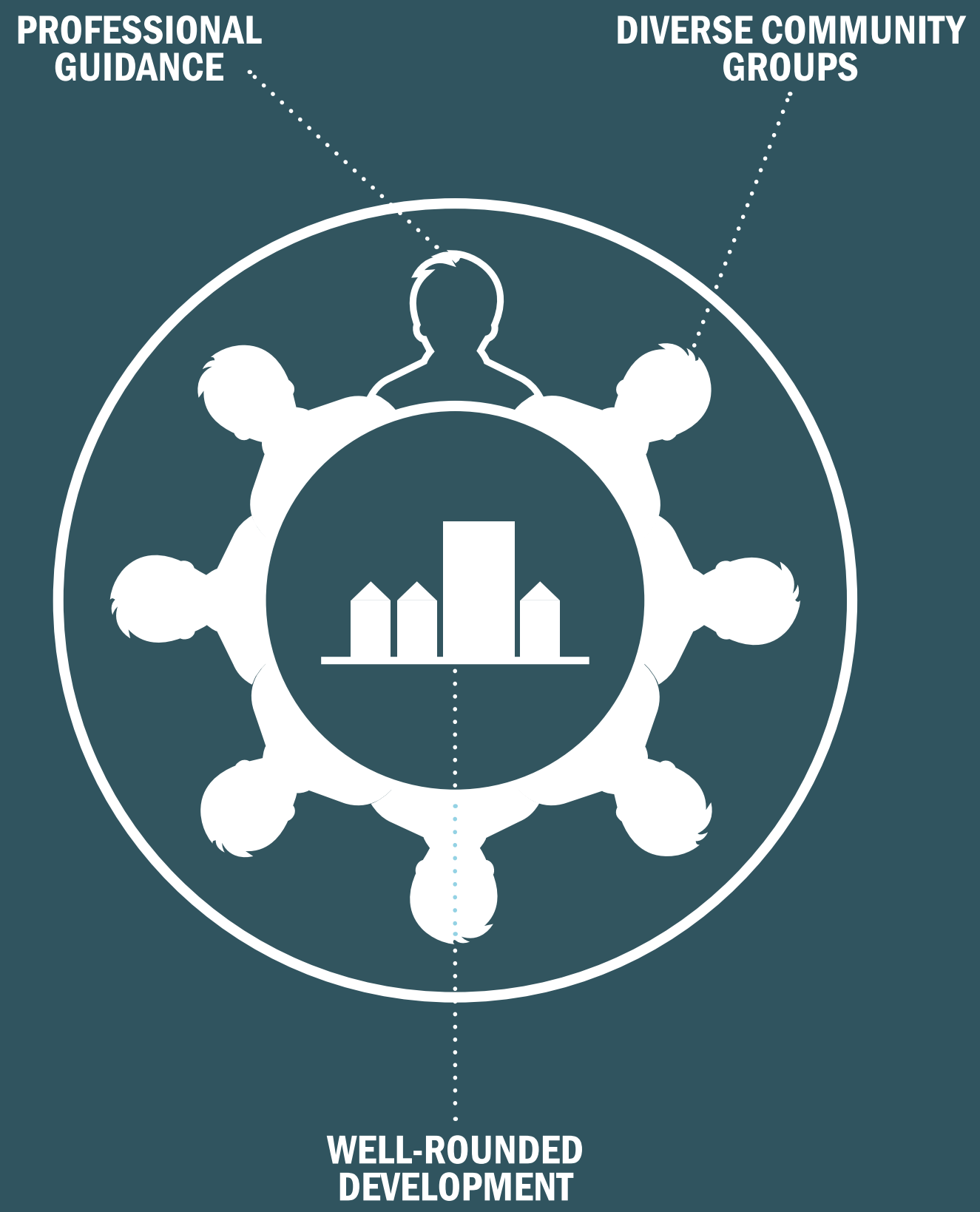




\section{Chapter 1: Introduction}

\section{Introduction}

Traditionally, urban areas expanded incrementally as population increased; this is often referred to as organic growth, sprawl or development. In other cases, financial powerhouses buy significant areas of land and develop them at larger scales. As with most business decisions, these developments are typically directed towards generating financial profits - with the wishes of local communities being an afterthought.

This research aims to acknowledge the importance of those most affected by these developments - the local communities. Community participation in the planning of urban areas is typically non-existent or at most, limited. This lack of consultation comes from implications of longer project timelines and limited resources where a developer's principal goal is to make a profit. This leads to a lack of transparency and a lack of say from the public.

An example of this is Shelly Bay in Wellington, New Zealand. Located on the western coastline of the Miramar Peninsula, Shelly Bay was developed during World War I and II by the New Zealand Defence Force. Since then, it has been left relatively untouched. A private developer (The Wellington Company) has plans to carry out a $\$ 500$ million development which will take 13 years to complete. The development plans to overhaul the existing site into a residential and commercial area which has been described as a "second Oriental Bay" by locals who have expressed their concerns around the plans (Stuff, 2018). The Wellington City Council had initially accepted this proposal, but public outcry sent the ordeal to the High Court and Court of Appeal where the Resource Consent was, eventually, overturned.

This research takes a step back from the role of a designer and instead assumes that of a facilitator. It will look at ways which the community can be actively involved in the master-planning of these projects. It will implement methods of consultation and interact with groups and individuals so that they can communicate their visions for Shelly Bay. The data extracted from these exercises will be studied, refined and pieced together into a final community masterplan.

While it may be too late to stop the Shelly Bay project from getting underway - despite the successful legal protests; the 13-year project timeline gives hope that the developer can be influenced to make changes to what is planned. However, that is only if they listen to what the community has to say. This research attempts to give the community their voice. 


\section{Research Scope \& Questions}

As the literature reviews and case studies will show (Chapter 2), there is vast room for improvement in participatory design. Current methods, which reach a level of collaboration, are taxing on the timelines and costs of both the project and the participants. Therefore, there is the opportunity to improve the efficiency of these interactions - making participatory design consultations easier (and more feasible).

This leads to the primary research question:

\section{"How can architects and urban planners involve disenfranchised community groups more effectively in the design of their own urban environments?"}

'More effectively' refers to how participatory design can become more feasible in urban-scaled design. What methods can be employed which make the process easier for both the designers and the participants?

The scope of this research limits itself to the participatory design tools used for Shelly Bay as a case study. However, it will make assumptions about how the techniques used here can be applied to other design situations. In terms of participant selection, the consultation process will be open to anyone with a vested interest in Shelly Bay - this could include, but is not limited to, residents of Wellington's Eastern Suburbs, Taranaki Whānui, local business owners and recreational users of the area.

Once the participatory process is complete, the design output will look to reconcile the information into a community masterplan for Shelly Bay. The scope here limits the design to solely reflect the gathered data. The design should not be significantly influenced by the designer. It will not consider construction costs or possible returns on investment.

This design output answers the secondary question of the research: "If it were up to the community, what would a future Shelly Bay look like?" The purpose of this is to develop a community masterplan which can be presented to key stakeholders in Shelly Bay. Additionally, it will be used to highlight the differences between what the community wants and what has currently been proposed. 


\section{Thesis Structure}

This thesis begins with literature reviews and case studies which look at why community participation in architecture and urban design is important. It will then explore previously employed methods of facilitating participatory design. This information will be used to define experiments and activities when shifting into the participatory stages of the research.

From here the research scope will narrow, to look specifically at Shelly Bay. It includes a detailed case study of The Wellington Company's development proposal 'Taikuru'. This case study will also detail the major stakeholders in Shelly Bay and analyse the protest against the development.

Chapter Four marks the beginning of Stage One. Here, a survey is produced and distributed to community groups who have a close connection to Shelly Bay (this will include Taranaki Whānui). The purpose of this survey is to gain an understanding of what the community want for Shelly Bay's future. As well as this, it will ask for their views on the current development plans and query them to identify if they were consulted about the development at any stage. During this, individuals and stakeholders will be approached for more in-depth interviews.

Chapter Five takes the information gathered from the initial participatory process and reconciles it into three conceptual masterplans for Shelly Bay. These masterplans will be used in Stage Two of the consultation process.
Stage Two designs a subsequent participatory interaction based on the findings of Stage One - this interaction will be the major milestone for the research. The consultation will inform the public on the current future for Shelly Bay and supply them with the means to communicate their own visions. This will focus on less-conventional methods of facilitating participation in design.

The work produced from this interaction will be collated and interpreted. This data will then be used, in Chapter Seven, as the basis for developing an alternative, community-based masterplan, 'Shelly Bay 2030'.

Following this, there will be a reflection to analyse the effectiveness of the participatory processes. Alongside this, it will compare the community masterplan to the Taikuru proposal, highlighting similarities and differences. Concluding statements and research findings will follow these reflections. 


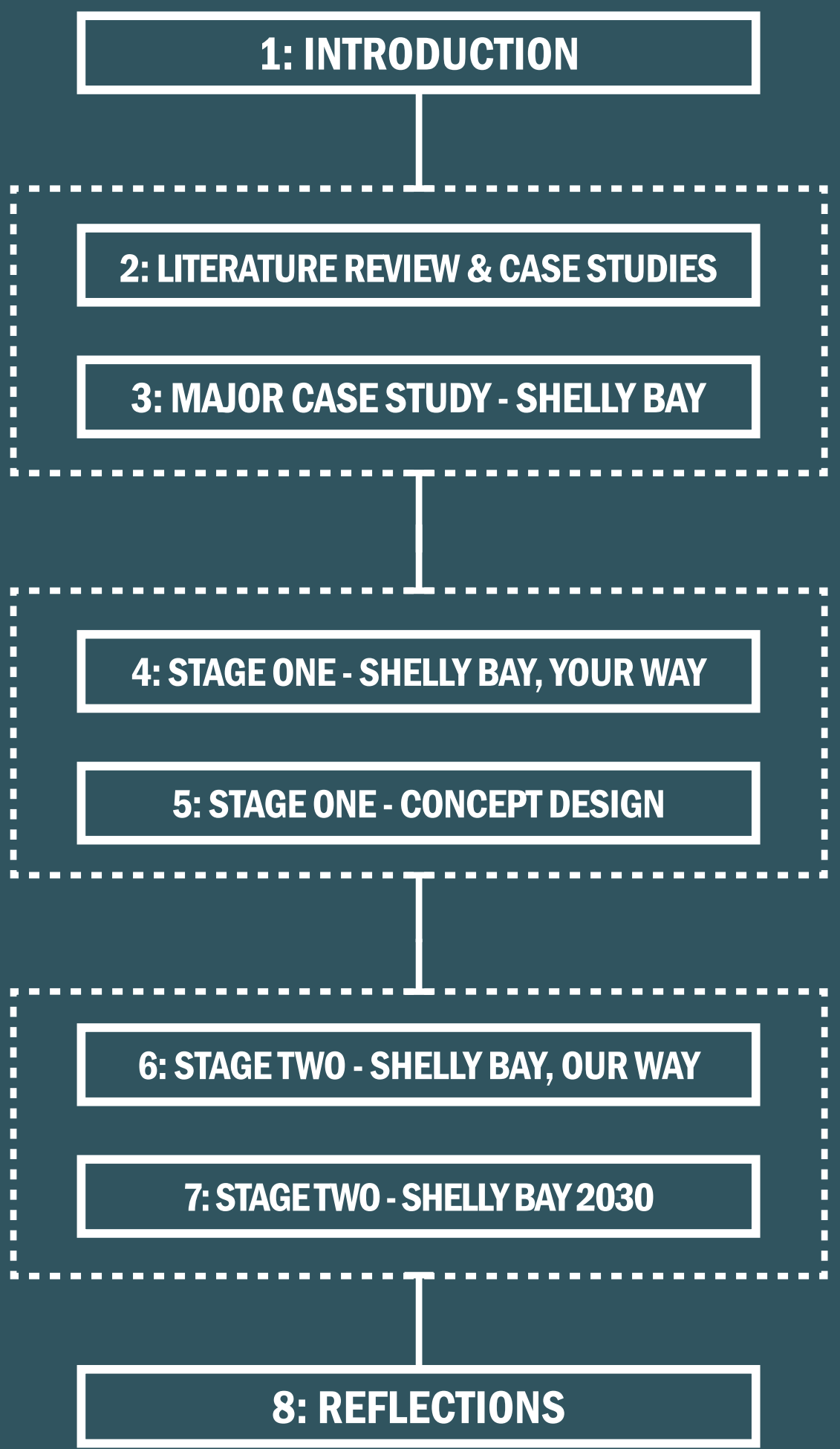




\section{THE PROCESS.}

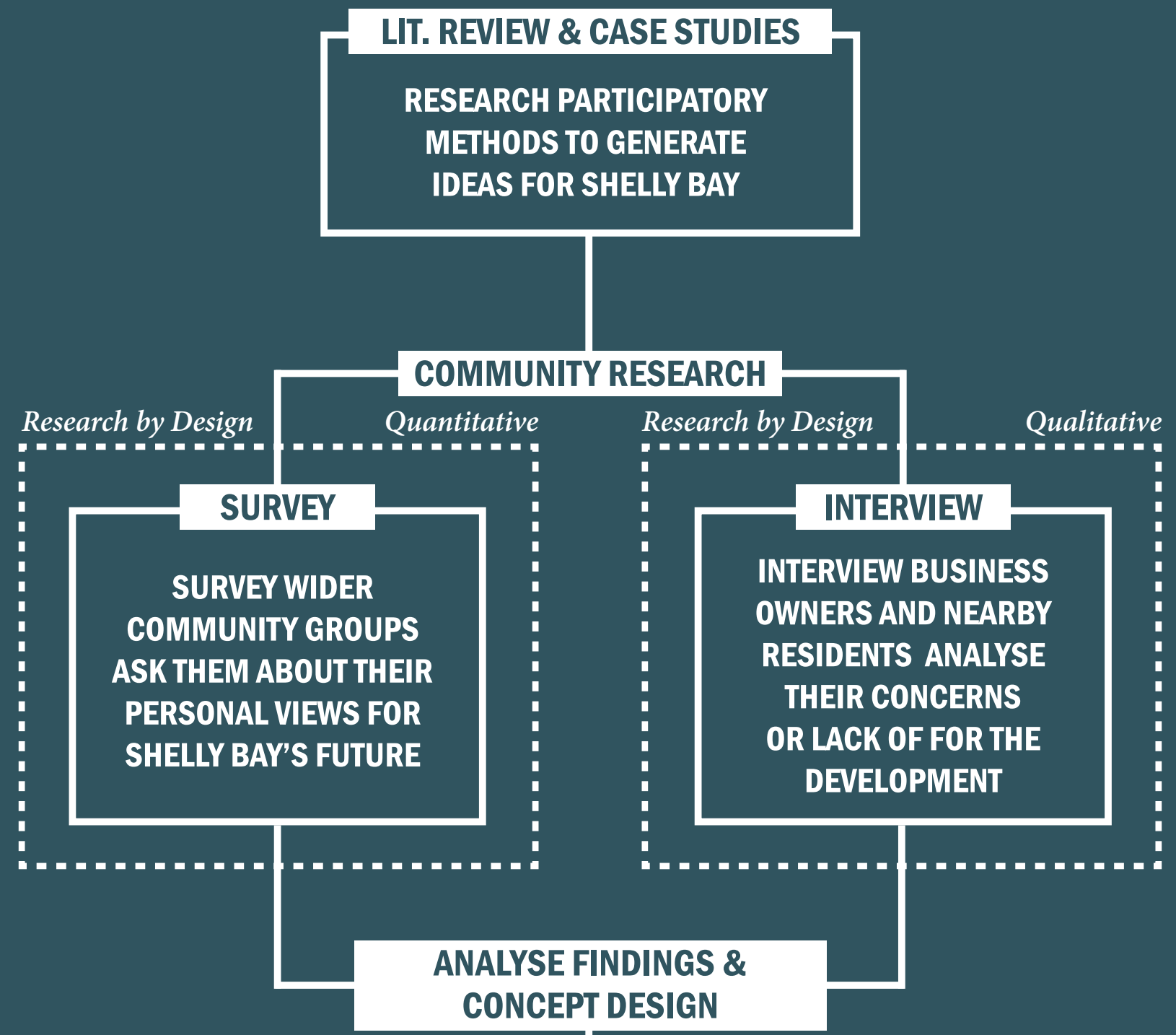


Quantitative \& Qualitative

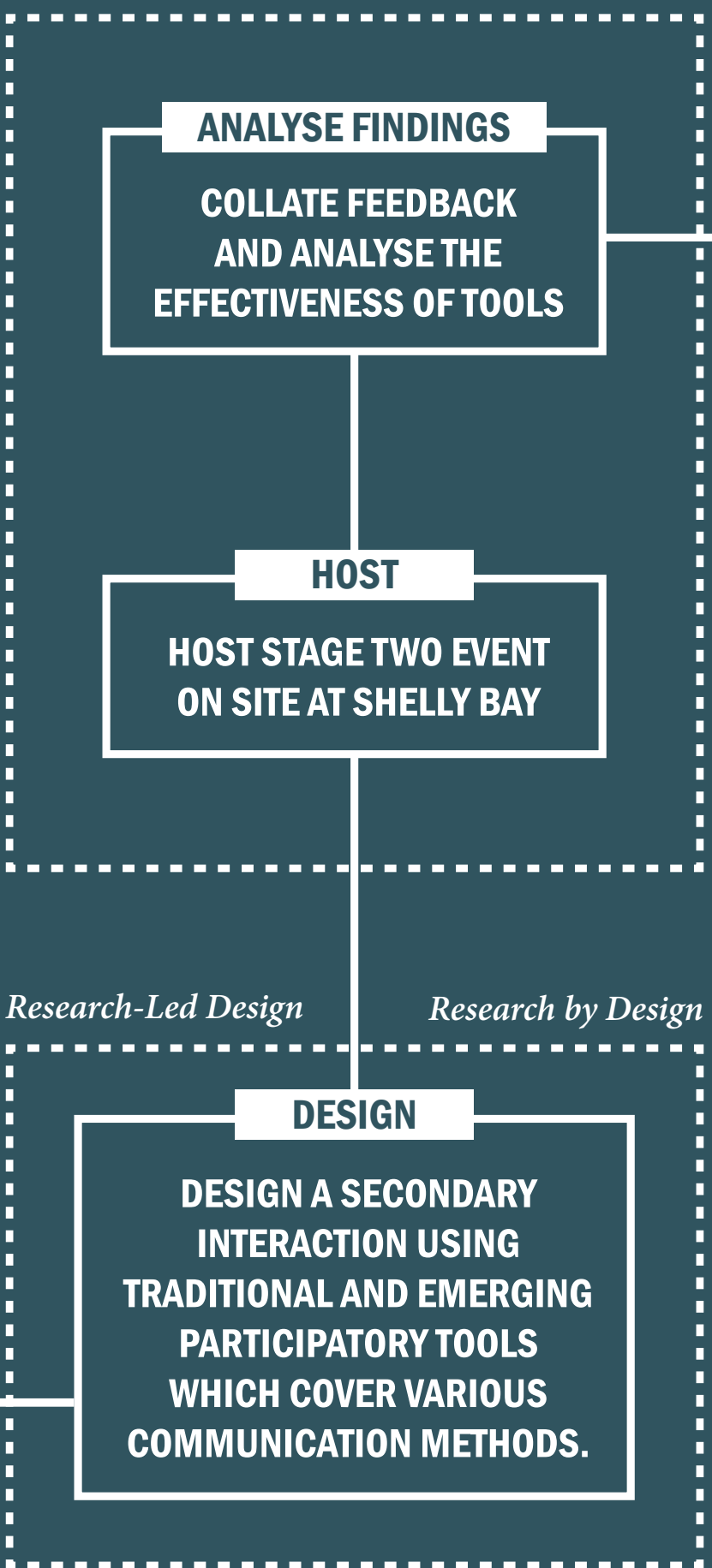

Research-Led Design

\section{DESIGN}

FROM THE RESEARCH ANALYSIS GENERATE A MASTERPLAN BASED OFF OF THE COMMUNITY'S WANTS AND NEEDS.

\section{REFLECT}

REFLECT ON THE EFFECTIVENESS OF THE PARTICIPATORY TOOLS + REFLECT ON THE MASTERPLAN BASED ON THE COMMUNITY FEEDBACK.

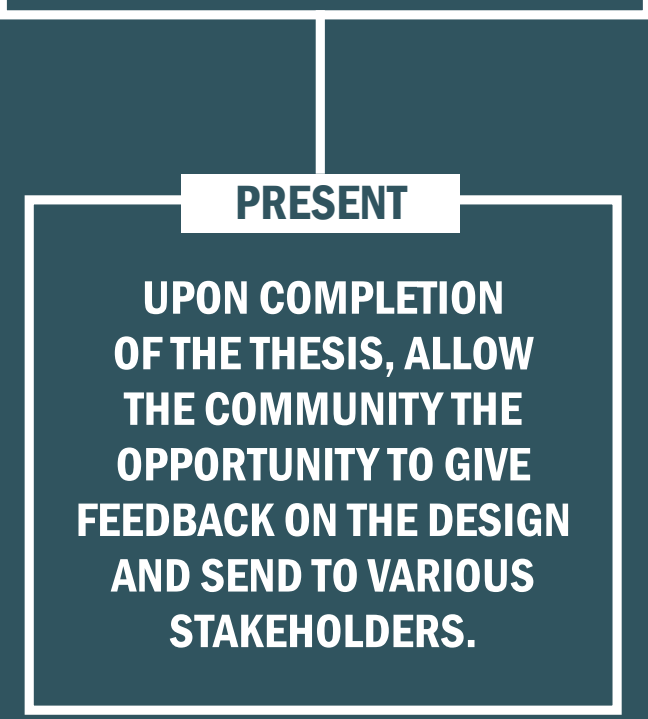




\section{Research Methodology}

There are three primary methodologies used throughout this research (highlighted in Fig 1.03), including: literature review, case study research and research by design. These are used to influence the research-led design, which is defined as, "a process of design that heavily relies on hard data and research, either qualitative or quantitative, to inform design decisions, rather than relying solely on the expertise and experience of the designer" (Enginess, 2015).

A 'research by design methodology' is defined as being, "any kind of inquiry in which design is a substantial part of the research process... the design process forms a pathway through which new insights, knowledge, practices and products come into being. " (Hauberg, 2011). In Stage One, the research by design looks at the design of the traditional survey and interviews as tools. While Stage Two takes a new approach. Through recognising the need for efficiency in collaborative participation - new tools are developed.

Fig 1.04 gives a chronological order of the research methodologies implemented in the Shelly Bay case study.

These include:

1) Literature review research - to develop an understanding of the importance of participatory design, its history and possible methods.
2) Case study research - to analyse projects which have used different methods of participatory design. To gain an understanding of what techniques are effective or ineffective and which should be applied given the context of the project.

3) Major case study - introduce Shelly Bay, the Taikuru development and identify the research target group.

4) Research by Design - design surveys and interviews to gather quantitative and qualitative data in regards to the effectiveness of traditional consultation tools and the public opinion on the future of Shelly Bay.

5) Research-led Design and Research by Design - develop concepts for Shelly Bay based on feedback and design the 'Shelly Bay, Our Way' workbook, based on the literature and case studies analysis.

6) Gather quantitative and qualitative data through the 'Shelly Bay, Our Way' workbook, in regards to the effectiveness of the workbook as a more efficient participatory tool; and, the public opinion on the future of Shelly Bay.

7) Research-led design - convert the quantitative and qualitative data into a community masterplan. Analyse where the tools were successful and where there were gaps in their use. 


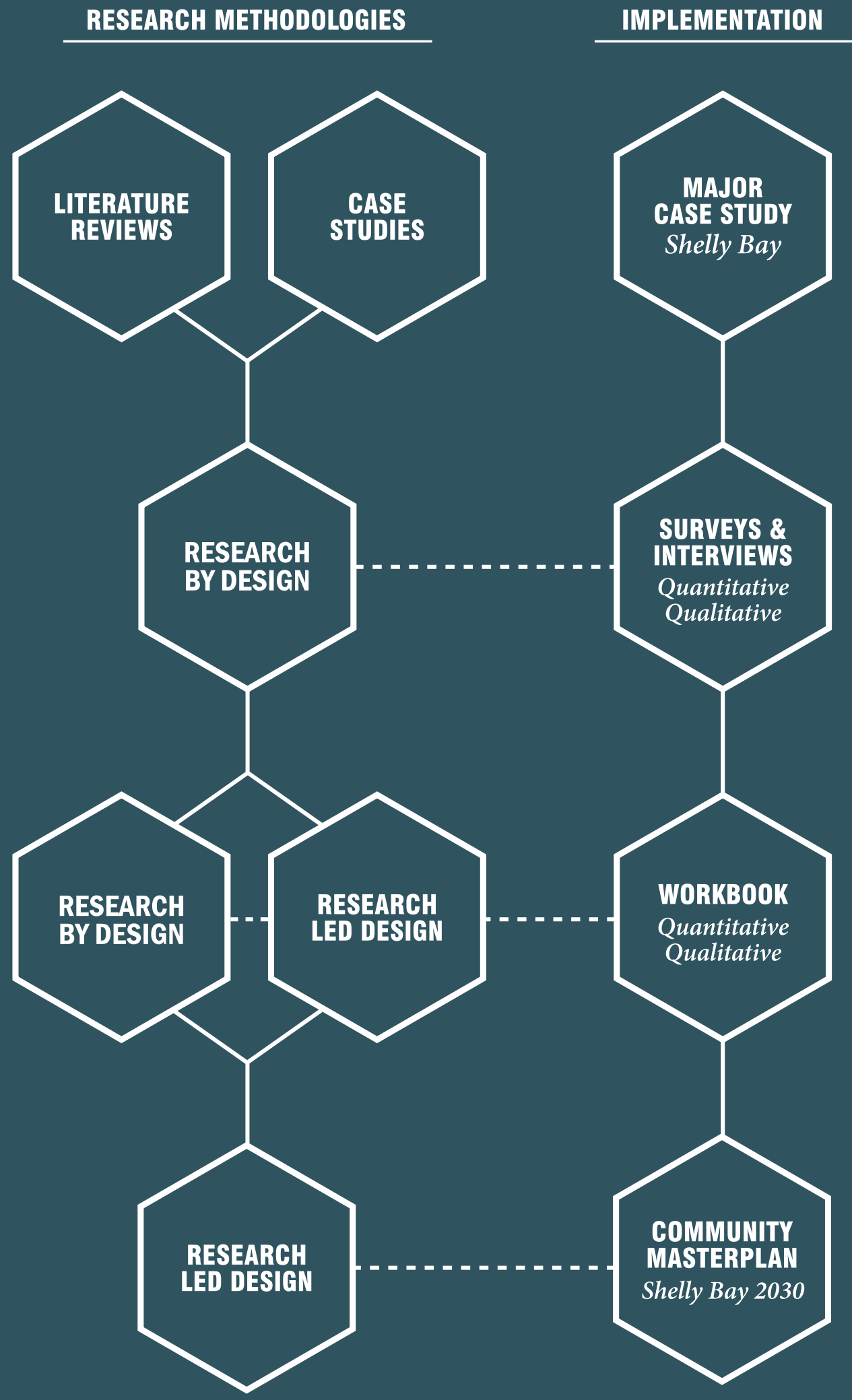




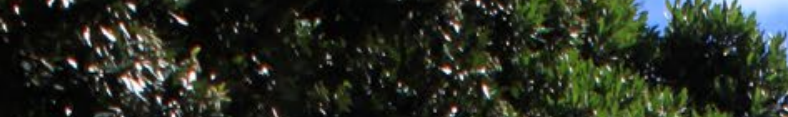

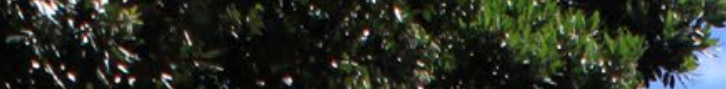

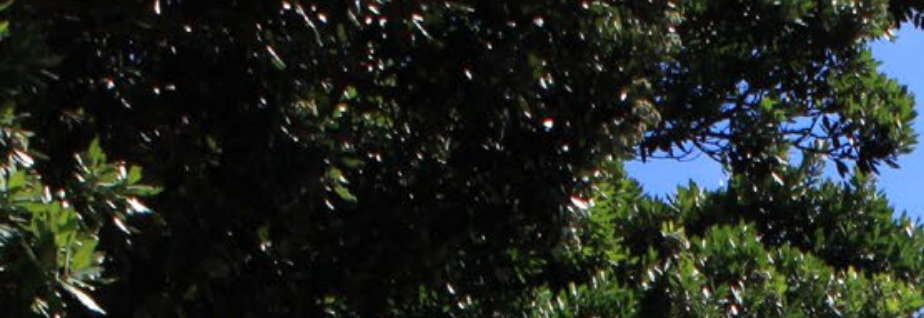

4 20

4 (3)

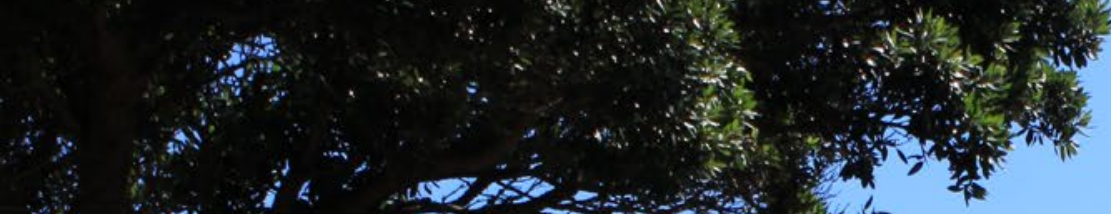

$3 \frac{1}{3}+\frac{1}{4}$

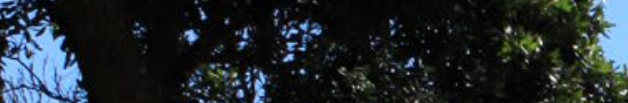

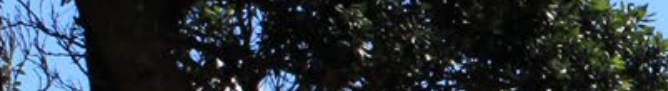

a 10

13 का (1)

and

(1)

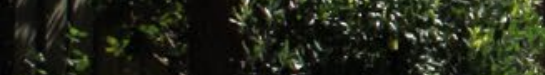

a

(3)

$x_{x}+2 x+m$

15. 


\title{
Chapter 2: Literature Review \& Case Studies
}

\section{Literature Review}

\author{
What is Participatory Design?
}

The paper, 'Design Participation Tactics: Redefining User Participation in Design' by Yanki Lee proposes the idea that, "Design Participation is about the interaction between the designer and user" (Lee, 2006). She defines design participation within the scope of the designer and the user through Stringer's derivative, "both words are ambiguous... Design can refer either to the design, in the sense of a plan for a product, or to the process of designing. Participation can mean having a piece of something in common with others - sharing the cake; or doing something in common with others - playing in a game of football" (Stringer, 1971). Stringer attempts to simplify the complications of participatory design by identifying, describing and developing a new understanding. Stringer also acknowledges that design is just as much about the end result as it is the process followed.

Participatory design brings together the knowledge base of designers, stakeholders, researchers and end-users to ensure a design is developed which meets the needs and wants of its intended user base (Anic, 2015). This collaboration is adaptable to all forms of design and provides the basis for which this thesis is founded upon. Taking this definition one step further this research looks explicitly at 'community participation' which is described as, "people involving themselves, to a greater or lesser degree, in organisations indirectly or directly concerned with the decisionmaking about, and implementation of, development"(Roodt, 1996).

Participatory design in the built environment has existed since early human history and was critical in the development of villages and settlements. This participation was eventually lost as architects and planners directed the future cities. It was not until more recently, in the mid-1960s, that an increased sense of social responsibility of architects and planners took root, when a new feeling of community consciousness prevailed over many low-income urban neighbourhoods (Sanoff, 1978).

Jeremy Till notes that it is not possible for participation and architecture to exist simultaneously if architecture is constrained to its traditional conceptual roots - the 'Vitruvian diet'. "The issue therefore becomes not to dismiss normative architectural knowledge, and the values on which it is based, out of hand, but to see them as part of a much broader, socially oriented mix: both participation and architecture" (Till, 2010). By realising that architecture has developed as a socially orientated profession from artistic roots, we recognise that participation is, in fact, a core component of creating socially acceptable architecture.

The purpose of participatory design is one based around a broader sense of function - thus aesthetics are a secondary consideration. As Till puts it; "The classic participatory schemes... would never win architectural beauty contests but positively resist the siren calls of the traditional norms of beauty and tectonic delight" (2010). Till acknowledges that participatory architecture will not win awards for beauty as it instead invests its time in generating an architecture which the community can thrive in. This back-seating of aesthetics is one reason why participatory architecture is often ignored in the field. 
'Participation', as a design technique, can be traced back to Plato's teachings in 380BC through his concepts of freedom of speech, assembly, voting and equal representation (Sanoff, 2008). These principles extend to participation on every level, for any project - not specific to the built environment. Sam Hickey and Giles Mohan recognise this in their article, 'Towards Participation as Transformation: Critical Themes and Challenges' - "Participation has a longer and more varied genealogy in development thinking and practice than is usually acknowledged, and had been periodically regenerated around new schools of thought, institutional agendas and changing political circumstances" (Hickey \& Mohan, 2004).

'Participation', as we see it today, originated from a point of politics - emerging from the call for democratic governance. The 1970's saw participation emerge from the realms of Information Technologies where it, "strove to enable workers to have more influence on the introduction of computer systems in the workplace" (Sanoff, 2008). Simultaneously, we begin to see a revival of participation in the built environment through the establishment of self-help housing in developing countries which exhibit a 'bottom-up' design philosophy (Mullins, 2010).

Participation in the built environment took hold as a reaction to the traditional 'top-down' design approach which had been prominent before, and during, the Modernist era. Post-Modernism exhibited a resurgence in architecture which listened and reacted to the people it served, during the 1980s. Here, design was less focused on aesthetic appeal, with more attention being paid to the function of architecture.
The majority of today's literature looks at case studies of Participatory Rural Appraisal (PRA's) which took root from the 1990s. The purpose of the PRA's are to "enable local communities to conduct their own analysis and plan to take action" (Chambers, 1992). The Appraisal contains several methods and techniques which act to empower the local populations to direct the future of their communities. The methods include tools such as focus groups, mapping, modelling and interviewing. The PRA has been developed continuously over the past three decades by organisations such as IDEO.org; however, project precedents remain almost entirely in the developing world - perhaps the commercial and political pressures of developed societies have hindered its crossover.

Today, the idea of a 'bottom-up' participatory design approach, in Western society, struggles to take hold. Land is primarily privately owned, making it difficult to justify the idea that those who develop it should listen to those whom it may affect. Those who do listen, however, do not leave it up to the public to direct the project. They begin with a traditional top-down design approach - employing the services of an architect or designer and then consult the community from here to a lesser or greater extent (Hickey \& Mohan, 2004). The question being asked now is, what level of participation is enough? How much is too much? This thesis aims to explore these questions at an urban scale. 


\section{PARTICIPATORY APPROACH}

Period of increased political participation in

North America.

Poor in developing countries begin to be considered as having something to offer development.

-Self-help housing begins to be seen more as solution than problem.

- Key figure: John Turner

'Populist' participation in development by

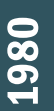

NGOs, World Bank, UN etc.

- Empower people

- Capture indigenous knowledge

- Monitor, evaluate

Rapid spread of PRA in work by NGOs etc.

(Chambers, 1997)

Wider main-streaming. 'Participatory-ornot' juxtaposition of post-modern period redundant, more blurred. 'Participatory governance' emerges (H\&M, 2004).

- Scale up methods

- State-civic partnerships

-Decentralisation

\section{ARCHITECTURAL HISTORY}

Widespread top-down development of modernist housing blocks in UK and US.

Little end-user involvement

Demolition of Pruitt Igoe (72'-76') touted as the death of modern architecture.

Post-modern period.

Responding to exclusionary Modernism.

General 're-humanising' of design process.

Recent rise of architect as enabler, serving more than just a select few.

- 'Community architects' South-East Asia in 1990s

- Architecture for Humanity formed in 1999

- 'Design like you give a damn'

- 'Design for the other 90\%' 


\section{The Importance of Community Participation in Placemaking}

Looking at the importance of participatory design; Yanki Lee refers primarily to the 1971 'Design Participation' international conference, "this conference was the first time to define 'Design Participation' as a specific field and bring 'everyman' into the design field" (Lee, 2006). The keynote speakers aimed to bring to light the importance of user participation, in various design applications, and to establish a community dedicated to pushing the idea of participation. The editor of the conference's proceedings stressed that, "there is certainly a need for new approaches to design if we are to arrest the escalating problems of the man-made world and citizen participation in decision making could possibly provide a necessary reorientation" (Cross, 1972).

Traditional architecture focuses largely on aesthetic and functional values; they are centred around making buildings which work for a select person or group of people. A flaw of conventional architecture is that it often alienates those who are secondarily affected by it - the wider public and communities. Paul Jenkins addresses this in his book 'Architecture, Participation and Society'; "Buildings should look good, function soundly, and also provide appropriate spaces. However, beyond this, they are an extremely important part of a larger whole - physically and culturally - in their impact on the local and wider built environment" (Jenkins \& Leslie, 2010).
Architecture is often self-absorbed in its goal to satisfy its function as an individual without consideration that it is, in fact, a part of a system - a neighbourhood, a community, a city.

Acknowledging architecture as a small piece of a larger puzzle, and realising that developments impact a wider community - it can be suggested that community participation in architecture should not only be encouraged, it should become a design standard. "Interest in user needs or user participation is not rooted in romanticism about human involvement but rather in the recognition that users have a particular expertise different than, but equally important to, that of the designer"(Sanoff, 1978). By bringing in public opinion, Sanoff believes that architecture can be developed to a higher standard than what is possible from a sole designer's standpoint. This is because they can draw upon the knowledge and expertise of those who live and thrive in the environments in question.

By involving the public in architecture and urban planning, this can not only improve the successfulness of the design outcome but also improve community morale and relations. "Public awareness must be approached through public participation. The reward for participation is power. The people will join together if it is clear that change can and will occur" (Sanoff, 1978). 
By gifting communities the opportunity to make a difference in their local built environment, Sanoff argues that this gives them a sense of power and thus unites them over a common goal. People will be more inclined to look after the eventual outcome if they are involved in its initial planning - leading to closer, tidier and safer communities.

So why is it that participatory architecture is still an anomaly in the profession? This comes down to the complexity it brings to projects and the increased pressure on resources (time and money). "Participation, as a nuanced mode of engagement, has in the past been treated as a form of intrusion into the idealised values of architectural culture, something that brings unwanted noise to an already complex process. Typically, it is at best tolerated, at worst played down, as much as is allowed. However, such tokenism in participation is increasingly unacceptable" (Till, 2010). In most cases, these difficulties make it almost impossible for clients and designers to justify putting in the effort to involve communities in the design process. However, in cases where entire communities are being shaped and the urban fabric altered (as is happening in Shelly Bay), it is not possible to develop an outcome which reflects the needs and wishes of the community without involving them from the early stages.
Jenkins furthers Till's argument of the emerging importance of participatory architecture adding that; "In parallel to these challenges [which participatory architecture brings] to the discipline and profession, there are increasingly important challenges and opportunities for architecture to serve rapidly urbanising societies, and this is beginning to be raised in architectural discourse" (2010). These opportunities are what make participatory design stand out from the architectural status quo. They give designers the ability to create something which has a significant impact on the local and wider environment while uniting communities. This is the beauty of participatory design and something which is sorely missed in most urban developments. 
Facilitating community participation is a difficult task, no matter how big or small the design project. This is because communities are primarily non-design orientated. "In order to regain a human concern for environmental quality, more attention should be directed towards methods of participation without the encumbrances of technological obstacles. Currently, employed methods of user participation disenfranchise the user because the methods of communication have not changed to accommodate a nondesign oriented population" (Sanoff, 1978). Thus in order to hold successful collaborations, the host must ensure that the methods implemented are appropriate for an audience who is not typically involved in a field of design. Henry Sanoff believes that this can be best achieved by developing existing methods of participation rather than inventing new, overly technical, methods. Keeping the practice as familiar as possible.

In Ron Kasprisin's book, 'Play in Creative Problem-Solving for Planners and Architects', context is defined under the Cultural-Spatial-Time Matrix (CST), meaning that context is neither spatial, spatial-cultural nor time-cultural but a combination of all three. It is his belief that innovative design, stemming from participatory methods, combines both 'divergent' and 'convergent' methods of creative problem-solving (see Fig 2.02).

Divergent thinking looks at "producing multiple answers through processes like shifting perspective on existing information (seeing it in a new way) or transforming $i t$, i.e. through unexpected combinations of elements usually not regarded as belonging together" (Cropley \& Cropley, 2009). Characteristics of divergent thinking include: being unconventional, seeing the known in a new light, combining the disparate, producing multiple answers, shifting perspective, transforming the known and seeing new possibilities (Kasprisin, 2016). These are achieved through creative-play techniques.

Convergent thinking looks at "deriving the single best answer to a given question. It emphasises accuracy and correctness" (Cropley \& Cropley, 2009). Characteristics of convergent thinking include: being logical, recognising the familiar, combining what belongs together, homing in on the single best answer, reapplying set techniques, preserving the already known, being accurate and correct. Information processing and simulation fall under this aspect of thinking (Kasprisin, 2016).

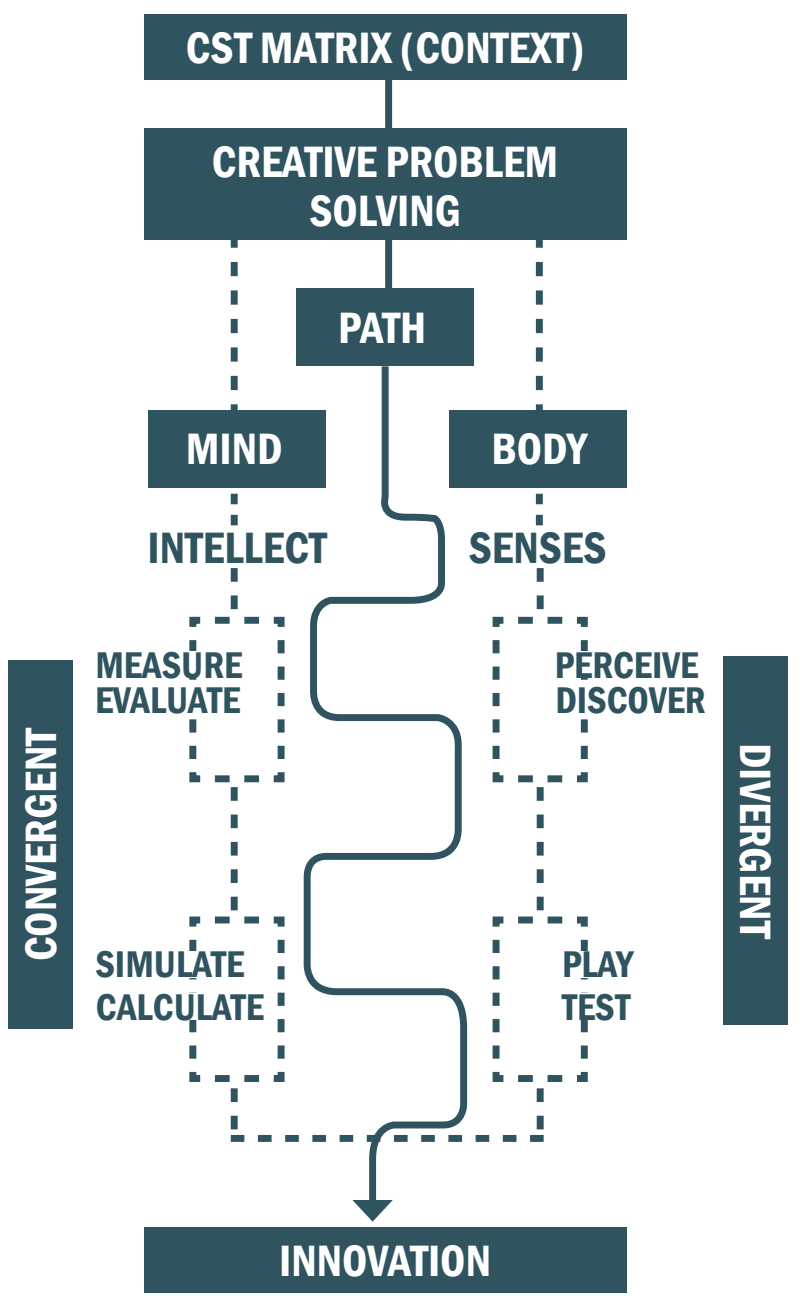

Fig 2.02 - Creative Problem-Solving methodology, combining convergent and divergent thinking. (Kasprisin, 2016) 
This crossover in convergent and divergent thought processes is vital in ensuring an outcome which is balanced between creativity and practicality. The point, at which, a project places itself along this convergent-divergent spectrum depends on the context the project presents.

To further Kasprisin's ideas of innovative design coming from a place of convergent and divergent thinking, Sanoff argues that developing a set of design principles is one of the most important steps of the participatory design process. He states, "in addition to the technical complexity of the issues, there is also the need to incorporate sound design principles in the developmental process." These guidelines will be pivotal in the design decision-making process, giving the designer the ability to interpret them where there is a gap in collected data.

Kasprisin uses tools which incorporate levels of abstraction through symbolism in various mediums. His primary methods use physical modelling systems coined as 'compositional structures'. These structures look to generate creative solutions to a design problem using symbolic hierarchical models rather than looking explicitly at form and function. Sanoff, on the other hand, uses more straight-forward approaches to obtain this convergentdivergent balance.

Sanoff stresses the usefulness of the traditional design workshop, "a workshop can be planned whereby participants learn from each other as they explore issues. This type of structured experience can focus the learning of the participants and permit them to engage effectively" (Sanoff, 1978). However, he also admits that, "the procedure should be tailored to the willingness level of those required to work together." Workshops are time-consuming endeavours which can last multiple days; this thesis looks to achieve a similar level of participation comprehensiveness while making the process less time-consuming and obligating.

Professor Sanoff is one of the major figures in modern participatory design research. His research influences much of the work explored in this thesis. He believes that the most crucial factor in participatory design is, "individual learning through an increased awareness of the problem" (Sanoff, 1978). Meaning that the better the public understands the problems of the design, the more successful the results the participation will be.

One of the newer organisations on the scene is IDEO.org who focus on humancentred design in impoverished countries. Their book, 'The Field Guide to HumanCentred Design', is based on the PRA's many NGO's have used since the 1970s. Their process has three phases: Inspiration, Ideation and Implementation. The Inspiration stage looks at the initial data gathering stages through methods such as surveying, interviewing and collaging. The goal here is to gather as much information as possible while remaining grounded to the design problem. The Ideation stage then takes the gathered information and attempts to make sense of it. In IDEO. org's case, it is the designers who are doing this, not the community. They produce the ideas, storyboards, concepts, design principles - amongst others - which look to solve the problem. The Implementation stage then puts this plan into action (IDEO.org, 2009). This research will look to expand on the Inspiration stage while leaving the Ideation stage in the hands of the community. 
Participation in architecture and urban design is never a simple 'yes' or 'no' question. Developed by the International Association of Public Participation (IAP2) the 'Spectrum of Public Participation' is used to help clarify the role of the public in the planning and decisionmaking processes. There are five levels of participation identified: Inform, Consult, Involve, Collaborate and Empower. These are defined and explained in the opposing table (Fig 2.03) - the further to the right in the table, the greater the level of participation.

This research analyses and incorporates methods from the 'Consult', 'Involve' and 'Collaborate' levels of participation. Urban design requires that there is some form of leadership so that there can be a cohesive end result. Therefore, while a collaborative approach is ideal in terms of being democratic, certain elements are often not feasible. This is where the 'Consult' and 'Involve' components come through with more merit. This thesis argues that there should be clear leadership in urban development; however, that leadership must take into account and feed off of the ideas, needs and desires of the community they are designing for.

The goal of the 'Involve' level is, "to work directly with the public throughout the process to ensure that public concerns and aspirations are consistently understood and considered". This is the next level up from 'Consult' which looks to "obtain public feedback on analysis, alternative or decisions." (IAP2 International Federation,
2018) These levels of participation can be achieved through surveying, public meetings, workshops/charettes etc. These methods primarily focus on the largerpicture outcomes or goals, i.e. "What do we need?", "What do we value?", "What do we want to stay away from?". These questions are useful for identifying key outcomes for a development but stay away from the details which are left up to the designer.

'Collaborate' takes participation a step further promising to, "look to you for advice and innovation in formulating solutions and incorporate your advice and recommendations into the decisions to the maximum possible extent" (IAP2, 2018). Collaboration means that the public will have a greater influence on the details of the development. Asking questions such as: "Where should we have public toilets?", "How many playgrounds do we need?", "What should the development look like (building materials, colour schemes, landscaping/planting)?”. This level of detail takes more time and effort with more thorough consultations required - this makes collaboration at a large scale difficult and often impractical. 


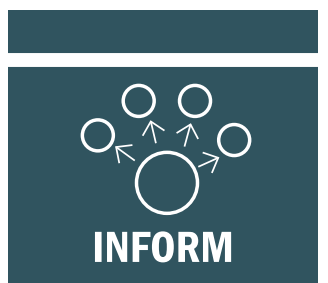

To provide the public with balanced and objective information to assist them in understanding the problem, alternatives, opportunities and/or solutions.
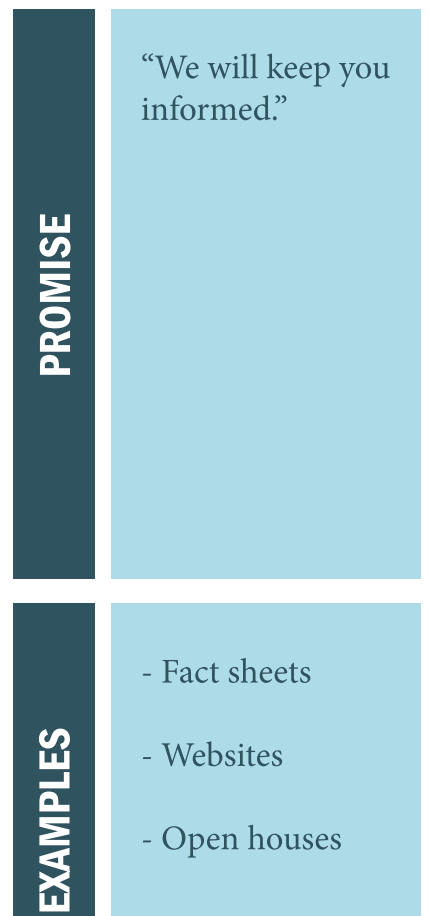

- Fact sheets

- Websites

- Open houses

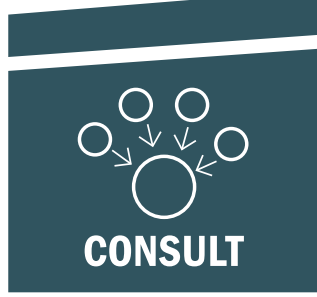

To obtain public feedback on analysis, alternative and/or decisions.

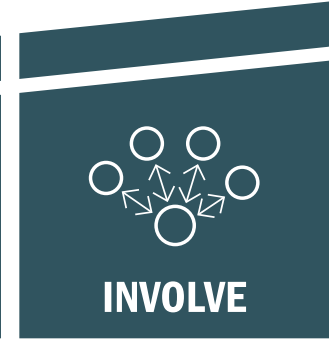

To work directly with the public throughout the process to ensure that public concerns and aspirations are consistently understood and considered.

"We will work with you to ensure that your concerns and aspirations are directly reflected in the alternatives developed and provide feedback on how public input influenced the decision."

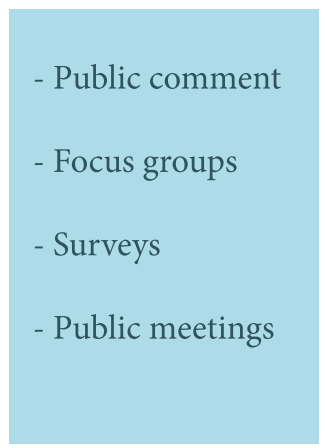

\section{- Workshops}

- Deliberative polling
"We will look to you for advice and innovation in formulating solutions and incorporate your advice and recommendations into the decisions to the maximum extent possible."
- Citizen advisory committees

- Consensus

building

- Participatory decision making
"We will implement what you decide."

- Citizen juries

- Ballots

- Delegated decision

\section{AREA OF RESEARCH}


Participatory Chinatown

Engagement Lab

2010

New York, USA
Minform donsult dinvolve acollaborate aempower

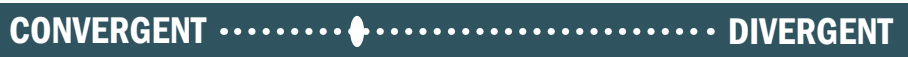

The Engagement Lab at Emerson College is an applied research and design team which explores and produces media and technology to make civic engagement exciting and meaningful to community members. They created 'Participatory Chinatown' in 2010 in collaboration with the City of Boston. It is a video game tool used to identify potential areas of development in Boston's Chinatown; "players assume the role of a fictional character in the Chinatown neighbourhood and they go on one of three missions: find a job, find a place to live, or find a place to socialize" (Engagement Lab, 2010).

The team made some interesting observations at the event; "Participatory Chinatown demonstrated that an immersive, role-playing experience can give participants in a community meeting a strong feeling of connection to the neighbourhood and a deep understanding of the issues in play. Players were willing to participate in the game, because it quickly became clear to them how the exercise was enhancing their sense of connection to the local context. The game did not feel peripheral to their civic participation, but rather part of it. Walking the (virtual) neighbourhood in someone else's shoes was a recognisable and enjoyable tactic to immerse players in a context of decision-making that is often not clear in the traditional meeting." (Engagement Lab, 2010).
The concept of using video game software as a participatory design tool is one which is in the early stages of development and has many challenges (high start-up costs, extended timelines for game development, the learning curve for the user, etc.). In addition to this, acquiring resources to set up a digital event like Participatory Chinatown poses other challenges.

Nevertheless, it is exciting to see what the future of participatory design could become.

Where this concept is successful is in its ability to put the user in a digital environment where they can spend time exploring and generating ideas in a way which is exciting and engaging. It is particularly useful when targeting the younger demographic who have been brought up surrounded by technology and video games. Traditional forms of design participation tend to lend themselves better to the older generations; "In addition to the traditional mechanism of engaging the community in town-hall-style meetings, Participatory Chinatown was introduced into the process, in order to create better learning and increase diversity of participants" (Engagement Lab, 2010).

While video games such as these will become more prominent in the future of participatory design, the skill-set and resources required to develop them make them impractical for most designers, architects and researchers. 
Fig 2.04 - A collection of images showing The Engagement Labs,

'Participatory Chinatown' video game workshop. 
Asili

IDEO.org

2014

Bukavu, DRC
Cinform Consult dinolve collaborate aempower

CONVERGENT $\cdots \ldots \ldots \ldots \ldots \ldots \ldots \ldots \ldots \ldots \ldots \ldots$ DIVERGENT
The Democratic Republic of the Congo (DRC) has one of the highest mortality rates in the world. One out of every ten children do not make it to their fifth birthday (Knoema, 2015). In 2014, IDEO. org in conjunction with the American Refugee Committee (ARC) entered a joint venture to launch 'Asili' - a sustainable community-owned health, agricultural, and water business with the goal of lowering the mortality rate.

IDEO.org have established themselves as one of the significant figures in modernday participatory design with a particular focus on third-world countries. They spent weeks living with the people of Bukavu to gain an understanding of the social dynamics they were dealing with. It was from here that they began their participatory process; "thanks to scores of interviews with the residents of Bukavu, the team came to insights that would guide Asili's design. One insight came from a woman who said that she used to seek prenatal care for her child, but she stopped because she never knew how much it would cost. The team realised that her child's future could be drastically improved with a little more clarity at the clinic, and from there, they knew that transparency and reliability had to be core to the solution" (IDEO.org, 2009).
From their discussions, the design team identified seven women to participate in a two-day workshop. "The two days were incredibly fruitful, with the women quickly jumping into the roles of designer, prototyper, and problem solver. By inserting these community members directly into the design process itself, the team came to grasp so much more than it could have by simply interviewing them." (IDEO.org, 2009). Over the two days, the women aided in designing the services, brainstorming a suitable name, creating a logo and more.

What resulted from the collaboration was a fully sustainable business designed to meet the needs of the people of the DRC.

IDEO.org takes a workshop approach to the majority of their design consultations. The major benefits of participatory design workshops (also known as charettes) are: a face to face consultation process dealing with real people and the possibility of generating many detailed responses to a single design problem through convergent and divergent thinking. The drawbacks of design charettes include: being timeconsuming - a typical workshop can last two to three days, being expensive to implement - making them unattractive to clients, and being difficult to set up meeting times and locations which suit everyone. 



\section{Community Arts Centers}

\section{Henry Sanoff \\ 1988}

North Carolina, USA
Dinform Lconsult dinvolve collaborate aempower

CONVERGENT $\ldots \ldots \ldots \ldots \ldots \ldots \ldots \ldots . . . \ldots$ DIVERGENT
In 2015, Henry Sanoff along with Evrim Demir Mishchenko published a book titled the 'Community Arts Center Handbook'. This booklet covers the research of Sanoff from the 1980s onwards in regards to the participatory design of various arts facilities. Over the years, Sanoff was able to develop an extremely thorough and detailed blueprint for modern participatory design in Western society which differs to the PRAs used in the developing world.

The majority of the information can be traced back to his work published in a 1988 research journal which looked specifically at arts facilities in North Carolina, USA. Here, Sanoff implemented two primary design tools, community surveys and community workshops.

Community surveys were used to identify the activities which required facilities, the locations of possible facilities, and whether or not these facilities would be centralised or dispersed throughout the communities (Sanoff \& Mishchenko, 2015). Sanoff opted for a series of public surveys to answer these questions ahead of public meetings as Purcell and Thorne have shown, "that public meetings are unreliable sources of accurate information about community needs" (Purcell \& Thorne, 1977).

Once the information from the surveys was gathered, it was then used to influence the next stage - community workshops. "Attendance at community workshops ranged from 25 to 100 people... it was necessary to devise an approach where aggressive individuals would not dominate the decision process" (Sanoff, 1988). This 'domination' is an interesting concern, one which Sanoff attempted to solve by splitting the community members into groups of 3-6 people which allowed them to work together more effectively. "From a list of objectives, participants made individual choices, defended their selections and finally reached a group decision. This process gave all group members equal voice in the final decision while learning about each others viewpoint" (Sanoff, 1998). While this method makes the process fairer, it also prolongs it. Extending the precious resource of time - which is a major deterrent of the participatory process.

Two of the more effective workshop tasks were the Objectives and Activities Identification sheets and the Spatial Layout Game Boards. The information gathered through the community surveys was used to put together a series of common objectives and activities. The groups could then go through these and record which ones they deemed most important. These could then be used to determine what activities the facilities needed to accommodate for. Once this was done, the groups took a Spatial Layout Game Board and (using a set of coded stickers) marked out on a plan where they wanted particular areas to be located in the facilities. While this tool has been used for a single building here, there are opportunities for it to be adapted to a public/urban scale. 



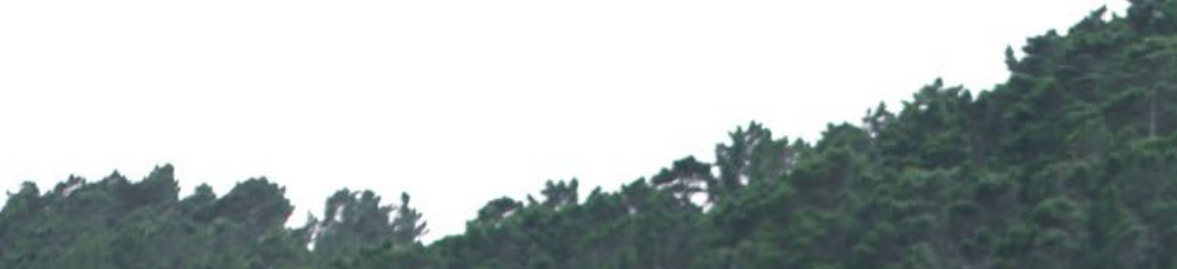




\section{Chapter 3: Major Case Study - Shelly Bay \\ Background}

Shelly Bay is located on the western edge of the Miramar Peninsula in Wellington, New Zealand. This gem of an area has been left relatively untouched since it was last occupied by the Royal New Zealand Air Force (RNZAF) between 1946 and 1995. The space has a mysteriously beautiful presence - filled with history and character.

In 2009, Shelly Bay was bought off of the New Zealand Government by the Port Nicholson Block Settlement Trust (PNBST) who represent various iwi of Taranaki. This purchase came about as Shelly Bay was first settled as Maru-kai-kuru by Te Ati Awa (one of the iwi originating from Taranaki) in circa-1830. Therefore, when the New Zealand Defence Force (NZDF) handed the land back to the New Zealand Government, they were given the first right of refusal to purchase the land - which they did, using money from their Treaty of Waitangi settlement.

Unfortunately, no one took responsibility for the upkeep of the existing buildings and infrastructure, and because of this, they have become dilapidated with many beyond repair, requiring demolition. This brings forward the question of how these buildings should be replaced. In 2016, the PNBST entered into a venture with Ian Cassells and The Wellington Company (TWC) to propose a development known as 'Taikuru'. The development can briefly be described as medium to high-density residential in addition to an aged care facility, hotel, retail and commercial spaces.
The development was passed through the Resource Consent process using the 'Housing Accords and Special Housing Areas Act 2013' (HASHAA), in 2017. The HASHAA was developed for the purpose of fast-tracking affordable housing projects to combat the current housing crisis. A part of this allows for a non-notified Resource Consent process - meaning that the public was not informed about the Taikuru application. Thus, the public was unaware of the project until after it was approved.

The Taikuru development has received criticism by many for using the HASHAA for purposes which will not only fail to provide affordable housing solutions, but also include non-residential buildings and services. In addition to this, many beneficiaries of PNBST are upset with their trustees for selling the land to Cassells when they failed to reach a $75 \%$ vote agreeing to the sale. Concerns around the impact the development will have on traffic congestion as well as costs to ratepayers, access to the public during the 13-year construction period and potential impacts to the environment have also been raised. 


\section{Port Nicholson Block Settlement Trust}

The Port Nicholson Block Settlement Trust represents the Taranaki iwi who migrated to the Wellington Harbour area in the 1800s. These iwi are collectively known as Taranaki Whānui ki Te upoko o Te Ika (Taranaki Whānui).

Established in 2008, the PNBST was set up to receive and manage the Taranaki Whānui Treaty of Waitangi Settlement package.

Their goal (as stated on their website) is, "to ensure that our members maintain their place within the rohe their tipuna occupied in 1840. The loss of years and the fragmentation of iwi and whanau over the decades challenges us to restore the rightful place of our people within the Port Nicholson Block rohe."

\section{The Wellington Company Ltd.}

Founded in 1990 by Ian Cassels, The Wellington Company Ltd. (TWC) defines itself as, "a major player in the redevelopment of Wellington city's urban environments and historic places. In addition to a breadth of residential and commercial development across the Wellington region." (The Wellington Company Ltd., nd.)

Over the past 20 years TWC has developed major commercial, residential, car parking and retail spaces - resulting in them having one of the largest property portfolios in Wellington. In 2017, Shelly Bay was added to this portfolio.

TWC's vision for Shelly Bay is as follows: "In time Shelly Bay will become home to over $850+$ new residents and a place
Their vision: "To restore, revitalise, strengthen and enhance the cultural, social and economic well-being of Taranaki Whānui ki Te Upoko o Te Ika" (Port Nicholson Block Settlement Trust, 2012).

The Trust is currently led by nine Trustees who are obligated to act in the best interests of their beneficiaries (Taranaki Whānui). This means that they are compelled to ensure the future of Shelly Bay (bought by PNBST in 2009) is developed with the best interests of the iwi in mind. Whether this is true or not is up for debate.

which many thousands more will seek to experience and enjoy. A key element of this new community is its underpinning commitment to sustainability and being a place that is shared and connected, founded on community building and sustainability principles that will preserve and enhance what already exists.

As a community, Shelly Bay will become a Wellington landmark, iconic for what makes Wellington a great city and most importantly a taonga tuku iho - a treasure to be passed down to future generations." (The Wellington Company Ltd., nd.).

In April of 2017, their plans for Shelly Bay were released to the public under the name 'Taikuru'. 


\section{The Deal}

In order to make 'major transactions' the PNBST is required to receive at least $75 \%$ vote in support of said transaction. In February of 2016, the PNBST held a vote with iwi members on whether or not they should sell their land at Shelly Bay - they did not get $75 \%$ in favour of the sale.

While no deals have been publicly confirmed three of the four parcels of land are now owned by Shelly Bay Investments Limited (SBIL). SBIL's only director is Ian Cassels who is also the founder of TWC. This confirms that Cassels has bought the land off of the PNBST - hence, the sales must be assumed to be 'minor transactions'.
At the PNBST's 2018 Annual General Meeting (AGM) it was revealed to iwi that the three parcels of land were sold for $\$ 2$ million plus an undisclosed profit share - just a fraction of the $\$ 13$ million it was bought for in 2009.

As the majority of the land is now owned by Ian Cassels it seems likely that even if the current Taikuru plans do not go ahead there will still be some form of development put in place by TWC.

\section{Housing Accords and Special Housing Areas Act 2013}

The Housing Accords and Special Housing Areas Act 2013 (HASHAA) came into effect on the 16th of September 2013. Its purpose is, "to enhance housing affordability by facilitating an increase in land and housing supply in certain regions or districts identified as having housing supply and affordability issues" (Anderson Lloyd, 2016).

The HASHAA allows the fast-tracking of certain residential developments, allowing developers to apply for Resource Consent without public knowledge. They are only required to inform neighbouring property owners of the application. The legislation also makes it more difficult to appeal against approved decisions.
Shelly Bay became a designated Special Housing Area in 2015. In 2016, TWC and the PNBST submitted their Taikuru Development to the WCC for Resource Consent. As all neighbouring land was owned either by iwi or the WCC no one was notified that the consent plans had been lodged. In April 2017, the Resource Consent was approved.

In August of 2018, Wellington City councillors voted to remove special housing areas from Wellington (as of September 2019) - the Shelly Bay case was a major driver for this decision. 


\section{Enterprise Miramar Peninsula Inc.}

Enterprise Miramar Peninsula Inc. (EMPI) was established in 2005 with the goal of assisting business development in the peninsula. EMPI and businesses in Miramar were then approached by the Wellington City Council in 2013 to create a formal Business Improvement District - the Miramar BID (MBID).

The Miramar BID website describes themselves as; "a non-political organisation driven by a voluntary executive committee dedicated to furthering economic development for Miramar. Together with the businesses, landlords and the community we are working to enhance prosperity, safety and security in Miramar" (Miramar BID, 2019). A few of their projects include; setting up a free Wi-Fi network in Miramar, installing bike racks, community artwork and murals, and the installation of emergency water tanks for disaster relief.

EMPI/MBID has been the main opposition to the Taikuru Development, taking the Resource Consent to the High Court and Court of Appeal where they successfully challenged the WCC for granting the Consent.

\section{Mau Whenua}

Mau Whenua is a group of Taranaki iwi members who are against the PNBST's decision to sell Shelly Bay. They have taken the initiative to begin their own legal challenge to the Taikuru Development (separate to that pursued by EMPI) where they are attempting to overturn the sale of the land.
They wish to see the land used in a way which benefits the people of Wellington and the Taranaki Whānui. They believe this should be done by staying away from a large scale residential development - instead opting to cater to recreation, culture and tourism.

EMPI has been the primary contact for this research and have been willing to assist in any way possible - including providing information on the legal proceedings. While this thesis attempts to be as unbiased as possible, EMPI was willing to work and co-operate with this research while TWC, PNBST and WCC were not. This means that most of the information presented has originated from EMPI and a slight bias is unavoidable.

Mau Whenua wants to see the land at Shelly Bay returned to the PNBST (and new trustees brought in) so that it can remain in the hands of the iwi and developed to provide a constant source of income for generations to come. 


\section{The Legal Battles}

There are two separate legal battles which concern Shelly Bay. The first is Enterprise Miramar Peninsula Incorporated versus the Wellington City Council over the approval of the Taikuru Development's Resource Consent. The second comes from the iwi members who are involved in the Mau Whenua group against the Port Nicholson Block Settlement Trust for the sale of land at Shelly Bay to Ian Cassels.

\section{EMPI vs. WCC:}

Following the public notification that the Taikuru Resource Consent (RC) had been approved in April of 2017, Enterprise Miramar took it upon themselves to challenge the decision. EMPI felt that because they are a WCCbacked organisation who are meant to look after the best interests of Miramar businesses (and have a Memorandum of Understanding with the Wellington City Council) that they should have been informed of the Resource Consent application when it was first lodged.

EMPI took the WCC to the High Court in March of 2018 arguing that there was a conflict of interest in the Council's decision to award the Resource Consent - they requested that independent commissioners come in to review the application and that the Miramar community should be able to have a say on the proposal. Unfortunately for EMPI, the High Court ruled in favour of the WCC stating that there was no evidence of bias in the decision and that, "HASHAA simply does not provide for the Miramar community to have a say on applications such as this" (Simpson Grierson, 2018).
Following the High Court's decision, EMPI took the case further to the Court of Appeal. Here they challenged the granting of the RC against the ' 1999 Shelly Bay Design Guide' which was put in place by the Environmental Court. The Court of Appeal ruled in favour of EMPI - throwing out the Consent. The judgement concluded that, "the Council's approach meant that the environmental effects of the development were not given the required recognition and weight" (Scoop Media, 2018). This means TWC will have to resubmit for RC and prove that they have considered the environmental impacts at greater length.

\section{Mau Whenua vs. PNBST}

The Mau Whenua group is set to launch their own legal battle against the PNBST and Ian Cassels for the sale of the land at Shelly Bay. They are arguing that the PNBST knowingly and purposely went behind the back of beneficiaries to sell the land in small blocks so that they would be considered 'minor transactions'. This comes after the trust failed to get the appropriate backing to sell Shelly Bay as a 'major transaction'. They also intend to argue that the amount the land was sold for was far below its actual value.

The legal battle is yet to begin; however, it looks set to move forwards in mid-2019. 


\section{THE TIMELINE.}
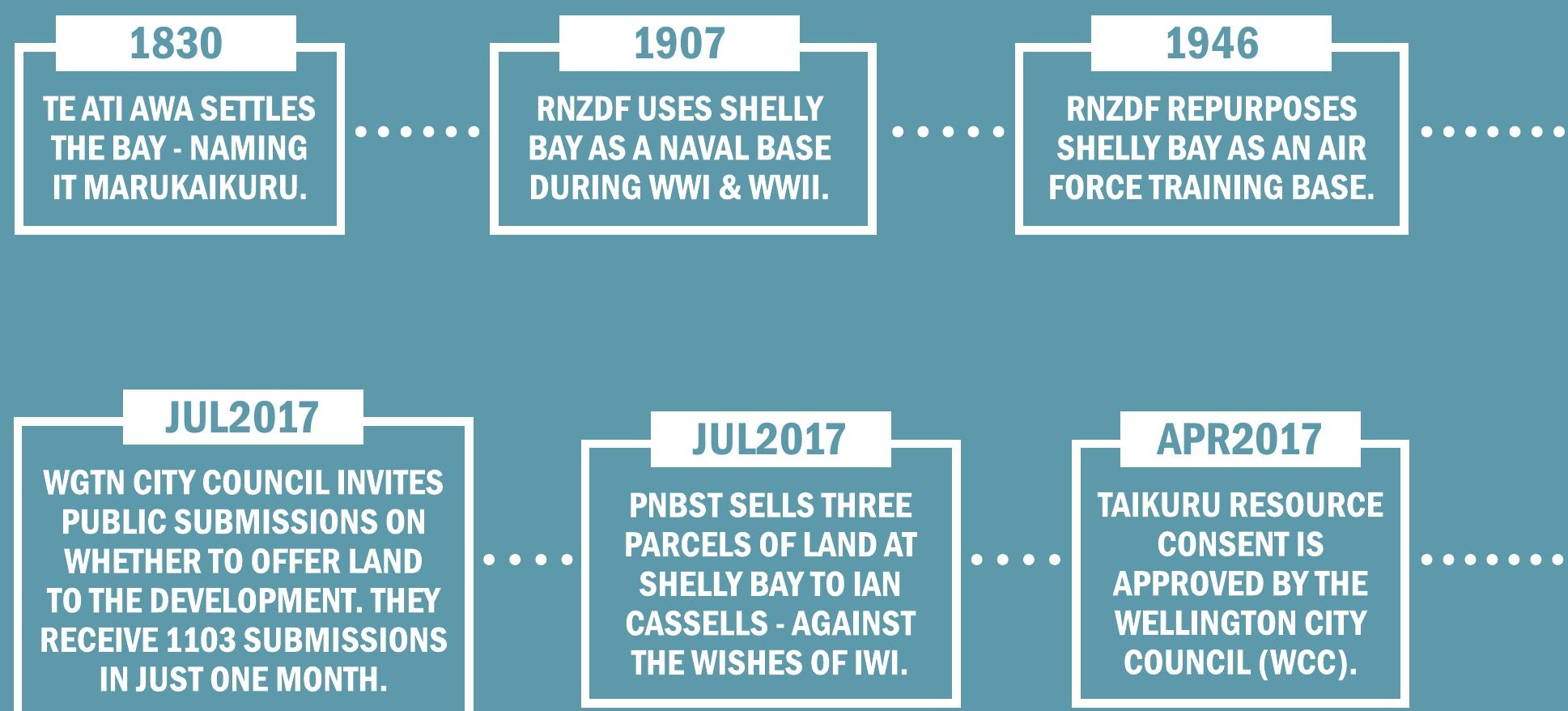

\section{APR2017}

TAIKURU RESOURCE CONSENT IS APPROVED BY THE WELLINGTON CITY COUNCIL (WCC).

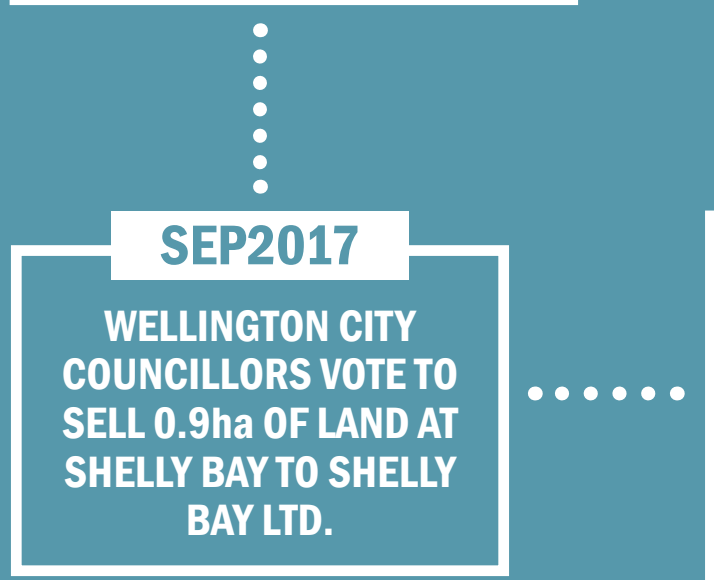

\section{MAR2018}

ENTERPRISE MIRAMAR PENINSULA INC. TAKES THE RESOURCE CONSENT DECISION TO THE HIGH COURT CITING BIAS IN COUNCIL DECISIONS.

\section{APR2018}

THESIS RESEARCH I COMMENCES.

ل

\section{MAY2019}

THE FATE OF SHELLY BAY IS STILL UNKNOWN - TWC PLANS TO RESUBMIT FOR RESOURCE CONSENT. MEANWHILE MAU WHENUA STILL INTENDS TO TAKE THE MATTER TO COURT TO RETURN SHELLY BAY TO IWI.

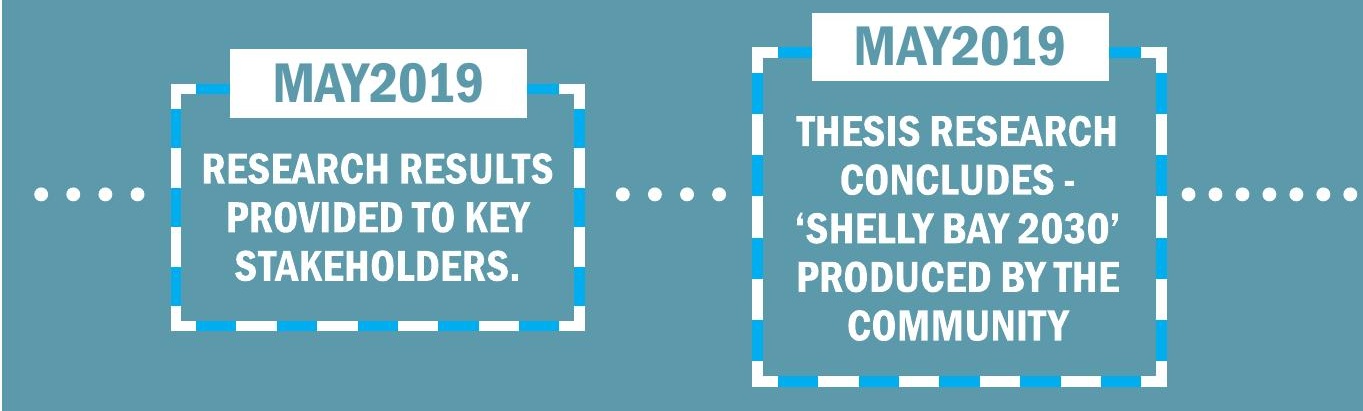


Fig 3.01 - Detailed timeline diagram documenting Shelly Bay's history, legal battles and thesis research concurrently.

\section{9}

NZ ENVIRONMENT COURT AGREES UPON AMENDMENTS TO THE DISTRICT PLAN AND A DEVELOP A DESIGN GUIDE FOR SHELLY BAY.

\section{9}

LAND BOUGHT BACK BY TARANAKI IWI USING TREATY SETILEMENT FUND - REPRESENTED BY THE PORT NICHOLSON BLOCK SETILEMENT TRUST (PNBST).

SEP2016
NON-NOTIFIABLE
RESOURCE CONSENT
IS APPLIED FOR BY
THE WELLINGTON
COMPANY AND
SHELLY BAY LTD.
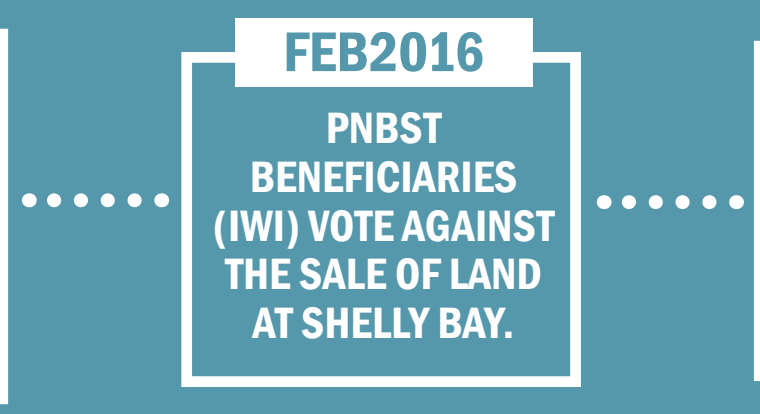

2015

SHELLY BAY BECOMES A SPECIAL HOUSING AREA (SHA) AFTER A PRIVATE REQUEST TO THE WELLINGTON CITY COUNCIL.

\section{APR2018}

THE HIGH COURT RULES IN

FAVOUR OF THE COUNCIL ARGUING THAT THERE IS NO BIAS IN THEIR DECISION AND THAT THE MIRAMAR COMMUNITY HAS NO LEGAL SAY IN THE DEVELOPMENT.

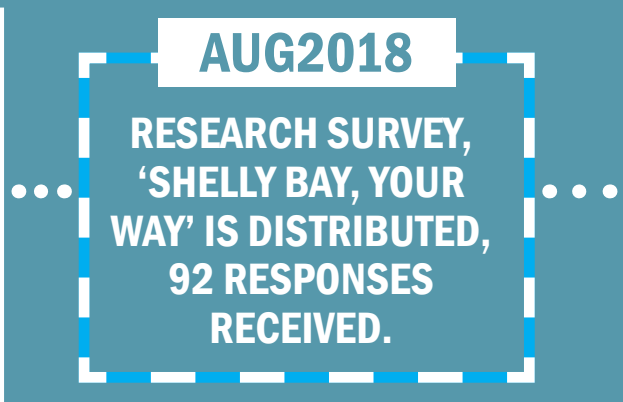

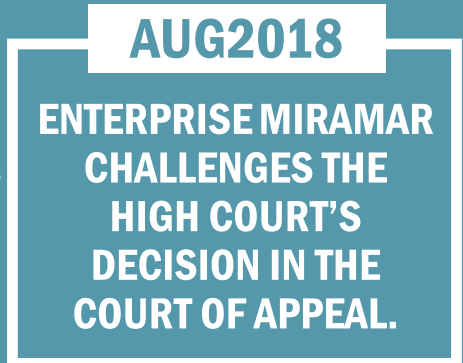

AUG2018

ETERRISE MIRAMAR CHALLENGES THE HIGH COURT'S DECISION IN THE COURT OF APPEAL.

FEB2019
'SHELLY BAY, OUR
WAY' WORKBOOKS ARE
COLLECTED FROM THE
FINAL COMMUNITY
CONSULTATION.

\section{DEC2018}

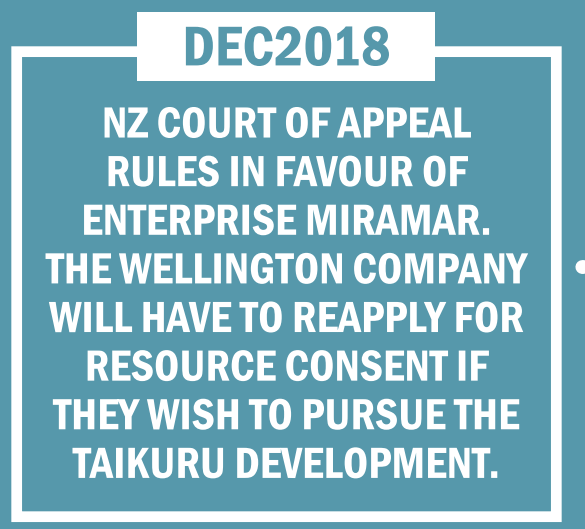

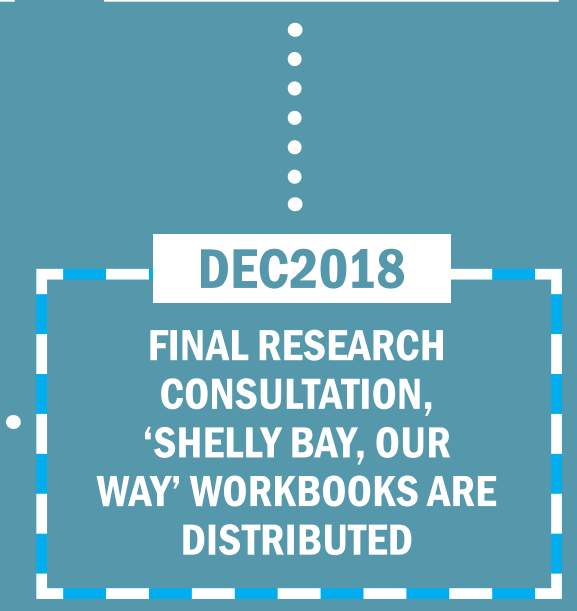




\section{Te Motu Kairangi - Miramar Peninsula}

Shelly Bay is nestled away in the north-western corner of the Miramar Peninsula. Figure 3.02 shows a graphical representation of the Miramar Peninsula and highlights particular amenities and zones. To understand what Shelly Bay could be it is important to understand what its surrounding context currently is.

Data from the 2013 census puts the population of the entire Miramar Peninsula at roughly 20,000 with an average density of 18.5 persons per hectare (or 185 people per square kilometre) (.idcommunity, 2013). The majority of this population, however, live in the central suburbs of Miramar, Seatoun and Strathmore - with the outskirts and coastal areas being more sparse. The bulk of housing in the Peninsula is low density.

A major feature of the Peninsula is its proximity to the Wellington International Airport. This makes it convenient for frequent travellers and offers various opportunities for tourism in the area. Unfortunately, its positioning has a significant impact on traffic congestion and, with only two roads in and out of the Peninsula, this puts a tight restriction on traffic at peak times.

There are 10 schools in the area; however, only one of these is a secondary school. This means that while there are plenty of opportunities for early education, the majority of secondary school students will be leaving the Peninsula for schooling.

In terms of public amenities and facilities, there is a decent public bus system which circulates people from the Peninsula to the Wellington CBD. However, this is impacted by traffic congestion, and it can take 45 minutes to an hour to make the trip into town which is less than $10 \mathrm{~km}$. 

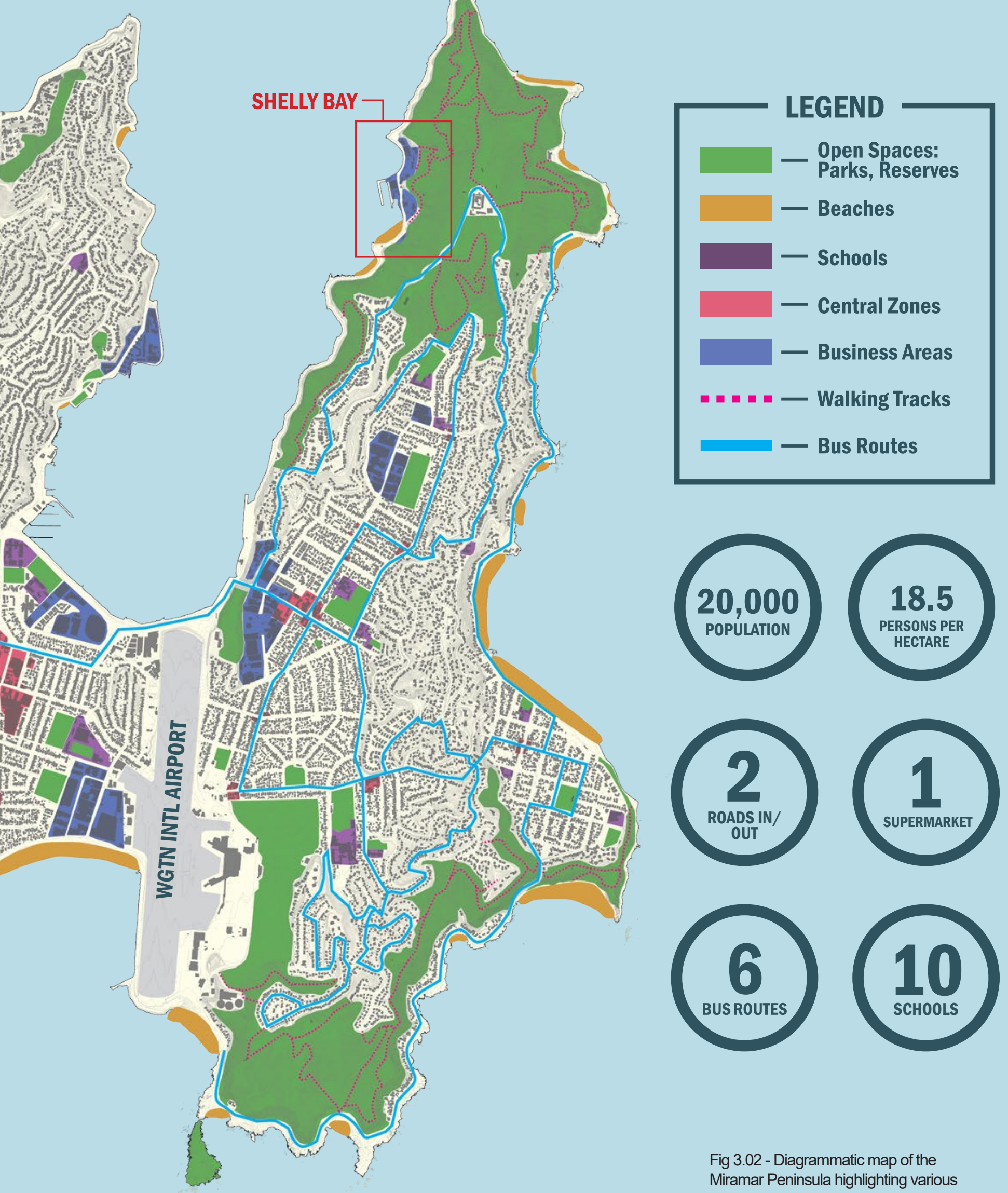

Fig 3.02 - Diagrammatic map of the Miramar Peninsula highlighting various amenities and zones 


\section{The 1999 Shelly Bay Design Guide}

Developed by the NZ Defence Force, the Wellington City Council and the NZ Environmental Court; the ' 1999 Shelly Bay Design Guide' was produced to ensure that the future of Shelly Bay would "recognise and respect the distinctive environmental qualities that give the area character and avoid creating potentially adverse effects on that character" (Wellington City Council, 2018).

The objectives of the Guide, as outlined in the document, are as follows:

1. To manage new development in a way that enhances Shelly Bay as a public destination and a point of interest along the scenic marine drive and protects its unique public amenity value of open texture and foreshore accessibility.

2. To manage new development in a way that respects the distinctive natural character of Shelly Bay, through its form, scale and siting, and which is visually related to the surrounding buildings.

3. To promote the historical significance of Shelly Bay and encourage development that respects any identified heritage buildings.

Shelly Bay is broken down into three areas (shown in Fig 3.03). These are the: Southern Bay Area (1), Northern Bay Area (2) and Wharf Area (3).

The Design Guide identifies five important historical or landmark buildings in Shelly Bay. These are the: Officers' Mess, Shipwrights Building, Warehouse \& Stores Building, Submarine Mining Depot Barracks and Hospital.

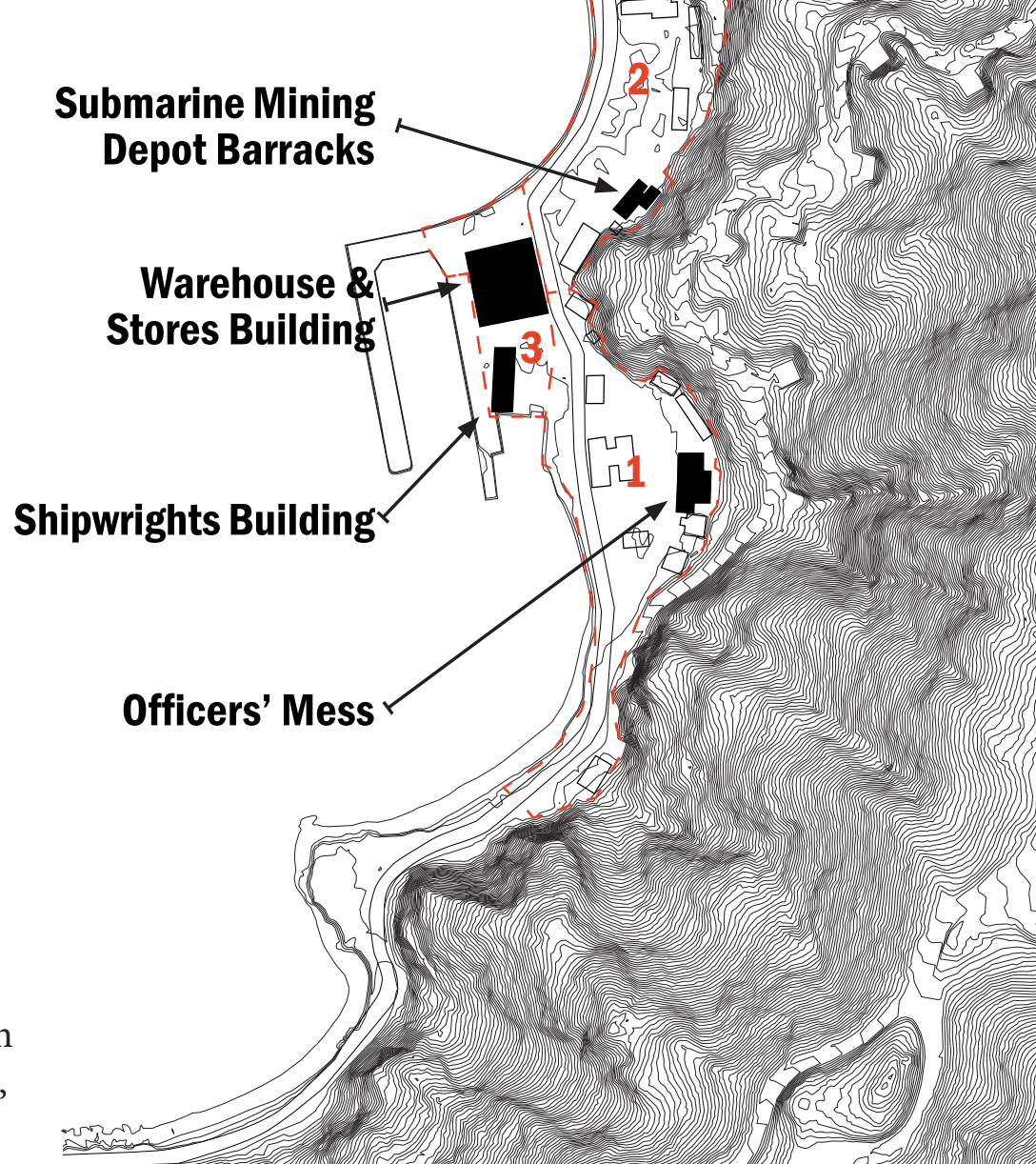


The Warehouse \& Stores Building along with the Shipwrights Building are considered iconic landmarks of Shelly Bay which are major contributors to the silhouette line. The Hospital and Officers' Mess buildings are also landmark buildings but have further significance due to their military use. In addition to this, "the most important building within Shelly Bay is the Submarine Mining Depot Barracks... constructed in 1887, [it] has a strong association with the history of the place" (Wellington City Council, 2018).

The Guide recognises that Shelly Bay is experienced at two levels: up close - moving between the buildings, and at a distance from across the harbour. This is an important consideration for any potential development.

The Guide then outlines specific details of what a development should look like. The first of these is a height restriction. There are four height zones. In the foreshore area, any building may only be $8 \mathrm{~m}$ tall (frontages may rise to $11 \mathrm{~m}$ ). In the two rear sections of either bay buildings can be $11 \mathrm{~m}$ tall (10\% of a building's footprint may rise to $12.5 \mathrm{~m}$ ) and any development at the hospital site may not exceed $7 \mathrm{~m}$.

Any development should refrain from the use of large buildings or blocks - instead, keeping the existing language of small, low, horizontal and linear forms with plenty of open space and access ways. Elements should be designed at a human scale and should include plenty of windows, balconies, canopies and verandah. Building tops should contribute to the areas collective silhouette line. The existing pedestrian walkways along the water's edge should be retained and enhanced to connect seamlessly. Refer to figure 3.07 for a collage of Shelly Bay design aesthetics.

\section{Left: Fig 3.03 - Identification of sub-areas within Shelly Bay and important historical buildings.}

Right Top: Fig 3.04 - Maximum height areas

Right Mid: Fig 3.05 - Diagram showing incorrect building massing density

Right Bottom: Fig 3.06 - Diagram showing correct building massing density
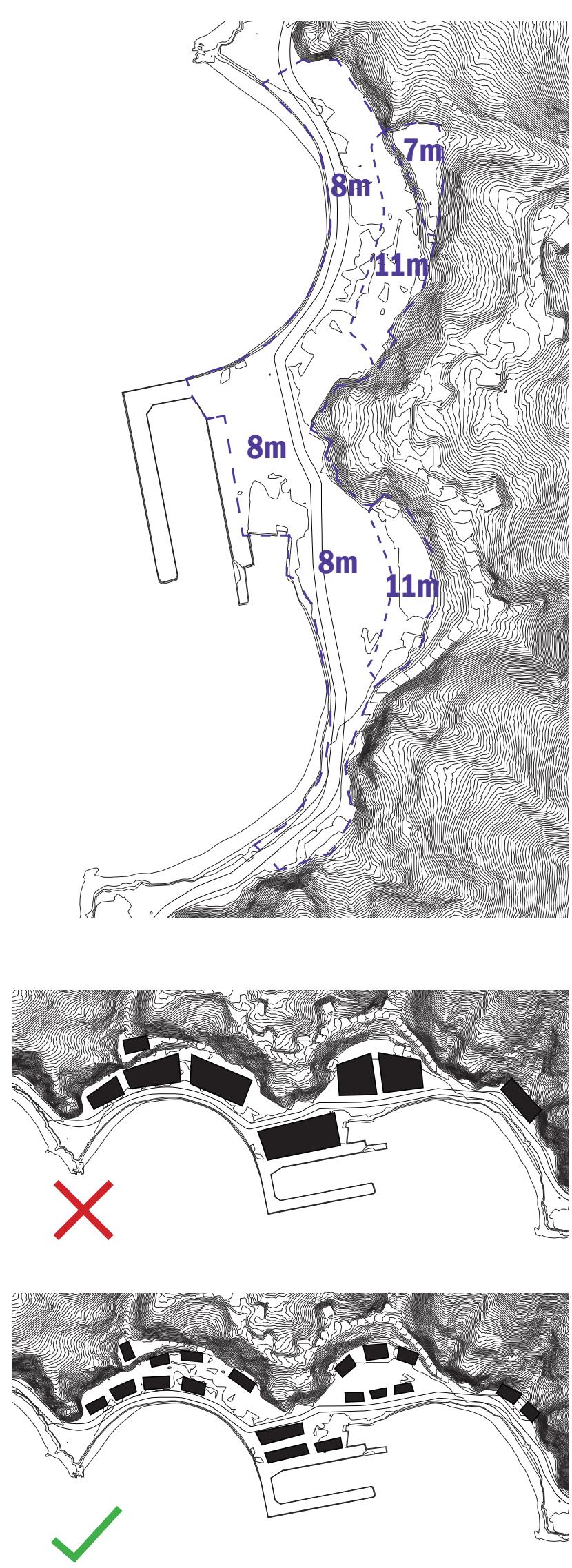

All diagrams are based on images and information from the ' 1999 Shelly Bay Design Guide'produced by the Wellington City Council. 



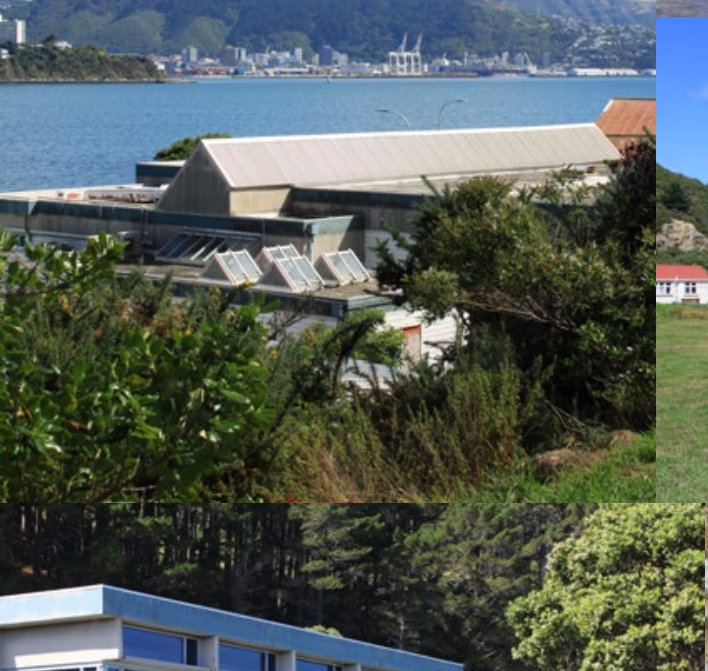

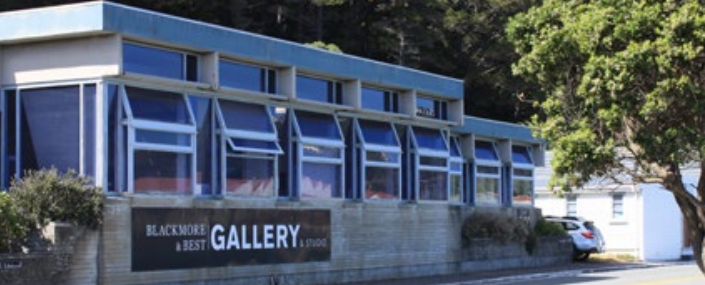

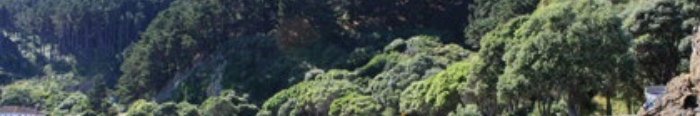

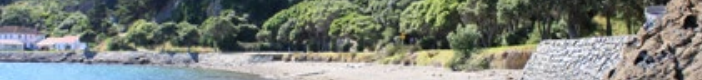
carthend

- 9

o:

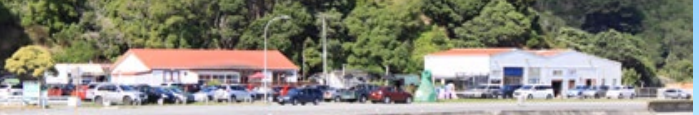

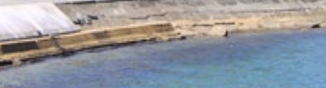

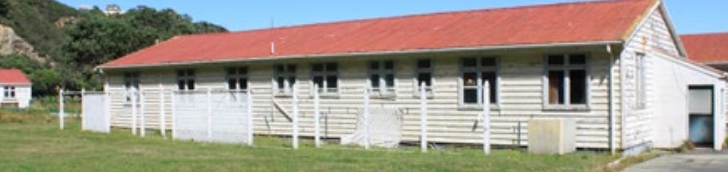

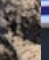

WEO SHELLY BAY (A) 0 CALLERY \& STUDIO BEAUTIFUL WALKS \& COAST ARTISANS AT WORK C스를 CREATIVE SPACES DANCE \& FITNESS PLEASE DRIVE CAREFULLY AND WATCH OUT FOR LUTIE BULE PENGUUS

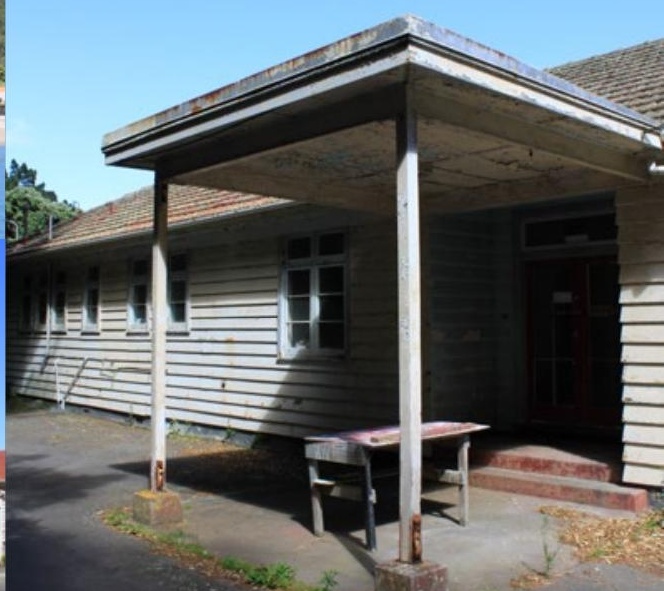

sentive

4
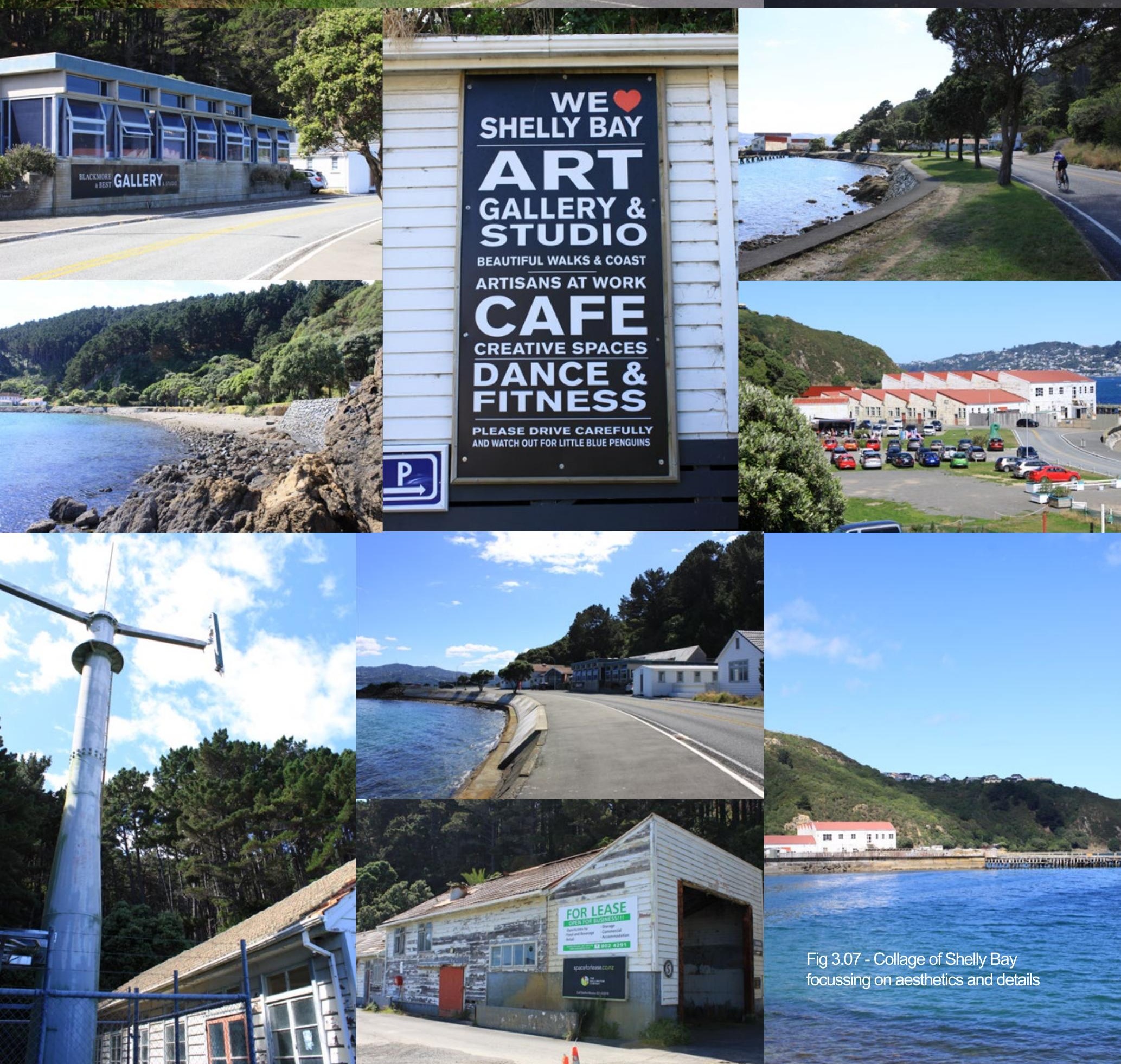


\section{The Taikuru Proposal}

The Wellington Company Ltd.

2017

Wellington, NZ

口INFORM $\square$ CONSULT $\square$ INVOLVE $\square$ COLLABORATE $\square$ EMPOWER

CONVERGENT $\cdot 0 \ldots \ldots \ldots \ldots \ldots \ldots \ldots \ldots \ldots \ldots$ DIVERGENT

The Wellington Company employed the services of Architecture+, McIndoeURBAN and Wraight+Associates to develop their Taikuru masterplan. This masterplan is what was passed by the Wellington City Council using the HASHAA legislation in April of 2017.

It is important to note, before exploring the masterplan, that the aesthetic appearance of the buildings in TWC's proposal are purely artistic and will most likely be different in the final output.

TWC, PNBST and the WCC worked together to produce a document titled, 'Have your say; Shelly Bay Development Proposed sale and lease of Council Land' in 2017. The purpose of this was to inform the general public on the development plans so that they could share their opinions to the WCC on whether or not they should sell and lease land to TWC. This was the only method of consultation in the process - coming after the Resource Consent had been approved.

The vision for the proposal is described by Shelly Bay Ltd. (TWC+PNBST) as; "incorporating new high quality housing, public facilities located in a mix of new and refurbished premises, and improved infrastructure. The development would compliment existing local attractions such as Scorching Bay, Massey Memorial and the proposed heritage reserve above Shelly Bay on the Miramar Peninsula Te Moti Kairangi" (Wellington City Council, 2017).

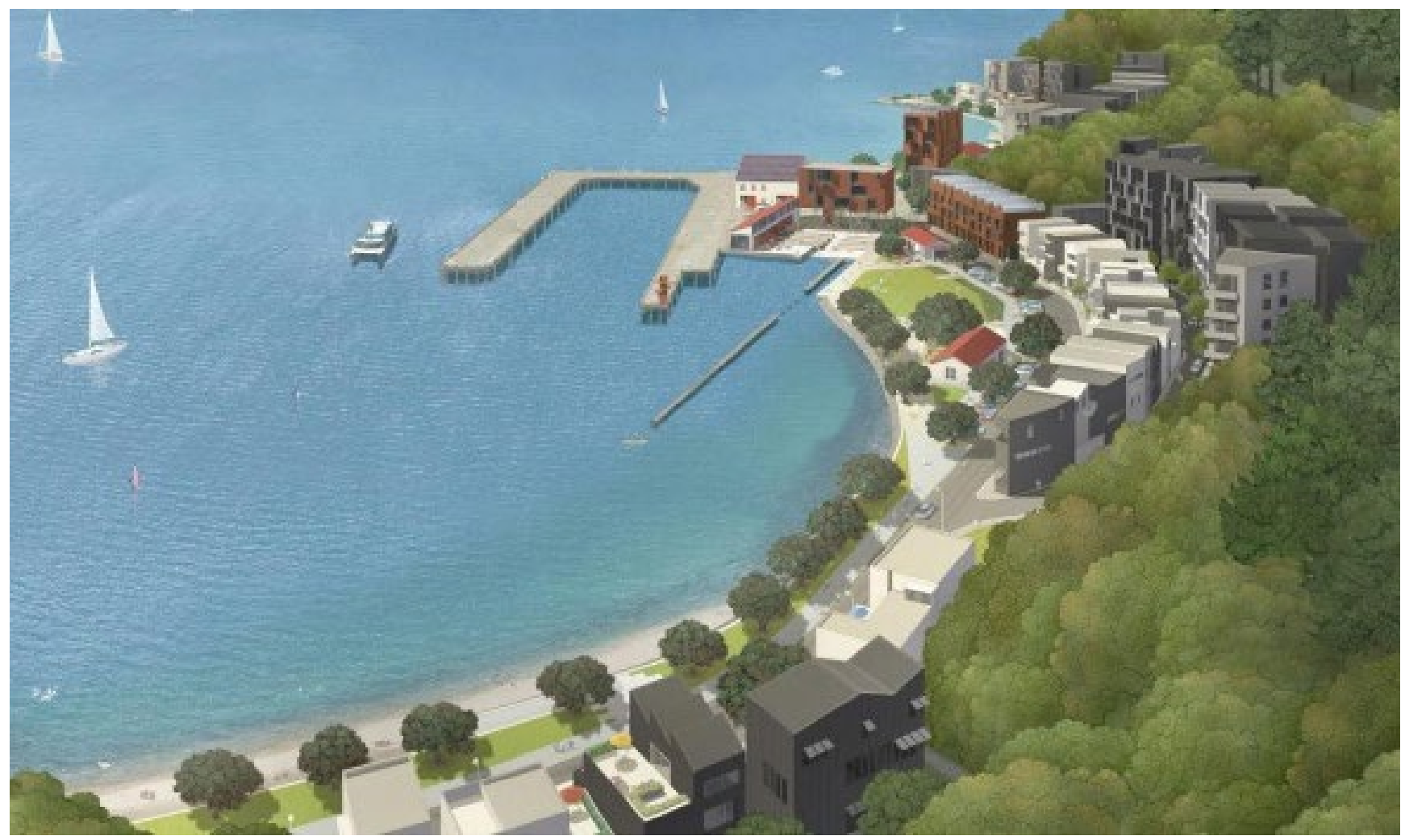

Fig 3.08 - Artists impression of the Taikuru Development. Image supplied by: The Wellington Company Ltd. 
The masterplan shows a high-density development including: 350 homes, a waterfront walkway, green space, parking and seating, cafés, bars and shops, a microbrewery, a 50-bed boutique hotel as well as an aged care facility. Images show a rebuilt wharf and ferry service - although these are not specified in the Resource
Consent and are outside the scope of the development. The plans acknowledge the buildings considered important by the '1999 Shelly Bay Design Guide' through the re-purposing of the Shipwrights Building, Warehouse \& Stores Building, Officers' Mess and Submarine Mining Depot Barracks.

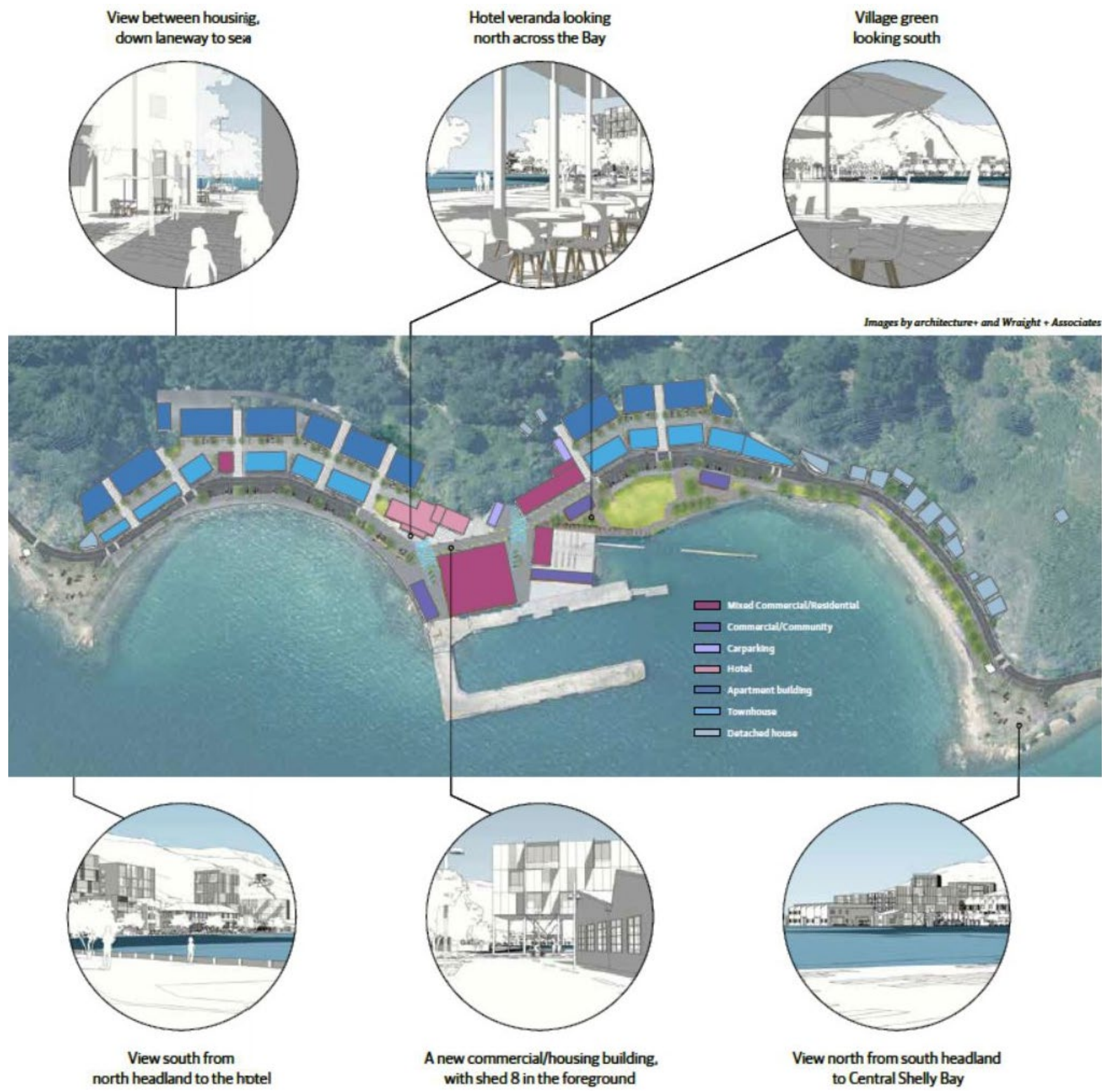

Fig 3.09 - Zoning plan for the Taikuru Development. Image supplied by: The Wellington Company Ltd. 
From above (figs $3.09 \& 3.11$ ) the Taikuru plans appear to comply with the ' 1999 Shelly Bay Design Guide' in terms of building size and fragmentation - as well as improving the connection to the water's edge. However, issues arise when looking at the development from elevation, section and perspective. 12 townhouses are specified up to $15 \mathrm{~m}$ tall in areas designated as $8 \mathrm{~m}$ zones and - in addition to this - 12 apartment buildings up to $27 \mathrm{~m}$ tall are being placed in areas specified at $11 \mathrm{~m}$ maximums. These are breaches of the Design Guide and the District Plan. TWC and the WCC initially believed the HASHAA status of Shelly Bay allowed for these heights; however, the Court of Appeal disputed this in their final judgement.
The soaring heights of the proposed residential buildings allow for a highly dense living population. This proposal could see $1000+$ new residents injected into a seaside community with only one road leading in and out. In addition to this, there is only one green area in the plans, a lawn located along the South Bay which is, "little bigger than a bowling green." (Enterprise Miramar Peninsula Incorporated, 2018).

Community members have spoken out about their concerns at various meetings with the WCC. In addition to these meetings, the WCC campaign, 'Have Your Say' led to 1103 public submissions over the space of four weeks - this raised other issues.

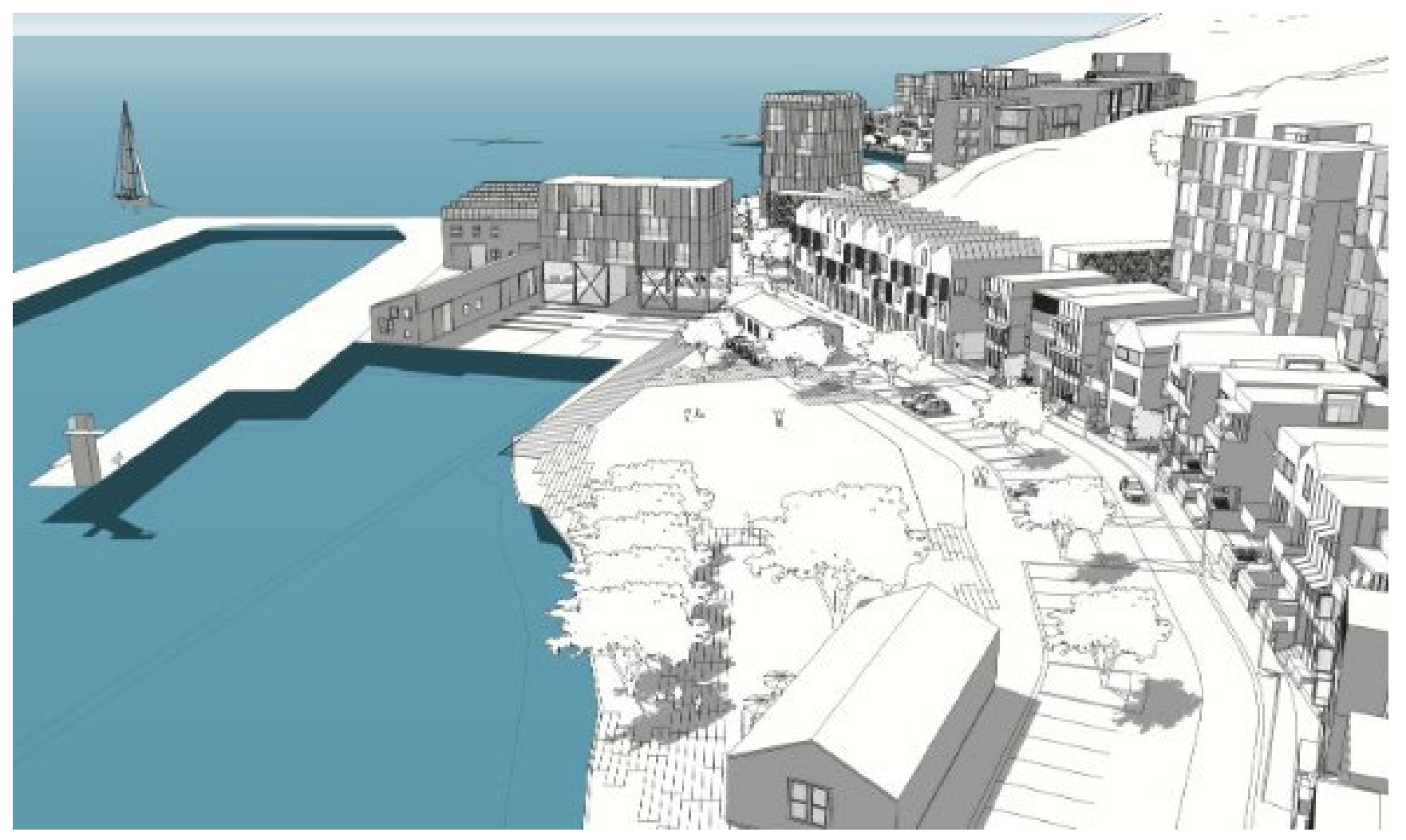

Fig 3.10 - Artists impression of the Taikuru Development. Image supplied by: The Wellington Company Ltd. 


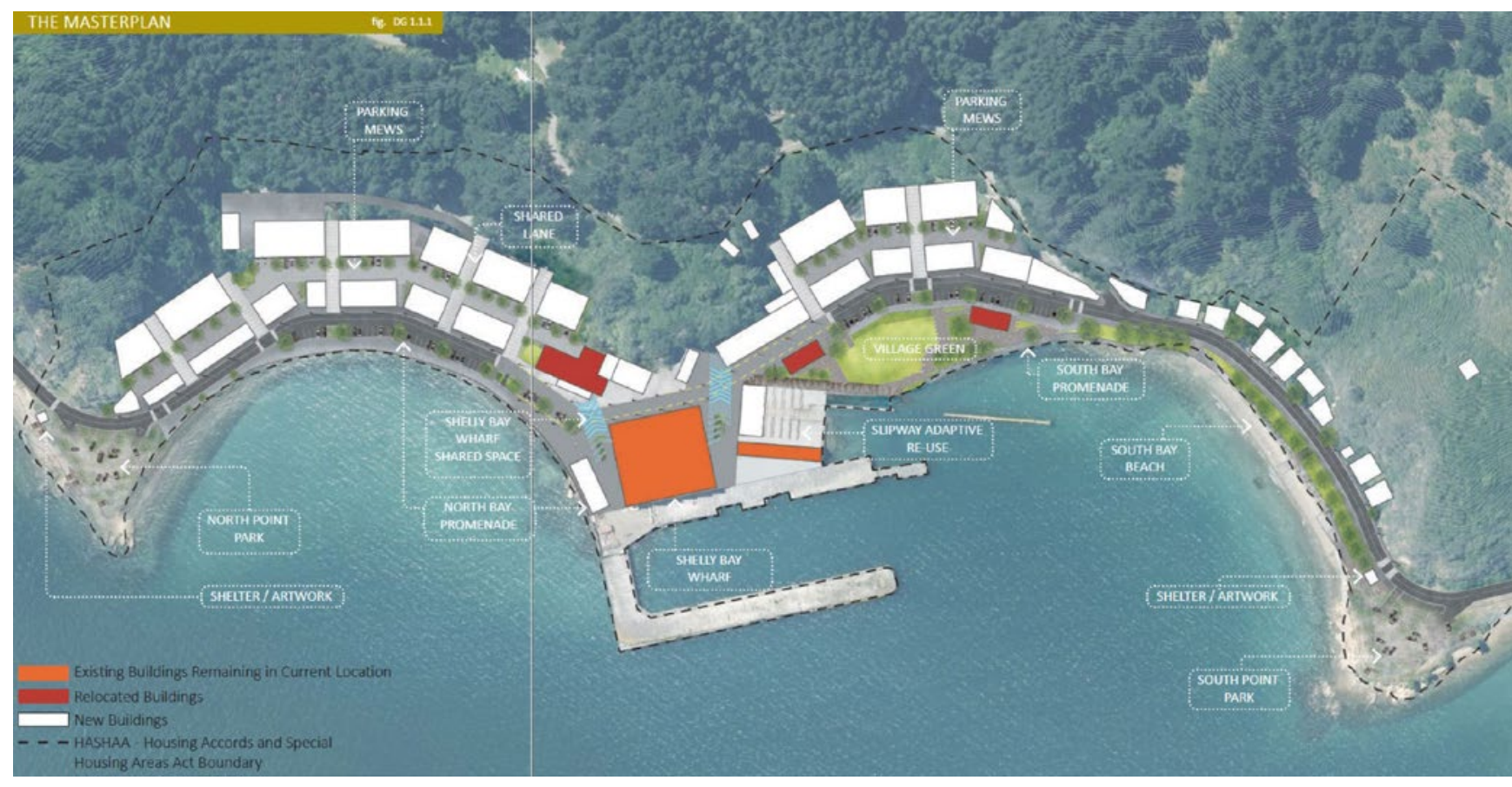

Fig 3.11 - Initial Masterplan of the Taikuru Development. Image supplied by: The Wellington Company Ltd.

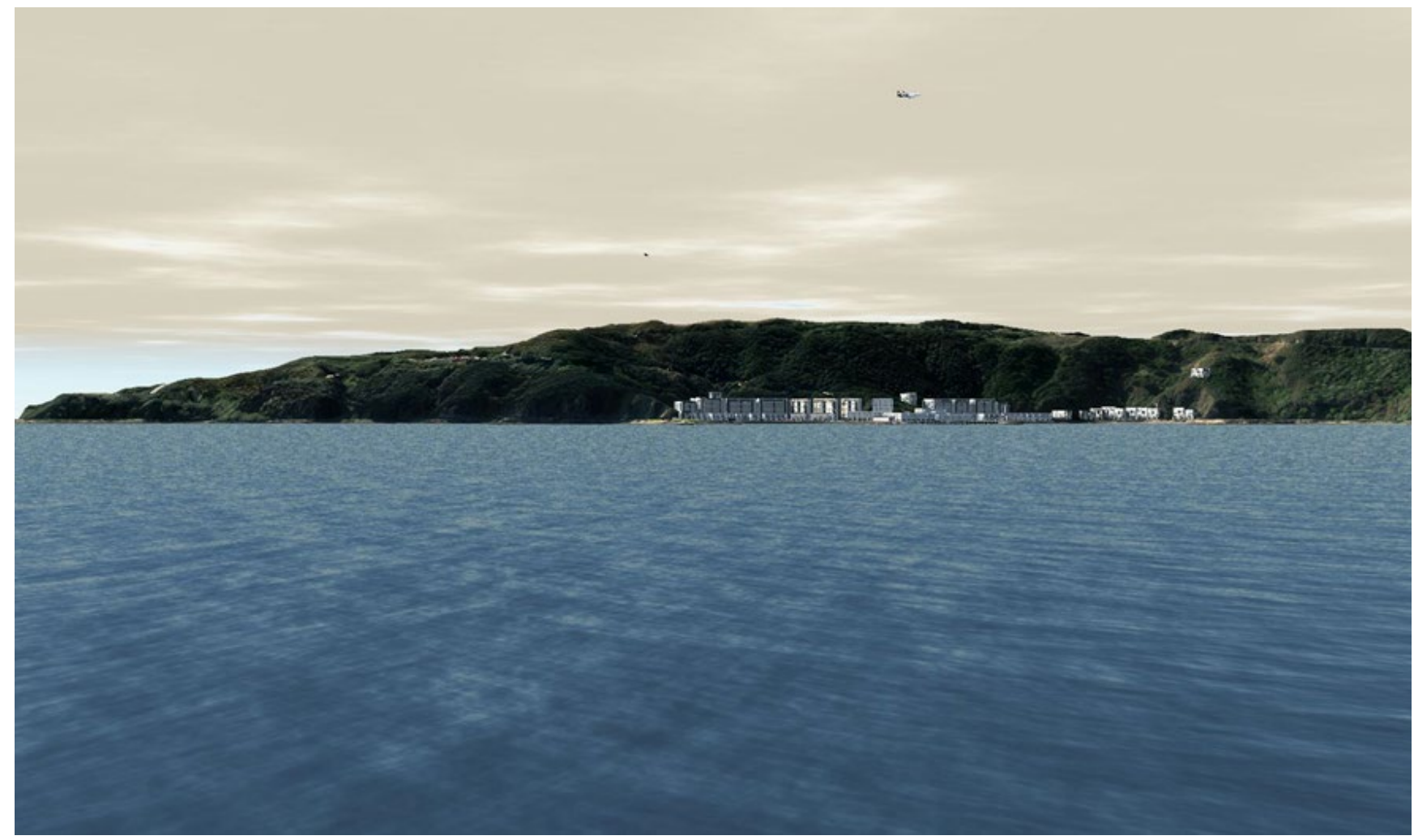

Fig 3.12 - External architects impression of the Taikuru Development - commissioned by Enterprise Miramar. Highlighting the density of the development to the surrounding coastline and hillside. Image supplied by: Enterprise Miramar 


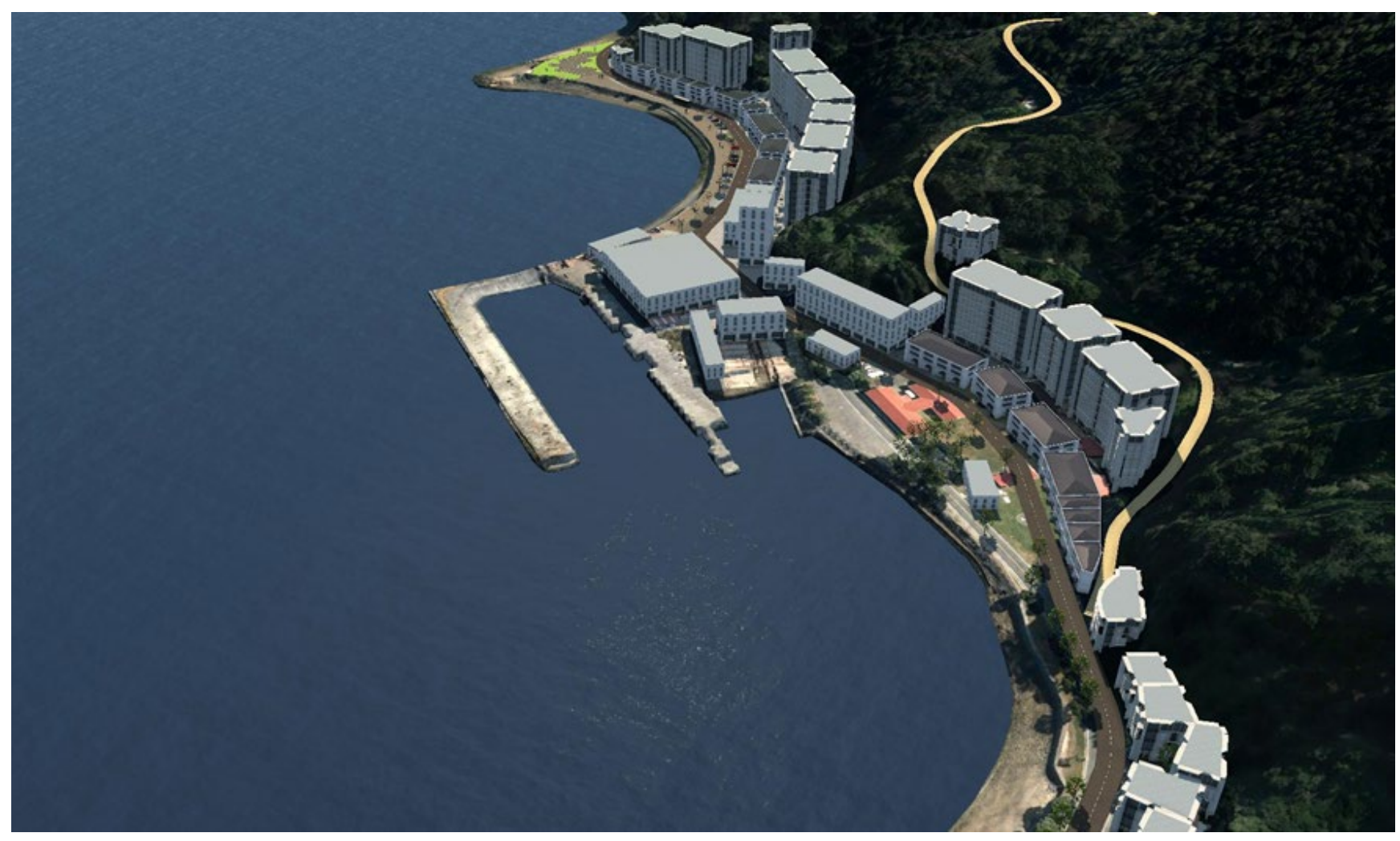

Fig 3.13 - External architects impression of the Taikuru Development - commissioned by Enterprise Miramar. Highlighting the density of the proposal. Image supplied by: Enterprise Miramar

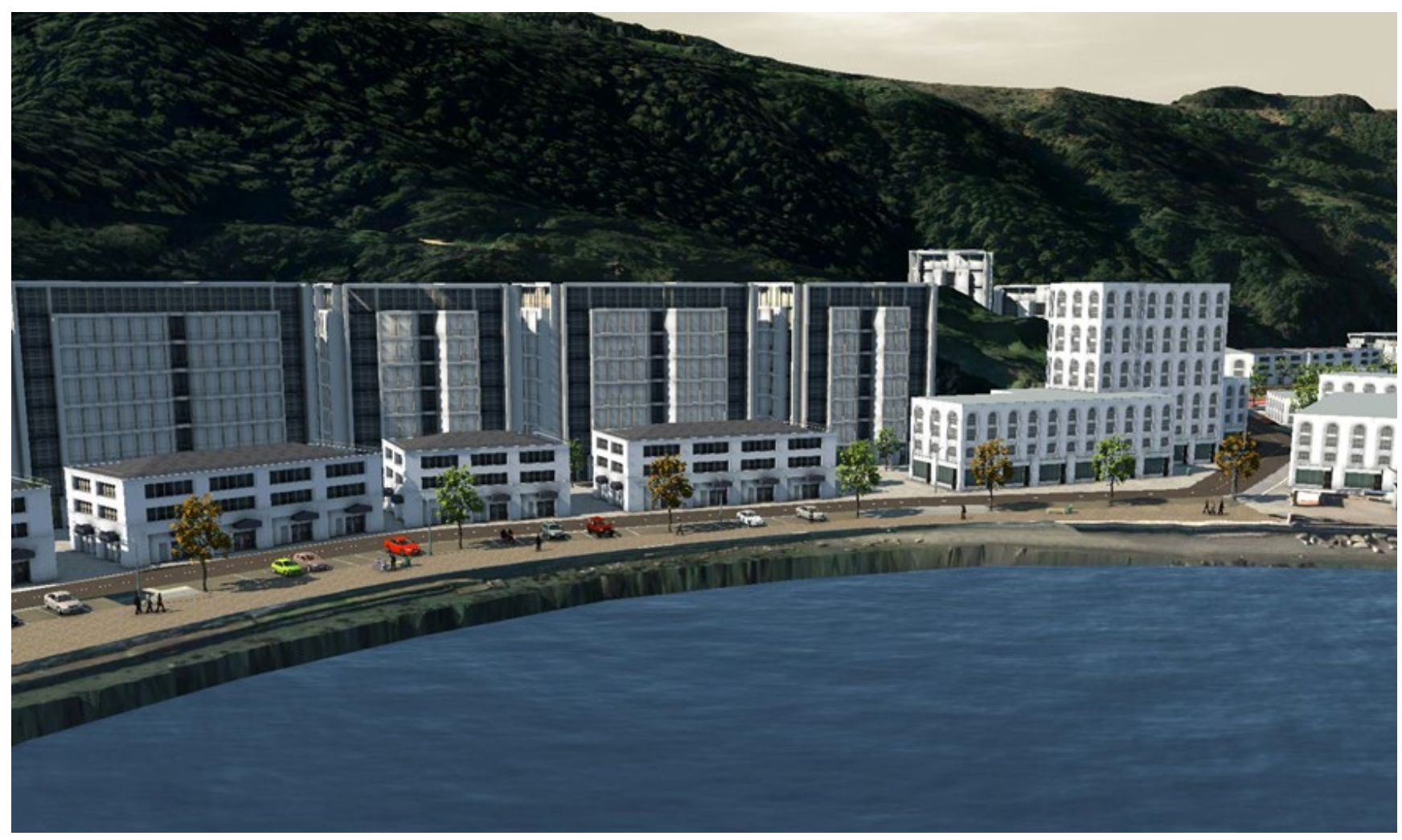

Fig 3.14 - External architects impression of the Taikuru Development - commissioned by Enterprise Miramar. Highlighting what the waterfront might look like and the proximity to the sea level. Image supplied by: Enterprise Miramar 


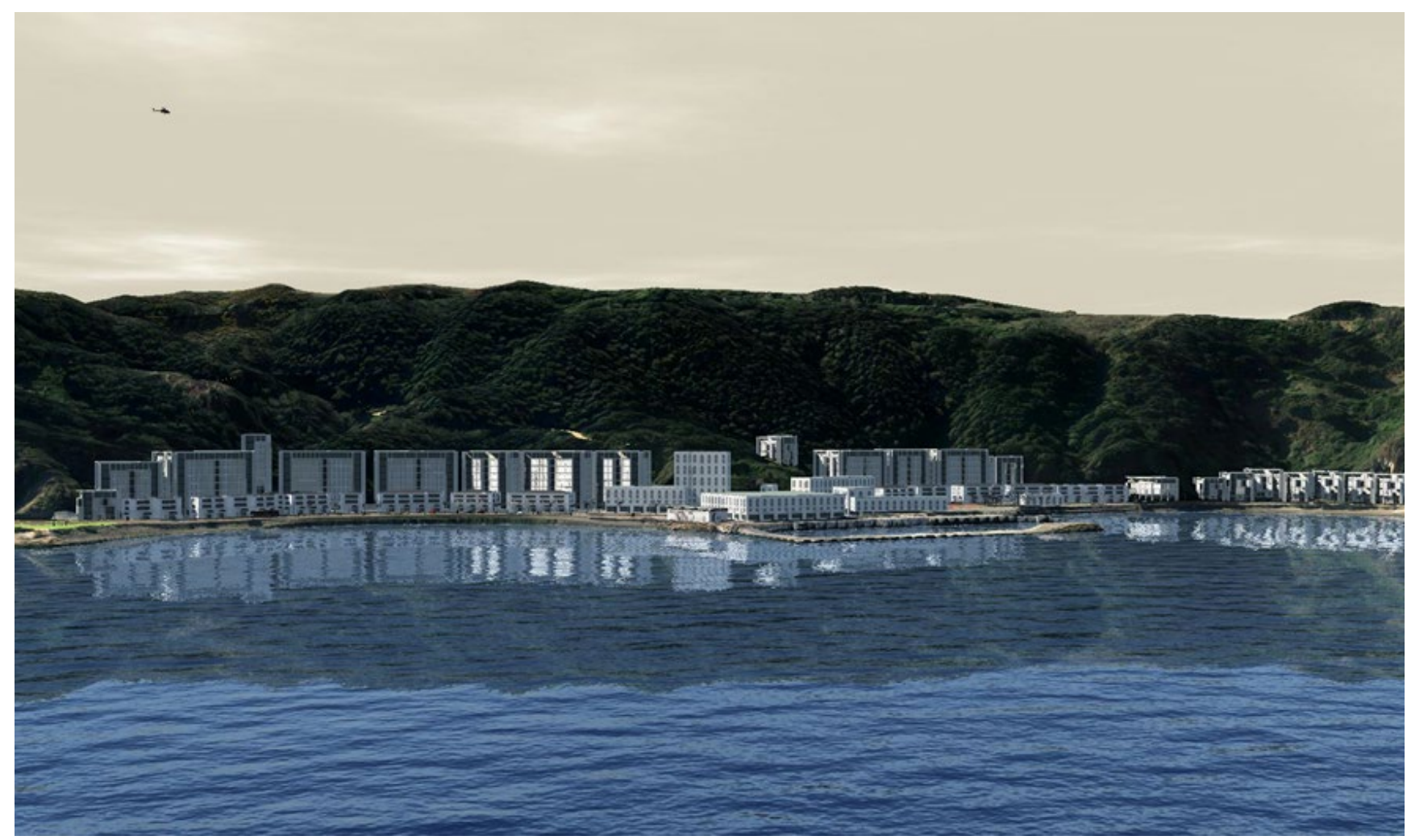

Fig 3.15 - External architects impression of the Taikuru Development - commissioned by Enterprise Miramar. Highlighting the heights of the apartment blocks against the hillside. Image supplied by: Enterprise Miramar

These include (but are not limited to): traffic congestion (estimated 4700 traffic movements per day), access to the coastline due to the widening of the road, access to the Northern end of the Miramar Peninsula over the 13 year construction period, environmental impacts, use of tax payer money towards a private development, use of the HASHAA for - presumably unaffordable housing as well as commercial services, the height and density of buildings, the lack of consideration to the wharf area, the impact and liability of rising sea levels on the future of the development as well as there being no input from the local community.
These issues are what led to EMPI launching their legal challenge over the Resource Consent application. As such the final design outcome of this research will reflect on the similarities and differences to the Taikuru development plans. 
1.7.

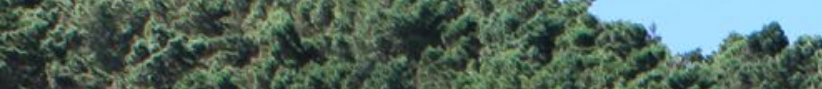

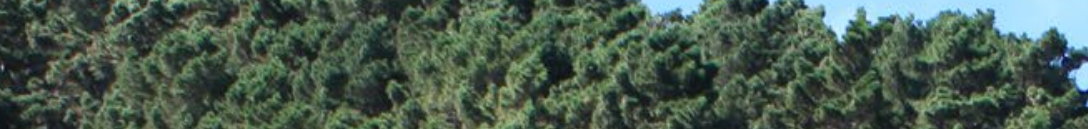

(2)

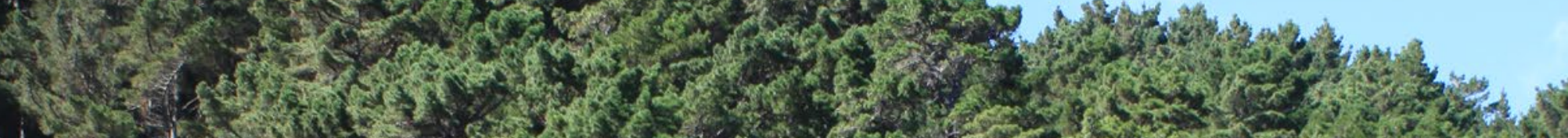

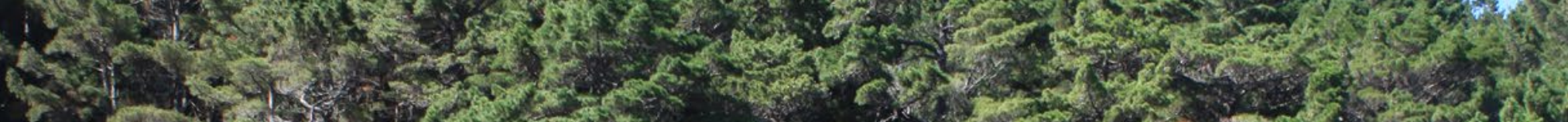

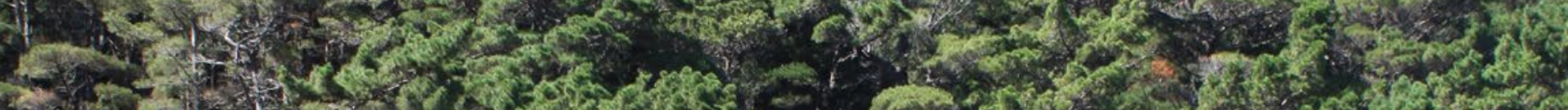

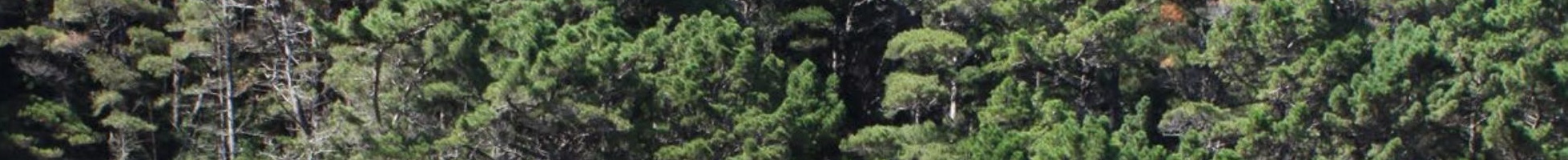

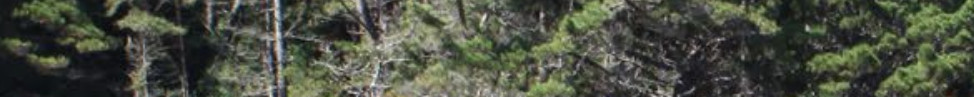

$* 2$. tist

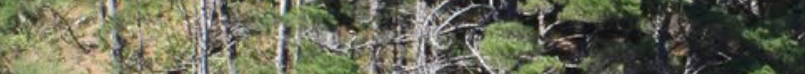

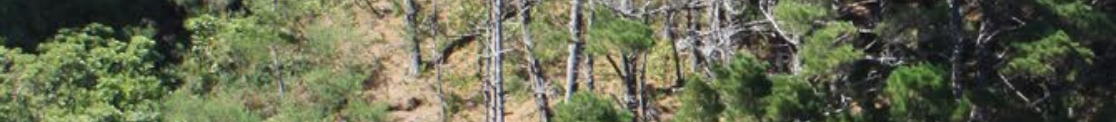

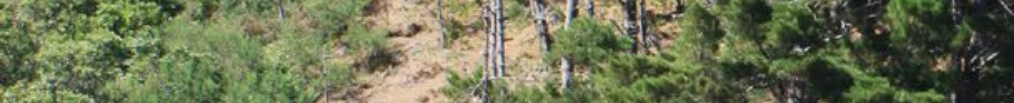

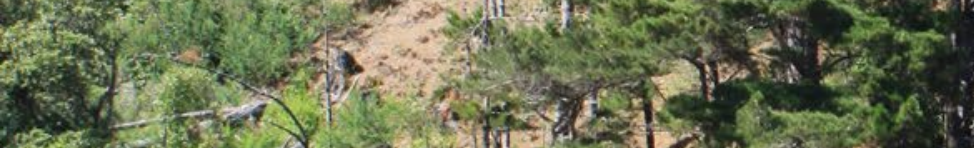

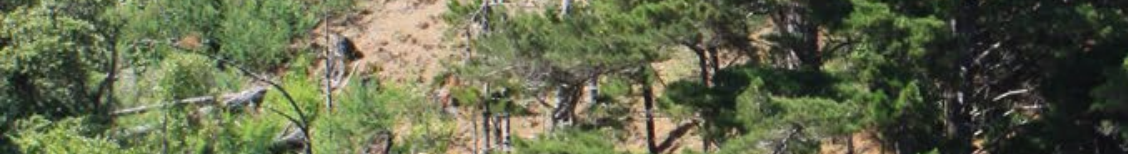

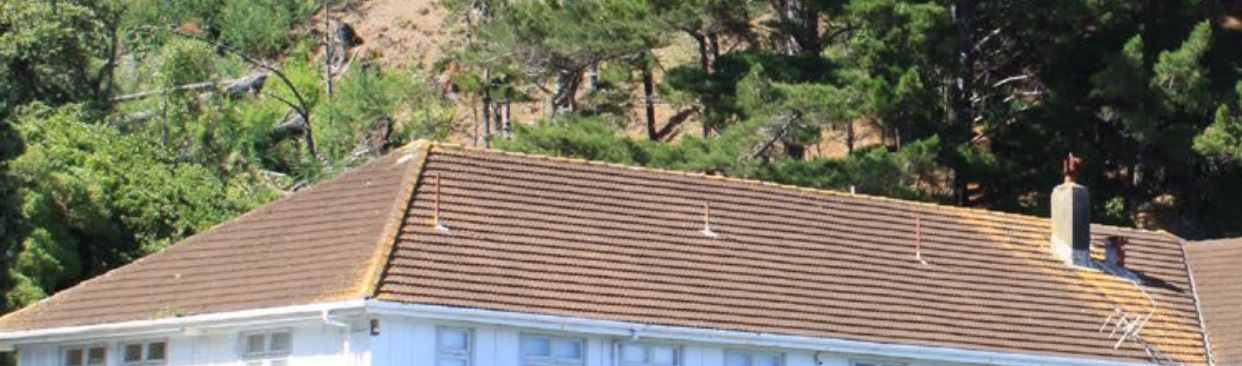

His

itit

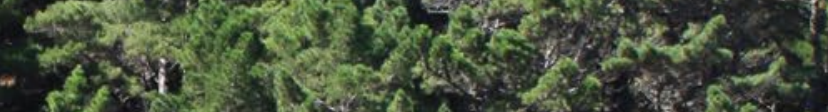

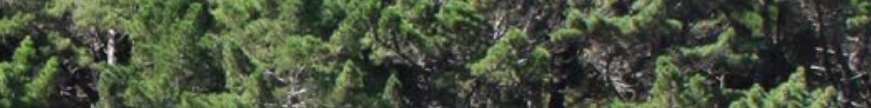

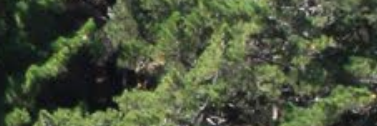
d.

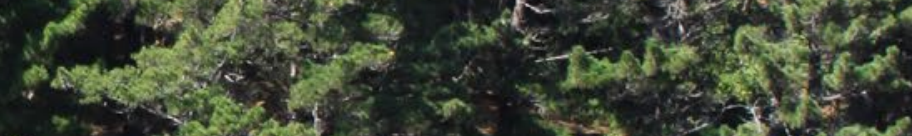

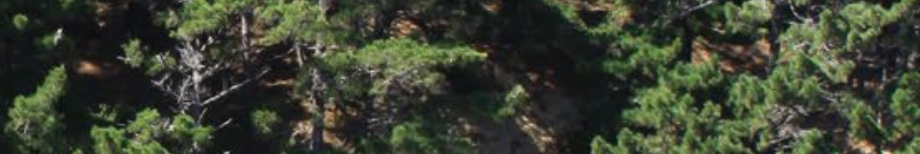
(1)

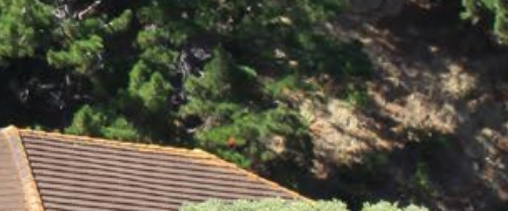

(2) 20.50

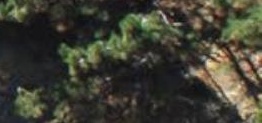
(1). II conder. 


\section{Chapter 4: Stage One - Shelly Bay, Your Way Introduction}

Stage One of this project looks at gathering both quantitative and qualitative data using traditional methods of facilitating participation.

The literature suggests that by creating and distributing a survey, it is possible to gather quantitative feedback from a larger audience and develop statistics which give a fair representation of the opinions of the community. In addition to this, interviews of members of the public and representatives of the major parties involved have been conducted to gain a qualitative understanding of what the public wants.
After collecting and analysing the data from the interaction, a series of conceptual masterplans are developed based on the findings. These masterplans are the starting point for Stage Two of the project where community members will be invited to critique the concepts. The masterplans are designed based on the trends which emerge from the public interactions - since no single plan will satisfy everyone, it is essential to derive a few options which the community can develop on. 


\section{The Survey \\ Sinform consult ainvolve $\square$ collaborate $a$ empower}

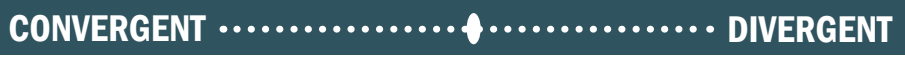

The survey titled, 'Community

Participation in Urban Design: Shelly

Bay, Your Way', was generated to gather information surrounding public participation in urban design.

Using Qualtrics' online survey software, the questionnaire was developed to collect and examine the public's consensus around what the future of Shelly Bay should look like. In addition to this, the survey asks for community members to comment on The Wellington Company's Taikuru proposal and asks them if they experienced any public interaction with the developer or design team (refer to Appendix A for a detailed list of questions and answers).

Several methods of circulation were implemented including; email, social media, community newsletters, word of mouth and flyer distribution with a goal of gaining 75-100 responses. The target group were members of the public who live in
Wellington's Eastern Suburbs; however, it was open to anyone with an interest in the area. One of the major groups of interest are Taranaki Iwi members, the rightful owners of the land, so it was important to invite them to fill out the survey as well.

The survey contained 29 questions and was estimated to take 15 minutes to complete; however, it was clear that people were passionate about getting their opinions across, with many of the responses taking in excess of 30 minutes. The survey was open to the public for three weeks, and in that time 92 responses were received; 73 of those came from people living in Wellington's Eastern Suburbs and 19 from other parts of the country. 


\section{THE RESULTS.}

Do you believe the Taikuru Development plans reflect the needs and wants of the surrounding communities?
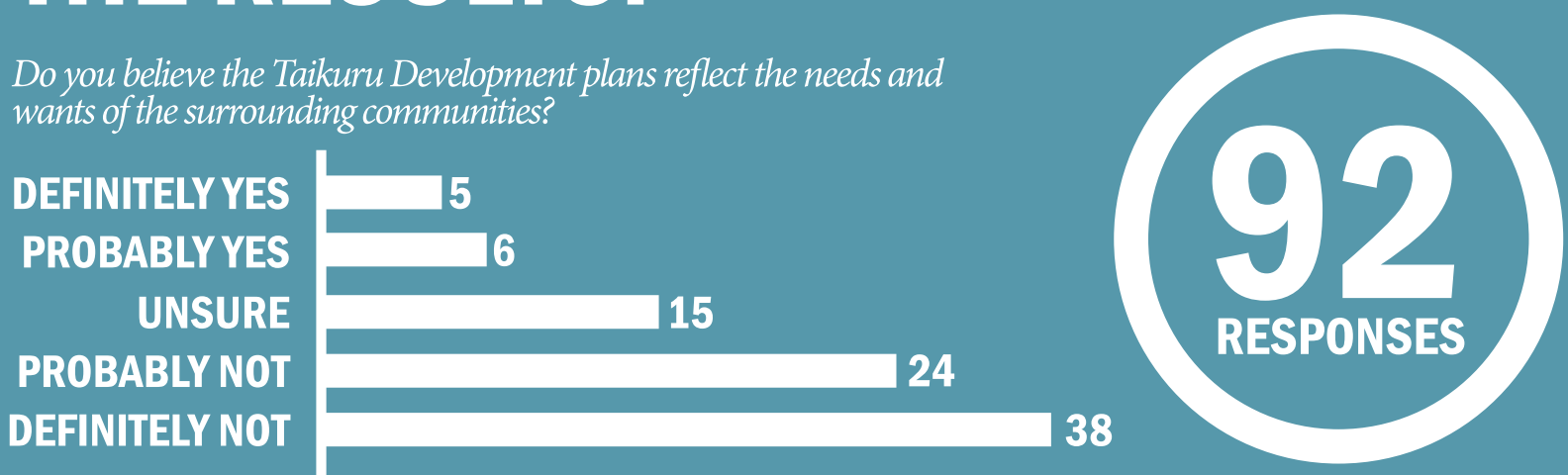

Would you like to be more involved in the planning of urban developments in your area?

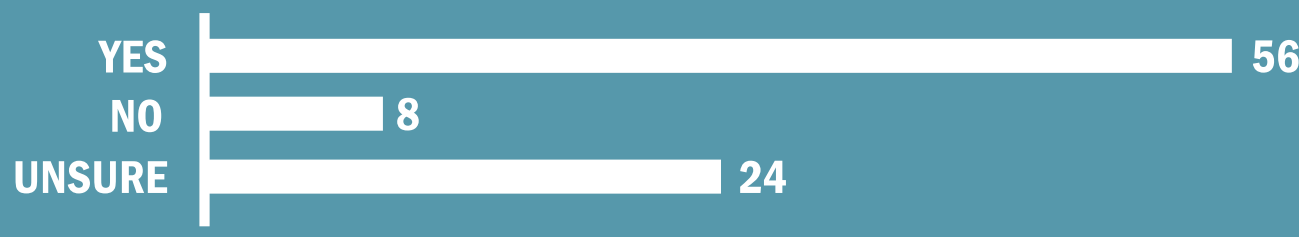

Top 5 most important contextual considerations/factors for a successful development at Shelly Bay as voted for by the public:

1. ENVIRONMENTAL IMPACT

2. ROADING INFRASTRUCTURE/TRAFFIC CONTROL

3. COASTLINE ACCESS TO PUBLIC

4. RECREATIONAL SPACES

5. COSTS TO RATE PAYERS

Were you aware of the Wellington City Councils campaign titled, "Have Your Say" where they invited public opinion as to whether they should offer land to the Shelly Bay Development?

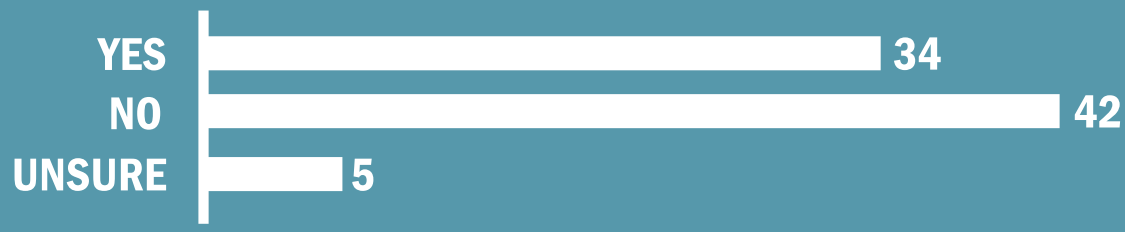

Other than the Wellington City Council's campaign titled, "Have Your Say" were you ever invited to give your opinion on the design of the Taikuru development?

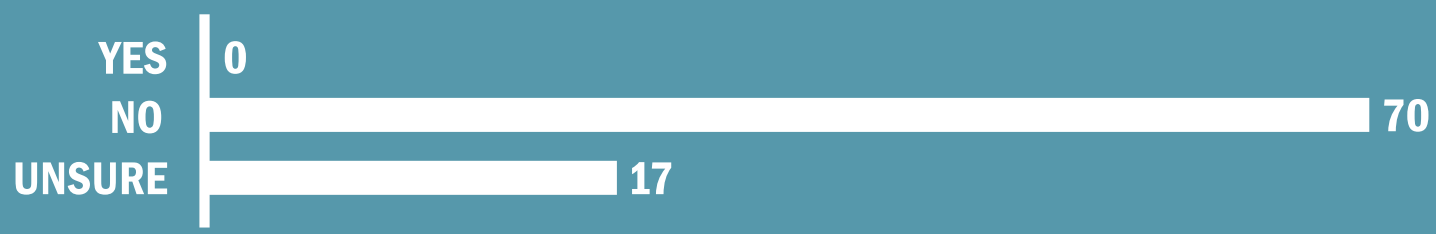

Do you believe owners of significant public assets (such as Shelly Bay) should have a duty to listen and act in the best interests of community members when developing an area?

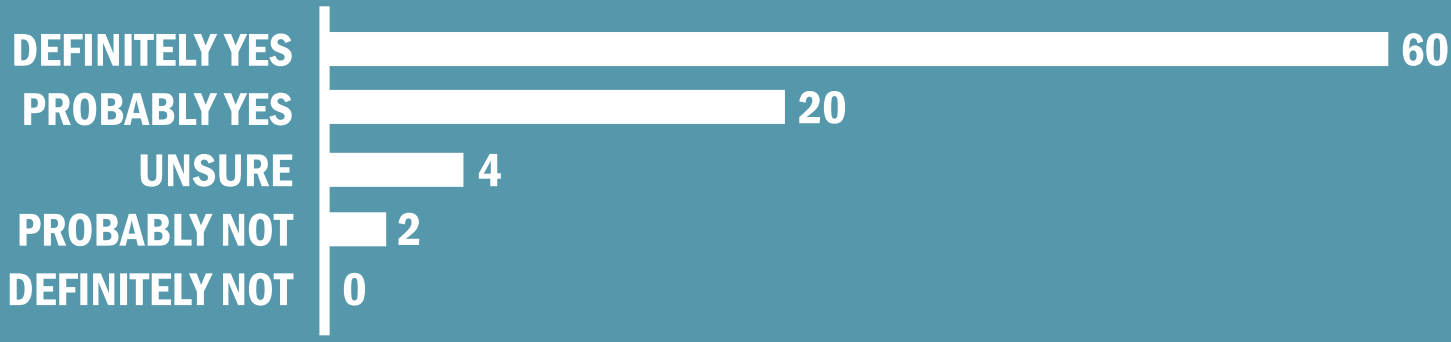




\section{Data Interpretation}

The online survey had three goals. The first was to analyse the effectiveness of an online survey as a participatory design tool. The second, to gather ideas on what the wider community want to see happen with the land at Shelly Bay. While the third was to gain a better understanding of the level of consultation community members have in urban projects compared to how involved they would like to be.

\section{Goal One:}

The survey successfully explored the Consult and Involve levels of participation, generating quantitative responses which were convergent - as a singular response but divergent as a whole. The survey had a good response rate, meeting its goal of between 75 and 100 responses. This shows that surveying, as a traditional method, works. This is likely due to its ease of access and familiarity to the public.

\section{Goal Two:}

Gathering opinions on land use through an online survey is no simple task. There is no, 'yes or no' question, which will lead to answering such a complex problem. In order to do this, people must be able to speak for themselves, in detail, through written responses. While these were cumbersome and time-consuming to analyse, they gifted the best insight into what the community actually wanted. A few of these responses have been recorded in the opposing figure (Fig 4.02).
There were a few 'check-box' questions which were useful in gathering quantitative data. The main one asked respondents to select the contextual considerations/ factors which they deemed to be important for a development at Shelly Bay. The data gathered from this ranked the factors from most important to least and set out guidelines to follow, as recommended by Henry Sanoff (seen in Fig 4.01).

\section{Goal Three:}

Researching real-world consultation, as per goal three, was much easier than goals one and two. Quantitative data can be gathered through asking simple questions such as, "were you ever asked your opinion on what should be built at Shelly Bay?" and, "would you like to be more involved in the decision-making process concerning urban developments near you?". Here the answers are straightforward.

It was found that $64 \%$ of the community wanted to be involved in the decisionmaking process for urban developments, 27\% did not and 9\% were unsure. Those who did want to be involved suggested community meetings, workshops and private submissions as possible methods of consultation.

Perhaps most importantly, when asked if they believe the Taikuru Development reflects the needs and wants of the community, $13 \%$ said yes or probably yes, $17 \%$ were unsure, and $70 \%$ responded no or probably not. 


\section{WHAT IS YOUR VISION FOR THE FUTURE OF SHELLY BAY?}

"I would like to see development that is ecologically and tikanga based with sustainability of people (especially Te Ati Awa) and environment central to it."

"Utilise the space to provide more housing and a few cafes; tidy up derelict wharf area and provide better public access. Offer public spaces so people can enjoy the area and harbour; open up better access to the walking tracks on the hill above."

"A shared recreational, housing and commercial area. A ferry service established to service the eastern suburbs and ease traffic heading into town. A few cafes that provide outdoor spaces, for visitors and locals alike. Perhaps an information office could be set up providing information for all to access on the history of the area."

"I would prefer the Defence land above Shelly Bay was developed as a recreational area open to all. Shelly Bay itself could be developed with cafes, shops and other businesses for those who use it as a recreational area. I do not favour it being a closed-off, private residential area that only benefits a few wealthy individuals and the developer."

"Needs complete overhaul; the coastal elements and the wharves should be maintained, upgraded and made fully accessible to public (including boat access). Residential volume should be managed carefully - the potential impact on traffic and resources is huge. The development itself should be a mixed use, but relatively low density affair. Cafes and restaurants, tasteful housing, perhaps some other elements."

"There should be no development prior to having the traffic and infrastructure issues resolved."

"Long-lasting development with consideration to Maori land interests and continuing the peninsula to be used for recreational purposes for sports clubs and sports events."

"We should develop Shelly Bay and the headland into a nature reserve and use Shelly Bay as the centre. Develop the forest and coast with walkways so Eastern Suburbs peoples well-being is looked after as cities get faster and denser."

"I personally love it as it is and would prefer it remain as is. If anything encourage more growth of nature. I think minimalistic development would be best -

information signs of interesting note of its history, walking routes displayed. I think the nicest idea would be create community space rather than retail space. Gardens, contemplative space, community gardens. Any environmental projects. Shelly Bay has attracted artisan craftspeople (potters, printmakers, breadmakers) so if any "retail" had to happen maybe encourage other such people to set up spaces which may be also open to workshops." public place like a specific museum or an aquarium. Something alive at day 


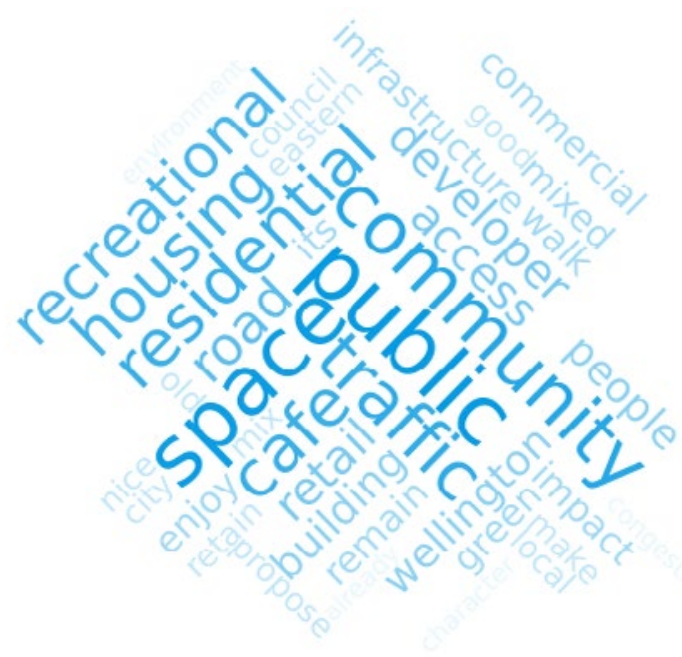

Fig 4.03 - Wordcloud generated in response to the question, "What is your personal vision for Shelly Bay?"

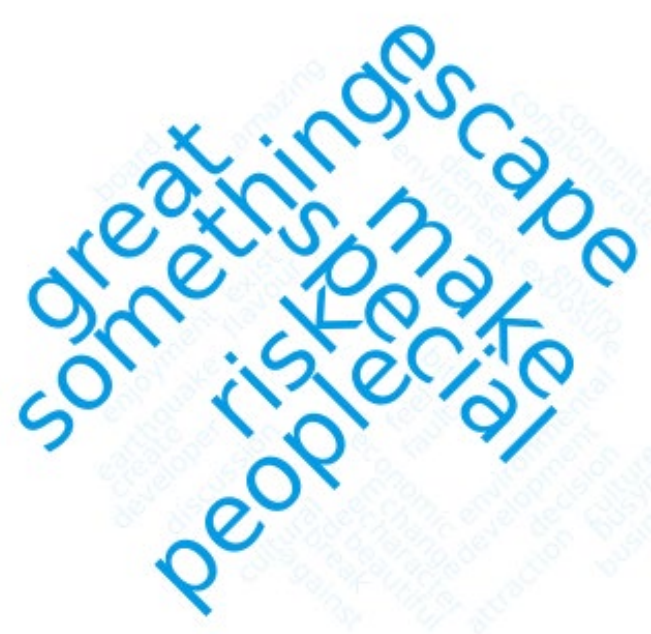

Fig 4.04 - Wordcloud generated in response to the question, "What other considerations do you see as important in a development at Shelly Bay?" 


\section{The Interview Process \\ Minform rconsult Minvolve acollaborate aempower}

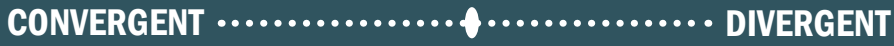

The survey stage gave the respondents the opportunity to request an interview. The purpose of these interviews was to get a better understanding of what people want to see happen with Shelly Bay; and, to gain an understanding of the interview process as a participatory design tool to gather qualitative data.

Of the 92 survey respondents, 11 requested to be interviewed further. From those 11 only 3 followed up on their request. While this is not a suitable figure to form quantitative statistics, that was not the purpose of the interview process. The interviews were initiated to gain a qualitative understanding on what a range of people with differing views would like to see considered for a development at Shelly Bay. The lack of interviewees shows that the obligation of attending an interview makes them less effective as a participatory tool.
The interviews were held in an informal manner to encourage open conversation to bring forward creative ideas. There was a basic set of questions followed (see Appendix B); however, the interviewee directed the flow of the interview. TWC, PNBST and the WCC were all approached for an interview, they either did not respond or refused, the invitation. 


\section{The Interviews}

\section{Susan Macaulay - Public Opinion}

Date: 7/09/2018

Susan established contact for an interview after seeing the survey advertised on Facebook by a local community group. Originally from Michigan, USA, Susan has lived in Wellington for the past 10 years and has been in Seatoun since 2010. Seatoun is also located on the Miramar peninsula (a 5-minute drive from Shelly Bay). She says her relationship to Shelly Bay began through her family's love for cycling and the "fantastic" Chocolate Fish Cafe.

Susan's primary concern for the planned development is safety for cyclists and access to the public; "kids on their bikes aren't always aware of their surroundings... when the weather is nice, on the weekends, there are always tonnes of cars. That is what worries me about the [proposed] Shelly Bay project". She wants to see that any development carefully considers the impact it will have on traffic congestion so not to endanger those who use Shelly Bay as a recreational area.

When questioned about the Taikuru development proposal, Susan noted her concerns; "I'm not against developing it... [but] the current plans are not family oriented and not affordable... 350 [dwellings] is too many". She compares the development plans to Oriental Bay, "but Oriental Bay has it's own traffic problems especially in the weekends". Susan believes that the current roading infrastructure is not suitable to cope with the scale of the development. It is well known amongst residents of the Miramar Peninsula that during peak times the existing roads struggle to handle the traffic with trips into the CBD (usually taking 10-15 minutes) taking in excess of half an hour.
Susan went on to describe her ideal vision for a future Shelly Bay; "I'd like to see some cafés, an ice cream parlour, [it would be] somewhere accessible by bike... it's a hub for artists in the community and I'd like to see that retained... there should be docks where boaties can come in and have lunch... nice homes, nice businesses - make it a really nice destination point!". She acknowledges that the site is not suitable for any sort of commercialised retail use and comments that she would prefer if Lyall Bay continued to expand its retail centre. Her vision for a boutique, small to medium scale destination is one shared by many of those who completed the online survey. Susan wants to keep Shelly Bay within its existing character but doesn't want heritage or history to get in the way of development - noting that while it would be "lovely" if some of the existing buildings could be retained, it is not a major concern for her (Macaulay, 2018).

Susan identified 11 factors which she deemed important to a development at Shelly Bay. These include (in no particular order): safety for cyclists, public access, traffic congestion, arts, cafés, family housing, docks/ferry service, infrastructure, history, costs to ratepayers and recreational areas. By linking each factor to those which directly relate to one another the following tree was produced (using a computer program) which groups and breaks down the factors into various branches (Fig 4.05). 


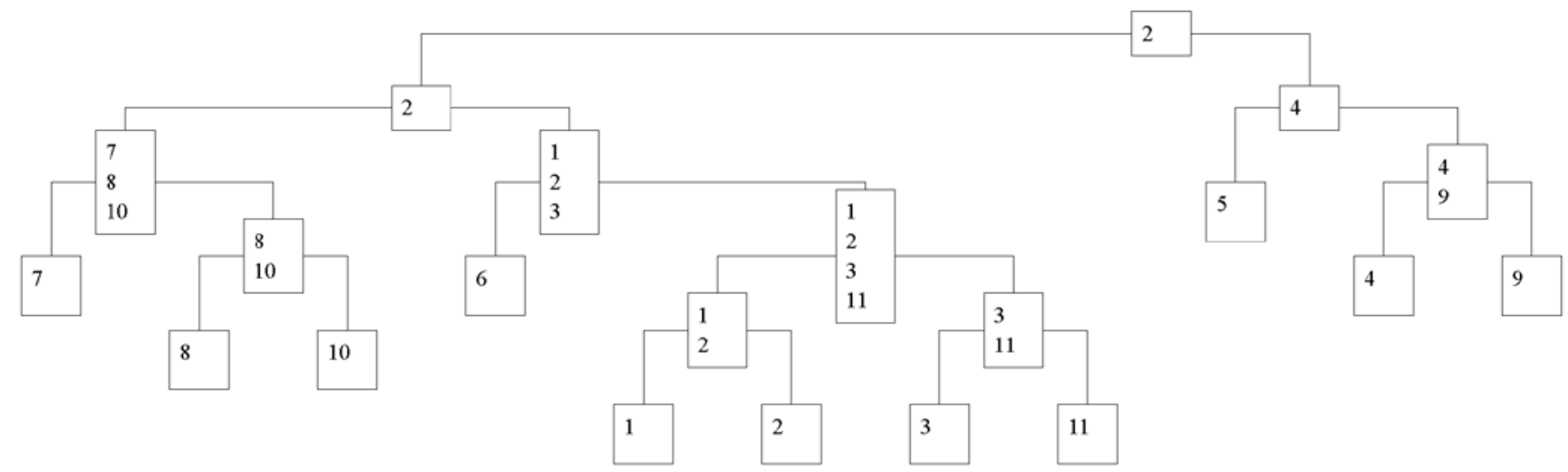

Fig 4.05 - Relationship breakdown diagram from the interview with Susan Macaulay

This diagram shows that Susan's major concern is the access of Shelly Bay to the public. This means that any development should carefully consider ownership of land, impacts of construction on road closures as well as traffic congestion and the design of suitable footpaths and cycle lanes.

From here the diagram splits off into two secondary groups, one headed by 'public access' and the other concerned with the 'arts'. The smaller group focuses on opportunities for artists and craftspeople and links them with cafés. Within this branch is a tertiary group which links 'arts' with 'history', therefore, there should be a clear connection made between the history of Shelly Bay and the spaces provided for artists and craftspeople.

The larger group is headed by 'public access' and breaks down into two tertiary groups. The smaller links together 'docks/ferry service' with 'infrastructure' and 'costs to ratepayers'. This group makes sense as any costs to infrastructure upgrades are likely to fall to the ratepayers. The final group creates links between 'safety for cyclists', 'public access' and 'traffic congestion'.
Diagram Key:

1. Safety for Cyclists

2. Public Access

3. Traffic Congestion

4. Arts

5. Cafe

6. Family Housing

7. Docks/Ferry Service

8. Infrastructure

9. History

10. Costs to Ratepayers

11. Recreational Areas

This leads to the final two breakdowns (and perhaps the most important to Susan's 'masterplan'). The first links 'safety for cyclists' with 'public access.' These were the primary concerns for Susan during the interview and go hand in hand in any design decisions. Finally, 'traffic congestion' and 'recreational areas' are grouped. This is an interesting pairing and one not apparently obvious. It may have further implications along the line as increased traffic will put recreational areas under pressure. 


\section{Mary Anderson - Public Opinion + MBID/EMPI Member}

Date: 4/09/2018

The leading figure in the protest against TWC's Taikuru proposal is Enterprise Miramar Peninsula Inc. (EMPI) - also known as MBID. Mary Anderson has worked for them since June of 2016 and since then has been heavily involved in the organisation of community projects which have had a positive impact for businesses in Miramar.

Although born in Lower Hutt, Mary spent much of her life in Taupo and Australia - on the Gold Coast. She says that living and experiencing these places which were, "very go ahead", in terms of development, she can see the issues the current plans would bring to the Miramar Peninsula. She brought up concerns around traffic congestion, environmental impacts as well as the extensive infrastructure upgrades which would fall on the shoulders of ratepayers; "It's not affordable housing, its going to cut off fishing, it's going to cut off cycling".

MBID's purpose is to look after the best interests of businesses in Miramar, "Shelly Bay is not a part of us. However, we have a memorandum of understanding [with the Wellington City Council] which says that they must consult with us on anything that will affect businesses in Miramar... we were not notified of the [Shelly Bay] resource consent application". The Taikuru development would have massive implications (both positive and negative) on Miramar, so it seems fair that Mary and MBID are upset with being kept in the dark. Unfortunately, the HASHAA only requires that the adjacent landowners are notified about the resource consent applications.

When asked on her opinion on the future of Shelly Bay, Mary responded, "I think the peninsula is an amazing place because; we've got Weta [film industry], we've got the foreshore, we've got military history, we've got Māori history. There's so much here to bring visitors in." Mary sees potential to set Shelly Bay up as an educational and recreational area to draw in tourism and is not phased on whether residential housing is included or not; "I'm not against some housing, but not on a large scale." She also notes that she would prefer to see the land which has been sold to TWC returned to the Taranaki iwi so that they can maintain ownership and earn money from their investment, "you need to ensure that money is coming in forever... not just a one-off" (Anderson, 2018).

Mary's relationship breakdown diagram identified the following 14 factors: environmental impacts, sea pollution, sea level rise, access to the public, military history, Māori history, infrastructure, costs to ratepayers, traffic congestion, education, hospitality, recreation, iwi ownership and private residential (Fig 4.06). 


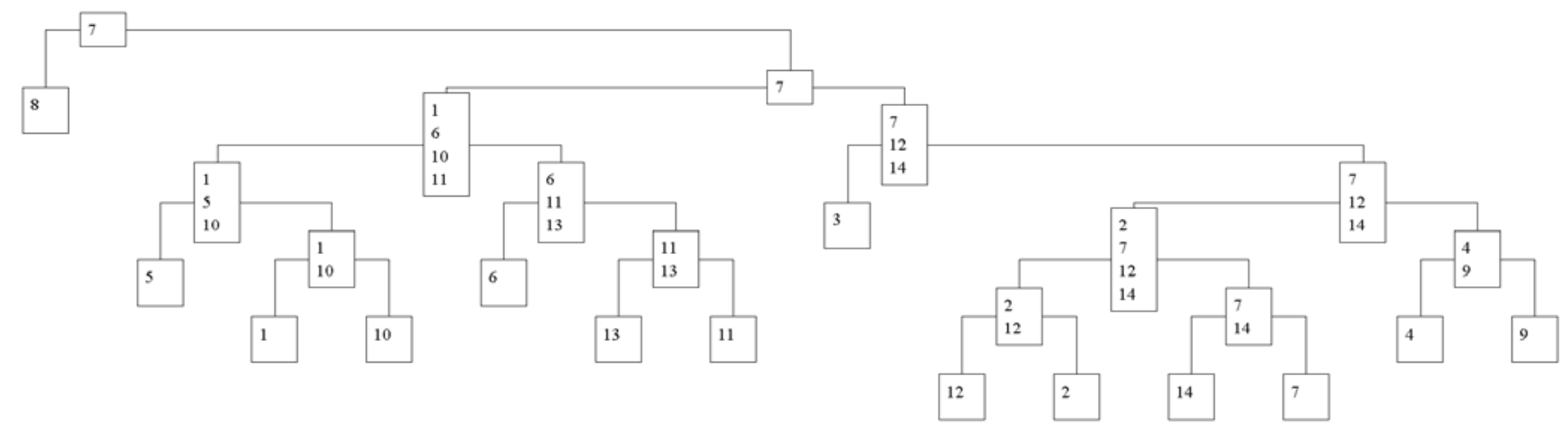

Fig 4.06 - Relationship breakdown diagram from the interview with Mary Anderson

Mary's diagram shows that her primary concern for any development at Shelly Bay deals with infrastructure. This means any plans must analyse what impact they will have on existing infrastructure and what infrastructure may need upgrading.

From here, the diagram splits into two branches. The first groups 'environmental impacts', 'Māori history', 'education' and 'hospitality'. The second links together 'infrastructure,' 'recreation' and 'private residential'. Analysing these groups it becomes clear that the first deals primarily with visitors to Shelly Bay while the second deals with potential residents.

The 'visitor' branch of Mary's tree brings forward some interesting observations. First, 'education' has been directly linked to 'environmental impacts' with 'military history' as a secondary factor. This suggests that any education facilities should be sympathetic to both its environment
Diagram Key:

1- Environmental Impacts

2 - Sea Pollution

3 - Sea Level Rise

4 - Access to Public

5 - Military History

6 - Māori History

7 - Infrastructure

8 - Cost to Ratepayers

9 - Traffic Congestion

10 - Education

11 - Hospitality

12- Recreation

13 - Iwi Ownership

14 - Residential - Private

and its previous use as a military base. The next observation links 'hospitality' and 'Iwi ownership' directly with 'Māori History'. Mary indicated this throughout her interview as she, on several occasions, insisted that the land should be owned by the Taranaki Iwi and any facilities run by them where possible. 


\section{Tim Alexander - Public Opinion + Weta Digital}

Date: 14/09/2018

Following the interview with Mary Anderson, she organised an interview with Tim Alexander. Tim is the data centre manager at Weta Digital and was a member of MBID for four years. He has been extensively involved in MBID/EMPI's court case against the Taikuru development and wanted to discuss his vision for the future of Shelly Bay.

Tim does not see Shelly Bay as an appropriate space for residential development and points to other suburbs in the Miramar peninsula better suited, such as Strathmore Park. He warns that the Taikuru plans will lead to something that looks like "Greta Point on steroids". Greta Point is located directly across the harbour from Shelly Bay and is an example of a large-scale residential development on the foreshore - it is criticised by many for being an eyesore. He would prefer to see it utilised as a recreational space to draw in tourists and provide enjoyment to all Wellingtonians, "there is no reason why with the Weta group of companies and the people of Wellington - that this could not be a successful development, away from housing."

In terms of recreation, Tim explains; "South Bay could be an open space... you could look at a pathway, up the hillside, through to the top of Watts Peninsula. It could be a very exciting area that would bring tourists in." He discussed the possibilities of having a luge run from the top of the hill along with mountain bike tracks and several picnic areas. In addition to this, he would like to see a new wharf with a ferry service which could connect people to the city, Somes Island and Eastbourne - creating a structured route for tourists.

Tim sees a wonderful opportunity to create an area of interest at Shelly Bay, "people could land and be there in less than 20 minutes". He played with the idea of creating a museum to house Māori artefacts and art and pointed to renowned Māori artist Darcy Nicholas who currently has an exhibition travelling the US but has nowhere to display it once it returns to New Zealand. This would also create an opportunity for iwi to get involved in the management of the museum.

Speaking in regards to the Taikuru plans, Tim queries the WCC's decision to support it as the New Zealand Government has instructed councils to not grant building consents for any buildings which lie within $1.9 \mathrm{~m}$ of the high tide line; "South Bay is $1.6 m$ above the high tide mark... there should be no building there until this is taken into account... North Bay is only $2.2 m$ high." This could result in insurance companies refusing to cover the project which would mean that the WCC (and thus Wellington ratepayers) would be responsible for covering major damages.

Tim also explored other ideas including creating educational facilities where Weta employees could teach when they are in between film contracts. As well as the potential to create augmented reality tours. Visitors could put on a headset and walk 


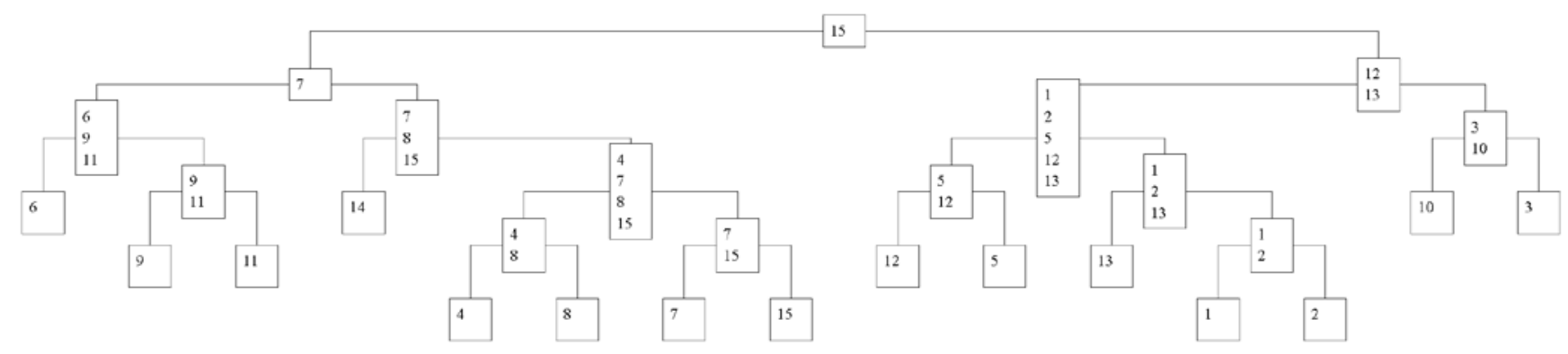

Fig 4.07 - Relationship breakdown diagram from the interview with Tim Alexander

around, exploring what Shelly Bay used to look like throughout various points in history; "people couldn't even imagine what it would be like [if Weta was involved] ... it is such a wasted opportunity... you need to have people with vision and motivation" (Alexander, 2018).

Tim's relationship breakdown diagram identified the following 15 factors: impacts on the bays before Shelly Bay, traffic congestion, sea level rise, blending into the hillside, costs to ratepayers, archaeological sites, history, Māori arts museum, iwi engagement and ownership, recreational and green spaces, education, cyclist safety, access to public, technology and tourism (Fig 4.07).

Tim's tree shows that his primary concern for any development at Shelly Bay deals with tourism. From here the tree splits off into two secondary branches; one headed by 'history' - the other 'cyclist safety' and 'access to the public'. The 'cyclist safety' and 'access to public' branch covers most of the primary concerns held by many around infrastructure, traffic congestion and costs to rate payers. All of these are important but require little in the way of analysis.
Diagram Key:

1. Impact on bays before Shelly Bay

2. Traffic Congestion

3. Sea Level Rise

4. Blend into hillside

5. Costs to ratepayers

6. Archaeological Sites

7. History (Military and Māori)

8. Māori Arts Museum

9. Iwi Engagement and Ownership

10. Recreational and Green Spaces

11. Education

12. Cyclist Safety

13. Access to Public

14. Technology (Augmented reality tours)

15. Tourism (Landmark)

The history branch splits into two tertiary groups; the first focuses on 'archaeological sites', 'education' and 'iwi engagement'. This could point to creating an education facility focussing on Māori teachings or Māori students - in collaboration with Weta. The second group focuses on the Māori arts museum and incorporates this with technology and history. Calling for a state-of-the-art facility that draws in tourism - creating a landmark for the city of Wellington and celebrating Māori arts and history. 


\section{Other Consultations}

Meetings with Enterprise Miramar Peninsula Inc. (EMPI)

Enterprise Miramar has been the major contact for this research thesis throughout its duration. There have been several meetings where they have discussed what they wish to see happen with Shelly Bay much of which is a combination of what both Mary Anderson and Tim Alexander envisage.

The consensus from the various meetings is that EMPI wish to see the land at Shelly Bay returned to the PNBST so that they can work together with the Mau Whenua group and come to an agreement to utilise the land better so that it can provide a steady revenue stream to beneficiaries for generations to come.

While EMPI would like to see the land used for recreational, cultural and tourist activities it recognises that Taranaki Iwi are the rightful guardians of the land and they can use it how they please. So long as the Trustees of the PNBST listen to the wishes of whom they represent, then there will be no further protest from EMPI.

EMPI has taken a great deal of interest in this research and its findings. As such they have taken it upon themselves to work with the researcher to hold their own community consultations where they are asking Wellingtonians to have their say on what they want to see happen to the Miramar Peninsula over the next few decades. This consultation not only includes Shelly Bay but the rest of the Peninsula as well. They have begun with an online survey and will move onto community meetings at later stages - once the survey data has been collated. These findings will then be presented to the Wellington City Council and a plan put in place. 


\section{Meetings with Mau Whenua}

Mau Whenua first became known to the researcher after a meeting with EMPI. This led to attending a hui (meeting) midAugust, 2018 with members of the Mau Whenua group and their lawyers. This was when they were in the early stages of attempting to get the land at Shelly Bay returned to the PNBST.

Since the initial encounter, there have been several meetings held with members of Mau Whenua. While most of them are focussed on their legal pursuit, there were occasions where they discussed their vision for Shelly Bay.
The members of Mau Whenua who were spoken to have a shared vision where Shelly Bay would not be used for a residential development but instead focus on Māori tikanga (culture) and showcasing this to tourists while also providing a home away from home for Taranaki Iwi who are living in Te Whanganui-a-Tara (Wellington).

Unfortunately, these meetings took place after Stage One was completed and midway through Stage Two. Because of this, it was not possible to include Mau Whenua's vision in either stage of the research. 


\section{Conclusion}

Stage One utilised traditional methods of surveying and interviewing; these methods relate to the 'Consult' and 'Involve' stages of the IAP2 Spectrum of Public Participation.

The online surveying phase was the most effective with 92 people responding.

While this number is small compared to the actual population of the Eastern Suburbs $\sim 35,000$ (.idcommunity, 2013), it is a large enough sample size to gain an understanding of the issues brought up by the public.

A reflection of the survey found that it was too long; many of the questions asked could have been taken out as they did not have a direct influence on the design outcome of this research. Some participants took close to an hour to finish, while others took barely 10 minutes. If there were to be another survey, it would ensure that every question asked would aid in resolving the design outcome. This would reduce the time spent by the participants and would stop people giving up halfway through.
The interviewing stage offered the public the chance to speak to the researcher directly about their views for Shelly Bay. This was successful in delving deeper into their personal view with the ability to discuss building types and design ideas.

However, the number of interviews conducted was poor (three members of the public plus consultations with Enterprise Miramar and Mau Whenua). Confirming that more time-consuming consultation approaches receive less responses.

Nevertheless, Stage One provided valuable quantitative and qualitative data which can be used to influence Stage Two. It also confirms that traditional methods of participation work due to their familiarity to the public and ease of completion. 


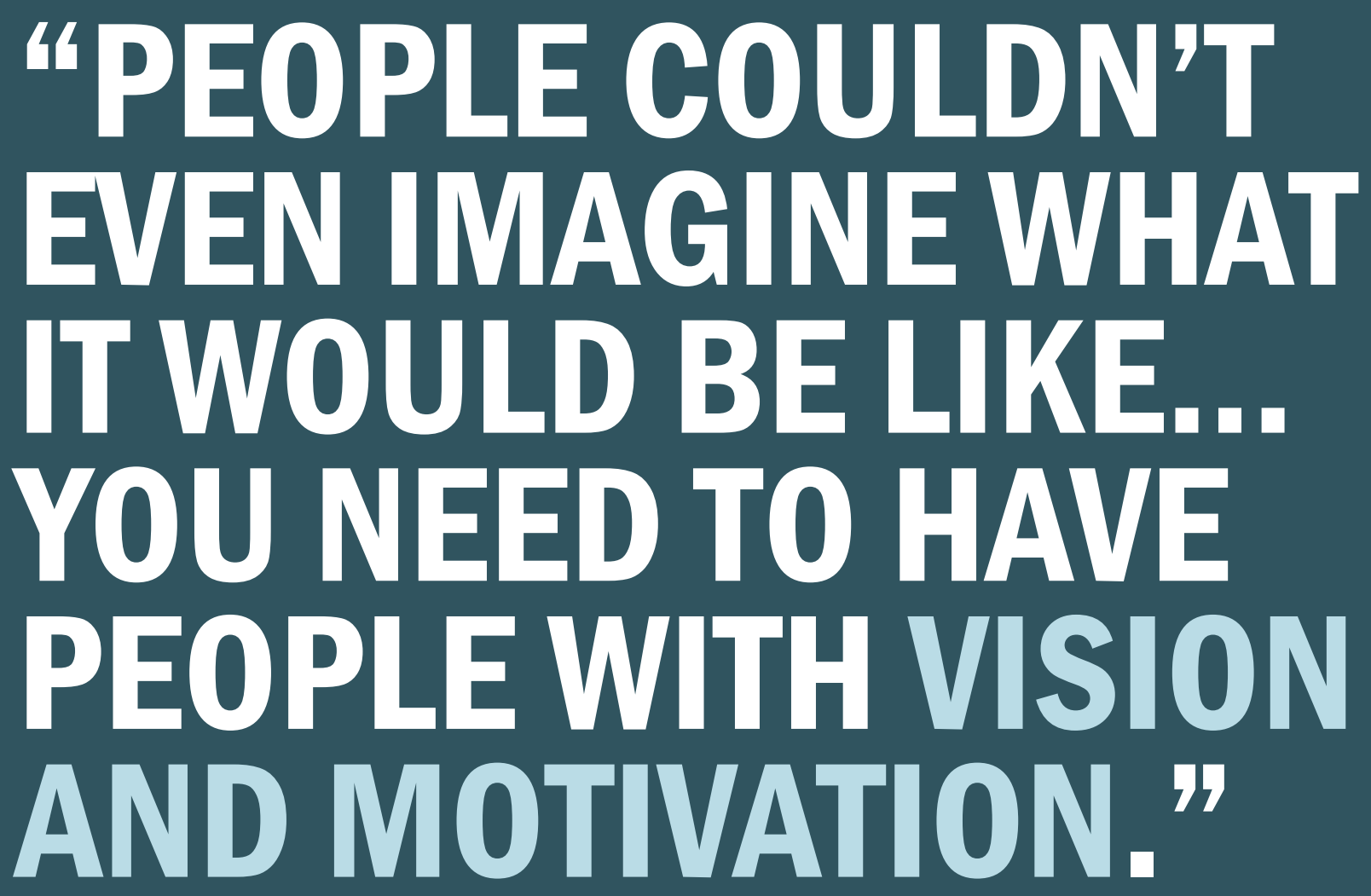

- TIM ALEXANDER (2018) 


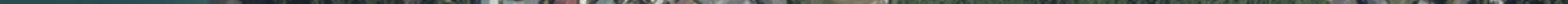




\section{Chapter 5: Stage One - Concept Design Background}

The data collected from Stage One has been analysed to pick out trends concerning collective visions for a future Shelly Bay. These trends have been distilled and refined into three concepts.

These concepts are defined as:

\section{Residential}

2. Tourism

3. Community Hub

From each of these concepts, a masterplan has been developed. These masterplans will then be presented to members of the public the second consultation where they can critique and alter each concept to fit what they desire.

At this stage, the purpose of the concepts are to inform the public on the possibilities of what Shelly Bay could be and; therefore, they are not refined at great detail. By keeping the concepts as a masterplan, using basic blocking to represent buildings, this gives the community more freedom to participate with design decisions. The public should feel like they have control over the design - not led to it. The role of the designer is not to enforce but rather to guide and facilitate the generation of creative ideas (Aguirre, M., Agudelo, N., \& Romn, J., 2017).

The concepts were not developed in the traditional sense where an architect might give a client a few different options and develop one from that point onwards. Instead, these concepts are to act as influencers or thought-provokers in Stage Two of the consultation process. It is likely that the final outcome will place itself somewhere in-between these three concepts.

It would have been useful to explore a concept based solely on the wishes of the iwi via the Mau Whenua group. Unfortunately, the majority of the consultations with Mau Whenua occurred after Stage One was completed, and after the Stage Two booklets were released to community members. The role of the iwi in the design is something which should be explored further following the completion of this research. 


\section{Concept One - Residential}

The results of the survey suggested that a significant proportion of the community want to see Shelly Bay become a lowdensity residential and mixed-use area. The key here is 'low-density' which is in stark contrast to what we see with the Taikuru Development plan.

This concept takes precedent from the rest of the Miramar Peninsula coastline where residential areas have been implemented. This includes areas such as the Karaka Bays, Worser Bay, Seatoun, Breaker Bay and Moa Point.

The residential development should look organic and draw upon the other bays from precedence; meanwhile, the town centre should reflect the history and character of Shelly Bay. A significant focus of the design is on recreational green spaces which tie into the beach areas and wharf space. The vision for this concept is a relaxing seaside community.
The key considerations for this concept include:

1. Environmental Impacts

2. Infrastructure \& Traffic Control

3. Coastline Access to the Public

4. Recreation

5. Low-Density Residential

6. Full or Partial Iwi Ownership

7. Safety for Cyclists \& Pedestrians

8. Functional Wharf \& Ferry Service

9. Wellington District Plan

10. Public Amenities \& Spaces

11. Retaining the Character of S.B 


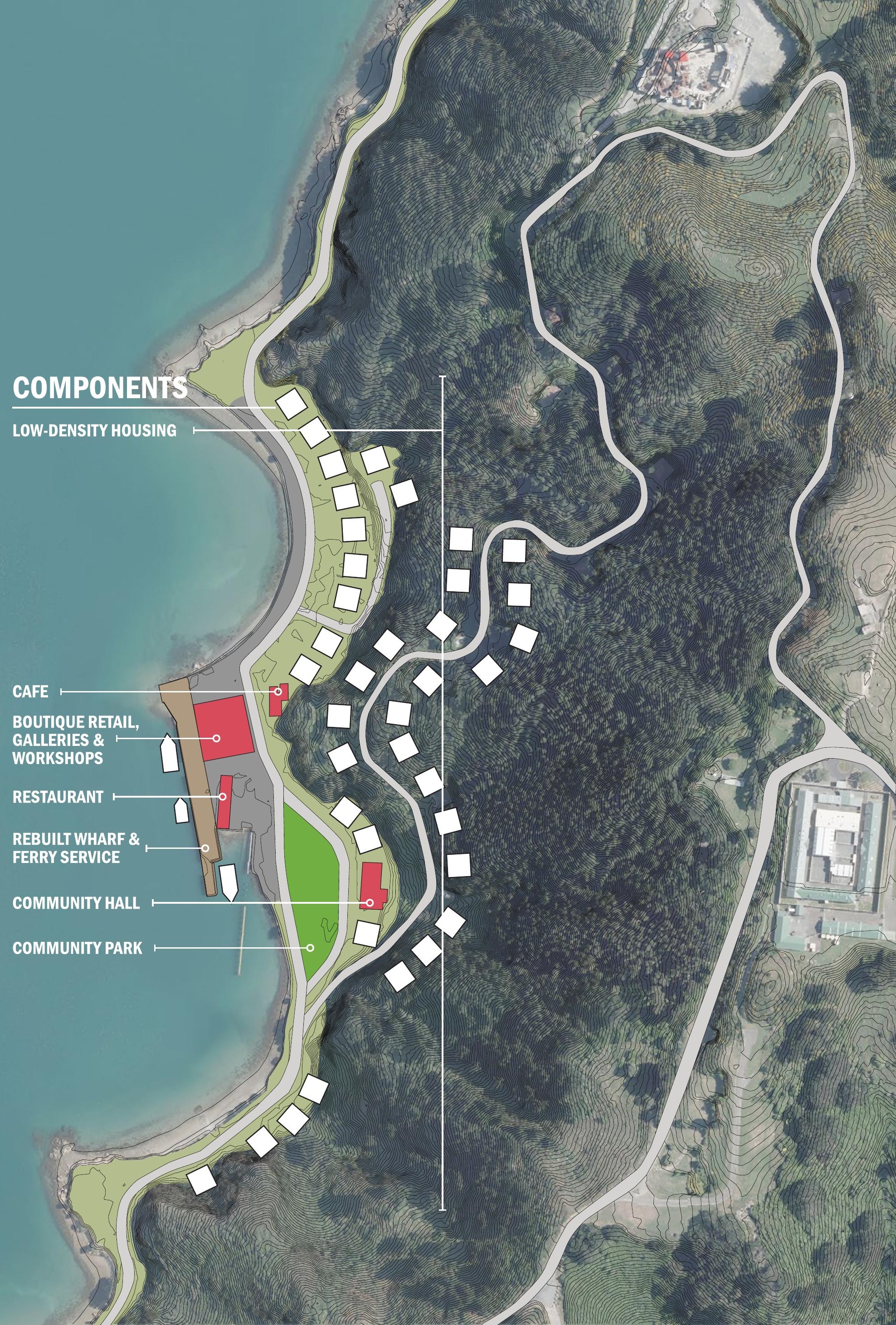




\section{Concept Two - Tourism \& Recreation}

The next concept was influenced primarily through interviews with Tim Alexander and Mary Anderson.

Flying into Wellington, during a southerly wind, leads planes low past Shelly Bay effectively advertising itself to tourists. One option is to utilise Shelly Bay for tourism through recreation, culture and leisure. This concept negates the impact of housing by ruling it out completely.

This concept intends to open up the hillside and link Watts Peninsula, Mt. Crawford Prison, the military bunkers and Massey Memorial to Shelly Bay. This will be achieved by introducing walking and mountain biking tracks as well as a luge and gondola service. It could also be an option to offer historical tours around the various sites.

A key point raised in the interviews is that both Tim and Mary (Weta and MBID/ EMPI representatives) wish the land to be owned by the Taranaki iwi so that they can continually earn a profit back on their investment. The suggestion of an iwioperated Māori arts and artefacts museum would suit both the site and its designation as a tourist destination.

The key considerations for this concept include:

1. Tourism \& Recreation

2. Coastline Access

3. Amenities to Support Tourists

4. Develop the Hillside for Recreational Use

5. Green Spaces \& Picnic Areas

6. Māori Arts \& Artefacts Museum

7. Connect and Express the History of S.B (Māori \& Military)

8. Make S.B a Landmark

9. Complement the Landscape

10. Environmental Impact

11. Wharf \& Ferry Service

12. Iwi Ownership 


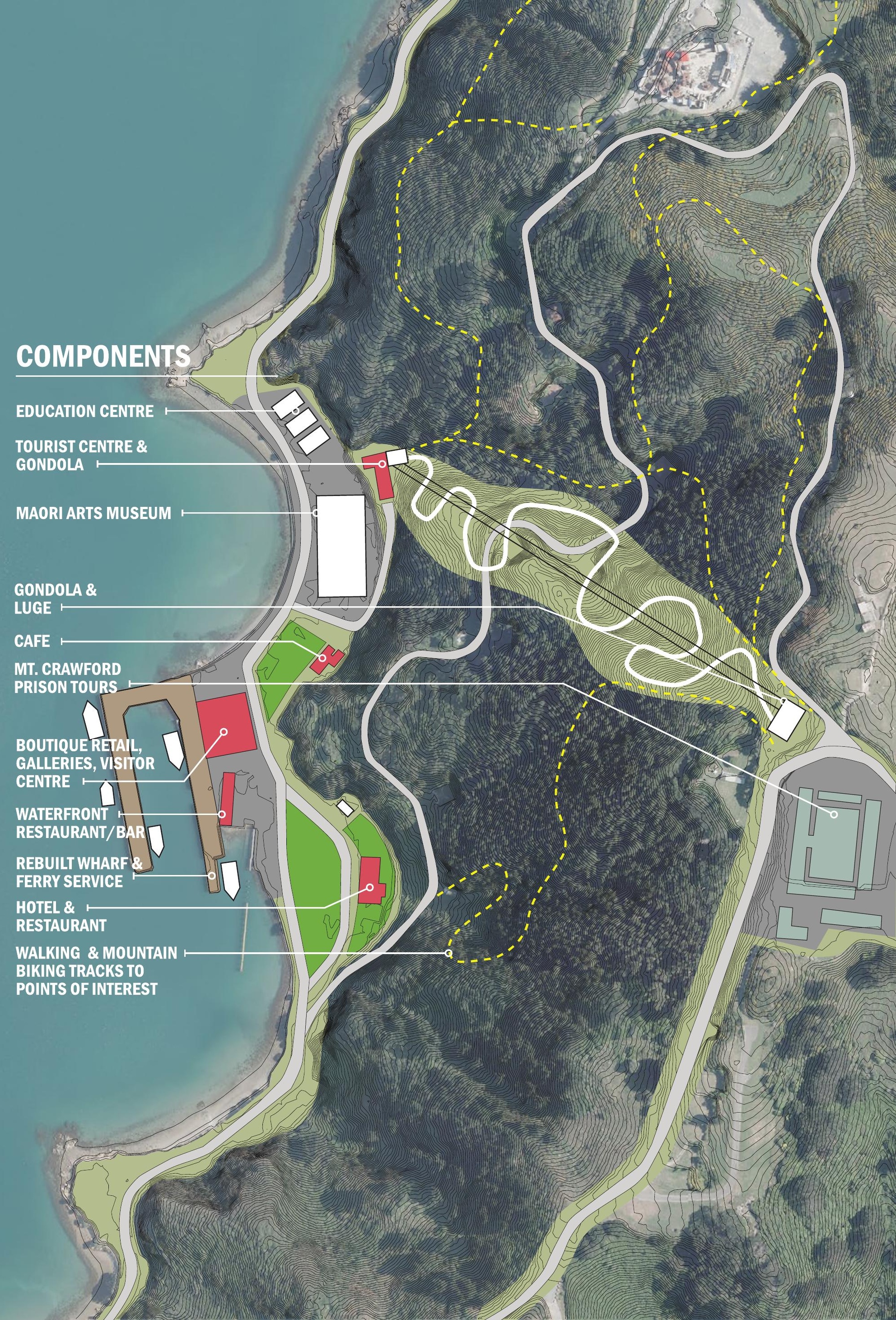




\section{Concept Three - Community Hub}

Concept three was influenced by feedback from the surveys and the interview with Susan Macaulay. It aims to support the existing craftspeople, artists, bakers, cafes etc. who are the heart of Shelly Bay as it exists today. It will build on this by transforming the area into a community hub where people can hire studios or workshops. There will be community gardens and a focus on green space.

The key considerations for this concept include:
1. Community Spaces
2. Community Gardens
3. Focus on Craftspeople, Artists etc.
4. Green Spaces/Park
5. Utilise the Hillside
6. Safety for Cyclists \& Pedestrians
7. Focus on Relaxation $\&$ the Connection to the Sea
8. Camp Site
9. Retain the Character of S.B
10. Enjoyment for Wellingtonians
11. Environmental Impacts
12. Coastline Access
13. Māori Culture and History

The concept aims to connect Shelly Bay to the sea and escarpment with a focus on nature and relaxation. Gardens will connect into the hillside with nature walks leading to the top of Watts Peninsula. Much of Shelly Bay will be reserved as green spaces, with the inclusion of a dedicated camping zone. Priority is given to cyclists and pedestrians to ensure their safety on the tight roads.

There is also a possibility here to introduce a marae (or at the least a Wharenui/ Meeting House) for Taranaki iwi who are located in Wellington. This marae would provide them with a 'home away from home' - a place to come together to celebrate, converse and connect with their extended iwi. 

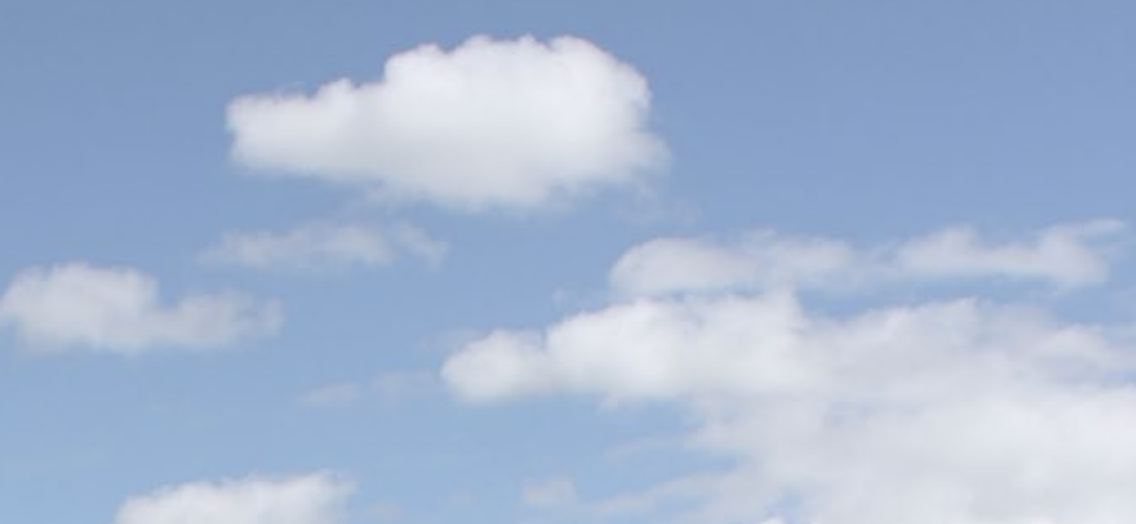

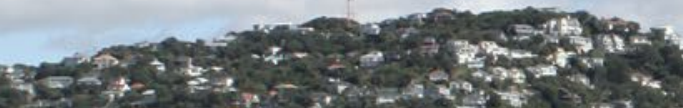

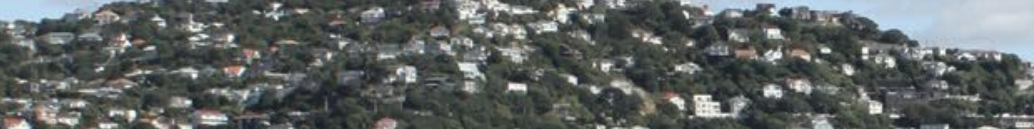

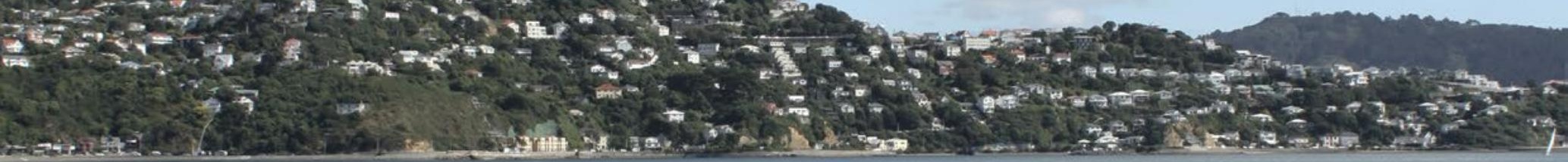




\section{Chapter 6: Stage Two - Shelly Bay, Our Way}

\section{Background}

Stage Two marks the beginning of the final component of the participatory research and design phases. Here, we ask the closer community about their views on Shelly Bay with reference to the concepts generated in Stage One.

This chapter details the intentions and methods of the final consultation phase as well as an analysis of the results.

The initial plan was to host an interactive exhibition on site at a cafe in Shelly Bay. However, this was soon ruled out due to a possible backlash from the landowners (The Wellington Company). Because of this, the final method of consultation was reconsidered as a small booklet which people could fill out at the cafe or take home with them and return upon completion.
The booklet titled, 'Shelly Bay, Our Way', contained an information section and workbook section. The information section aimed to inform the public on the research, the history of Shelly Bay, the results of Stage One and a few critical considerations. From there, the workbook section was used to generate further design ideas and to come up with a set of principles to follow for the final design phase.

The use of the booklet as a participatory design tool is one not seen in the literature. The tools inside, however, are influenced heavily by Henry Sanoff in his work regarding the participatory design of community art centres (1988). 


\section{Consultation Context}

A household name amongst

Wellingtonians, the Chocolate Fish Cafe was initially established in Scorching Bay where it operated for ten years. In 2009, the Cafe re-opened around the corner in Shelly Bay where it is famed for its seafood barbecue. Situated in the Submarine Mining Depot Barracks, it is the only cafe in the area and operates seven days a week.

The Cafe was chosen to host the consultation due to its high traffic rate, particularly during the weekends. The initial plan was to set up an interactive exhibition which included larger master planning gameboards and physical 'play' models; however, they had spatial restrictions which meant this would not be possible. They suggested asking the Miramar Library to set the exhibition up there. Unfortunately, the Miramar Library (and all Wellington Libraries) are set up and funded by the Wellington City
Council. Because of this, they did not want to be seen as supporting the protest against the development and, therefore, refused the offer.

The owners of the Chocolate Fish Cafe also had their concerns about the research. As Ian Cassels is now their landlord, they did not want to be seen as supporting the protest against the Taikuru Development. Hence, the booklet had to be designed and worded in a way which did not reject Taikuru but instead acknowledged the current plans and asked for opinions on what else it could become (refer to Appendix C).

Sixty booklets were produced and handed out on tables at the Cafe. The participants had the option to either fill it out on the spot, take it home to complete or ignore it altogether. Responses were cut off after four weeks. 

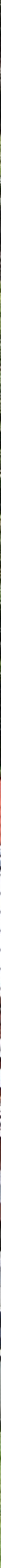


\section{'Shelly Bay, Our Way' Booklet \\ Dinform LConsult Dinvolve Collaborate aempower}

\section{CONVERGENT...$\ldots \ldots \ldots \ldots \ldots \ldots \ldots \ldots$ DIVERGENT}

'Shelly Bay, Our Way', is a 24-page document produced to facilitate the second stage of community design participation. The booklet contains two sections - an information section and a workbook section. The purpose of this booklet is to assess the use of a workbook as a participatory design tool and to gather quantitative and qualitative data regarding the future of Shelly Bay.

The information section covers the purpose of the research, the history of Shelly Bay, the proposed Taikuru plans, important considerations for a development and the results from Stage One of the consultation process.
From here the booklet moves into the workbook section where there are five exercises implemented. These exercises include:

1. Objectives \& Components Identification

2. Masterplan Gameboard

3. Vision - Written

4. Design Principles Identification

5. Vision - Drawn

These exercises are detailed within this chapter. Refer to Appendix C to view the entire booklet. 


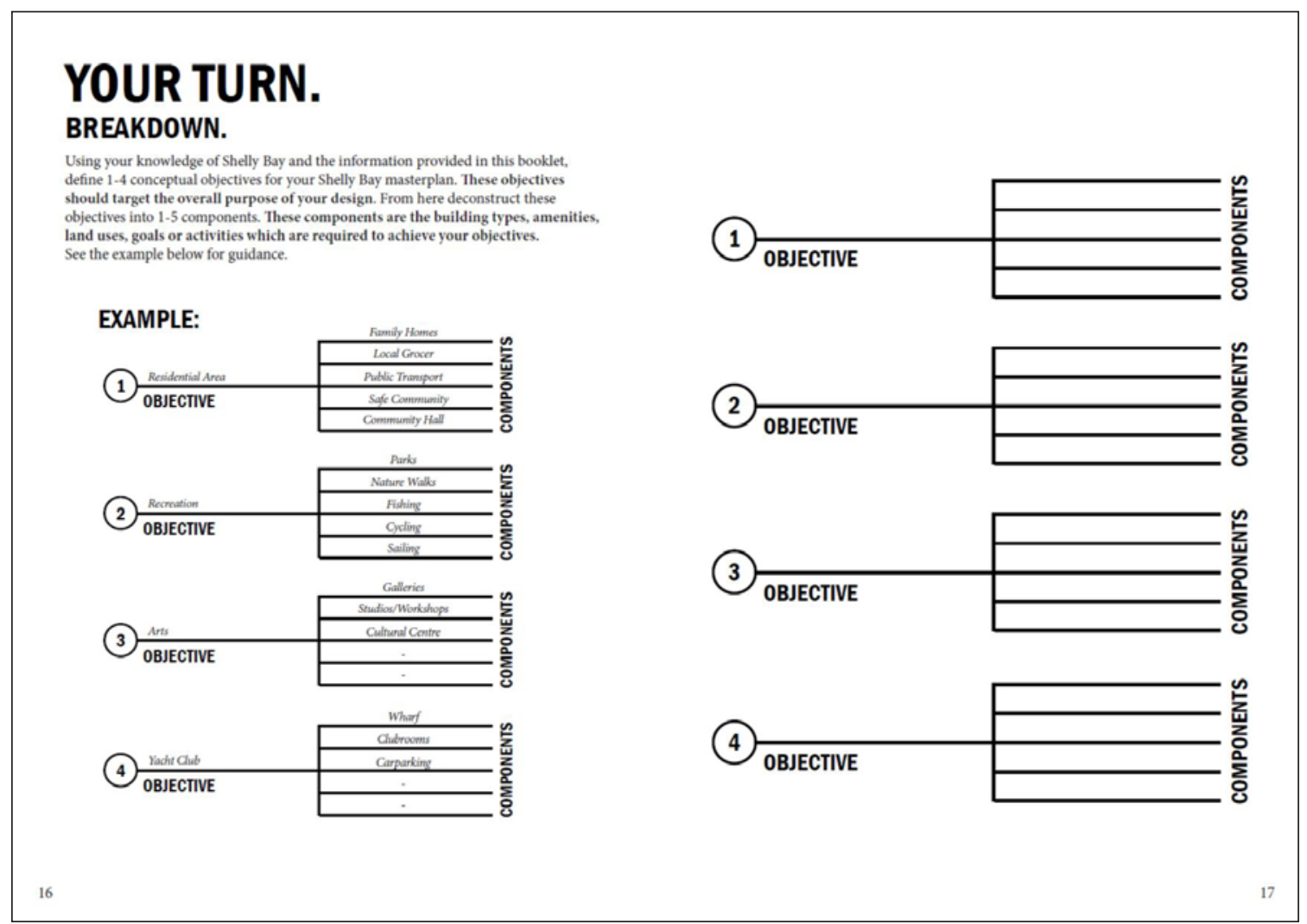

Fig 6.01 -

The first exercise of the workbook asks participants to identify one to four objectives of their Shelly Bay vision and detail the components of these objectives.

These objectives serve the same purpose as the 'Conceptual Objectives' identified in Stage One - they are the primary goals/ purposes for the area. Examples of possible objectives include: recreation, residential, creative/arts, culture and hospitality.

The next step is to identify one to six components which go into making these objectives a reality. These components could be building types, land uses, amenities or activities which make the objectives feasible. For example, if they chose residential as their objective, then their components could be family homes, high-density apartments, a local grocer, public transport, safety or a community hall.

This technique was introduced by Henry Sanoff in his participatory design research surrounding community arts facilities (Sanoff, 1998). 


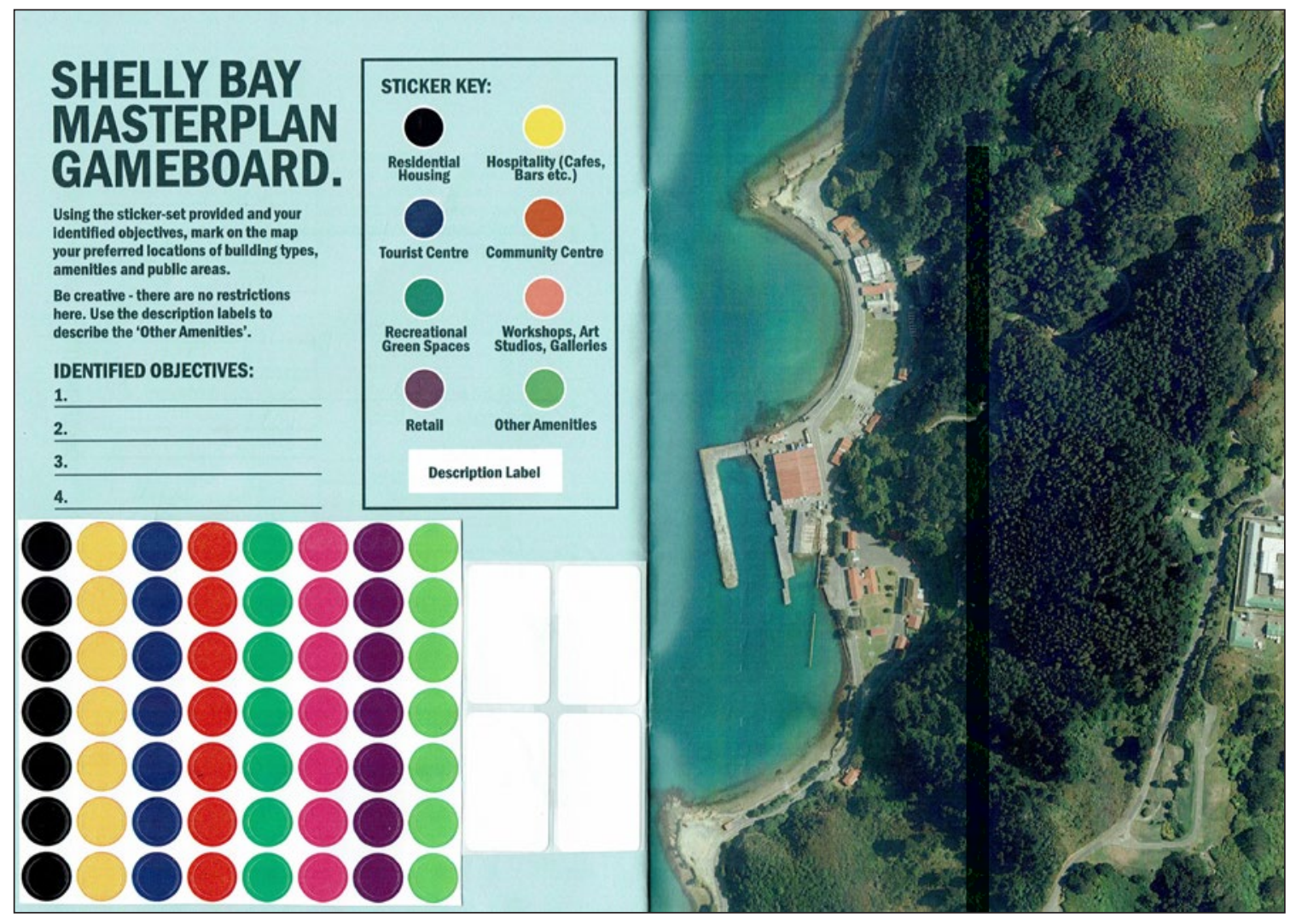

Fig 6.02 -

Shelly Bay Masterplan Gameboard from 'Shelly Bay, Our Way' booklet
Once participants have outlined their objectives and defined their components, they move on to the 'Shelly Bay Masterplan Gameboard'. This tool uses a basic colourcoded sticker-set and accompanying map where users can mark the position of building types and land uses around the site.

It is not possible to have a coloured sticker for each building type or land usage; therefore, the sticker-codes were influenced by the responses from Stage One. They are defined as: Residential Housing, Hospitality, Tourist Centre, Community Centre, Recreational Green Spaces,
Workshops + Art Studios + Galleries, Retail and Other Amenities. In addition to these, there were four description labels included so that they can explain specific areas of their design.

These spatial maps can be collated and overlaid after the consultation process to generate a community map which highlights the favourable places for the selected building types and land uses.

This technique was introduced by Henry Sanoff in his participatory design research surrounding community arts facilities (Sanoff, 1998). 


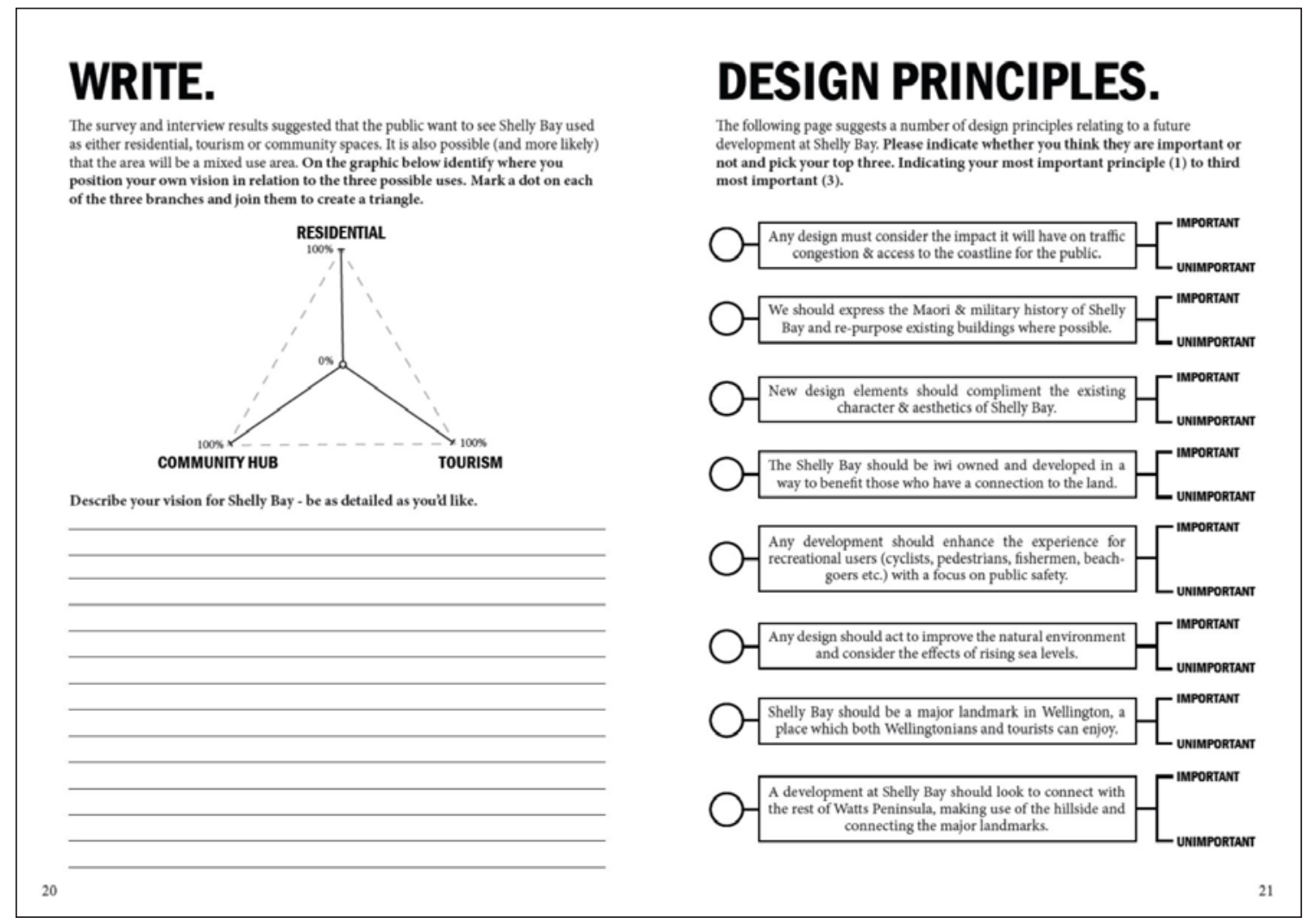

Fig 6.03 -

Written Vision and Suggested design principles from 'Shelly Bay, Our Way' booklet

Once the participant has defined the goals of their masterplan and completed the gameboard, they are given the opportunity to write about their vision. This allows them to provide further detail about things such as size, aesthetics and the utilisation of existing buildings.

In addition to this, there is a diagram in which the user defines the balance of residential, community hub and tourism in their design - the three conceptual objectives identified in Stage One. This will create a triangle which can be overlaid with the other responses and used to analyse how the average participant aligns themselves to the concepts.
Next, the users are questioned on the appropriateness of design principles. Eight principles are offered (Refer to Appendix C) and respondents are asked to decide whether they think they are 'Important' or 'Unimportant' to a development at Shelly Bay. Additionally, they are asked to rank their top three design principles.

This data will form a hierarchical set of design principles which will be followed during the design of the final outcome. The defining of design principles is an idea suggested by Sanoff (1988). 


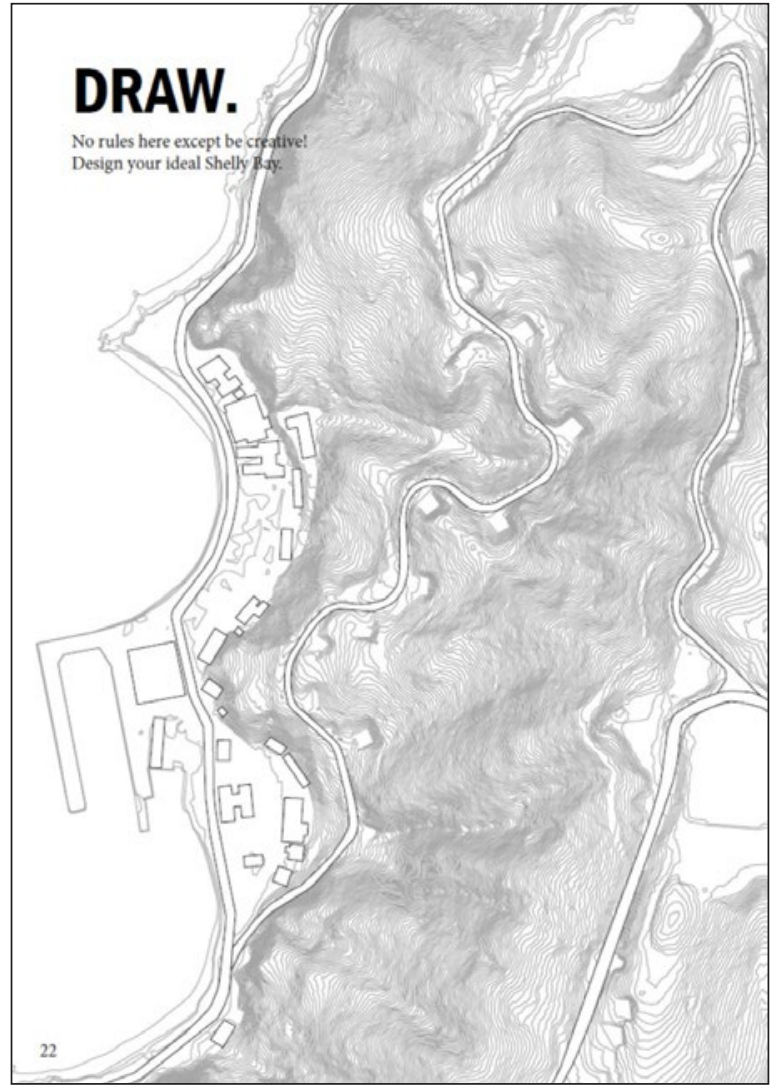

The final tool implemented in the 'Shelly Bay, Our Way' booklet is a basic line drawing of Shelly Bay and the surrounding area. Respondents are given the opportunity to draw their vision. This is not a compulsory exercise; however, it gives the user the chance to play with scale, form and density at a more refined level.
Fig 6.04 - A basic site plan allows respondents the opportunity to draw their vision for Shelly Bay.
The maps can then be collected and studied. The building types and land uses identified can be colour-coded and, in the same way as the gameboard, overlaid to create a community masterplan which can influence the location, scale, form and density of the final design outcome. 

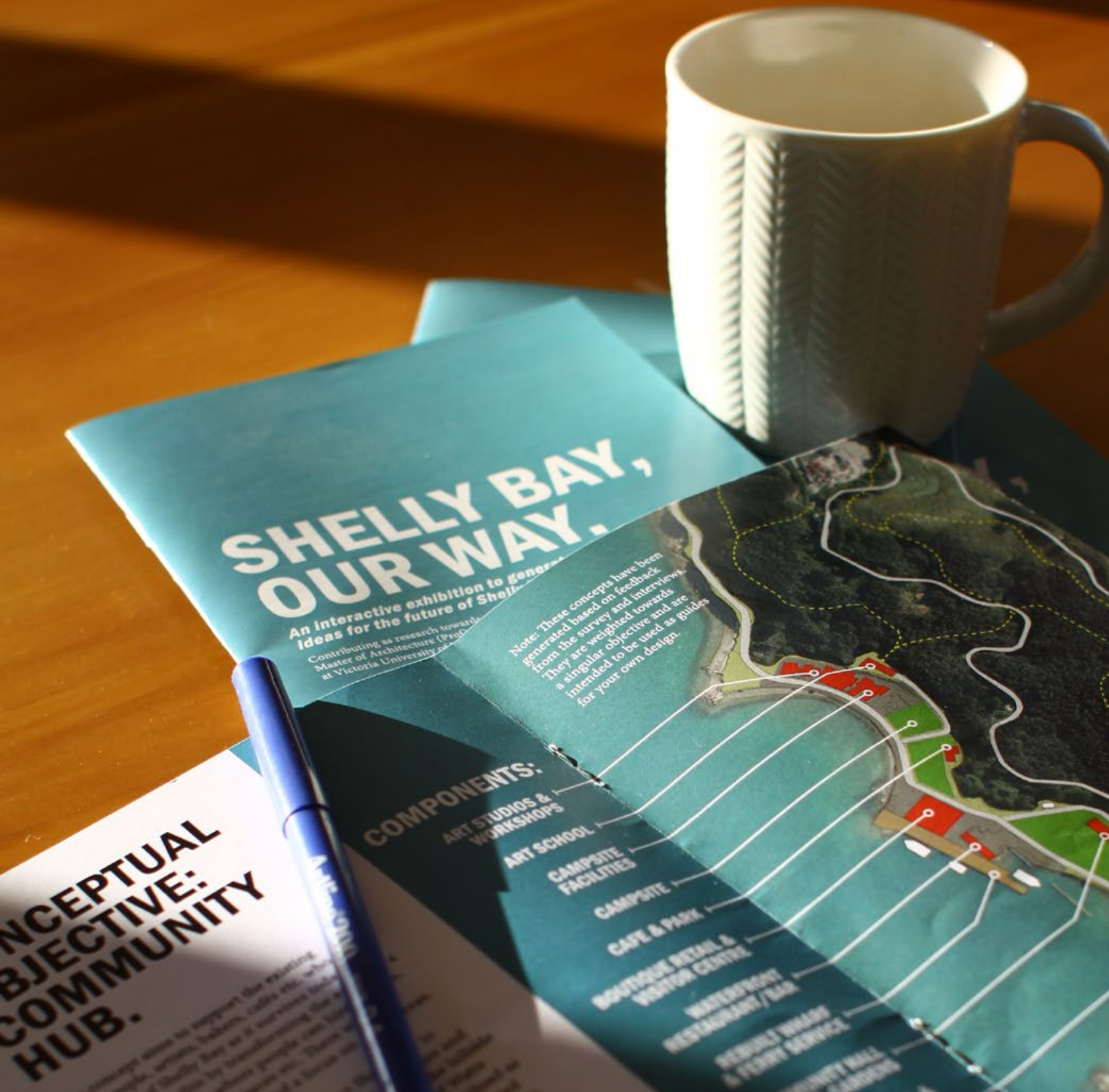

J

shlikntist.

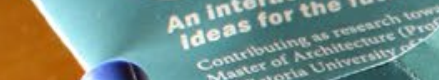
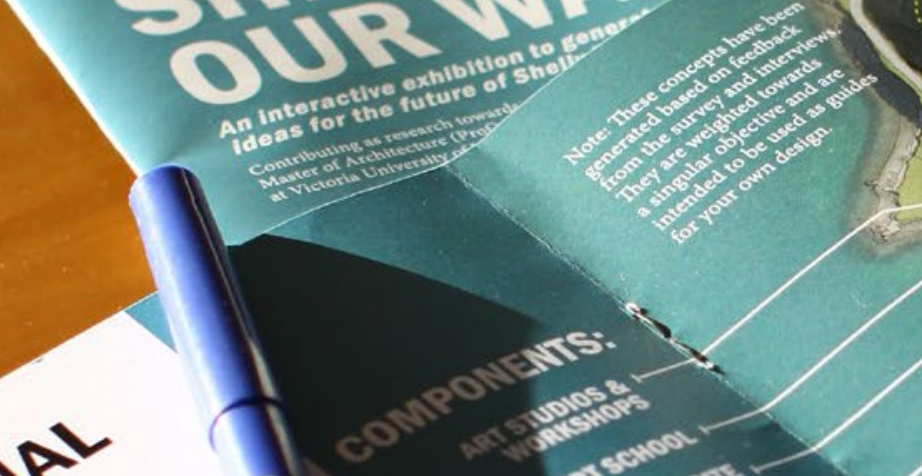


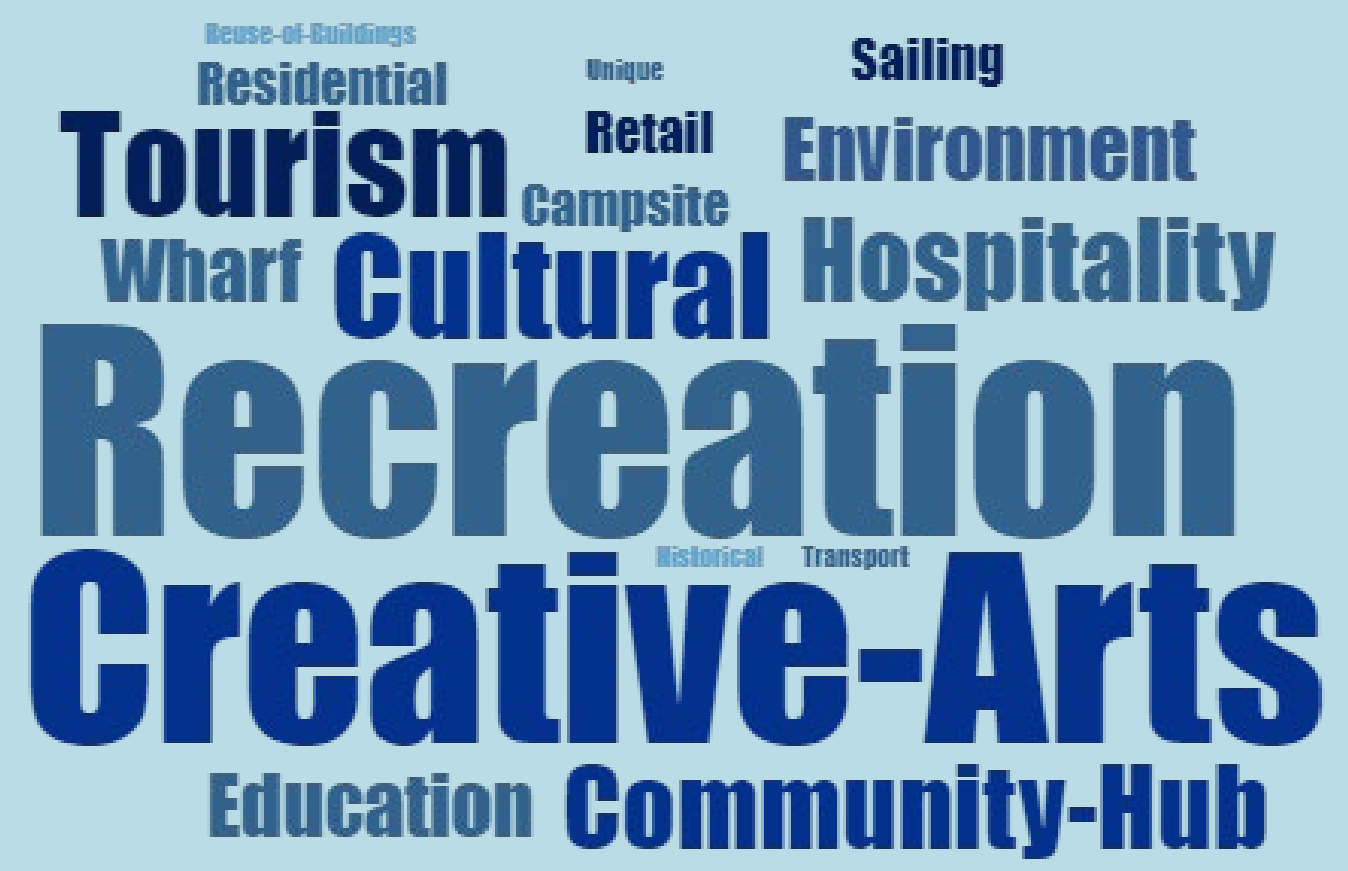

Fig 6.05 - Word Cloud generated to show hierarchy of identified objectives.

\section{MOST POPULAR OBJECTIVES:}

\section{(1) RECREATION}

(2) CREATIVE ARTS

(3) CULTURE TOURISM
The first participatory tool led to the identification of 17 objectives. By tallying and collating the results, the above Word Cloud was produced which visually represents the hierarchy of objectives (Fig 6.05).

The most popular objective was recreation, followed by the creative arts. For third place, there was a two-way tie between culture and tourism. As such these options should be weighted evenly.

Surprisingly, 'residential' scored very low in the outcomes. Therefore, the community plan will forego any private residential input. Retail, hospitality and education were also low-scoring; however, could be included in the creative arts, culture and tourism sections as secondary amenities. 


\section{OBJECTIVE ONE: RECREATION}

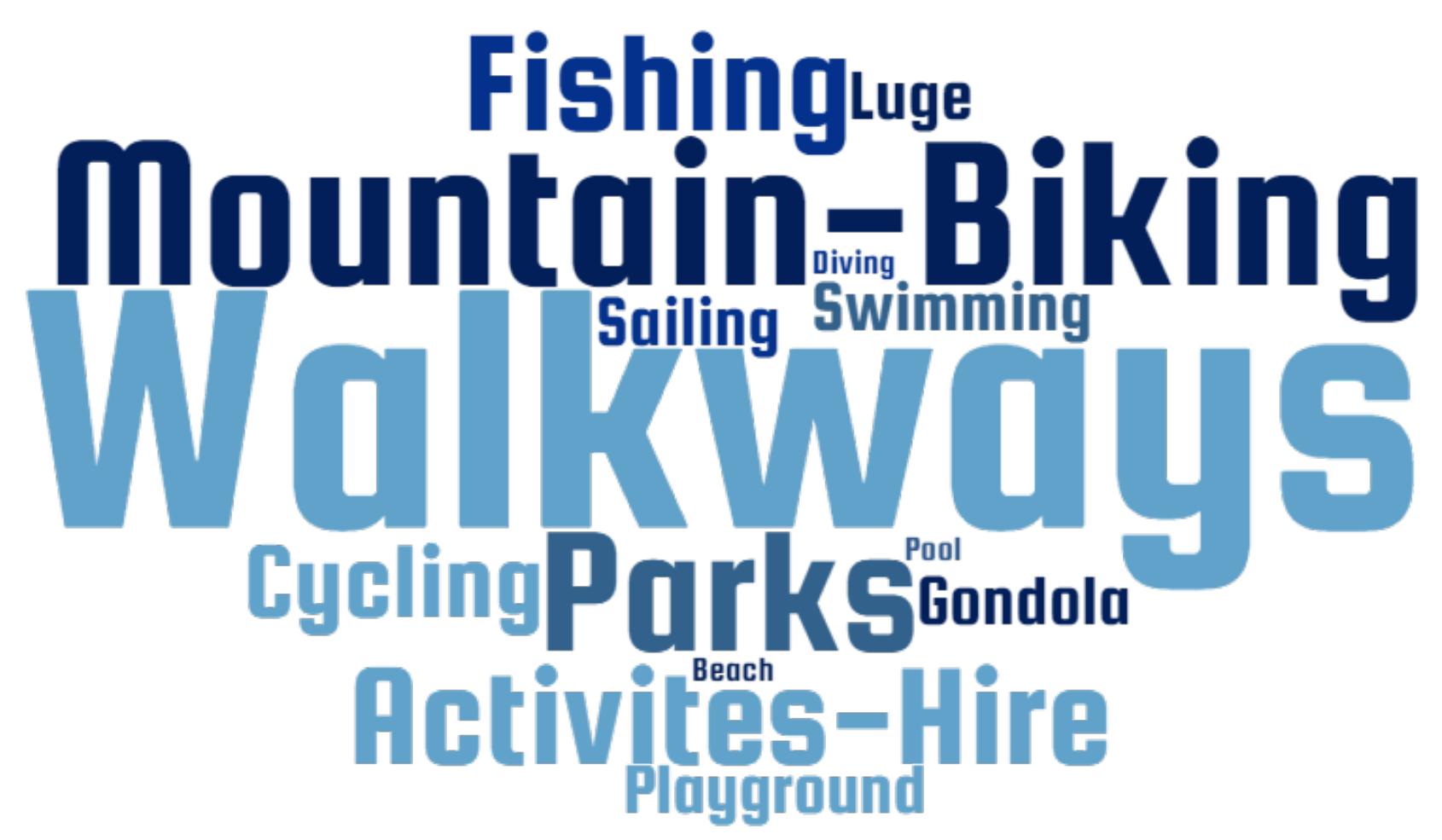

Fig 6.06 - Word Cloud generated to show hierarchy of recreation components.

MOST POPULAR COMPONENTS:

(1) WALKWAYS

(2) MOUNTAIN BIKING

(3) PARKS

(4) FISHING \& DIVING ACTIVITIES HIRE
Recreation was identified as the principal objective to which there were 14 individual components offered by the community. These components have been documented in the above Word Cloud where the size represents its popularity (Fig 6.06).

The most popular recreation component was walkways followed by mountain biking and parks, with fishing and diving tying with activities hire for the fourth position.

The idea of having luge (offered in the conceptual outcomes of Stage One) did not appeal to most, however, it appeared in a few of the more extreme/visionary plans - suggesting that participants were considering potential construction costs. 


\section{OBJECTIVE TWO: CREATIVE ARTS}

\section{StudiossWorkshops Holleries ArtseCrafts-5chool Dutdoor-Stage}

Fig 6.07 - Word Cloud generated to show hierarchy of creative arts components.

\section{MOST POPULAR COMPONENTS:}

\section{ART GALLERIES}

(2) STUDIOS \&
WORKSHOPS

3 ARTS \& CRAFTS SCHOOL
While creativity/the arts was the second most sought after goal, there was not much offered in the way of components, with only five identified. These are shown in the above Word Cloud.

The top three include art galleries, studios and workshops, as well as an arts and crafts school. The popularity of this option, no doubt, stems from Shelly Bay's current working demographic as many of the existing buildings are studios and workshops with the Blackmore \& Best Gallery being a major attraction in the area.

The addition of Māori culture into the art galleries and education should be considered to show respect to Taranaki Whānui and the history of Shelly Bay. 


\section{OBJECTIVE THREE: COMBINATION OF CULTURE \& TOURISM}

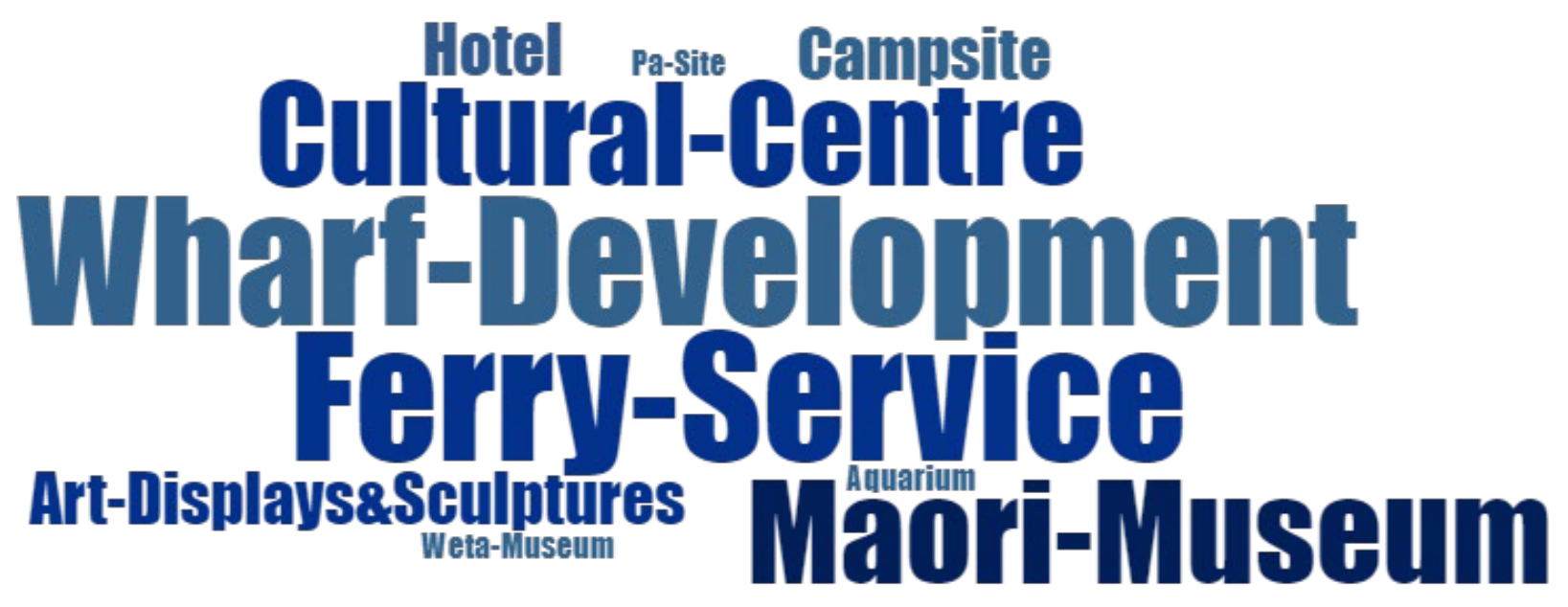

Fig 6.08 - Word Cloud generated to show hierarchy of culture and tourism components.

MOST POPULAR COMPONENTS:

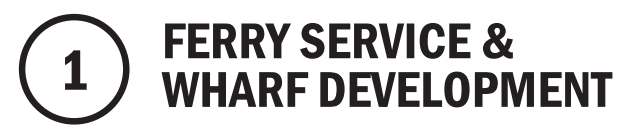
(2) CULTURAL CENTRE \&
MAORI MUSEUM

3 ART DISPLAYS \& SCULPTURES ACCOMMODATION
Because the third most popular objective was tied between culture and tourism, their components have all been included in the Word Cloud (Fig 6.08).

The most popular component from this combined pool was a ferry service and wharf development followed by cultural centre and Māori museum, with art displays and sculptures tying for the third position alongside accommodation.

The cultural centre and Māori Museum would work well grouped together, in addition to this the arts school could be incorporated to create a single multi-use space. 


\section{Masterplan Gameboards}

Perhaps the most successful activity in the booklet, in terms of answer rate - the Shelly Bay Masterplan Gameboards provided a quick and easy way to translate ideas onto a site plan.

While it is not possible to provide a sticker for every building type/objective/ component, the seven options covered the vast majority with the 'Other Amenities' sticker and description labels provided for the more specific wants.

Fig 6.09 shows an overlay of all of the received gameboards prioritised hierarchically by the most popular objectives to least (i.e. recreation shown on top, followed by creative arts, cultural, tourism etc.). By studying these results, it is possible to identify potential areas for the identified components. This will be valuable once the final design brief has been produced. They also allude to which elements can be combined with others to create mixed-use spaces.

\section{LEGEND:}

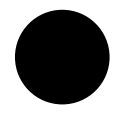

Residential Housing

Hospitality (Cafes, Bars etc.)

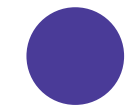

Tourist Area

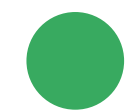

Recreation \& Green Spaces
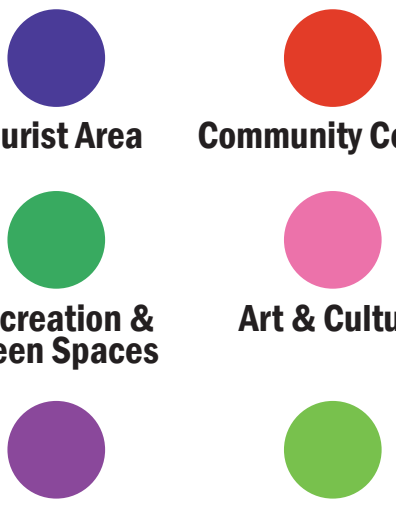

Community Centre

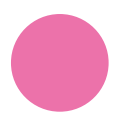

Art \& Culture

Retail

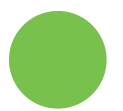

Other Amenities 


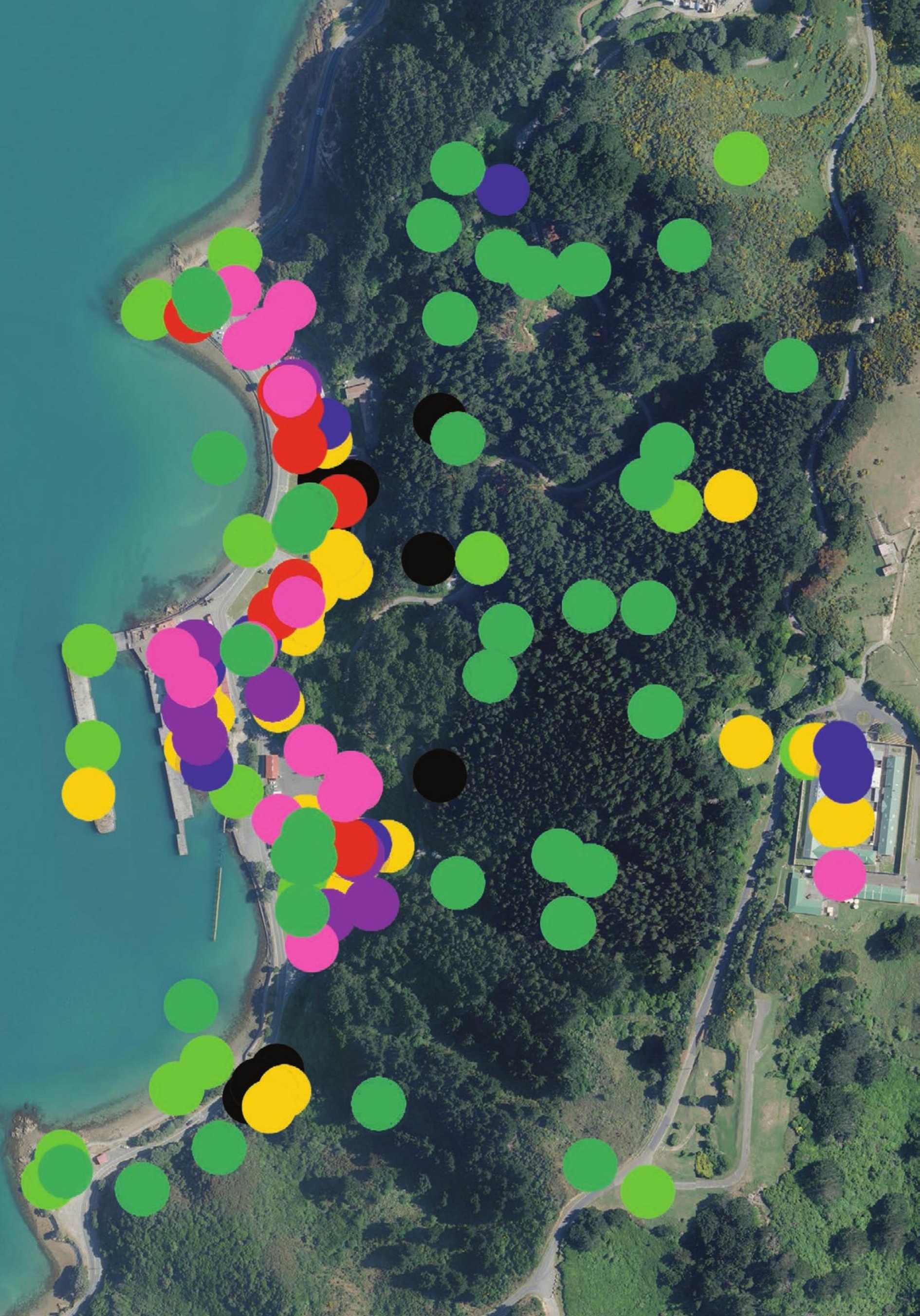


Shelly Bay should be a major landmark in Wellington, a place which both Wellingtonians and tourists can enjoy.

Any design must consider the impact it will have on traffic congestion $\&$ access to the coastline for the public.

Any development should enhance the experience for recreational users (cyclists, pedestrians, fishermen, beach-goers etc.) with a focus on public safety.

A development at Shelly Bay should look to connect with the rest of Watts Peninsula, making use of the hillside and connecting the major landmarks.

We should express the Māori \& military history of Shelly Bay and re-purpose existing buildings where possible.

New design elements should compliment the existing character $\&$ aesthetics of Shelly Bay.

Any design should act to improve the natural environment and consider the effects of rising sea levels.

Shelly Bay should be iwi owned and developed in a way to benefit those who have a connection to the land.

Fig 6.10 - Identified design principles, in order of importance.

The ranking of design principles made it possible to create a hierarchical list. The survey results in Stage One influenced the definitions of these principles.

Turning Shelly Bay into a major destination in Wellington - a place to be enjoyed by both Wellingtonians and Tourists, was identified as the highest priority design principle. This lends itself to the tourism and cultural objectives. The next most important principle was to consider traffic congestion and coastline access - balancing this with the tourism aspect will be challenging. The third principle looks to prioritise the recreational side of Shelly Bay - something that was identified in the early stages of the consultation. 


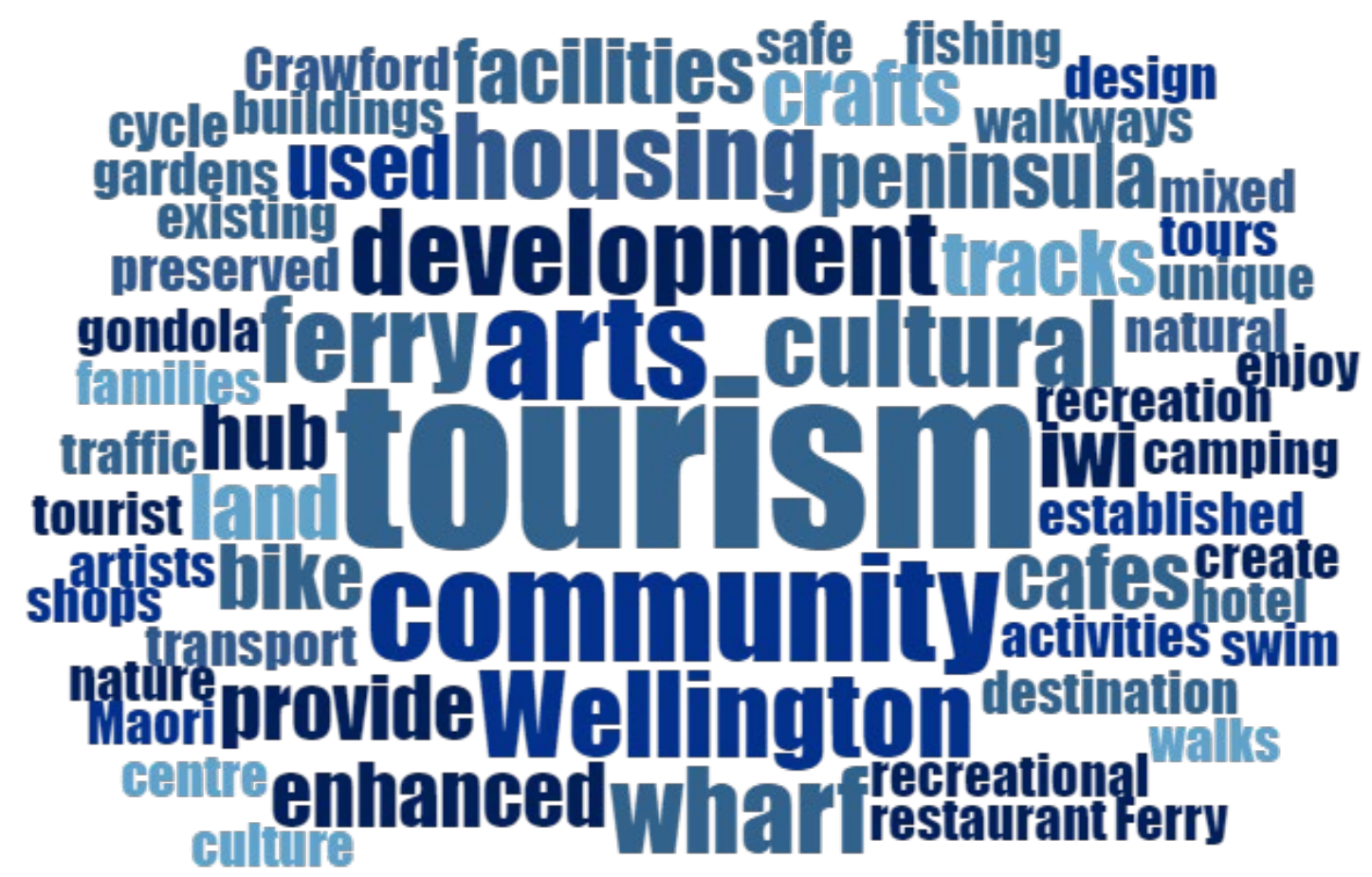

Fig 6.11 - Word Cloud generated to show hierarchy of positive words in written vision statements.

The written vision along with the weighting diagram were both successful means of gathering information. The weighting diagram gives a good idea of the views of the majority with most of the focus around community and tourism and less around residential (as shown in Fig 6.12).

The word cloud (Fig 6.11) has been generated from the written responses. The negative connotations (what we do not want/like/ care for) have been removed so that the diagram only shows the positive elements, i.e. what the public wants. The results from this were similar to the rest of the exercises with tourism, community, arts, cultural and a ferry service being the most mentioned elements.

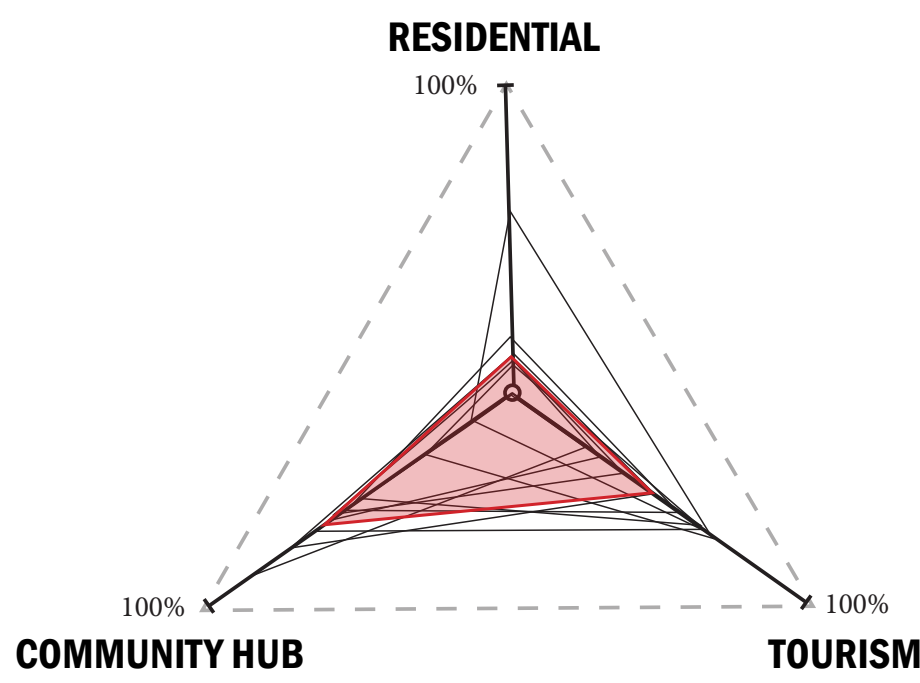

Fig 6.12 - Diagram documenting overall development weighting by participants during the written and drawn vision consultation process. 


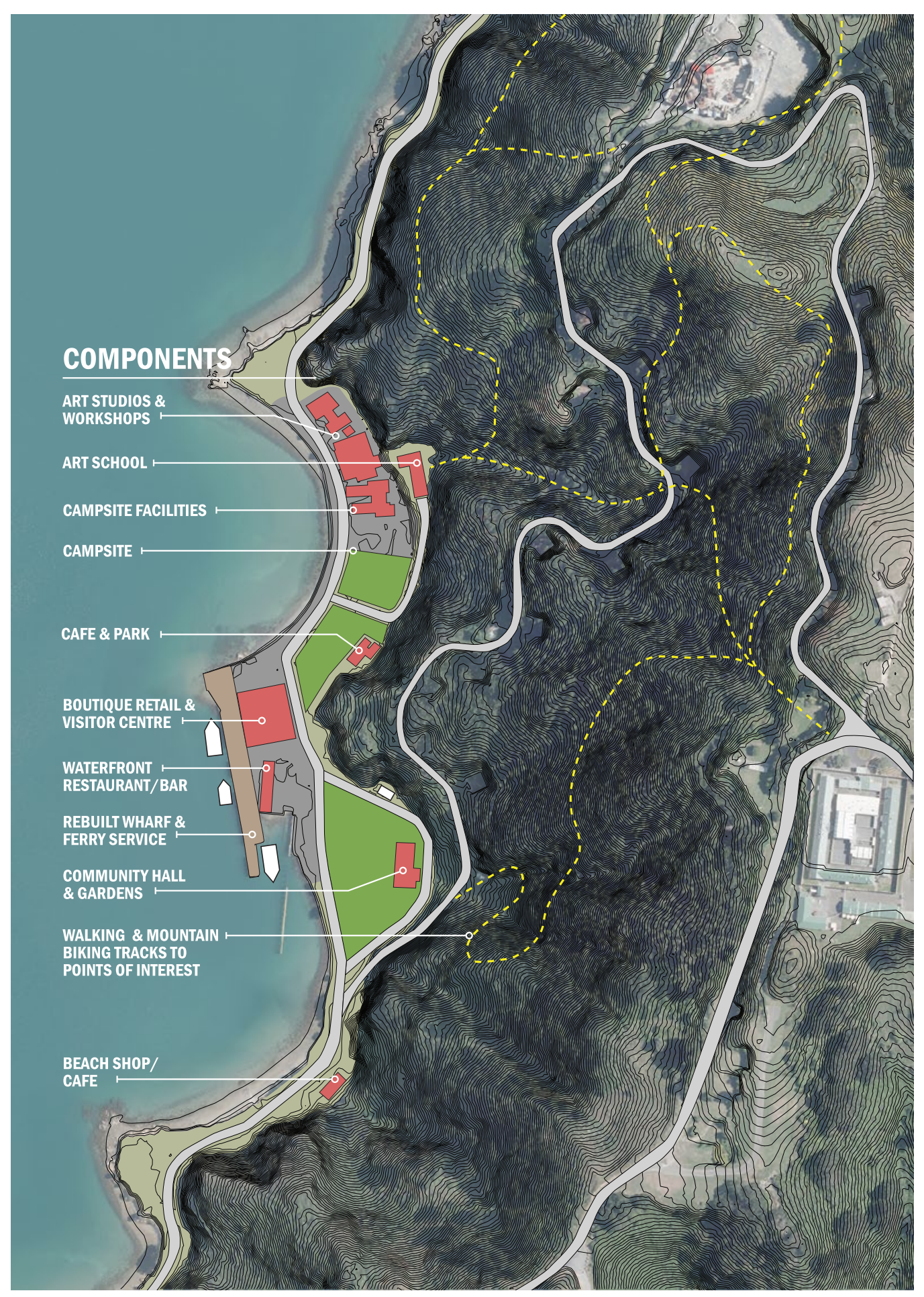

Fig 6.13 - The community hub concept proved to be the most popular design.

The weighting diagram (Fig 6.12) dictated that a community centred design (Fig 6.13) was the most popular option with tourism and recreation (Fig 6.14) coming in at a close second. These concepts should be given weighting in the final design planning in conjunction with the other consultation results. 


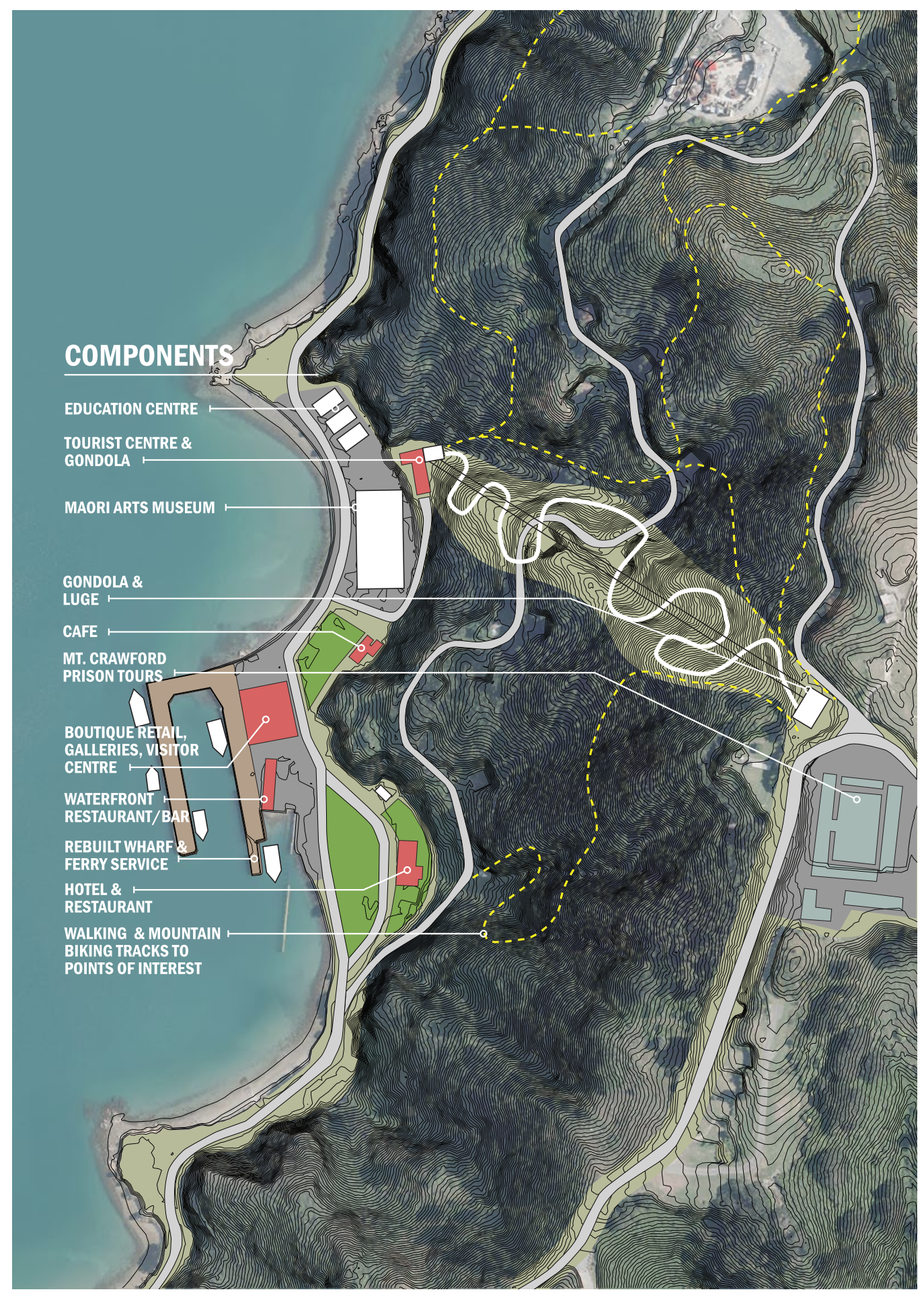

Fig 6.14 - The tourism and recreation concept was the second most popular design. 


\section{'Shelly Bay, Our Way' Conclusion}

The booklet, 'Shelly Bay, Our Way', proved to be an effective consultation tool which was self-explanatory and did not require face-to-face guidance. This is a tool which can easily be adapted to any architectural or urban planning consultation process particularly lending itself to larger-scale projects. The ability to produce and release these to clients or community members to fill-in, in their own time, takes the stress away from both parties and allows the architects/designers to continue with other stages of the project.

Unfortunately, there were a couple of issues with the booklet. There were only 15 handed back out of the 60 distributed, which is only a $25 \%$ success rate. This, perhaps, was due to the theoretical nature of the project. If this had been an actual project with real-world consequences, it is likely that there would have been a better response rate. Also, the time it took to read and fill out the booklet (roughly 30 minutes) is time that not everyone is willing to spend on a theoretical project. In addition to this, allowing people to take the booklet home to complete meant they would have to return to the cafe to hand it in.

Overall, there was a lot of valuable information gleaned from the Stage Two participatory process. It will be important to weight the responses in this stage with those gathered in Stage One to ensure a balanced final design outcome.

The majority of tools used inside the booklet proved to be effective means of gathering quantitative and qualitative information. The only unsuccessful tool was the 'drawn vision', with no valuable responses. This tool would be removed in future uses of the booklet. 
"THERE IS NO

LOGIC THAT CAN BE

SUPERIMPOSED ON THE

CITY; PEOPLE MAKE IT,

AND IT IS TO THEM, NOT

BUILDINGS, THAT WE

MUST FIT OUR PLANS."

- JANE JACOBS (1961) 


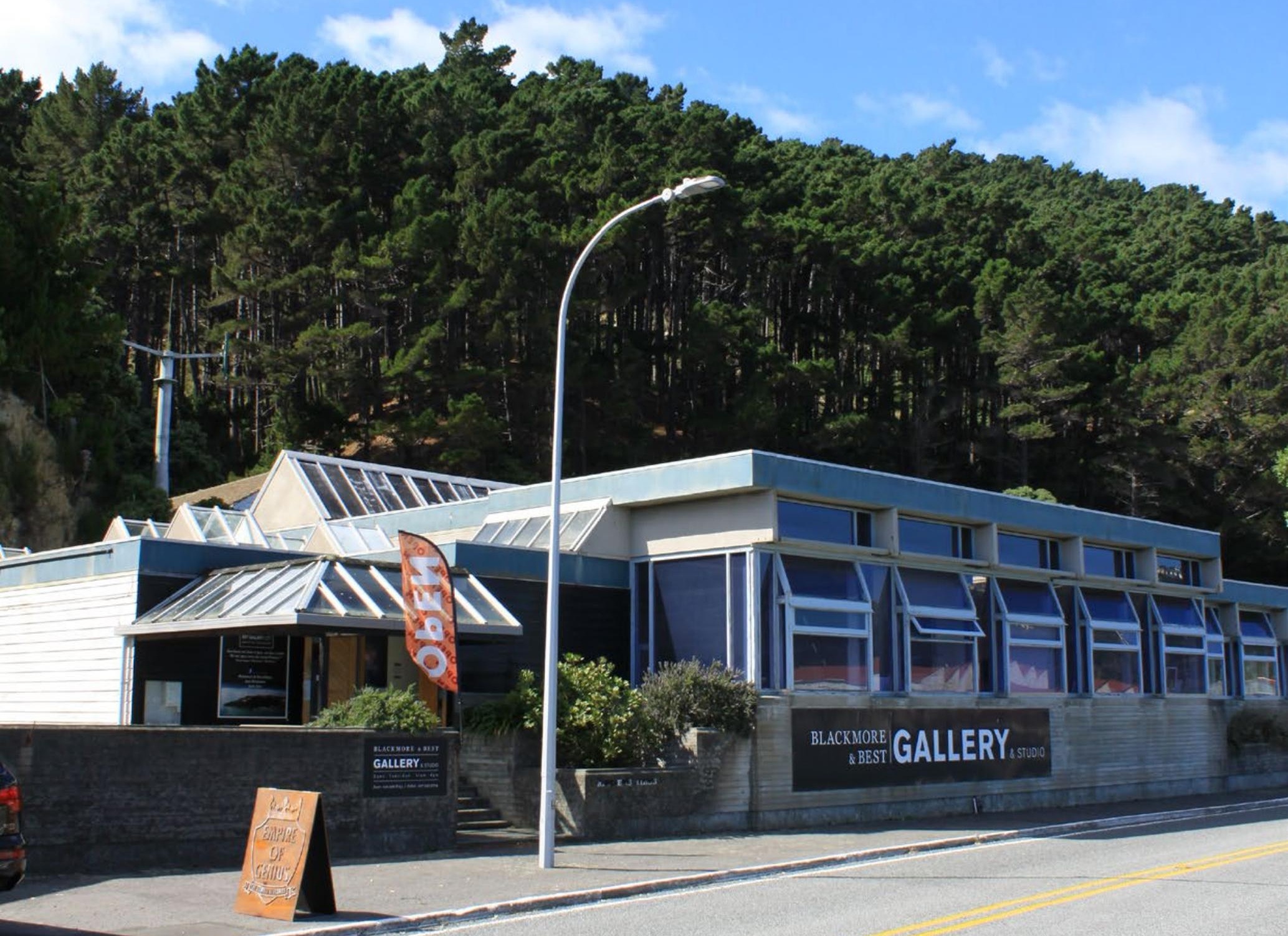




\section{Chapter 7: Stage Two - Shelly Bay 2030 Background}

With the two participatory stages complete, In addition to this, the results from the it is time to bring the research together masterplan gameboards will dictate the and create a final community masterplan. The major challenge here is the creation of the design brief - it must reflect the majority trends in the gathered data. This will ensure a masterplan which is genuinely community-based.

Once the brief has been set, it becomes the role of the designer to ensure that the final outcome represents the wishes of the community. This is achieved through the application of the design principles. positioning of buildings (categorised by their objectives and components).

The success of the design will be reflected on in the following chapter. However, whether it is successful or not does not come from an aesthetic standpoint. A successful design here is one which truly reflects the needs and wants of the local and wider community. It should rationalise these needs and wants into a cohesive design. 


\section{Data Weighting \& Interpretation}

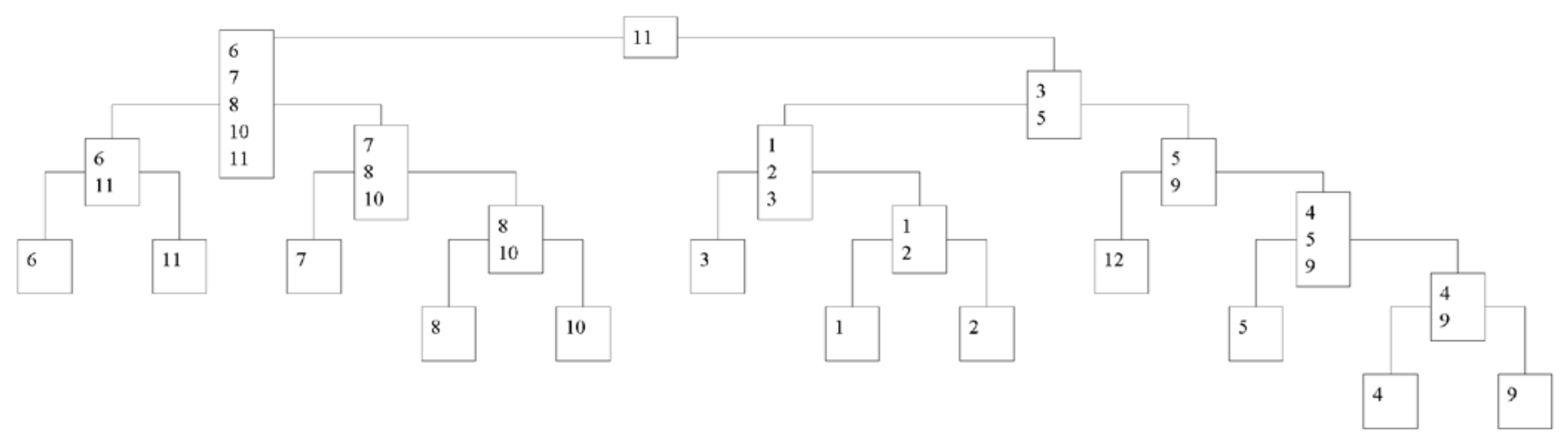

Fig 7.01 - Diagram showing the relationship breakdown between identified components from Stage Two.

Diagram Key:

1 - Walkways

2 - Mountain Biking

3 - Parks and Gardens

4 - Fishing and Diving

5 - Activities Hire

6 - Art Galleries

7 - Studios and Workshops

8 - Arts and Crafts School

9 - Ferry Service and Wharf Development

10 - Cultural Centre and Māori Museum

11 - Art Displays and Sculptures

12- Accommodation

Using computer software, the relationships between the components identified from Stage Two's results have been graphically represented (fig 7.01).

As expected, the majority of the components group within their parent objectives, i.e. art galleries matched with other components from the creative arts objective, likewise, walking tracks matched with mountain biking under the recreational objective. The interesting information here, however, are the points at which the components crossover each other into other respective objectives. For example - the majority of the recreational components are directly related to tourism components. In particular, accommodation directly correlates to activities hire, fishing and diving and the wharf development - offering a rationale to design these together, centred around the wharf area. Similarly, an arts and crafts school is grouped with the cultural centre and Māori museum - suggesting an opportunity to create a mixed-use facility, or series of facilities, here.

The diagram has grouped the components into two clear branches (with several subbranches amongst these). These point to two immediate goals - one of arts and culture and one of recreation and tourism. They should be the focus of the development.

Additionally, the order of the design principles has been finalised. The principles from the survey responses have been given more weighting (due to the survey response size) with the responses from the booklets completing the set. 


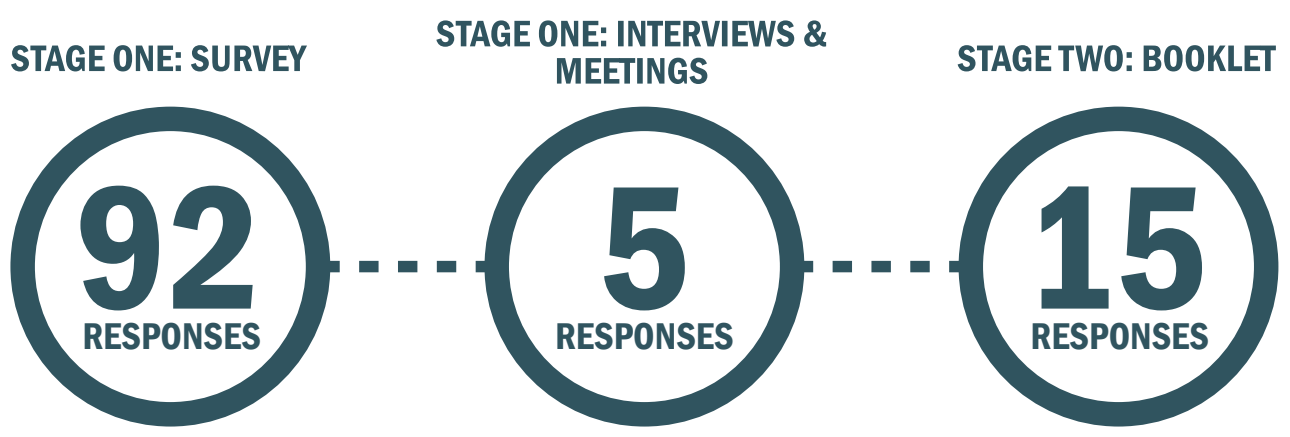

CONCEPT POPULARITY:

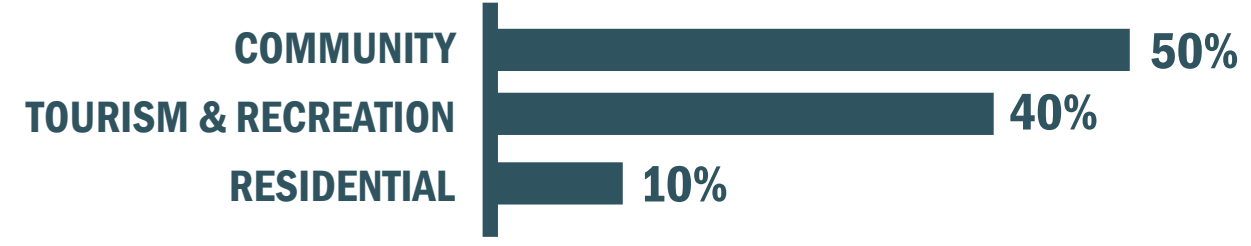

\section{FINALISED ORDER OF DESIGN PRINCIPLES:}

1. Any design must act to improve the natural environment and consider the effects of rising sea levels.

2. Any design must consider the impact it will have on traffic congestion.

3. The design must maintain and improve coastline access to the public.

4. Any development must enhance the experience for recreational users (cyclists, pedestrians, fishermen, beach-goers etc.) with a focus on public safety.

5. Shelly Bay should be iwi owned and developed in a way to benefit those who have a connection to the land.

6. Shelly Bay should be a major landmark in Wellington, a place which both Wellingtonians and tourists can enjoy.

7. A development at Shelly Bay should look to connect with the rest of Watts Peninsula, making use of the hillside and connecting the major landmarks.

8. We should express the Māori \& military history of Shelly Bay and re-purpose existing buildings where possible.

9. New design elements should compliment the existing character \& aesthetics of Shelly Bay. 


\section{The Brief - Shelly Bay 2030}

\section{Project Scope}

The final design outcome should be reflective of the information collected in both Stage One and Two of the consultation process. Influence from the designer should be kept to a minimum.

As the most significant response came from Stage One, priority to those responses will be given over Stage Two. However, Stage Two answers specific questions which the survey does not - these should be followed accordingly. The most significant influence of the survey comes from the identified design principles.
The design will be produced under the assumption that the land is returned to Taranaki Whānui. Therefore, the outcome must be financially viable in theory providing a constant source of income to Taranaki Iwi for years to come. The construction costs of the design are beyond the scope of this research.

The design should focus primarily on the flat areas of Shelly Bay (including the wharf area). The hillside leading up to the ridge-line of the Watts Peninsula will be a secondary consideration (including the Mount Crawford Prison site).

\section{Project Objectives}

Overall project objectives include:

1. To produce a masterplan which is representative of the information gathered in the two participatory design stages.

2. To produce a masterplan which could be financially viable and sustainable to the Port Nicholson Block Settlement Trust.

3. To produce a masterplan which carefully considers the ' 1999 Shelly Bay Design Guide’.

4. To provide a masterplan which could be considered a 'major attraction' for Wellington city and be accommodating for both locals and tourists.

5. Consideration of the impacts on traffic congestion and the local environment are a priority. 


\section{Design Objectives \& Components}

Project design objectives and components include:

Arts \& Culture:

- Arts and Crafts Schools

- Cultural Centre, Wharenui \& Museum

- Art Galleries, Studios and Workshops

- Public Art and Sculpture Displays

Recreation \& Tourism:

- Activities Hire

- Fishing and Diving orientated

- Wharf Development (Cafes, Restaurants, Bars, Tourist Centre, etc.)

- Ferry Service

- Walking and Mountain Biking Tracks

- Boutique Hotel

- Parks and Gardens

- Gondola to Mt. Crawford

+ Supporting Amenities:

- Reclaimed Golden Sand Beach

- Waterfront Walkway Overhaul

- Beach-side Cafe

- Car Parking

- Bus Stop Terminal Area

- Rebuild Main Road (Dirt Road) 


\section{Design Process}

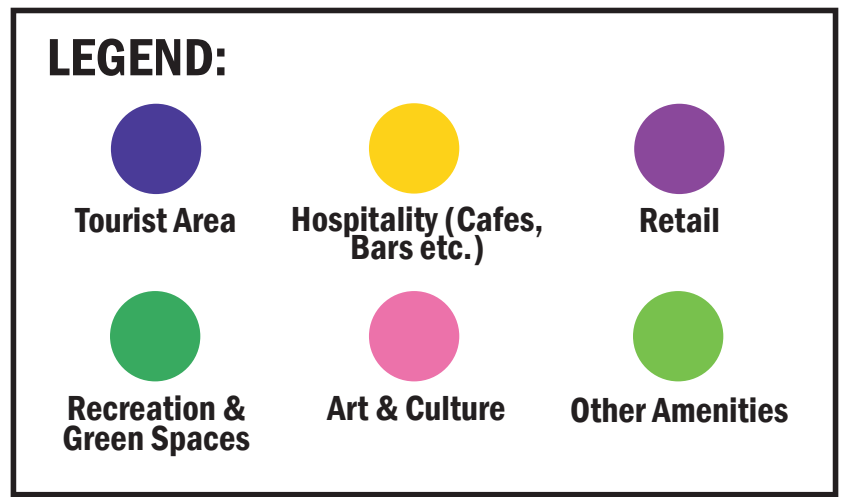

Using the results of the masterplan gameboards from Stage Two and overlaying the primary objectives identified, the participatory process begins to produce a true community-based masterplan - as seen in Fig 7.02. From here, the plan is simplified into larger massing areas, clarifying what areas are suited to the various objectives (as seen in Fig 7.03).

Fig 7.04 overlays the supporting amenities which tie the plan together into a feasible community. These supporting amenities include hospitality, retail and miscellaneous. Moving to Fig 7.05, these supporting amenities are simplified and density, controlled. Fig 7.06 shows the initial footprint for a community masterplan at Shelly Bay.

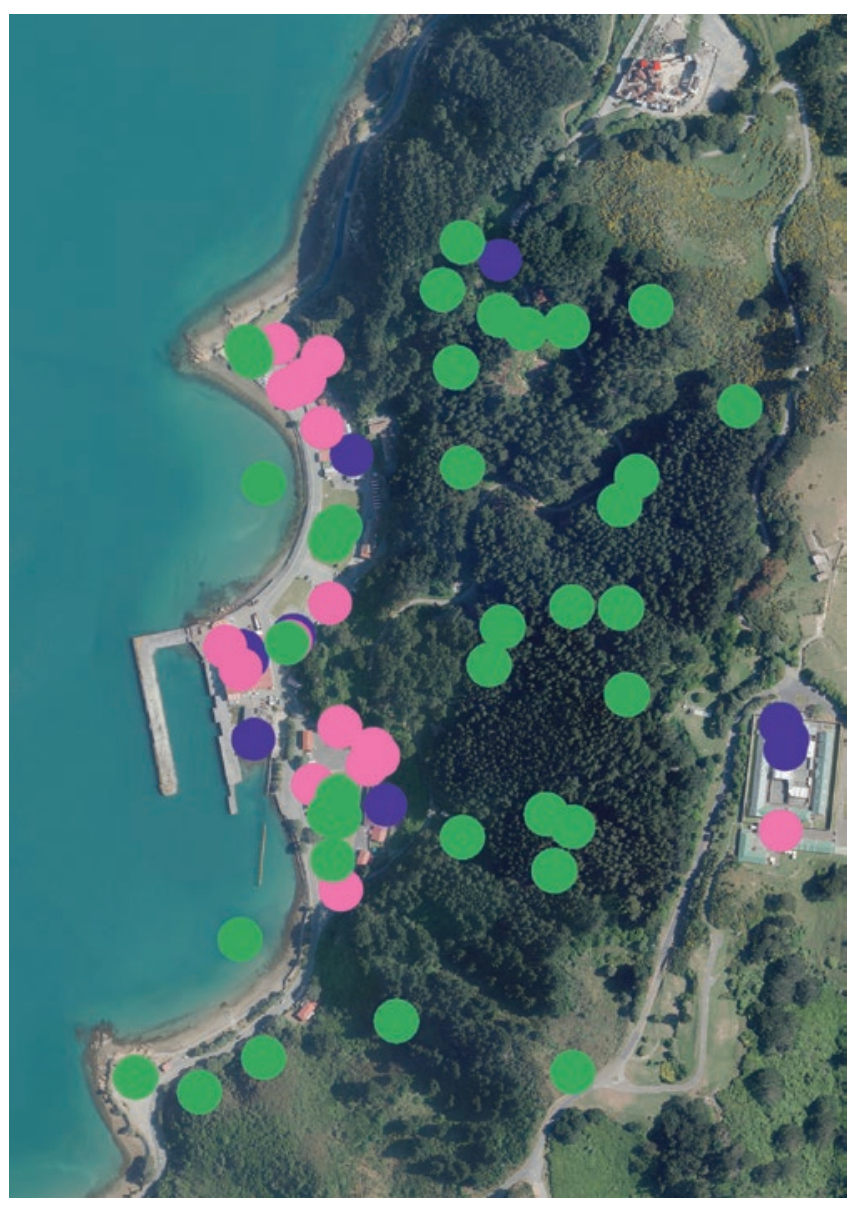

Fig 7.02 - Map showing placement overlay of publicly identified objectives. 


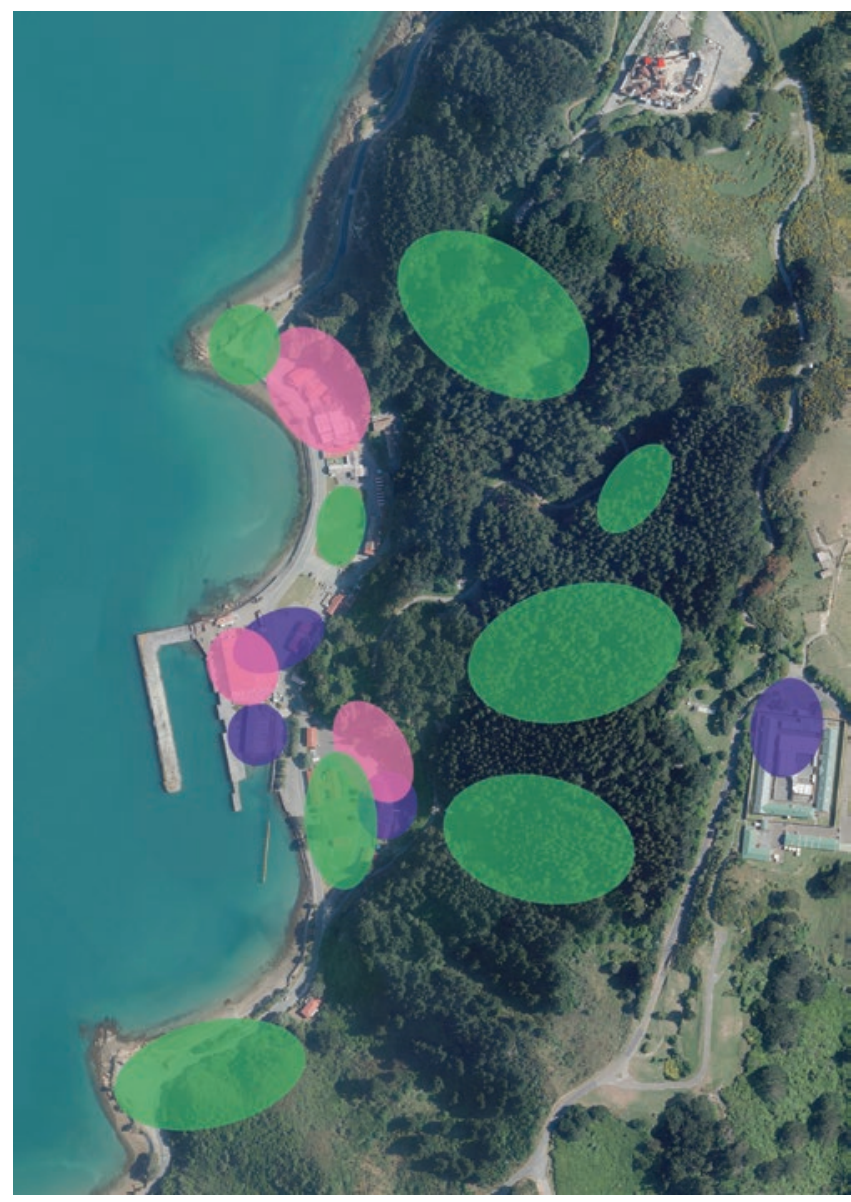

Fig 7.03 - Map showing simplified placement overlay of publicly identified objectives.

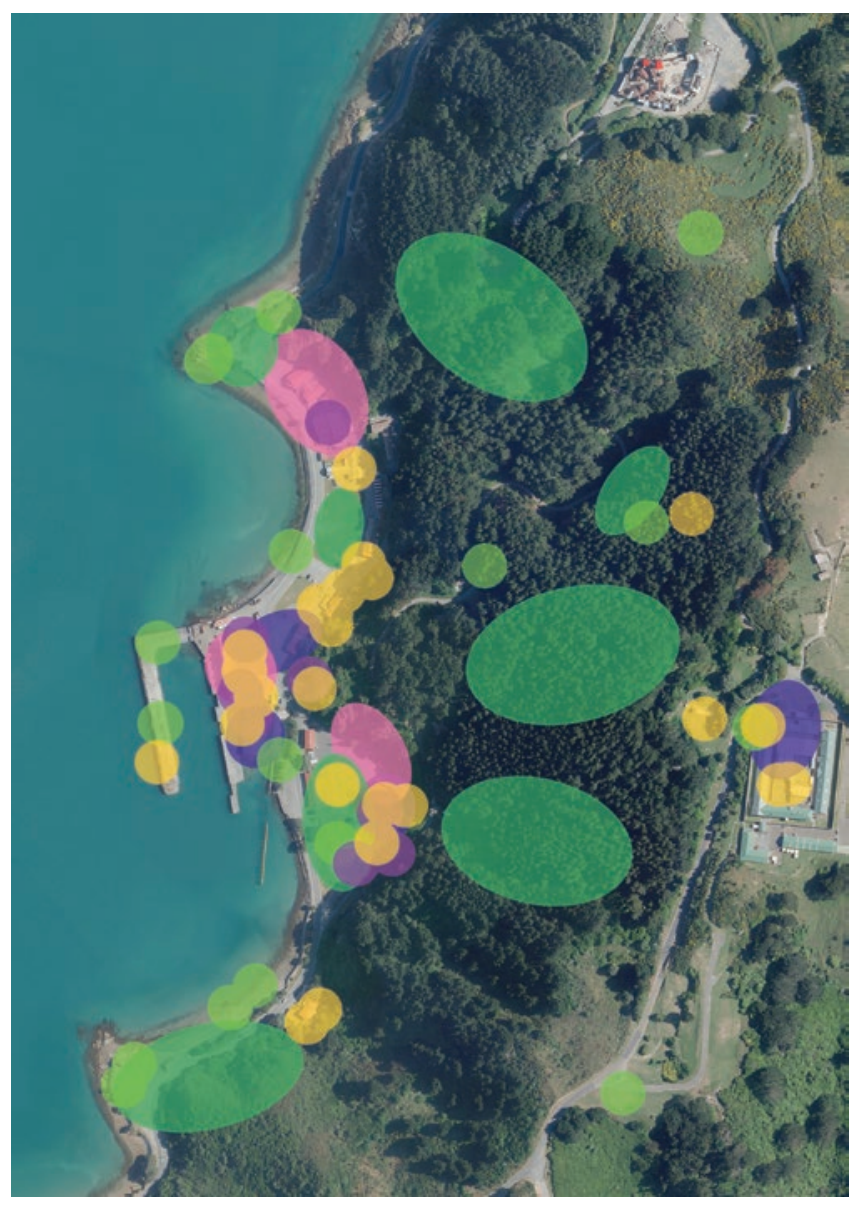

Fig 7.04 - Simplified map with possible amenities overlay (hospitality, retail and miscellaneous). 


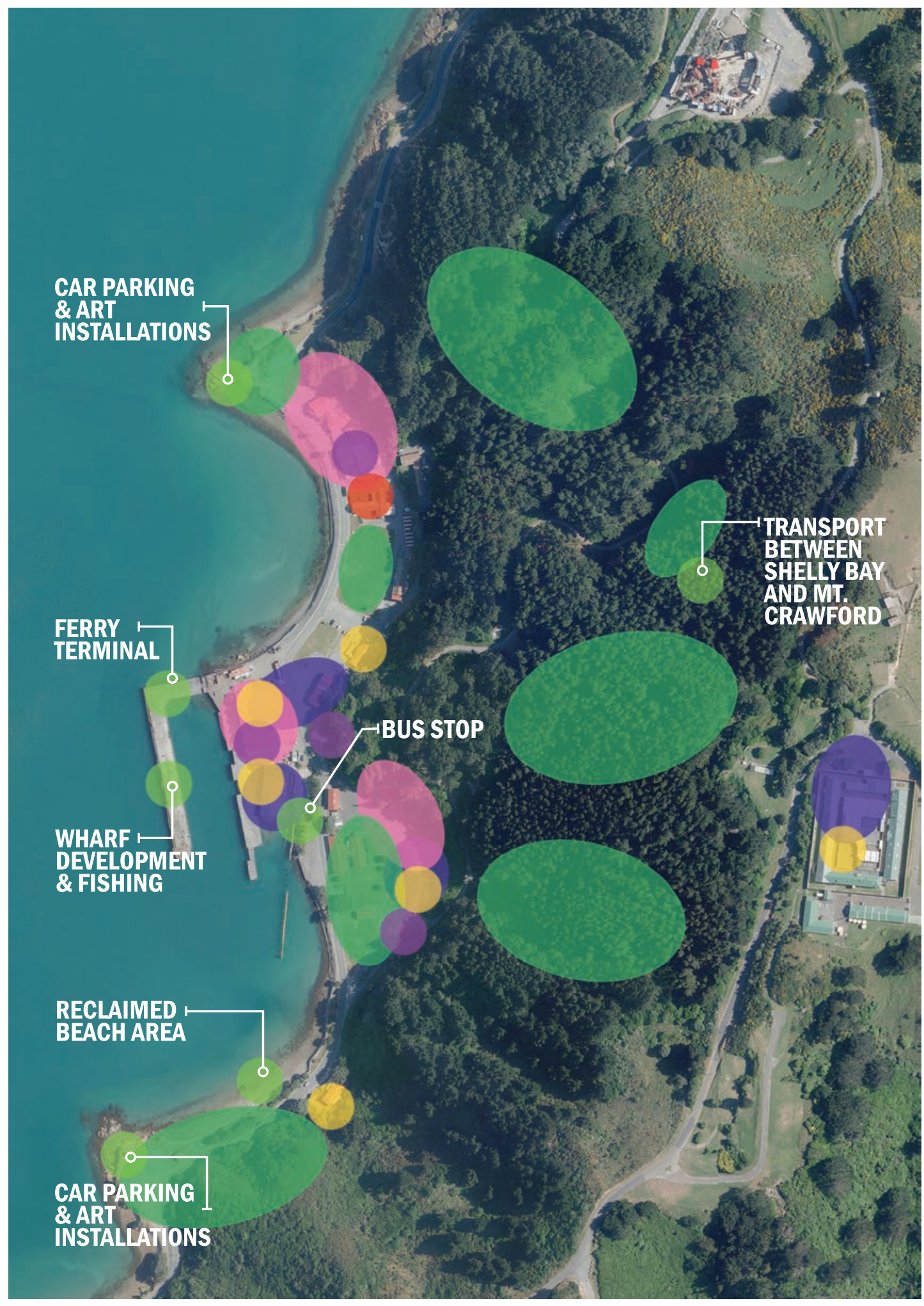

Fig 7.05 - Simplifying location and density of identified supporting amenities - identifying miscellaneous amenities. Adding a community dot (orange) to signify cultural centre area. 


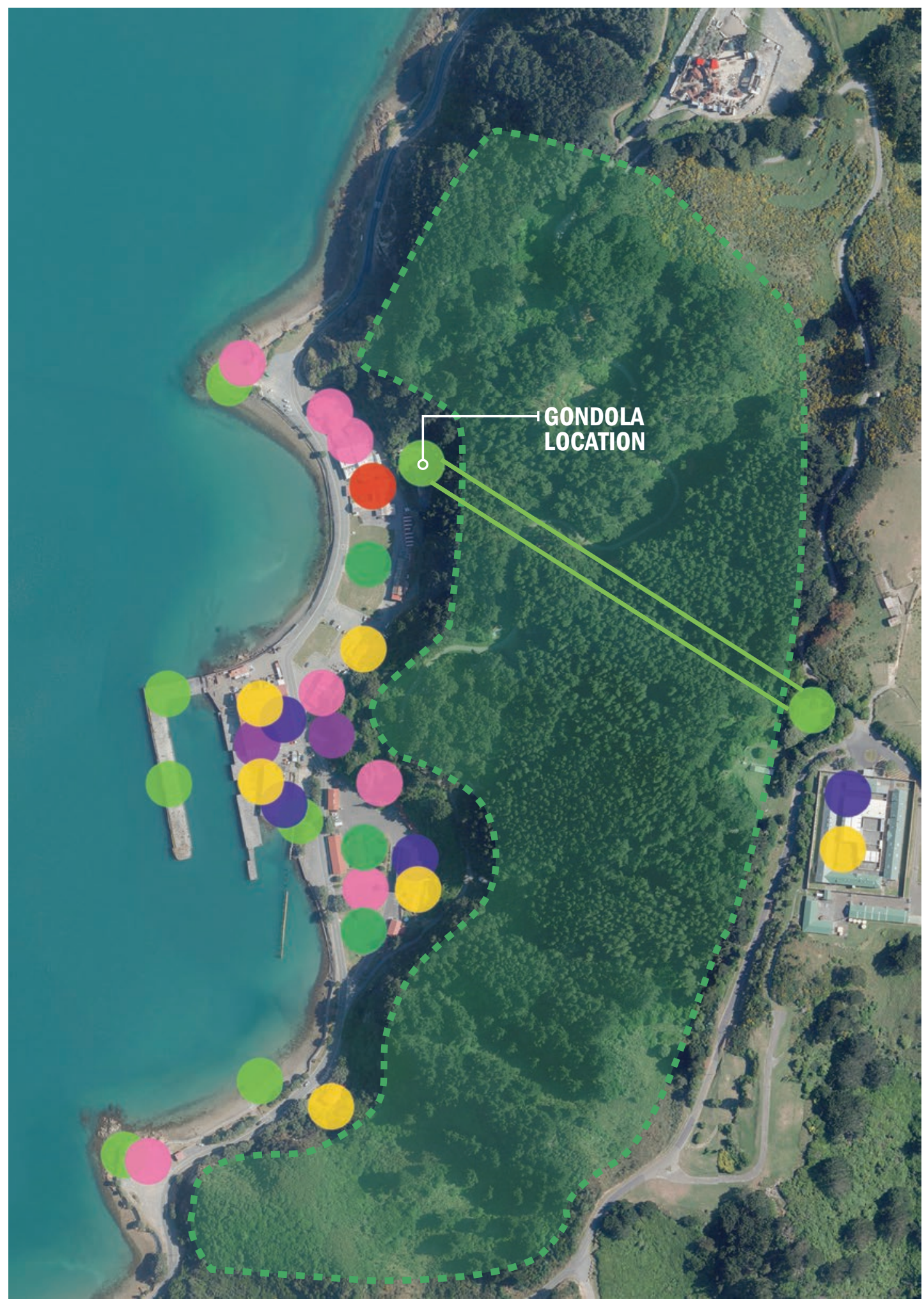

Fig 7.06 - Initial masterplan mapping study, showing the location of a gondola connecting Shelly Bay to Mt. Crawford. 


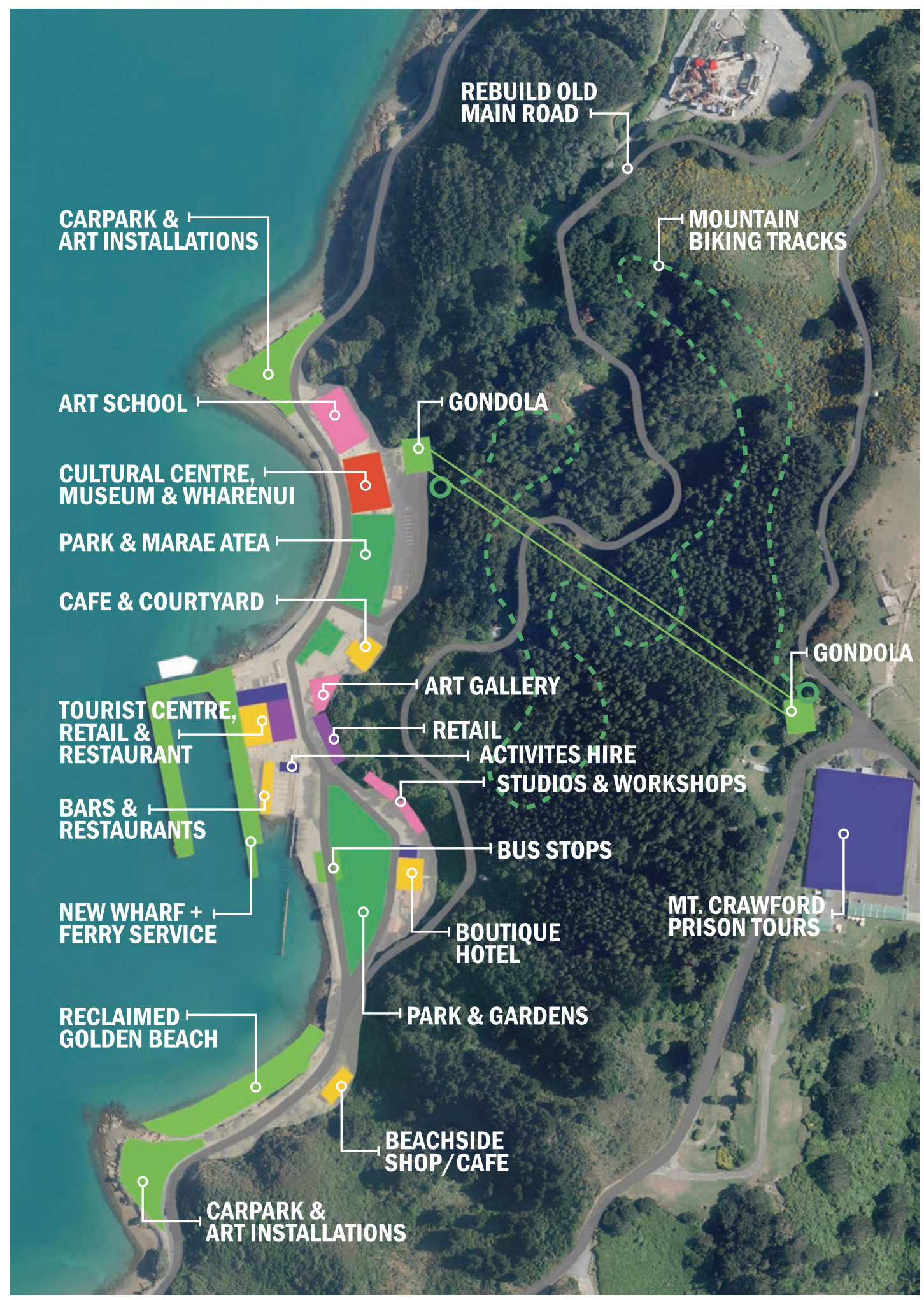

Fig 7.07 - Massing iteration one, basic blocking 


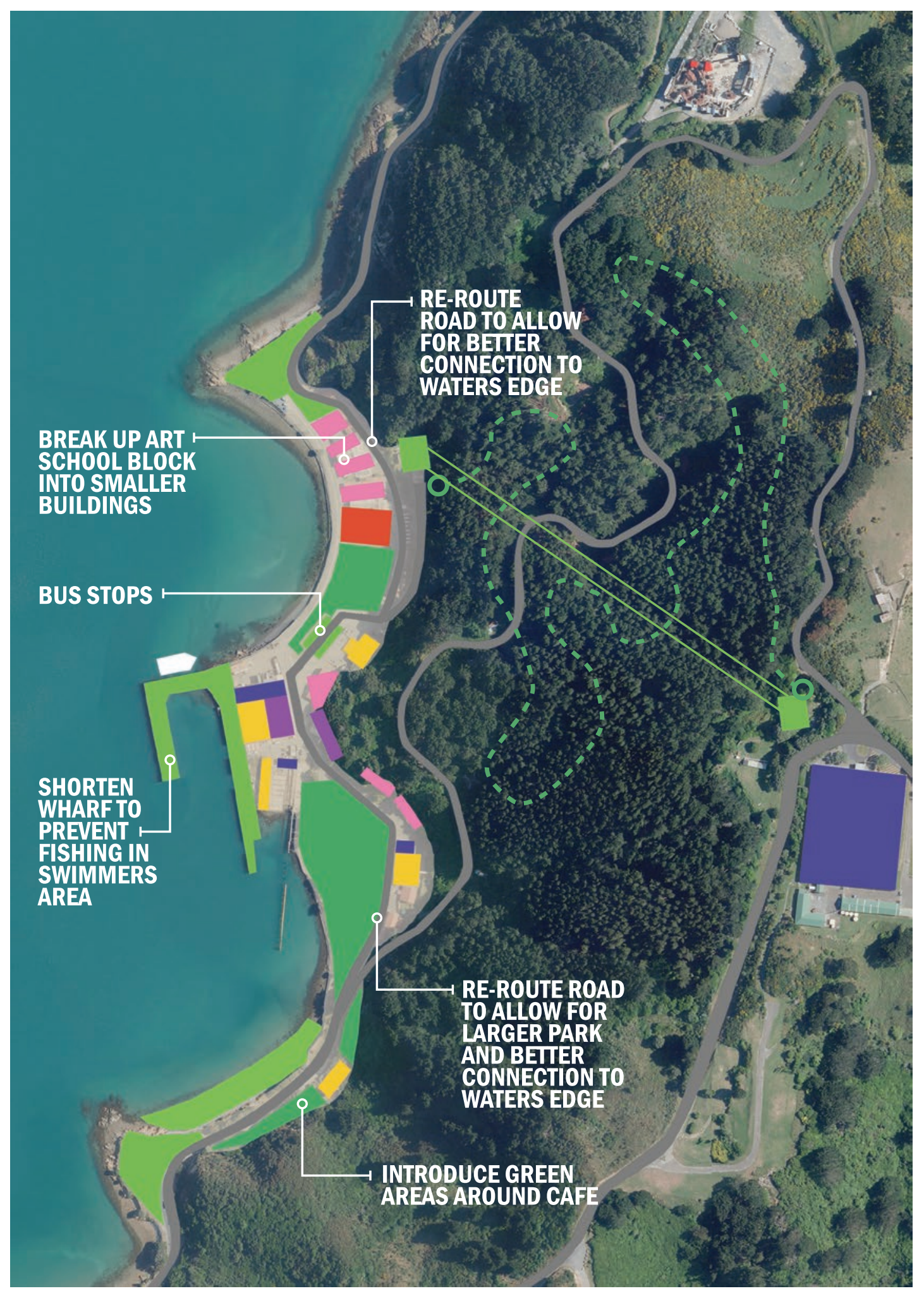

Fig 7.08 - Massing iteration two, re-routing roads towards the hillside to improve pedestrian access to coastline break up large blocks into smaller buildings as per '1999 Shelly Bay Design Guide' 


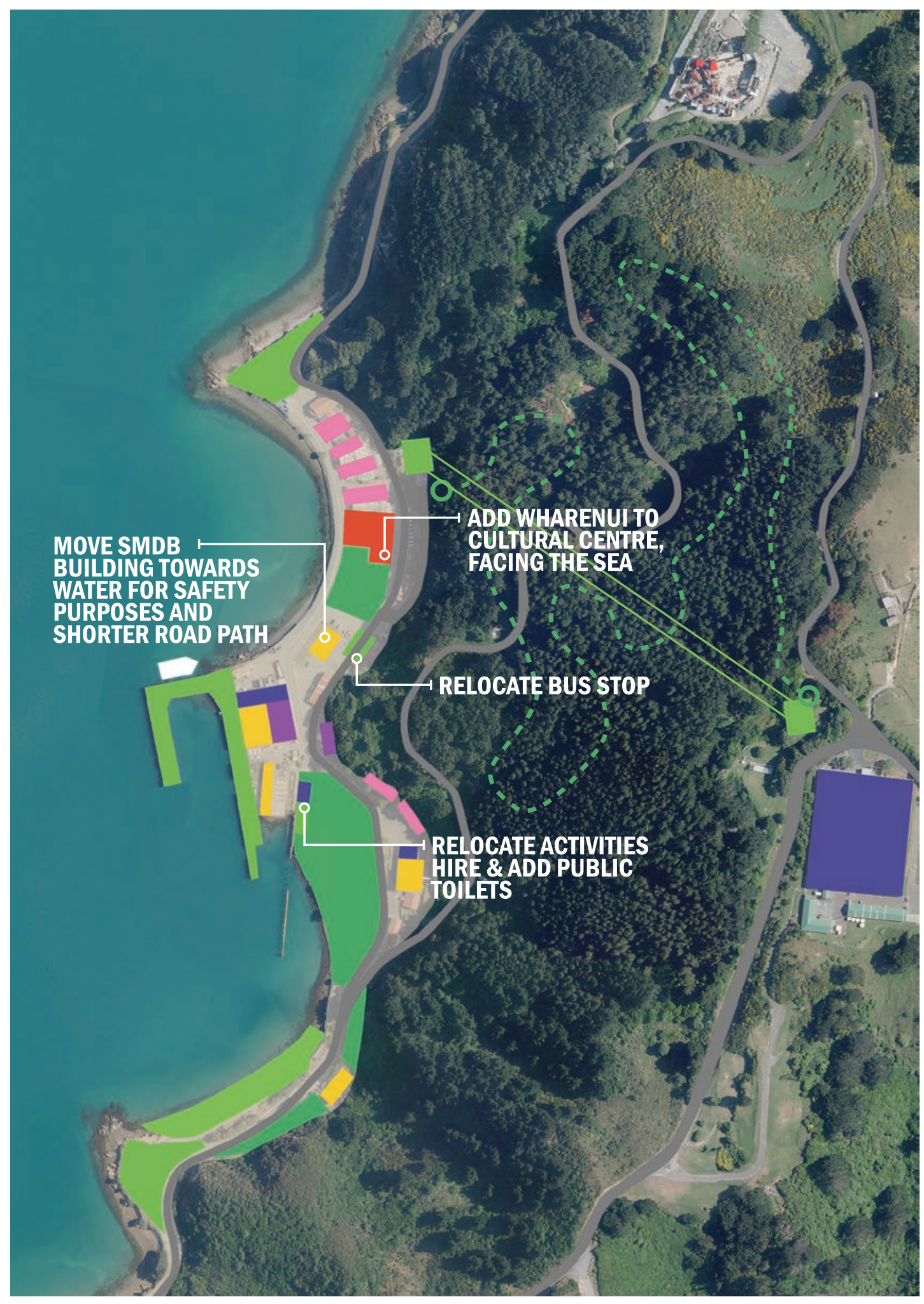

Fig 7.09 - Reconsidering Submarine Mining Depot Barracks location. Moving road towards escarpment. 


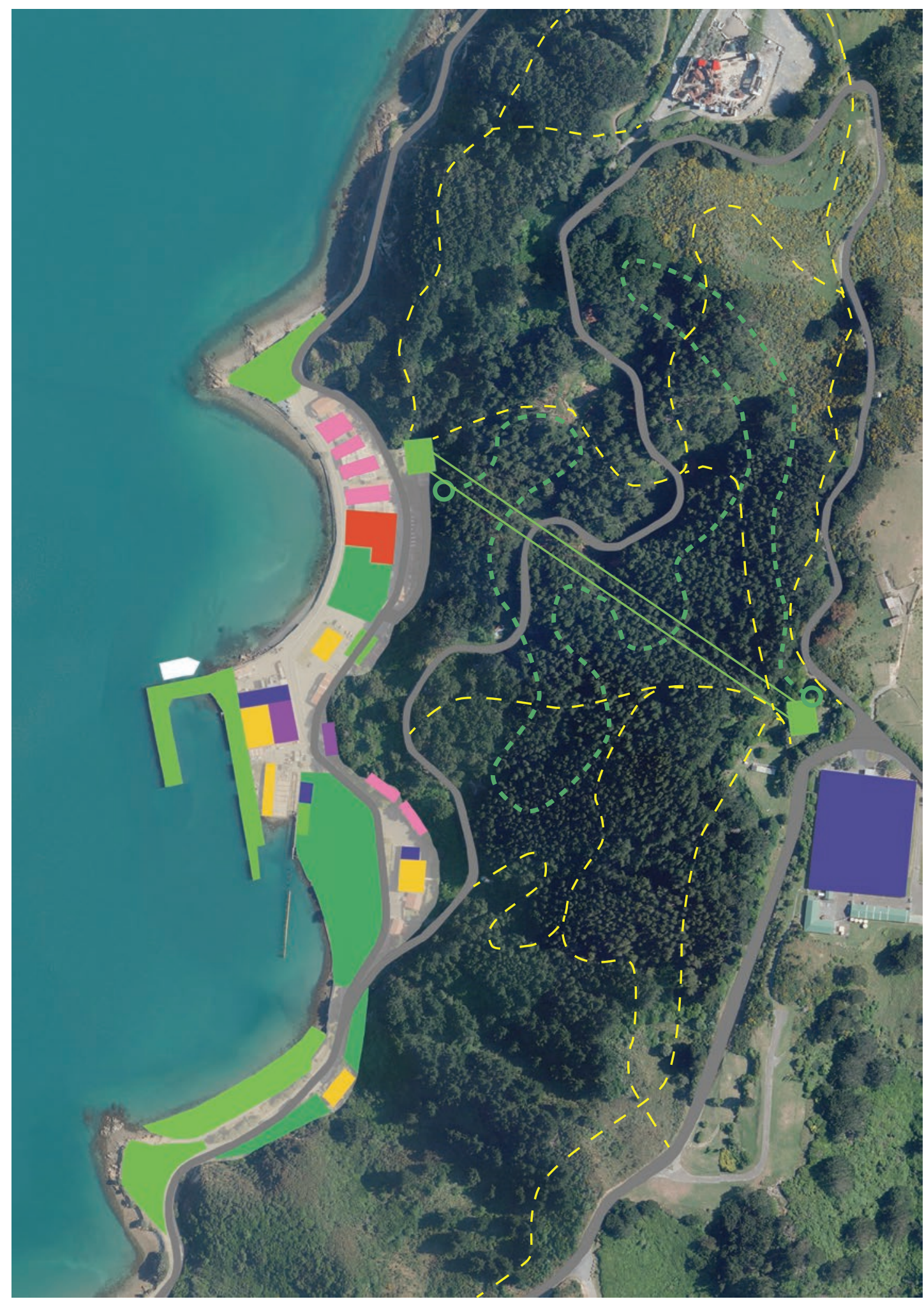

Fig 7.10 - Adding walkways. Bridges will lead walkers above mountain biking routes and roads. 


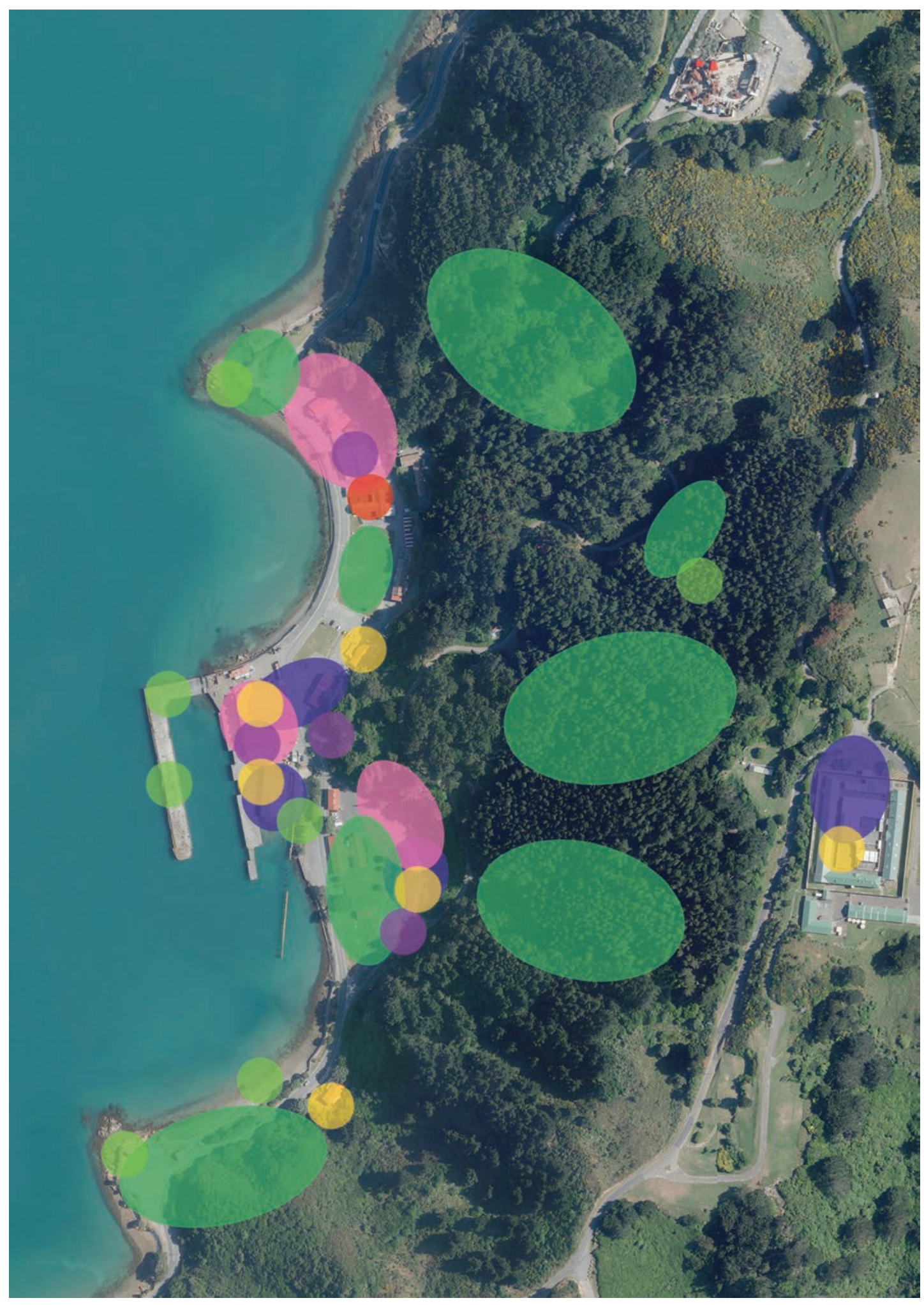

Fig 7.11 - Initial community zoning study for compare and contrast purposes. 


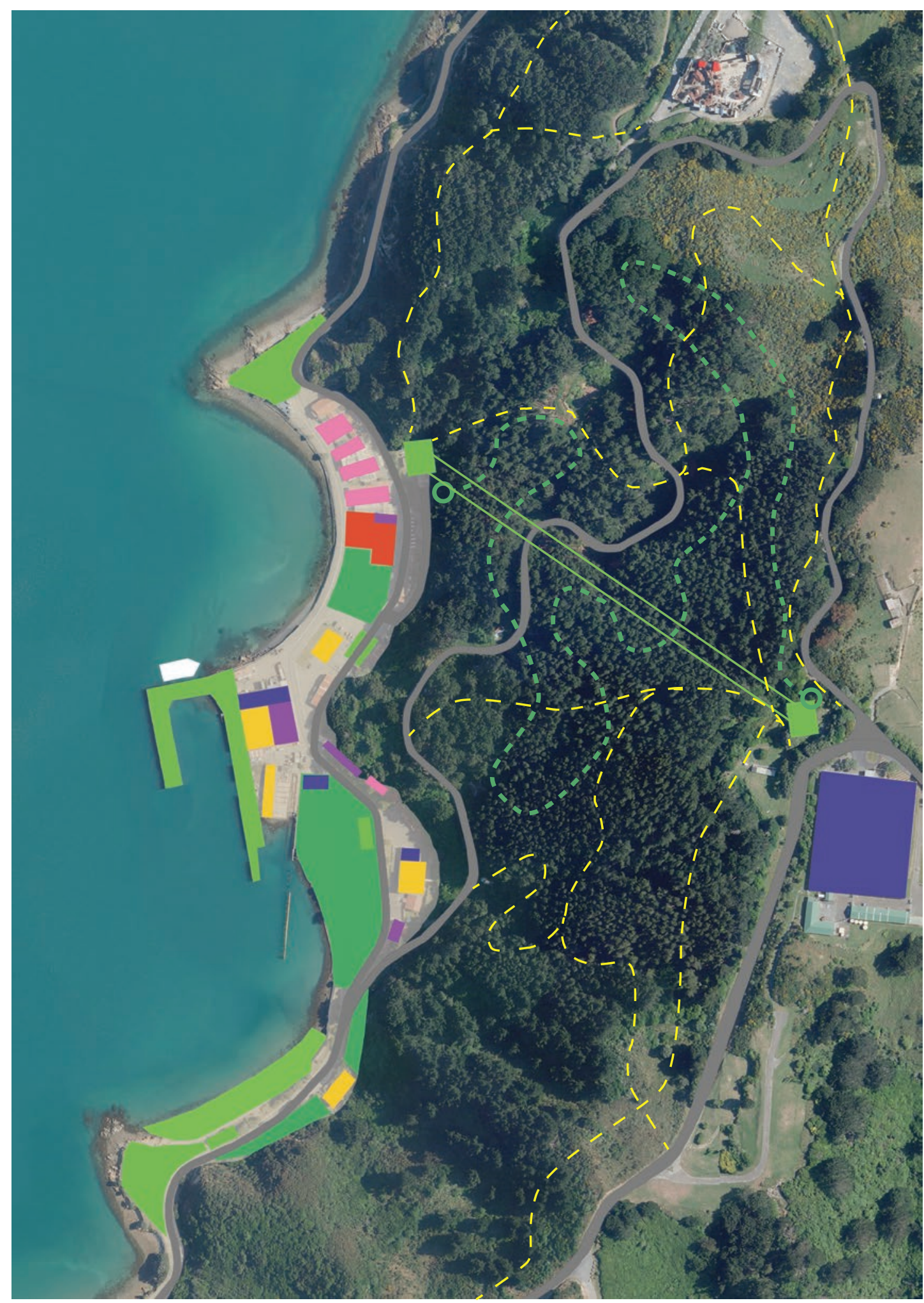

Fig 7.12 - Finalised zoning masterplan after reconsidering community data. 


\section{SHELLY BAY 2030}

A masterplan produced by the community,

for the community.

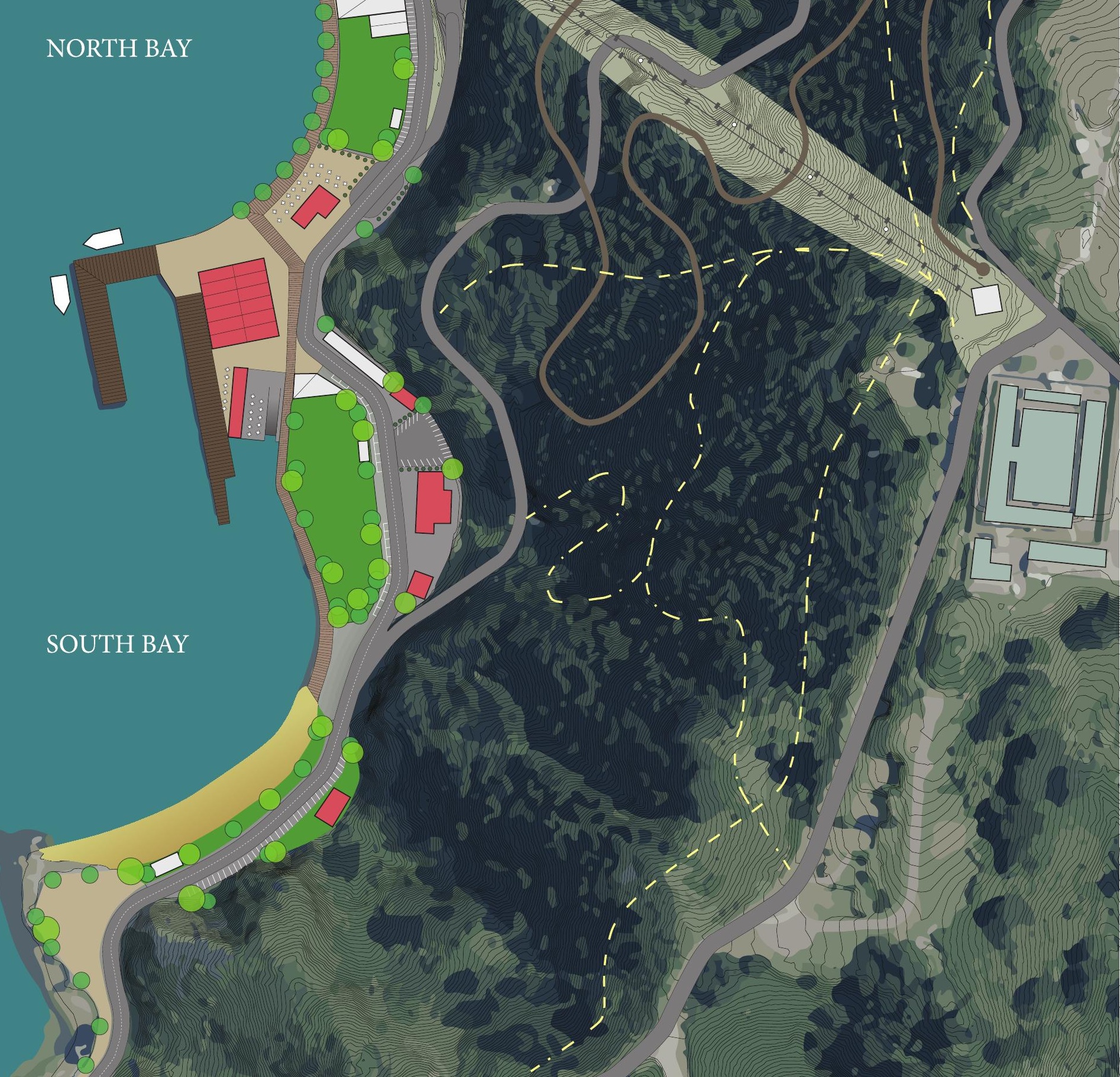




\section{Final Masterplan - Shelly Bay 2030}

The culmination of the two participatory design stages have led to a finalised community masterplan, 'Shelly Bay 2030'. It has taken the information gathered from the community, quantified it, analysed it and, through this analysis, a brief and masterplan have been produced.

Shelly Bay 2030 has four primary objectives. These are to satisfy the needs for recreation, the creative arts, culture and tourism.

The North Bay focusses on the creative arts and culture, the wharf area predominantly looks at tourism and the South Bay lends itself to recreation. In addition to this, the hillside has been developed for recreation and as a connection to the Mt. Crawford prison site.
The major alteration to the site comes through moving the road towards the escarpment; this means the majority of public spaces can be against the water's edge - improving safety and access. Sand is brought into the South Bay to create an artificial beach, and the green spaces which currently exist have been enlarged and improved upon. Connecting the extremes of the site is a boardwalk.

Note: Red buildings (in the plan views) are re-purposed existing buildings - white buildings are new builds. 


\section{North Bay}

The North Bay of Shelly Bay is primarily occupied by buildings relating to the visual arts and Māori culture. The northern-most tip is used as a car park with art and sculpture displays. Moving south, there are four buildings which service differing facets of the visual arts. The Mãori arts school ties into the cultural centre and Māori museum - capable of displaying and teaching traditional carving and weaving techniques. Attached to the cultural centre is a wharenui - this wharenui serves two purposes. First, as a meeting house for Taranaki whānui; second, as a welcome area to the cultural centre on special occasions. Next, a large green area to be used for recreation or events as well as the bus terminals for tourists and regular commuters alike. To the east of the Māori Arts School is the recreational centre and gondola access - housed in the old Hospital building.

Fig 7.15 - 'Shelly Bay 2030', North Bay close up 


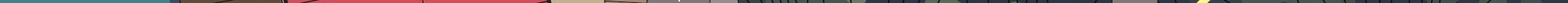




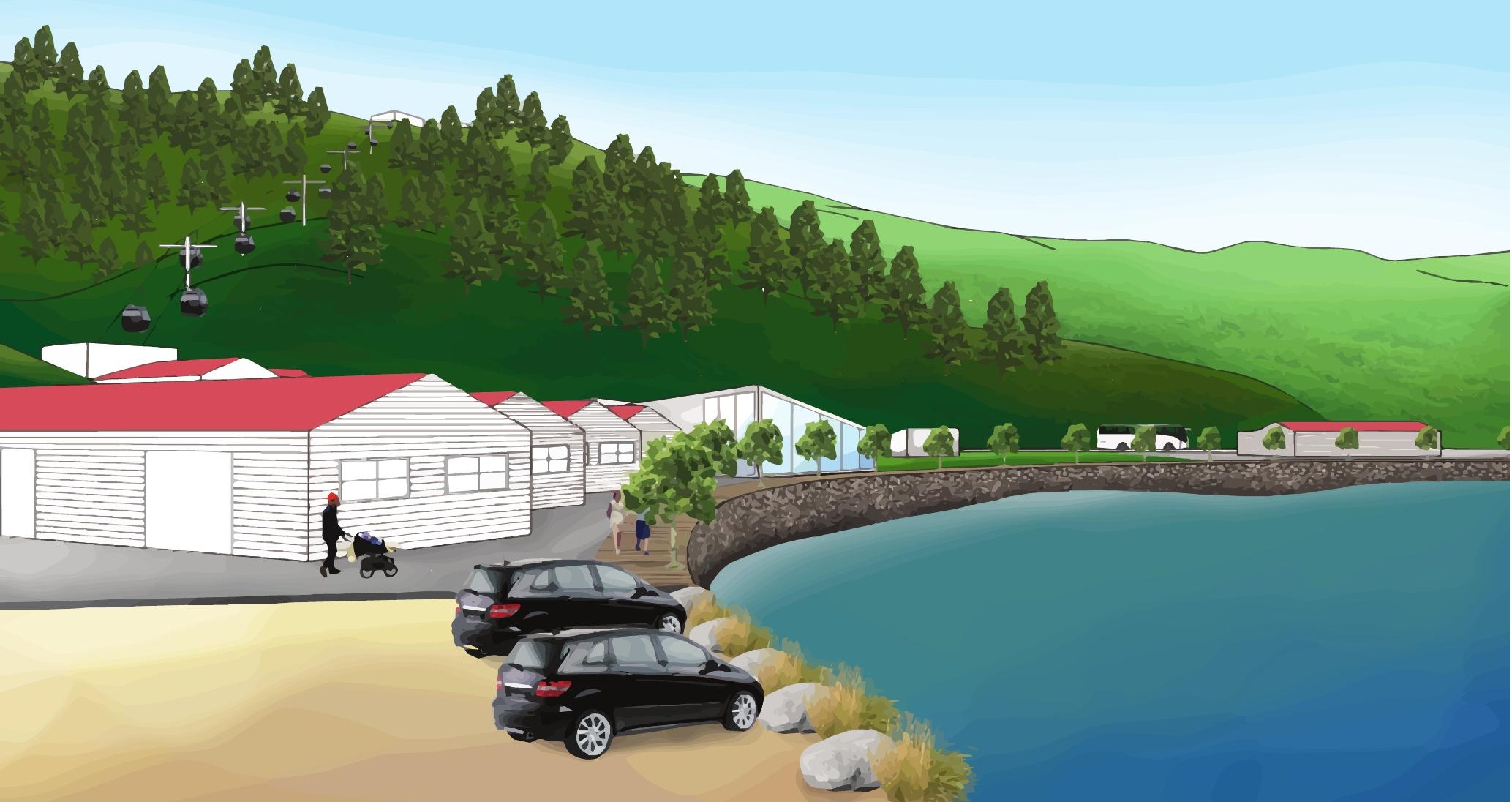

Fig 7.16 - Artistic impression of North Bay from camera C1 


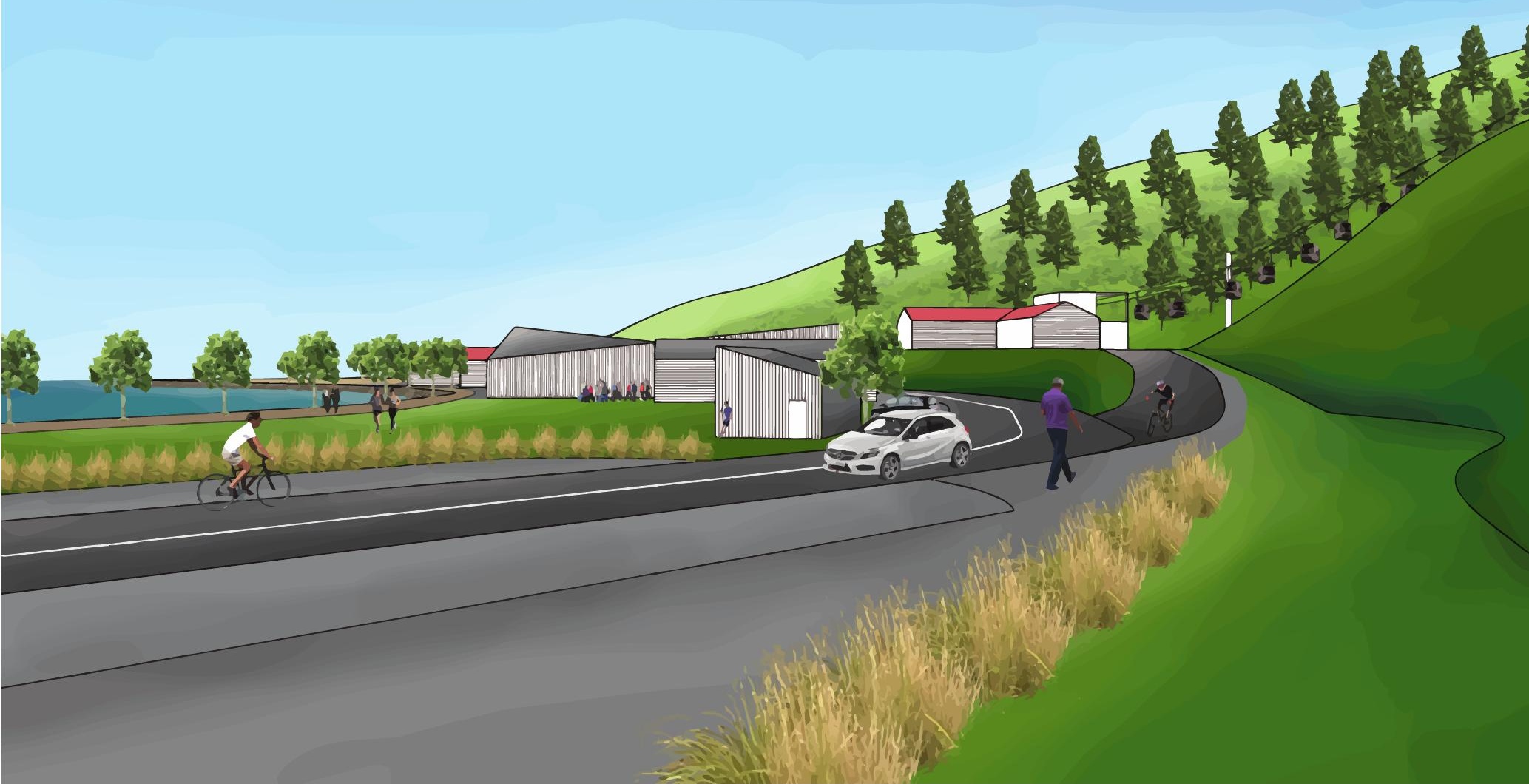

Fig 7.17 - Artistic impression of North Bay from camera C2 


\section{Wharf Area}

Perhaps the most important section of the site - the wharf area houses the majority of the hospitality, retail and tourist zones. The redevelopment of the wharf is slightly shorter than the original (to prevent fishermen from fishing into the swimmers/water-sports area) - however, it introduces a commuter ferry service which will connect Shelly Bay to the Wellington CBD, Days Bay, Seatoun and Matiu/Somes Island. The existing Warehouse and Stores building will be redeveloped to house a tourist centre and military museum along with retail and administrative areas. The Shipwrights building is re-purposed as a restaurant and bar area with the slipway being reworked to serve the activities hire building as an area to launch kayaks and small sailboats. Attached to the activities hire building will be an ice cream parlour. To the east of this will be a series of art galleries and workshops.

Fig 7.18 - 'Shelly Bay 2030', WharfArea close up 


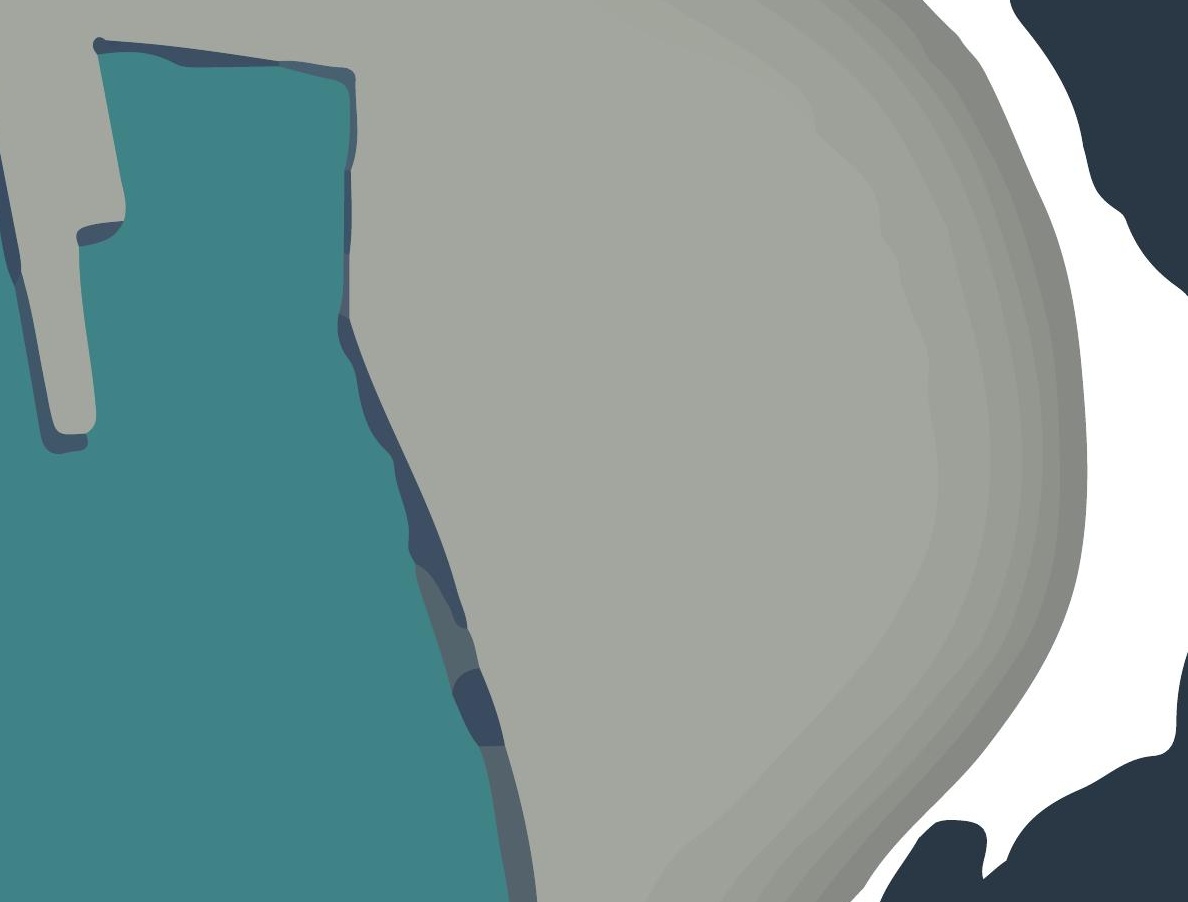


Mat

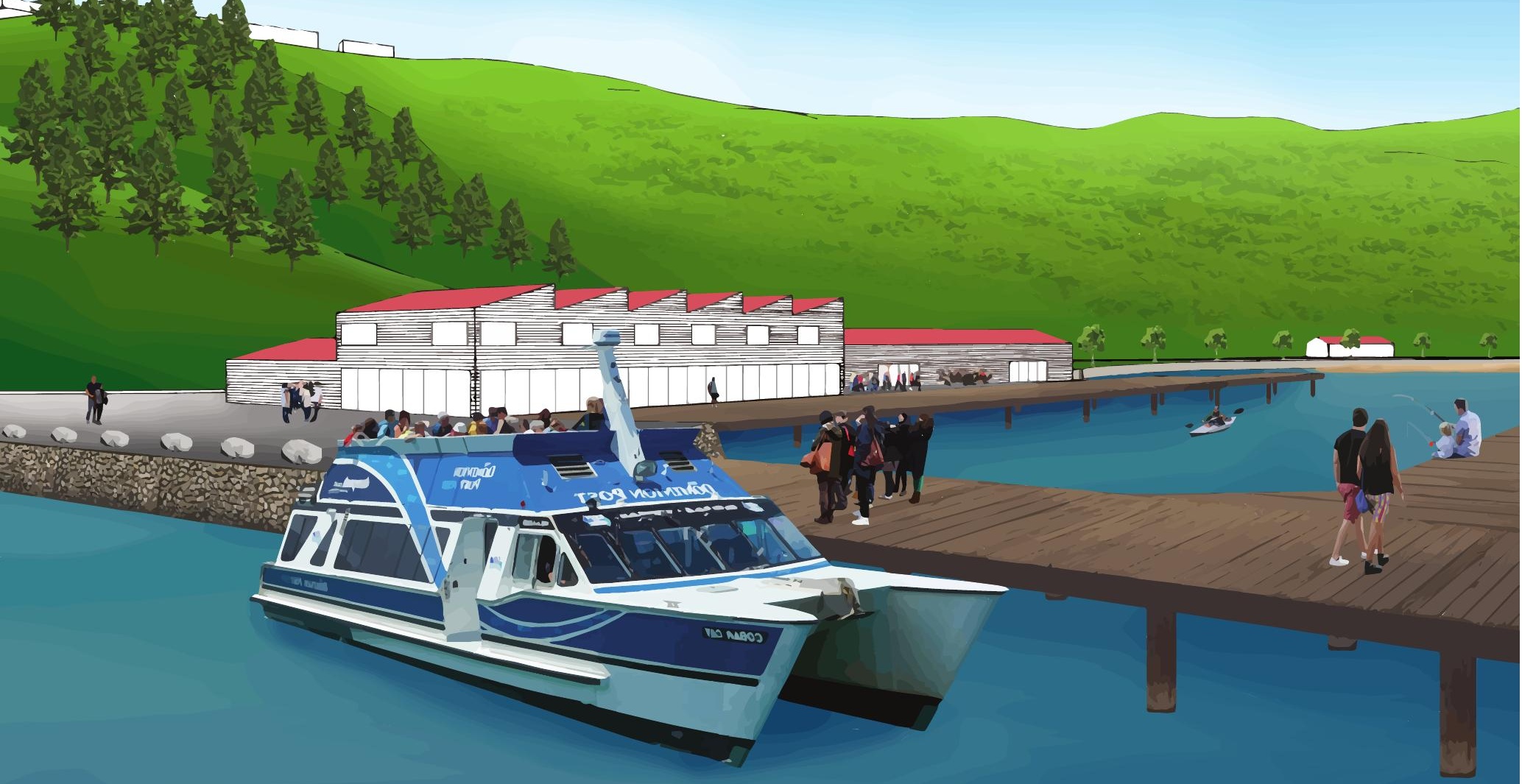

Fig 7.19 - Artistic impression of Wharf Area from camera C1 


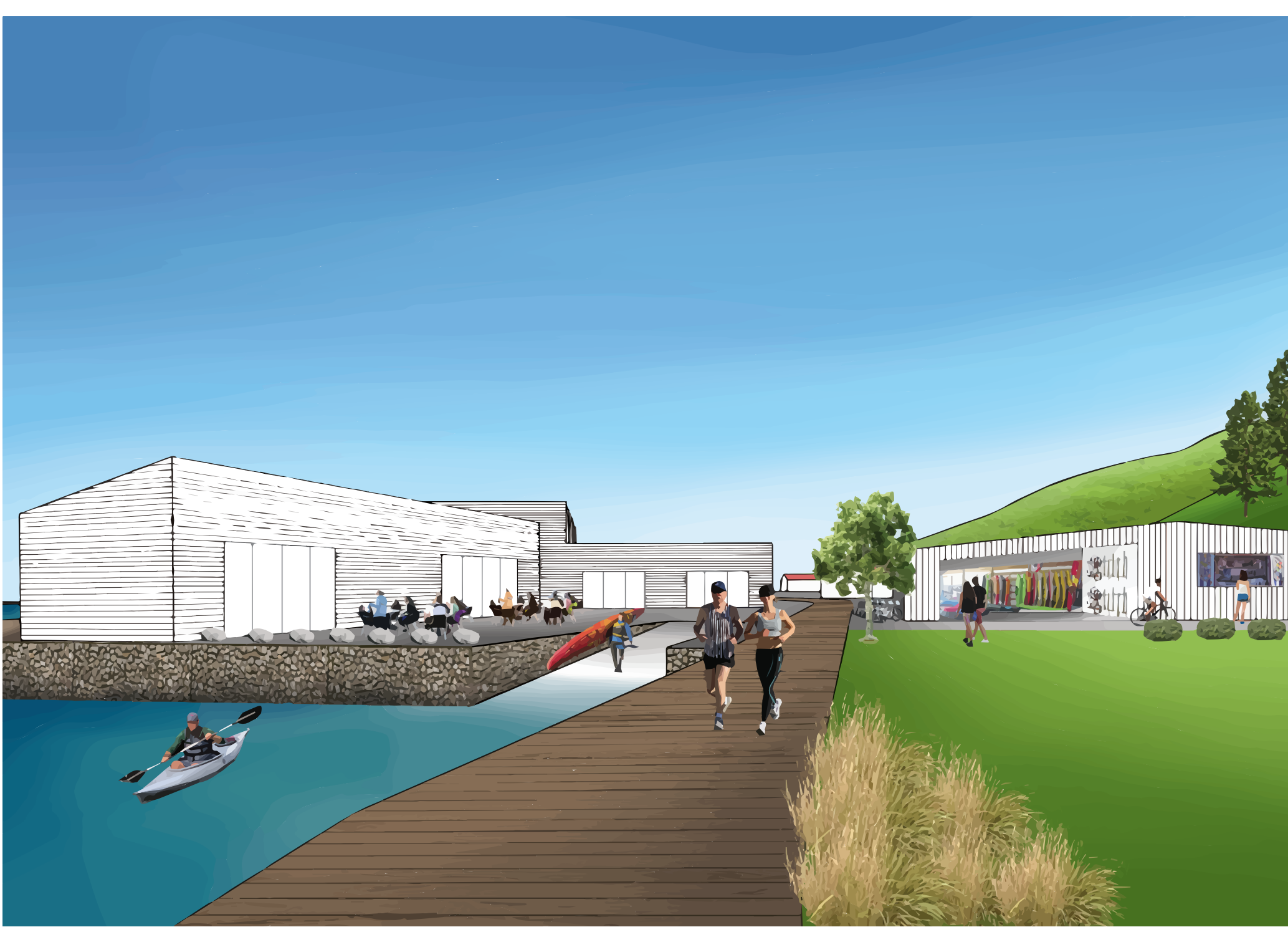

Fig 7.20 - Artistic impression of Wharf Area from camera C2 


\section{South Bay}

The South Bay is primarily used for recreation. The major feature here is the artificial beach - similar to what is seen at Wellington's Oriental Bay. This will be a major attraction for locals, and it is suggested that the Chocolate Fish Cafe relocates into the beach-side cafe here to service the area. South of the beach is another car parking/sculpture display area while north of this is the larger recreational park and native gardens. East of this green area is a boutique hotel which occupies the old Officers' Mess Hall and a small retail area.

Fig 7.21 - 'Shelly Bay 2030', South Bay close up 


\section{SOUTH BAY}

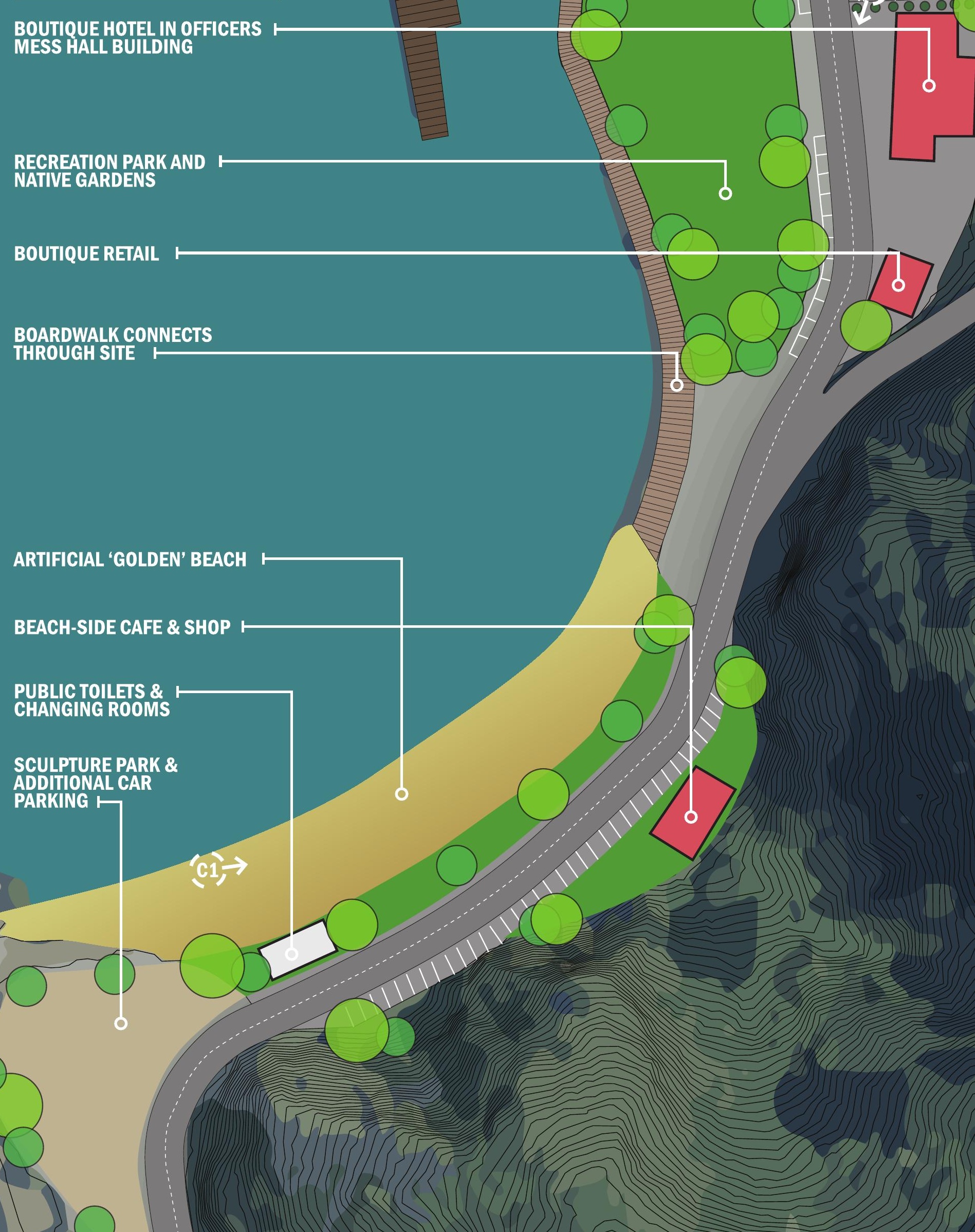




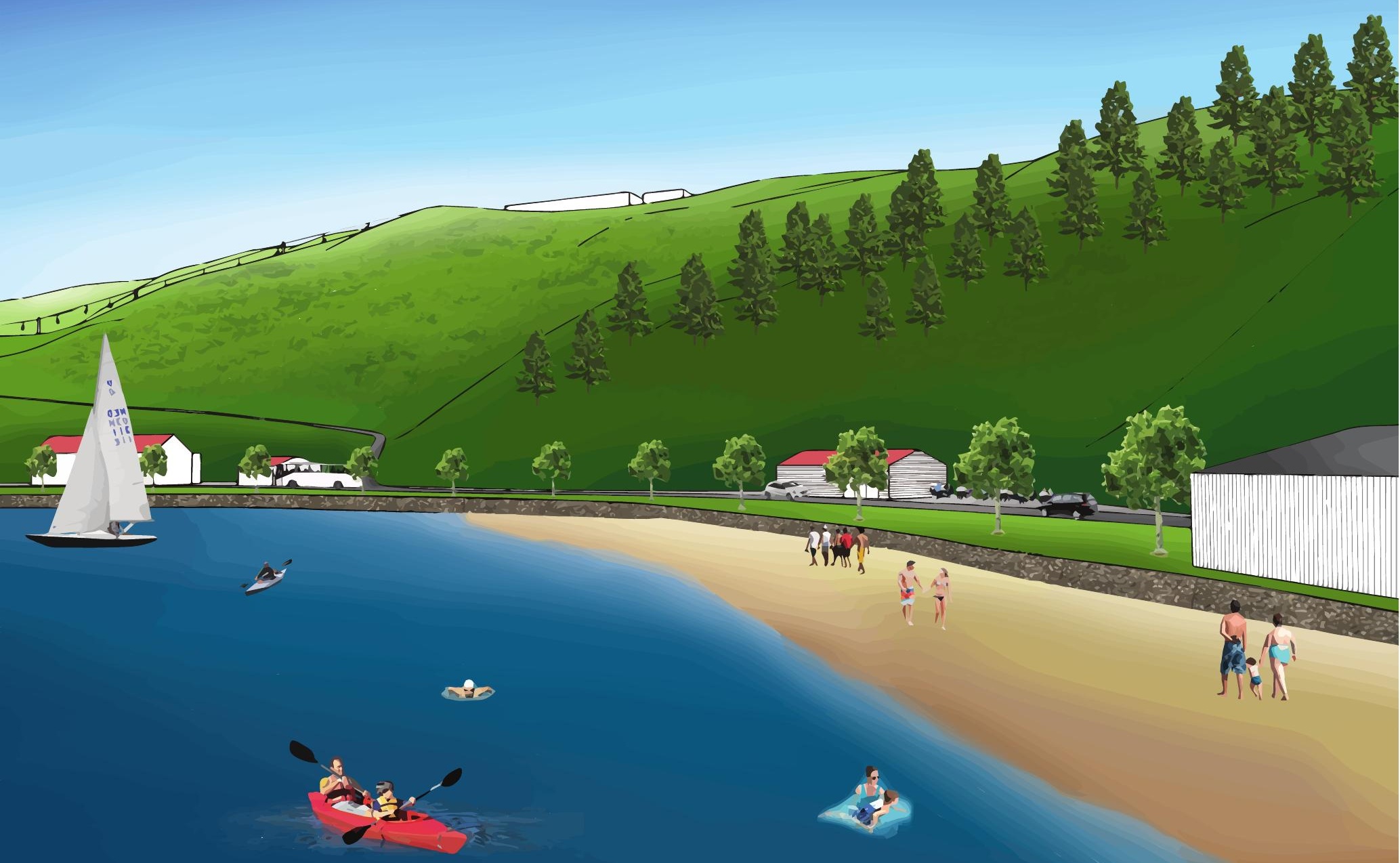

Fig 7.22 - Artistic impression of South Bay from camera C1 


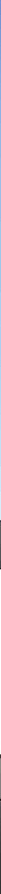

Fig 7.23 - Artistic impression of South Bay from camera C2 


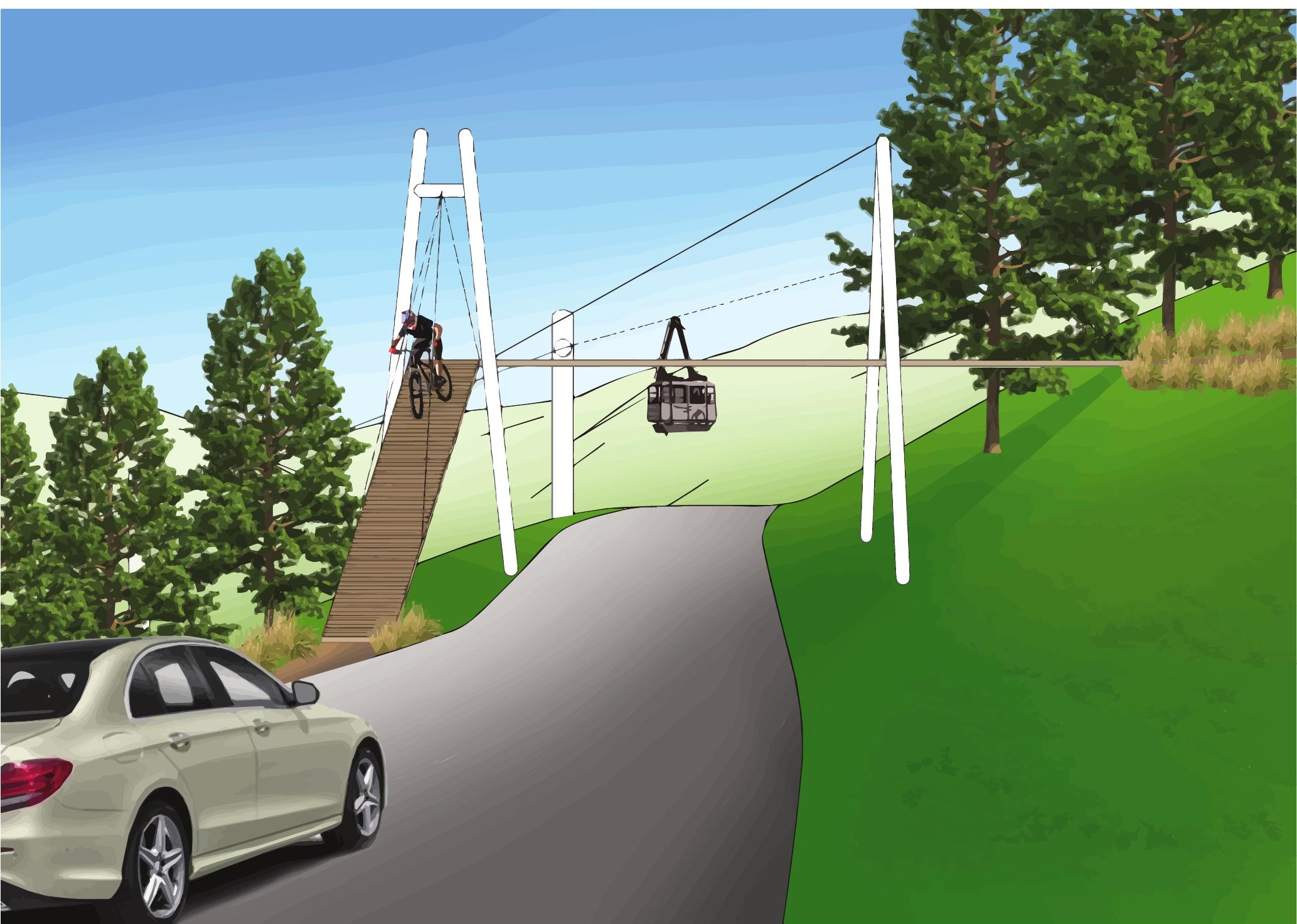

Fig 7.24 - Artistic impression of biking tracks and road interaction 


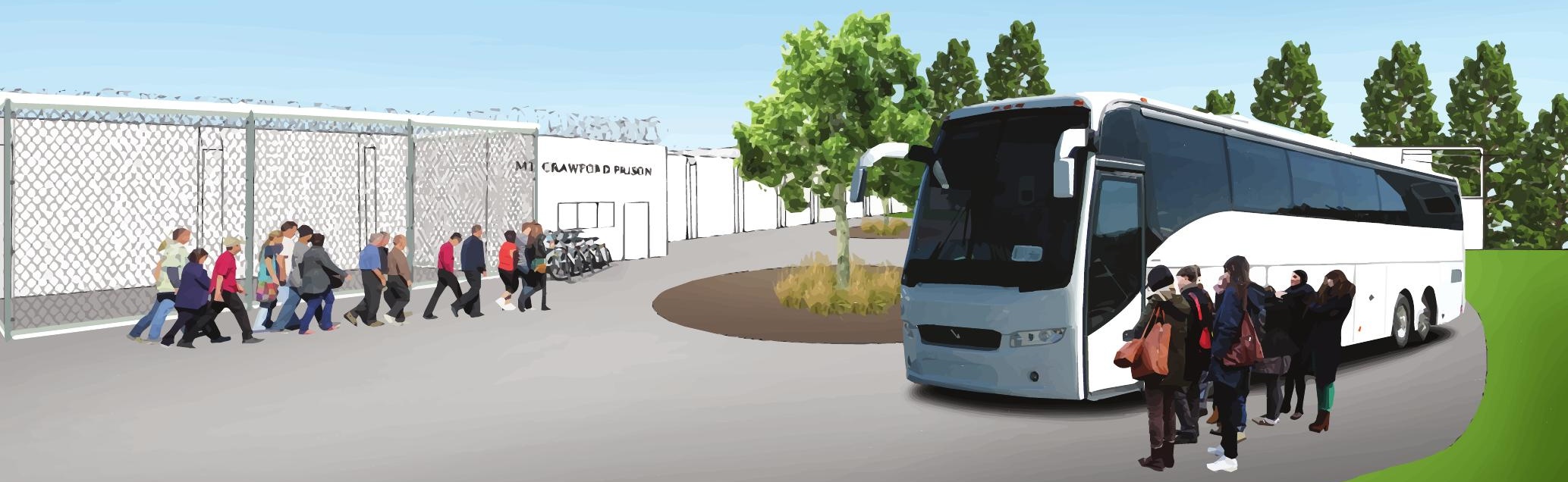

Fig 7.25 - Artistic impression of Mt. Crawford Prison site 


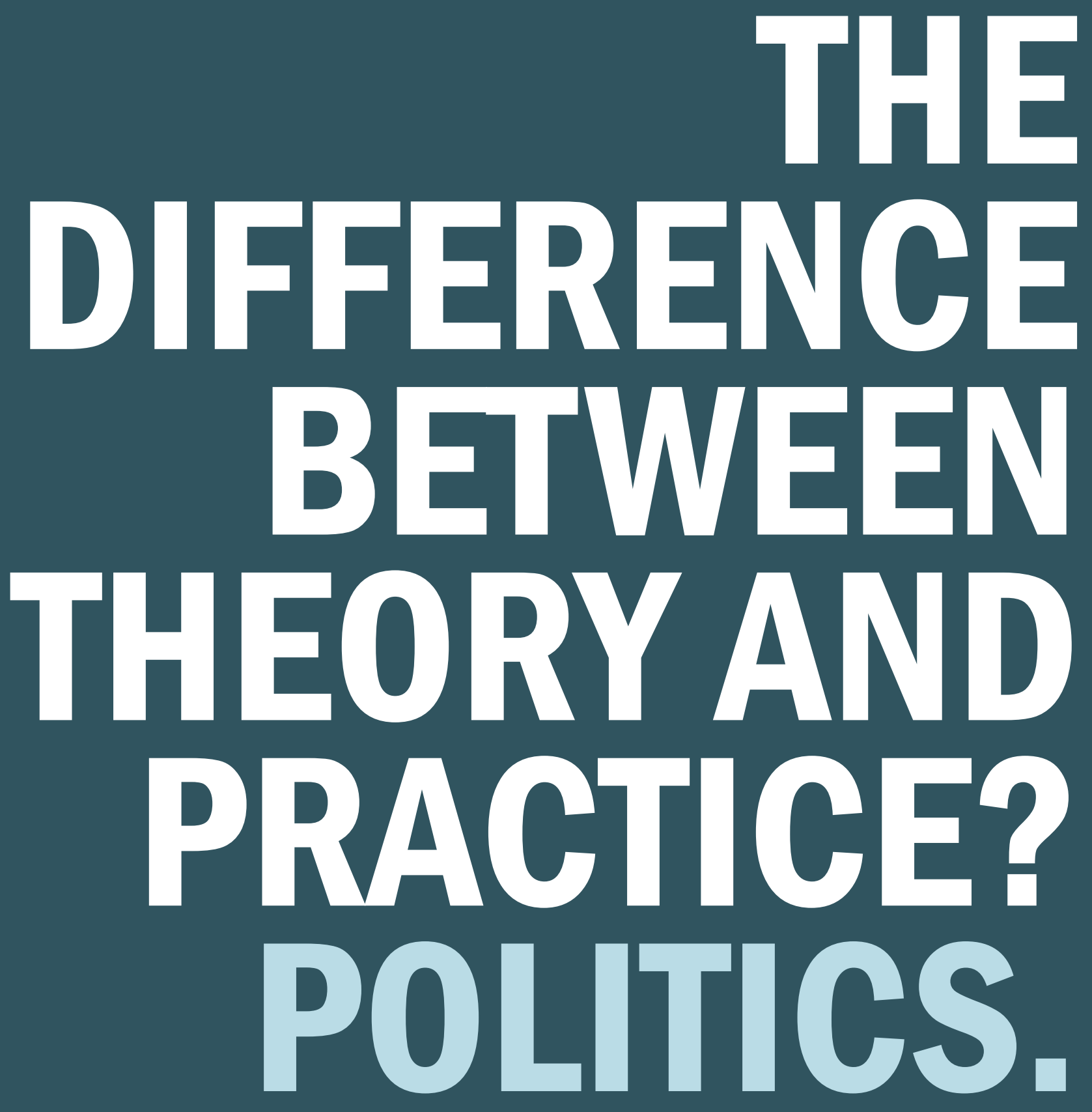




\section{Chapter 8: Reflection Reflection of Participatory Process}

The method this participatory design research offers is useful up until the point of finalising a design. It provides the necessary starting point for the project; however, does not provide the means to develop a complete final design. Once a final concept is identified, the leap from final concept to final design is so large and detailed that it is not reasonably practicable to achieve this at a level of public collaboration.

For example, if 'Shelly Bay 2030' were to be a participatory project in its entirety. The only practical way to do this is to shrink the size of the consultation into a series of focus groups to iron out the details of the design. By narrowing the scope from a community design, to one which is finalised by only a small percentage of the community, introduces problems. For example, if we ask one focus group what they want the cultural centre to look like their answer will almost certainly be different to what every other focus group decides.
The conclusion from this observation is that it is practical to utilise the knowledge of the community in the conceptual stages of the design process as what is important to them is not what the development looks like but, instead, what that development includes and how it functions. Once these are identified, the project shifts from one which is community led to one which is professionally led - i.e. this is when the architects and urban planners should take over.

This reinforces the idea that a top-down design approach is still required at this public scale. The role of the architect or urban planner should be to take the information provided by the public through the participatory design stages - and turn that into a final design which reflects the needs and wants of the community while being functionally and aesthetically beautiful. 


\section{Reflection of Participatory Design Tools}

The participatory tools used in this research were split into two stages. Stage One utilised the traditional consultation methods of surveying and interviewing. Stage Two adopted several alternative techniques and packaged them into a single format via a booklet. The goal of these tools were to facilitate consultation, involvement and collaboration in public design as defined by the IAP2 Spectrum of Participation (IAP2 International Federation, 2018).

Surveying and interviewing are the consultation staples of participatory design. It is no surprise, therefore, that these were also the most effective in terms of gaining responses. The public are constantly asked to fill out surveys, whether it be for companies, legislation, product feedback or anything else, they have become a part of everyday life. They are familiar to people, and people know how they work.

The survey served two purposes. First, to gain an understanding that people wanted to be more involved with urban development in their community and that current involvement is lacking. Second, that they could share their vision for Shelly Bay by asking various pointed questions. On reflection, the only issue with the survey (refer Appendix A) was that it was too long. There were many questions which did not need to be included as they did not have a significant effect on the final information derived from its analysis. Many respondents were taking upwards of 30 minutes to complete it; where, ideally, a survey should take no longer than 20 minutes, with 10 minutes being ideal (Revilla, M., \& Ochoa, C., 2017).
The interviewing stage was more, complicated. Of all 92 people who responded to the survey, only three of these followed through on their request to be interviewed. In addition to this, it was not possible to interview representatives from The Wellington Company, The Wellington City Council or The Port Nicholson Block Settlement Trust (as they all failed to respond to requests for an interview). The three interviews which did take place, however, were instrumental in gaining qualitative information around the Shelly Bay problem. The interviews had a few set questions but were generally left open to keep the conversation flowing. Introducing the relationship breakdown exercise was a useful tool in defining precisely what elements they wanted to see in Shelly Bay and how these elements related to one another.

Stage Two had its own problems. The initial plan was to design an interactive exhibition to be held on site. Unfortunately, Shelly Bay business owners were hesitant in supporting a project which looked to reject the Taikuru plans. The alternative option was to ask one of the local libraries. The libraries, however, are funded by the Wellington City Council, and they too did not want to support the project. The plan then changed from an interactive exhibition to designing a booklet/ workbook which could be distributed through the Chocolate Fish Cafe.

This booklet, titled 'Shelly Bay, Our Way' utilised several participatory design tools. The major tool missing, as a result of using the booklet, was an interactive physical model (Fig 8.01). With this, participants would have better control over form and height, while also being able to react to 
the contours of the hillside in a way which was difficult in the other exercises. These models were meant to be rudimentary to encourage creative play (divergent tool). This activity would have generated data which would have, more precisely, dictated the positioning and sizing of building components.

Nevertheless, there were many positives which came from the information gathered through the booklets. The most effective tools were (in order); the identification of objectives and components, the masterplan gameboard and the design principle rankings. The drawing component was left mainly blank. This could be because it was at the end of the (already lengthy) booklet or because the general public finds it difficult to communicate through drawing. For the most part, the written responses were so similar to the responses gained in the survey that - while they were useful they did not add much to the data. It is also difficult to incorporate multiple written visions into a manageable data set which can be translated into a design.
The only issue with the booklet was the response rate. Of the 60 distributed only 15 were returned (25\%). This meant the sample size was not reflective of the entire community. For this to be an accurate representation of the community, it would have to be distributed to all 35,000 people in the Eastern Suburbs to give them a chance to fill it out - an unrealistic goal. However, a sample size of even 100 booklets could form a reasonable representation. Unfortunately, the costs to do this, along with the time it would take to receive them all back would make the task impractical.

Based on feedback from those who did fill out the booklet, it is the opinion of the researcher that if the booklet were made shorter, it would have had a higher success rate. Most reported that it took them around 40 minutes to read and complete if this could be reduced to 20 minutes, this could improve the response rate (following the same logic as the online survey). If this were to be redone the booklet would remove both the written and drawn tools as well as shorten the background information provided at the beginning of the booklet.

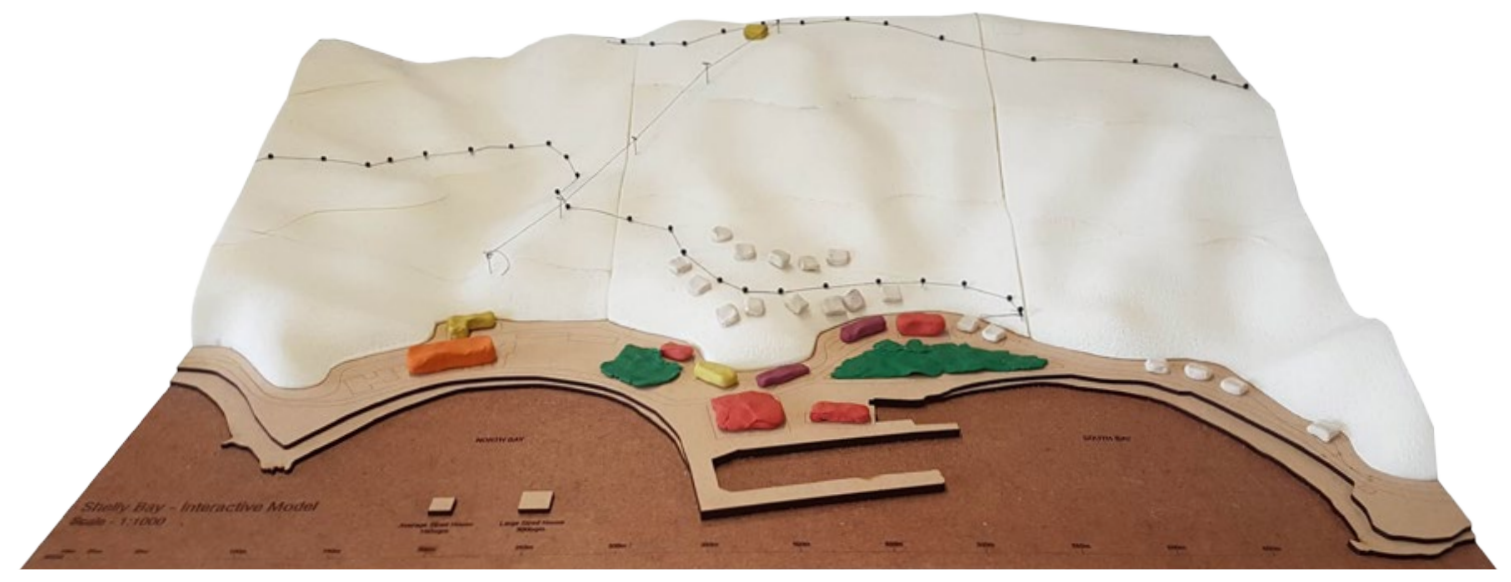

Fig 8.01 - An interactive physical model of Shelly Bay would allow community members the opportunity to play with building scale, placement and density. 


\section{Reflection of Final Design Outcome}

The participatory processes applied throughout this research only explored the initial stages of the design process. This is because it was not reasonably practicable to consult every member of the community on the final design details in a project of this scale - thus it is not possible to form a final design from the collected data. From here a professional would take over to fill in the blanks - recognising that a top-down approach is still needed.

Therefore, a reflection of 'Shelly Bay 2030' (SB2030) will not follow a traditional architectural critique. It is not a question of if the design outcome is architecturally aesthetic nor functional - it is a question of whether or not the design reflects the findings of the research. Is Shelly Bay 2030 a reflection of the wants and needs of the community it serves?

To answer this question, the design is critiqued against the information gathered and Stage One and Two of the participatory design processes. In particular, it will be compared to the finalised design objectives and components, the finalised design principles, as well as the community zoning plan. These were the three major influences extracted from the research.

Stage Two identified the community objectives and components as follows:

\section{Recreation}

- Activities Hire

- Fishing \& Diving orientated

- Walking Tracks

- Mountain Biking Tracks

- Parks \& Gardens

\section{Arts}

- Art Galleries

- Studios and Workshops

- Arts \& Crafts Schools
3. Culture \& Tourism

- Ferry Service

- Wharf Development

- Cultural Centre

- Māori Museum

- Art Displays

- Accommodation

- Tours

These were integrated into 'Shelly Bay 2030' through the initiation of the project brief. The brief slightly re-worked the objectives and components by grouping them based on their identified relationships. This process recognised that Arts \& Culture were better suited together - as was Recreation and Tourism. By grouping Arts and Culture together this led to the addition of a Māori Arts school in the design brief - something which was not identified by the public but made sense in terms of the other Māori and Arts identifications. The only other significant additions to the design components were the gondola and artificial beach. A smaller proportion of the community identified both of these elements. They were added because of the design principles looking at ensuring that Shelly Bay would become a major landmark in Wellington.

These design principles (detailed on the opposing page) were finalised by being weighted first through the Stage One survey, followed by the Stage Two booklet. This weighting was done to recognise that the survey received substantially greater responses.

The principles indirectly expressed what supplementary amenities or alterations Shelly Bay needed. For example, principle 3 and 4 look at improving coastline access and safety for the public. The result of this was to redirect the road towards the hillside - ensuring that the majority of the 

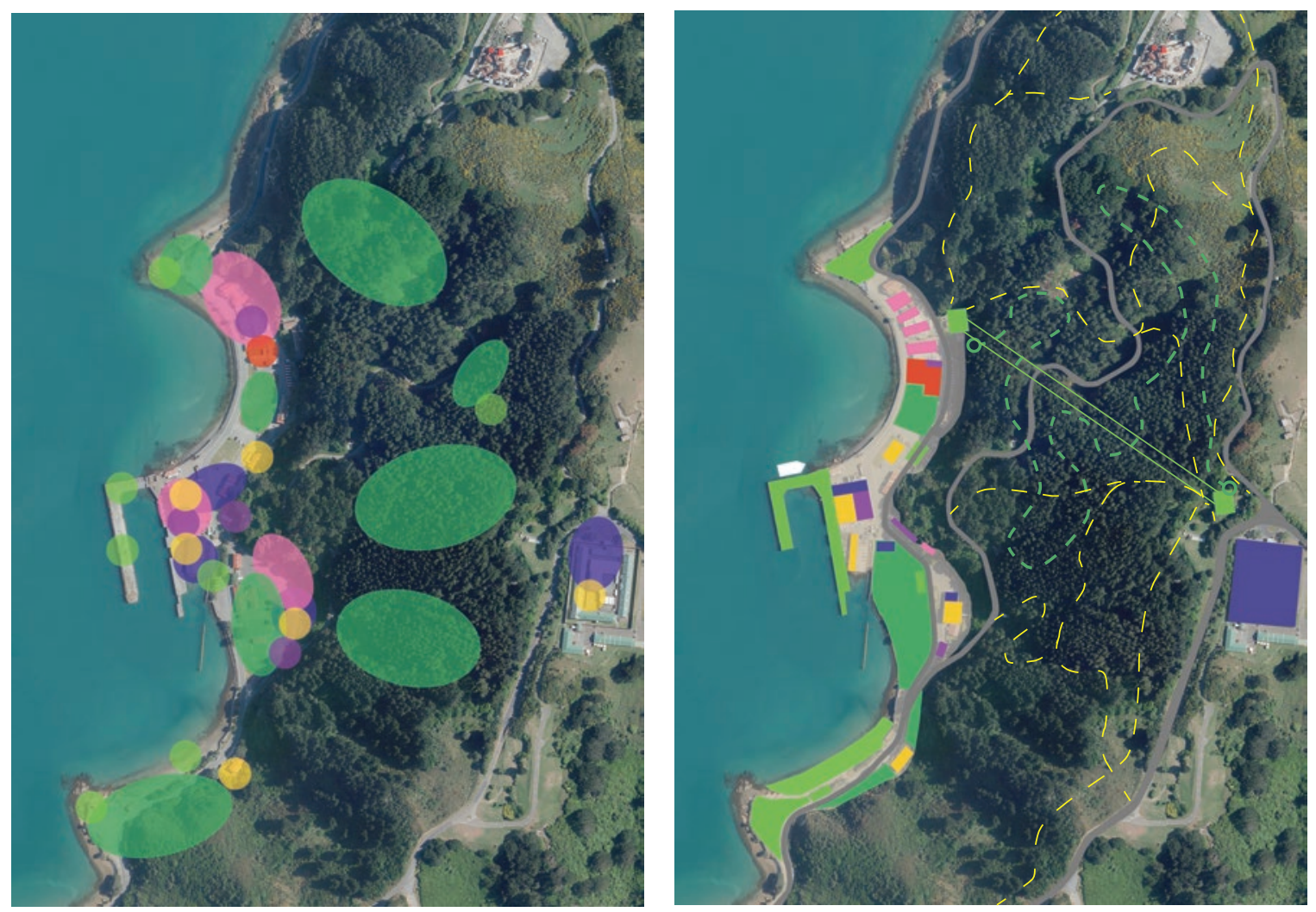

Fig 8.02 - Comparison between final community zoning plan (left) and final community masterplan (right).

public spaces were against the water's edge. Additionally, as many buildings as possible were retained and redeveloped in alignment with principle 8 . These principles directed the fundamental design decisions seen in Shelly Bay 2030, yet they were not sufficient enough to design entire buildings and public areas from - this is why the output is considered a final concept, not a final design.

The third tool used to dictate design decisions was the analysis of the Masterplan Gameboards - used in Stage Two. This analysis produced the community zoning plan seen in Fig 8.02. This zoning plan uses a colour coding system to place components around the site. The finalised masterplan then took this information and translated into the various buildings and amenities described in the analysis.

\section{Design Principles:}

1. Any design should act to improve the natural environment and consider the effects of rising sea levels.

2. Any design must consider the impact it will have on traffic congestion.

3. Maintain and improve coastline access to public.

4. Any development should enhance the experience for recreational users (cyclists, pedestrians, fishermen, beach-goers etc.) with a focus on public safety.

5. Shelly Bay should be iwi owned and developed in a way to benefit those who have a connection to the land.

6. Shelly Bay should be a major landmark in Wellington, a place which both Wellingtonians and tourists can enjoy.

7. A development at Shelly Bay should look to connect with the rest of Watts Peninsula, making use of the hillside and connecting the major landmarks.

8. We should express the Māori \& military history of Shelly Bay and re-purpose existing buildings where possible.

9. New design elements should compliment the existing character \& aesthetics of Shelly Bay. 
In conclusion, Shelly Bay 2030 took the information gathered through the two stages of community participation and interpreted this into a masterplan which effectively represented the data to its greatest extent. There was, however, a notable influence from the designer through the addition of a few design components and the subjective application of the design principles. This research demonstrates that this is unavoidable. If there is someone in charge of producing a final product, there will always be a degree of misalignment or bias in interpretation. Does this mean this is not good design? Does it mean this is not a genuinely community-based masterplan? These questions could only be answered through further consultation with those same community members. They would need to be asked if they agree on the plans or if they would change anything - this would require another round of design, followed by further consultation. This cycle could be a potentially never-ending process. There must, therefore, come a point in time where a design-lead takes charge and directs the course of the project.

On another note, a comparison between Shelly Bay 2030 (Fig 8.04) and The Wellington Company's Taikuru Development (Fig 8.03) is one which is critical to the research. The analysis explores the differences between what a private developer wants versus what the community wants.
The Taikuru masterplan is centralised around residential spaces with commercial, hospitality and recreational goals being secondary considerations. Selling houses/ apartments is the most efficient way of earning money quickly - this is what developers want.

Shelly Bay 2030, on the other hand, forgoes any residential development. Instead, opting to prioritise recreation, culture, the arts and tourism. These alternative goals immediately reduce pressure on infrastructure as no permanent residents are relying on it $24 / 7$.

There are similarities in the two development plans. Both look to restore important historical buildings and both centre the activities around the wharf area. The South Bays are quite similar - both relocating the road towards the escarpment. SB2030 provides a larger green space and an artificial beach while Taikuru looks to increase density through townhouses and apartment buildings. Both also look to re-adapt the slipway area. In terms of the North Bay, Taikuru keeps the road at the water's edge to provide more space for residential development in the rare. SB2030 moves the road to the hillside and introduces more green areas, a cultural centre \& museum, a wharenui \& marae atea as well as buildings oriented around the creative arts. 


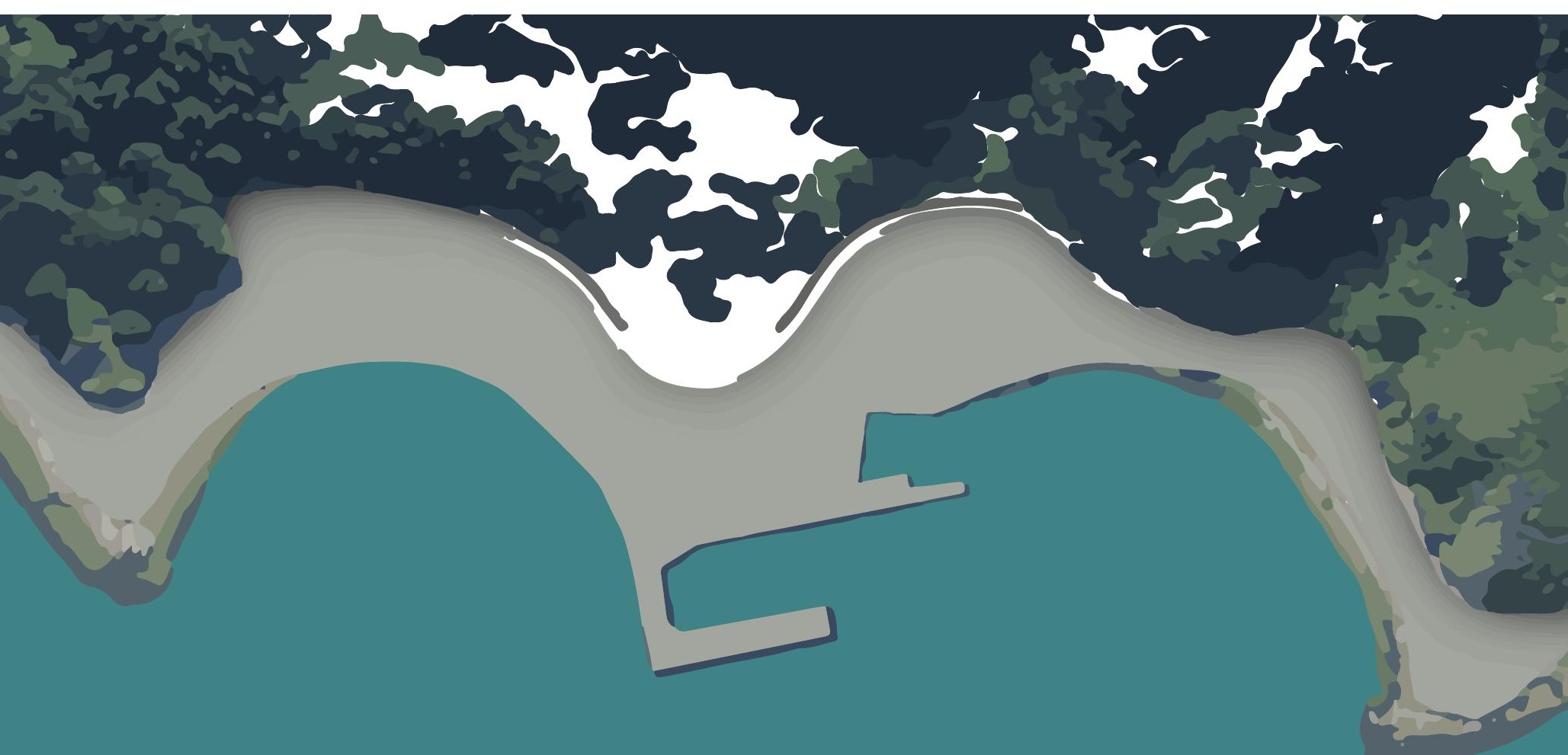




\section{Research Findings \& Applications}

Shelly Bay is a complicated site. The background issues with ownership, politics, history, infrastructure and environment make it an inherently complex case study.

This research initially looked at following a traditional participatory method starting with surveys and interviews and moving into workshops through interactive exhibitions. Political and commercial pressures, however, led to a transition into a non-contact, anonymous interaction through the booklet, 'Shelly Bay, Our Way'. Using the booklet, as a participatory design tool, was not mentioned in the literature nor case studies. However, the tools used inside it were - work from Henry Sanoff, in particular, was very influential (Objective Identification and Gameboard tools).

The benefits and drawbacks of the booklet as a form of non-contact, anonymous participation have been recognised as follows:

\section{Benefits of non-contact, anonymous participation:}

- No workshops, saving time and money.

- No commitments required from participants.

- Anonymity allows people to speak their mind without the fear of being judged.

- Data is often easier to interpret (through pointed questions and exercises).

- Can be split into less time-consuming stages (three or four short stages vs multi-day workshops).
Drawbacks of non-contact, anonymous participation:

- Restrictions in activities which require high levels of guidance.

- No face-to-face contact, are their opinions being listened too?

- Distribution and collection of data is more difficult (if using a physical booklet or similar tool).

This research argues that a basic workbook is an under-utilised consultation tool which can be very useful in providing both background information and the participatory tools required to generate effective quantitative and qualitative data. This is a tool which could be adapted endlessly to any design project.

The Objective Identification and Gameboard tools - in particular - could be adapted effectively to the design of a family home, shopping mall, community centre or entire town (for example). The workbook is a more cost and time effective solution compared to the traditional workshop and charrette process, allowing the designers/ architects the opportunity to spend time on other stages of the project simultaneously.

The approach taken through this research was sufficient enough to generate a community masterplan for Shelly Bay which defines building types, area uses and basic design principles. It is not sufficient enough, however, to produce a finalised design. This is because it is not reasonably practicable to consult the community on the design details of every inch of the design. This is true, to some degree, for any participatory design project. This is 
the point, therefore, that the design lead must take over - either going back to the community for a final consultation or completing the design based on the collected data. For a project such as Shelly Bay (which is highly criticised in the eyes of the public), it would be wise to revisit the community with the finalised concept to seek approval and look to generate ideas for design details. This extra step might not be needed in projects with less public scrutiny.

The traditional methods of surveying and interviewing were useful; however, this was to be somewhat expected. Surveys, in particular, are straightforward to distribute and collect using an online survey service such as Qualtrics. While this research did not push these methods further, it reinforced the idea that traditional methods work for a reason - they are simple and familiar to the public.

In terms of the research concerning Shelly Bay, the public showed overwhelmingly that they support its development. What they do not support, however, is highdensity residential development. Stage Two of the participatory process showed that the vast majority wanted no residential development whatsoever. Instead, the public wants to see Shelly Bay developed into an area focussing on recreation, the arts, culture and tourism. This information will be distributed to all parties involved (The Wellington Company, The Wellington City Council, The Port Nicholson Block Settlement Trust, Enterprise Miramar Peninsula Inc. and Mau Whenua).
Whether that information is seriously considered or not is out of our control. Indeed, both Mau Whenua and EMPI (possibly the WCC as well) will be interested; however, the real challenge will be getting both TWC and PNBST to listen to the community.

The issues that faced this research stemmed not only from the complex problem that is Shelly Bay, but also from the substantial gap in the literature regarding participatory design on an urban scale, in developed countries. The majority of public-scale participatory design projects originate from NGO's who work with community groups in developing countries (such as the Asili project). While there are many similarities, each has its own, very different, challenges. This research has shown that there is still much work to be done to develop publicscaled participatory precedents in the developed world. 


\section{A Final Word}

'Shelly Bay 2030' is a product of the community - stemming from a system of participatory design processes. The design itself is not fundamentally important in answering the question this research explores. Thus, the outcome is more rudimentary compared to what a traditional architecture thesis would produce. The merit of this research, therefore, comes not from the proposed masterplan, but from the design of the participatory tools used, and the process undertaken. It reinforces the idea that introducing participatory processes in the early stages of urban design (or architectural design in general) will positively impact the end product.

The design of the 'Shelly Bay, Our Way' booklet was the major design achievement of this thesis (appendix C). It is what led to the research findings which answer the research questions.

This research recognises that reaching a level of 'collaboration' (as defined by IAP2), is difficult in large-scale urban design projects. 'Consultation' and 'involvement', however, are relatively cost effective and you will gain the most important information at these levels. There is no reason why developers/landowners cannot implement the basic tools of surveys and interviews to gather a better understanding of what the community wants. The booklet is the next step up; and, while it takes more time and money to set this up, it is insignificant compared to the time and money required for a traditional workshop or charrette.

It is the opinion of the researcher that, if The Wellington Company and the Port Nicholson Block Settlement Trust, had involved the community from the early stages of the Taikuru project then the development would have more public support. If this were the case, construction might have already begun. Instead, they have to re-apply for Resource Consent which could, again, be challenged by opposition groups.

It is a shame that Shelly Bay has found itself in this situation. While this thesis only briefly touches on the background deals surrounding the area. It is the Iwi here who have been truly let down - and by their own people. Shelly Bay should have never been sold to a private developer, as the PNBST did not have permission from its beneficiaries. At the time of writing this conclusion, media outlets are starting to feed information to the public surrounding the deals made. Hopefully, these allegations are taken seriously and investigated accordingly. There should be no tolerance towards these secretive dealings in modern-day New Zealand. 
"IT IS A MISUSE

OF POWER TO TAKE

RESPONSIBILITY FOR

SOLVNG PROBLEMS

THAT BELONG TO

OTHERS."

- PETER BLOCK (1993) 


\section{List of Figures}

NB: All unattributed figures are the author's own.

Fig 1.01 - Hypothesis diagram.

Fig 1.02 - Thesis structure diagram.

Fig 1.03 - Detailed process diagram highlighting moments of methodology

Fig 1.04 - Chronological methodology diagram

Fig 2.01 - A history of participatory design. Definitions sourced from: Leckie (2012)

Fig 2.02 - Creative Problem-Solving methodology, combining convergent and divergent thinking. Sourced from: Kasprisin (2016)

Fig 2.03 - IAP2 Spectrum of Participation. Sourced from: IAP2 International Federation (2018).

Fig 2.04 - A collection of images showing The Engagement Labs, 'Participatory Chinatown' video game workshop. Sourced from: http://www.gamesforcities.com/database/participatory-chinatown/

Fig 2.05 - A collection of images showing IDEO.org's interaction and resolution 'Asili'. Sourced from: https://www.ideo.org/project/asili

Fig 2.06 - A collection of images from Henry Sanoff's 'Community Arts Center Handbook'. Sourced from: Sanoff \& Mishchenko (2015)

Fig 3.01 - Detailed timeline diagram documenting Shelly Bay's history, legal battles and thesis research concurrently.

Fig 3.02 - Diagrammatic map of the Miramar Peninsula highlighting various amenities and zones.

Fig 3.03 - Identification of sub-areas within Shelly Bay and important historical buildings. Based on images from the '1999 Shelly Bay Design Guide'. Wellington City Council (2018)

Fig 3.04 - Maximum height areas.

Based on images from the '1999 Shelly Bay Design Guide'. Wellington City Council (2018)

Fig 3.05 - Diagram showing incorrect building massing density.

Based on images from the '1999 Shelly Bay Design Guide'. Wellington City Council (2018)

Fig 3.06 - Diagram showing correct building massing density.

Based on images from the '1999 Shelly Bay Design Guide'. Wellington City Council (2018)

Fig 3.07 - Collage of Shelly Bay focussing on aesthetics and details.

Fig 3.08 - Artists impression of the Taikuru Development. Image supplied by: The Wellington Company Ltd.

Fig 3.09 - Zoning plan for the Taikuru Development. Image supplied by: The Wellington Company Ltd. 
Fig 3.10 - Artists impression of the Taikuru Development. Image supplied by: The Wellington Company Ltd.

Fig 3.11 - Initial Masterplan of the Taikuru Development. Image supplied by: The Wellington Company Ltd.

Fig 3.12 - External architects impression of the Taikuru Development - commissioned by Enterprise Miramar. Highlighting the density of the development to the surrounding coastline and hillside. Image supplied by: Enterprise Miramar.

Fig 3.13 - External architects impression of the Taikuru Development - commissioned by Enterprise Miramar. Highlighting the density of the proposal. Image supplied by: Enterprise Miramar.

Fig 3.14 - External architects impression of the Taikuru Development - commissioned by Enterprise Miramar. Highlighting what the waterfront might look like and the proximity to the sea level. Image supplied by: Enterprise Miramar.

Fig 3.15 - External architects impression of the Taikuru Development - commissioned by Enterprise Miramar. Highlighting the heights of the apartment blocks against the hillside. Image supplied by : Enterprise Miramar.

Fig 4.01 - A summary of a few of the questions asked in the survey, 'Shelly Bay, Your Way'.

Fig 4.02 - A selection of visionary responses from the survey.

Fig 4.03 - Wordcloud generated in response to the question, "What is your personal vision for Shelly Bay?".

Fig 4.04 - Wordcloud generated in response to the question, "What other considerations do you see as important in a development at Shelly Bay?".

Fig 4.05 - Relationship breakdown diagram from the interview with Susan Macaulay.

Fig 4.06 - Relationship breakdown diagram from the interview with Mary Anderson.

Fig 4.07 - Relationship breakdown diagram from the interview with Tim Alexander.

Fig 5.01 - Residential concept developed from Stage One feedback.

Fig 5.02 - Tourism \& Recreation concept developed from Stage One feedback.

Fig 5.03 - Community Hub concept developed from Stage One feedback.

Fig 6.01 - Objectives identification tool from 'Shelly Bay, Our Way' booklet.

Fig 6.02 - Shelly Bay Masterplan Gameboard from 'Shelly Bay, Our Way' booklet.

Fig 6.03 - Written Vision and Suggested design principles from 'Shelly Bay, Our Way' booklet.

Fig 6.04 - A basic site plan allows respondents the opportunity to draw their vision for Shelly Bay.

Fig 6.05 - Word Cloud generated to show hierarchy of identified objectives. 
Fig 6.06 - Word Cloud generated to show hierarchy of recreation components.

Fig 6.07 - Word Cloud generated to show hierarchy of creative arts components.

Fig 6.08 - Word Cloud generated to show hierarchy of culture and tourism components.

Fig 6.09 - Overlay map showing placement of components for all participants.

Fig 6.10 - Identified design principles, in order of importance.

Fig 6.11 - Word Cloud generated to show hierarchy of positive words in written vision statements.

Fig 6.12 - Diagram documenting overall development weighting by participants during the written and drawn vision consultation process.

Fig 6.13 - The community hub concept proved to be the most popular design.

Fig 6.14 - The tourism and recreation concept was the second most popular design.

Fig 7.01 - HIDECs tree showing relationships between identified components from Stage Two.

Fig 7.02 - Map showing placement overlay of publicly identified objectives.

Fig 7.03 - Map showing simplified placement overlay of publicly identified objectives.

Fig 7.04 - Simplified map with possible amenities overlay (hospitality, retail and miscellaneous).

Fig 7.05 - Simplifying location and density of identified supporting amenities - identifying miscellaneous amenities. Adding a community dot (orange) to signify cultural centre area.

Fig 7.06 - Initial masterplan mapping study, showing the location of a gondola connecting Shelly Bay to Mt. Crawford.

Fig 7.07 - Massing iteration one, basic blocking.

Fig 7.08 - Massing iteration two, re-routing roads towards the hillside to improve pedestrian access to coastline break up large blocks into smaller buildings as per '1999 Shelly Bay Design Guide'.

Fig 7.09 - Reconsidering Submarine Mining Depot Barracks location. Moving road towards escarpment.

Fig 7.10 - Adding walkways. Bridges will lead walkers above mountain biking routes and roads.

Fig 7.11 - Initial community zoning study for compare and contrast purposes.

Fig 7.12 - Finalised zoning masterplan after reconsidering community data.

Fig 7.13 - 'Shelly Bay 2030', final community-based masterplan.

Fig 7.14 - 'Shelly Bay 2030', full site perspective.

Fig 7.15 - 'Shelly Bay 2030', North Bay close up.

Fig 7.16 - Artistic impression of North Bay from camera C1. 
Fig 7.17 - Artistic impression of North Bay from camera C2.

Fig 7.18 - 'Shelly Bay 2030', Wharf Area close up.

Fig 7.19 - Artistic impression of Wharf Area from camera C1.

Fig 7.20 - Artistic impression of Wharf Area from camera C2.

Fig 7.21 - 'Shelly Bay 2030', South Bay close up.

Fig 7.22 - Artistic impression of South Bay from camera C1.

Fig 7.23 - Artistic impression of South Bay from camera C2.

Fig 7.24 - Artistic impression of biking tracks and road interaction.

Fig 7.25 - Artistic impression of Mt. Crawford Prison site.

Fig 8.01 - An interactive physical model of Shelly Bay would allow community members the opportunity to play with building scale, placement and density.

Fig 8.02 - Comparison between final community zoning plan (left) and final community masterplan (right).

Fig 8.03 - The Wellington Company’s Taikuru Masterplan. Image supplied by: The Wellington Company Ltd.

Fig 8.04 - 'Shelly Bay 2030', a community masterplan. 


\section{References}

.idcommunity. (2013). Wellington City, Community Profile. Retrieved from https://profile.idnz.co.nz/wellington/ about $/$ WebID $=280$

Aguirre, M., Agudelo, N., \& Romn, J. (2017). Design Facilitation as Emerging Practice: Analyzing How Designers Support Multi-stakeholder Co-creation. she ji. Norway: The Oslo School of Architecture and Design.

Alexander, T. (2018) Public Opinion on Shelly Bay/Interviewer: J. Short. Wellington.

Anderson Lloyd. (2016). Three more years of affordable housing legislation. Retrieved from https://www.al.nz/ three-more-years-of-affordable-housing-legislation/

Anderson, M. (2018) Public Opinion on Shelly Bay/Interviewer: J. Short. Wellington.

Anic, I. (2015). Participatory Design: What is it, and what makes it so great? Retrieved from https://www. uxpassion.com/blog/participatory-design-what-makes-it-great/

Block, P. (1993). Stewardship; Choosing Service Over Self-Interest. San Fransico: Berrett-Koehler Publishers Inc.

Chambers, R. (1997). Whose Reality Counts? Putting the First Last. London: Intermediate Technology

Publications.

Cropley, A., \& Cropley, D. (2009). Fostering Creativity: A Diagnostic Approach for Higher Education and Organizations. Cresskill, NJ: Hampton Press Inc.

Cross, N. (1972). Design Participation: Proceedings of the Design Research Society's Conference, UK.

Engagement Lab. (2010). Participatory Chinatown. Retrieved from https://elab.emerson.edu/projects/ participatory-chinatown

Enginess. (2015). The Ethos of Research-Led Design. Retrieved from https://enginess.io/insights/the-ethos-ofresearch-led-design

Enterprise Miramar Peninsula Incorporated. (2018). Save Shelly Bay Campaign. Video.

Hauberg, J. (2011). Research by Design - a research strategy. Architecture \& Education Journal, 51.

Hickey, S., \& Mohan, G. (2004). Towards Participation as Transformation: Critical Themes and Challenges. In: Participation: From Tyranny to Transformation (pp. 3-24). London: Zed.

IAP2 International Federation. (2018). IAP2 Spectrum of Public Participation. Retrieved from https://cdn.ymaws. com/www.iap2.org/resource/resmgr/pillars/Spectrum_8.5x11_Print.pdf

IDEO.org. (2009). Human Centered Design: Field Guide: IDEO.

Jacobs, J. (1961). The Death and Life of Great American Cities. New York: Random House.

Jenkins, P., \& Leslie, F. (Eds.). (2010). Architecture, Participation and Society. Oxon: Routledge.

Kasprisin, R. (2016). Play in Creative Problem-solving for Planners and Architects. New York: Routledge.

Knoema. (2015). Democratic Republic of the Congo - Under-five mortality rate. Retrieved from https://knoema. com/atlas/Democratic-Republic-of-the-Congo/topics/Demographics/Mortality/Under-5-mortality-rate

Leckie, N. (2012). Who Knows Best?, Victoria University of Wellington.

Lee, Y. (2006). Design Participation Tatics: Redefining User Participation in Design. Lisbon. 
Macaulay, S. (2018) Public Opinion on Shelly Bay/Interviewer: J. Short. Wellington.

Miramar BID. (2019). Miramar Peninsula - BID. Retrieved from http://www.miramarpeninsula.org.nz/bid Moore, P., \& Conn, C. P. (1984). Disguised! A True Story. USA: Word Books.

Mullins, D. (2010). Self-help housing: Could it play a greater role? Third Sector Research Centre.

Port Nicholson Block Settlement Trust. (2012). Port Nicholson Block Settlement Trust. Retrieved from https:// www.pnbst.maori.nz/

Purcell, T., \& Thorne, R. (1977). Assessment of Community Needs for Arts Cultural Facilities in an Urban Local Government Area (A. P. R. Unit Ed.): University of Sydney.

Revilla, M., \& Ochoa, C. (2017). Ideal and Maximum Length for a Web Survey. International Journal of Market Research, 59(5), 557-565.

Roodt, M. J. (1996). Participatory development, a jargon concept? In: Reconstruction, development and people, edited by J. K. Coetzee and J. Graaf. Johannesburg: International Thomson Publishing.

Sanoff, H. (1978). Design with Community Participation. Pennsylvania: Dowden, Hutchinson \& Ross, Inc.

Sanoff, H. (1988). Community Arts Facilities. 53 Research Papers in Social Architecture 1965-2005, 9

Sanoff, H. (2008). Multiple Views of Participatory Design. Internation Journal of Architectural Research, 2(1), 5769.

Sanoff, H., \& Mishchenko, E. D. (2015). Community Arts Center Handbook. Turkey: Graham Foundation for Advanced Studies in the Fine Arts and Scientific and Technological Research Council of Turkey.

Scoop Media. (2018). Judgment: Enterprise Miramar v Wellington City Council. Retrieved from http://www.scoop. co.nz/stories/AK1812/S00034/judgment-enterprise-miramar-v-wellington-city-council.htm

Simpson Grierson. (2018). Better late than never: Enterprise Miramar Peninsula Incorporated $v$ Wellington City Council. Retrieved from https://www.simpsongrierson.com/articles/2018/better-late-than-never-enterprisemiramar-peninsula-incorporated-v-wellington-city-council

Stringer, P. (1971). A Rationale for Participation. Paper presented at the Design Participation: Proceedings of the Design Research Society's Conference, UK.

Stuff. (2018). Shelly Bay would become second Oriental Bay, court told Retrieved from https://www.stuff.co.nz/ business/property/101927174/shelly-bay-would-become-second-oriental-bay-court-told

The Wellington Company Ltd. (nd.). The Wellington Company - About Us. Retrieved from http://www. thewellingtoncompany.co.nz/about-us/

Till, J. (2010). Foreword. In P. J. L. Forsyth (Ed.), Architecture, Participation and Society. Oxon: Routledge.

Walters, D. (2007). Designing Community: Taylor \& Francis.

Wates, N., \& Knevitt, C. (1987). Community Architecture: How People are Creating Their Own Environment: Penguin.

Wellington City Council. (2017). Have your say, Shelly Bay development, Proposed sale and lease of Council land.

Wellington City Council. (2018). Shelly Bay Design Guide. In: Wellington District Plan (Vol. 2). 


\section{Appendices}

Appendix A - Survey Results

Q2.1 - Do you currently, or have you previously, lived in Wellington's Eastern Suburbs?

Q3.1 - Which of the Eastern Suburb's do you live in/have you lived in most recently?

\begin{tabular}{|c|}
\hline $\begin{array}{c}11 \% \\
\text { Hataitai }\end{array}$ \\
\hline
\end{tabular}

Q28 - If you are not from the Eastern Suburbs, please describe your relationship to Shelly Bay. I.e. why are you interested in the development plans for Shelly Bay?

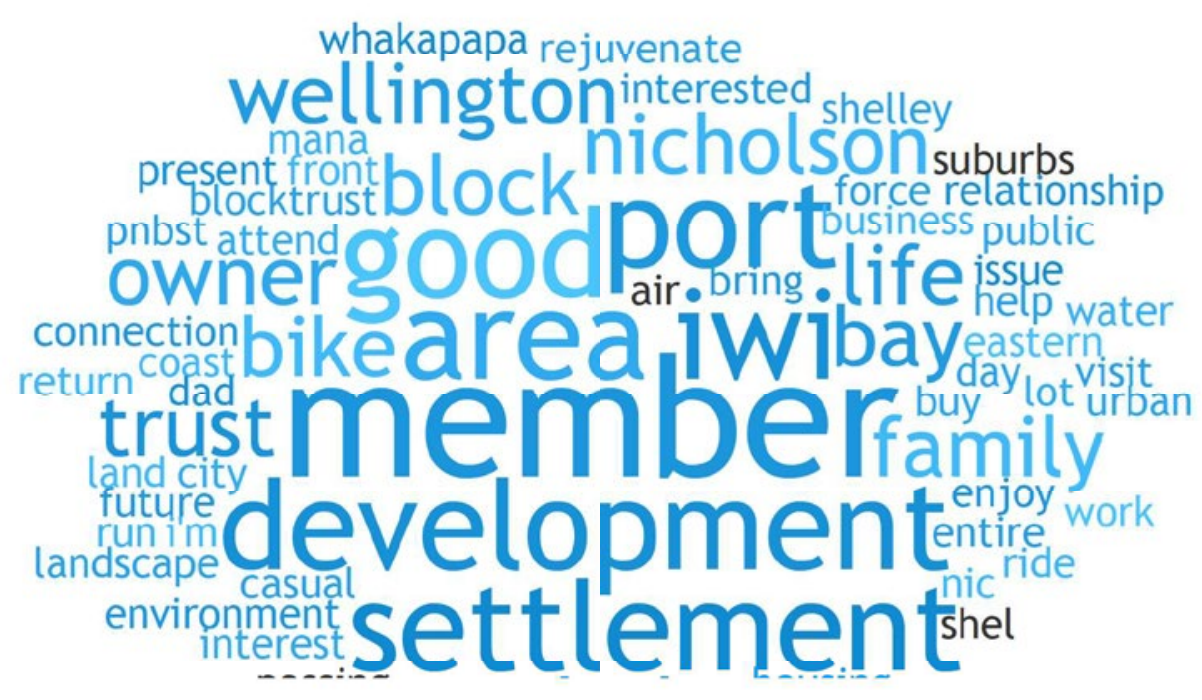

Q31 - How would you rate your knowledge of local businesses? (Local $=$ In your community/suburb) 
Q32 - How would you rate your support of local businesses? (Local = In your community/suburb)

Field

Choice Count

Don't shop locally

Occasionally shop locally 23

Shop locally whenever possible

Q33 - How would you rate your involvement in local community groups/organisations?

Field

No Involvement

Involved with one group

Involved in more than one group

Q34 - How safe do you feel in the public areas of your community?

Unsafe during the day and at night

Safe during the day, unsafe at night

Safe during day and night

Q35 - How well do you know other community members?

Field

Keep to myself

Know my neighbours

Know my neighbours plus a few other community members

Know many community members

Q36 - How would you rate the tidiness of your community? 
Public areas are littered with rubbish and not maintained

Q4.2 - Do you believe you have a say on urban developments in your community? (These include medium to large scale housing, commercial, industrial and recreational developments which will have an impact on your community as well as wider communities)

Unsure

Probably not

Q4.3 - Would you like to be more involved in urban developments in your area? This involvement could be in the way of: suggesting changes to the current built environment, generating design ideas, being involved in planning stages, being involved in construction etc. 
Q38 - How would you like to be involved?

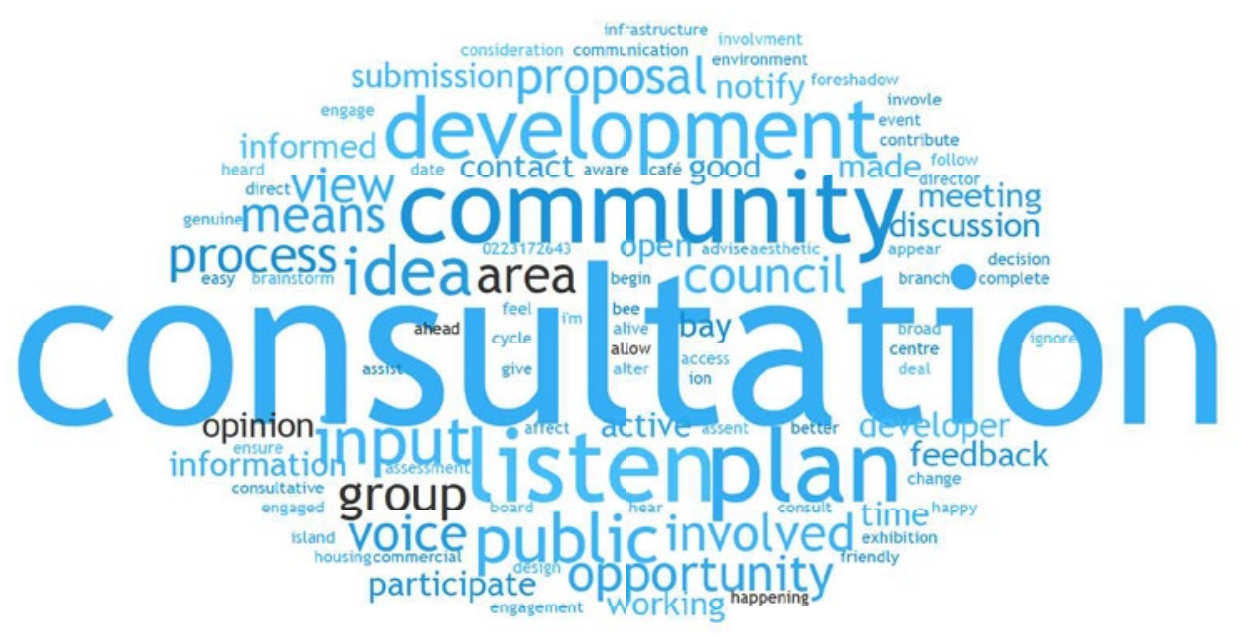

Q5.1 - How aware are you of the current plans to develop Wellington's Shelly Bay into a mixed-use area comprising of housing, retail, commercial and recreational spaces as well as introducing a hotel and aged care facility? (Known as the Taikuru Development)

Q5.2 - Do you think the proposed development at Shelly Bay reflects the needs and wants of you and other community members in the Eastern Suburbs? 
Q5.3 - Have you ever attended any meeting or consultation about the Shelly Bay development?

Q5.4 - Please give details of that consultation. (e.g. date, who was involved, what was the general opinion towards the development, were the involved parties actively listening to public concerns?)

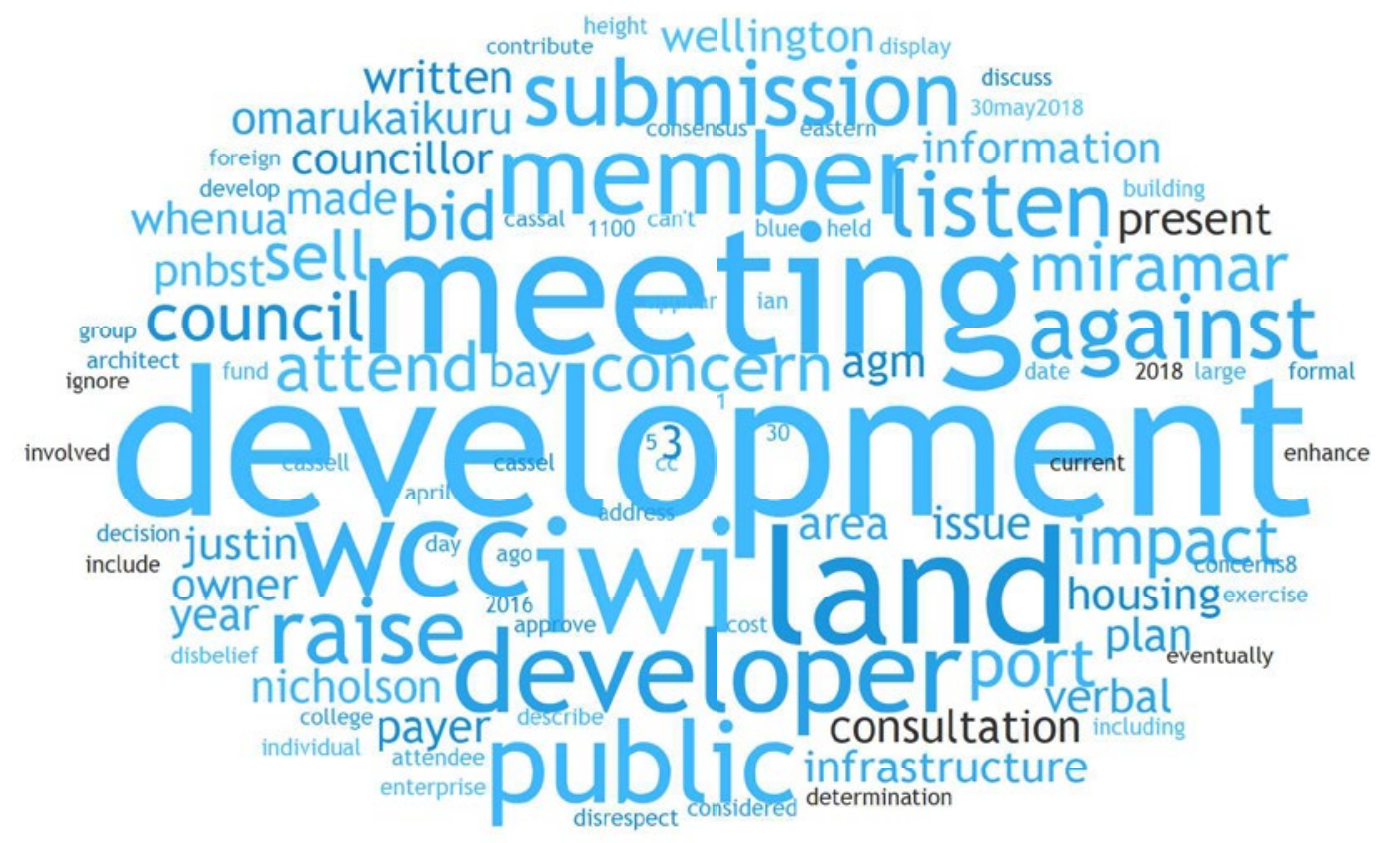

Q6.1 - Were you ever invited to give your opinion on the design of the Taikuru development proposal at Shelly Bay? 
Q6.2 - Who invited your opinion on the development?

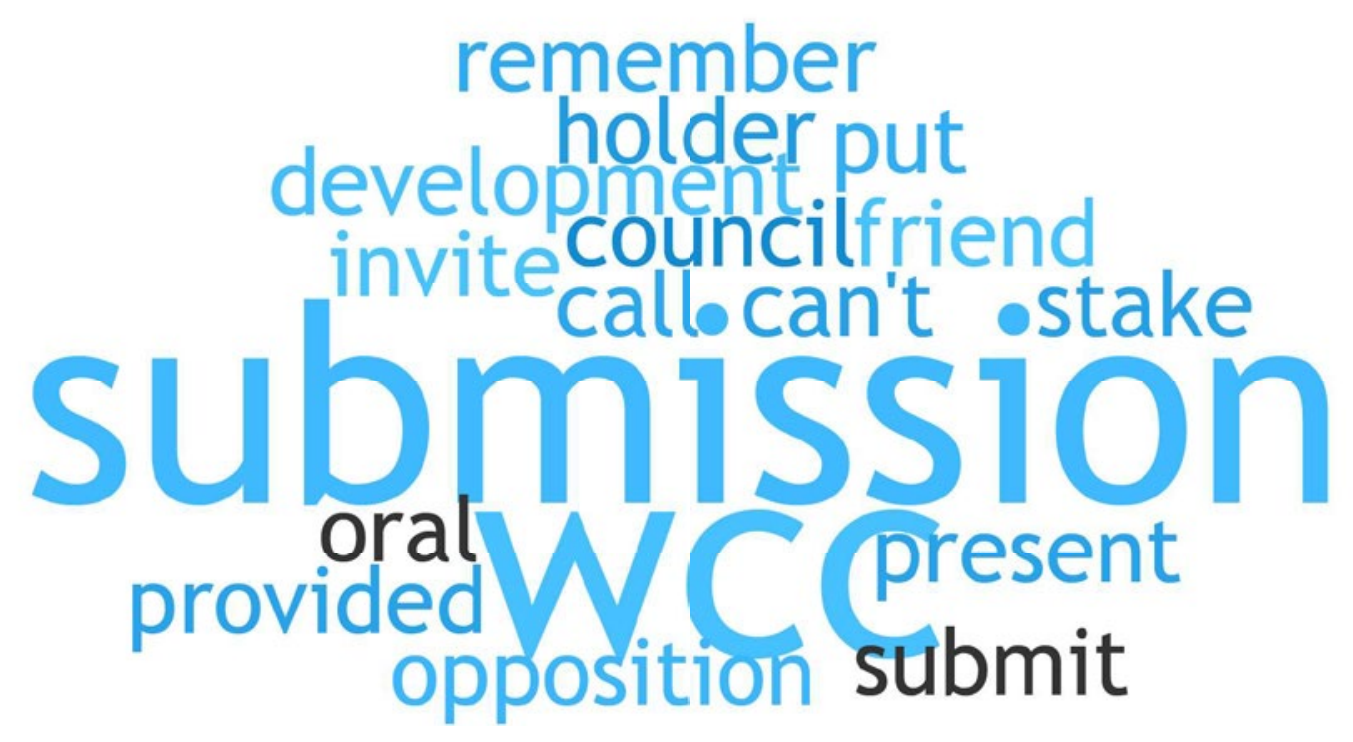

Q23 - Do you feel that your opinion was listened to?

Field

Choice Count

Yes

No

Q7.1 - Do you believe that owners of significant public assets (such as Shelly Bay) should have a duty to listen and act in the best interests of community members when developing an area? 
Q37 - Where do you think the Wellington City Council should position themselves itself in a development at Shelly Bay?

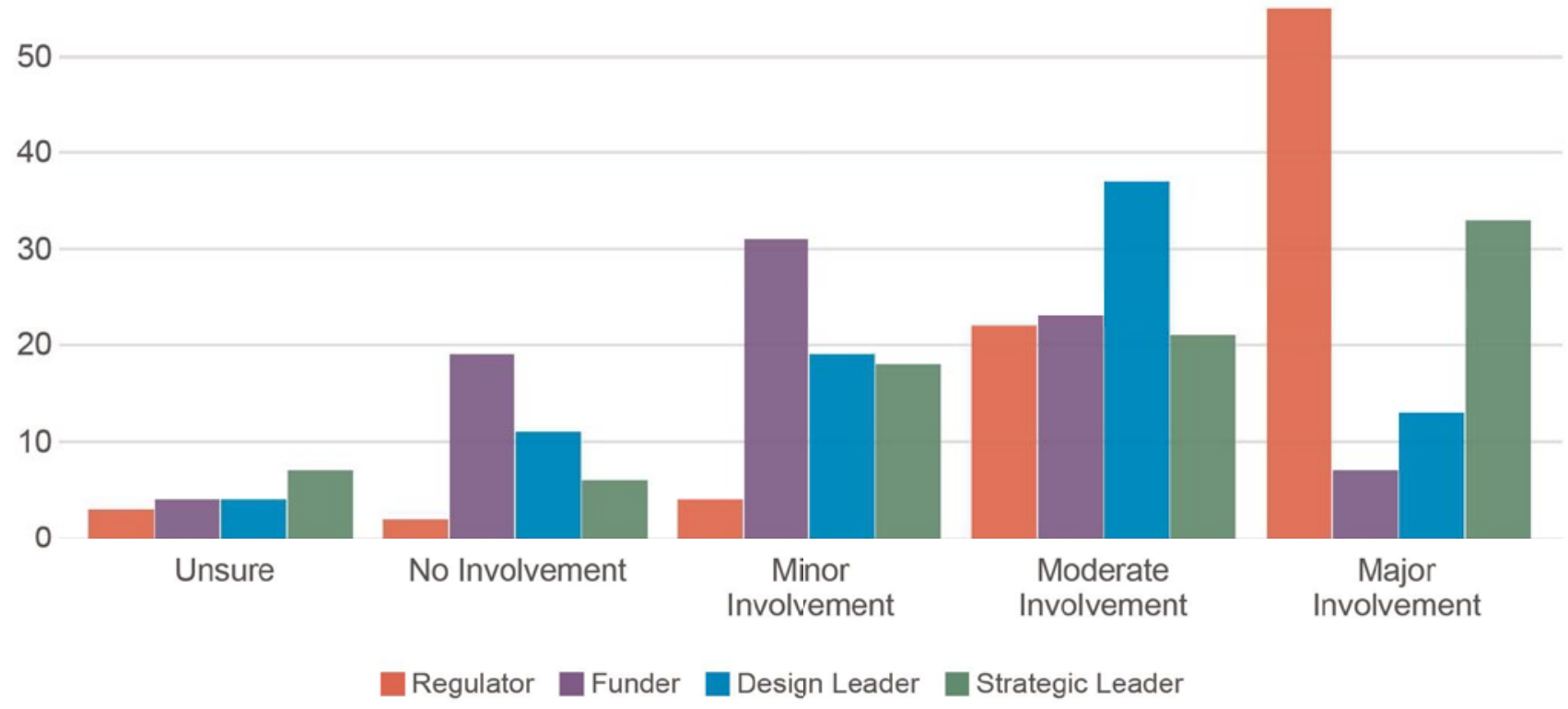

Q7.2 - Were you aware of the Wellington City Council's campaign titled, "Have Your Say" where they invited public opinion as to whether they should offer council land to the Shelly Bay development? (The campaign ran from 17/07/2017 - 14/08/2017)

Field

Choice Count

Yes

No

Q7.3 - Did you submit an opinion to the Wellington City Council? 
Q7.4 - Can you give some details on your submission? Were you for or against? Why? (Note: You do not need to answer this question, all details given are only available to the researchers and are otherwise confidential)

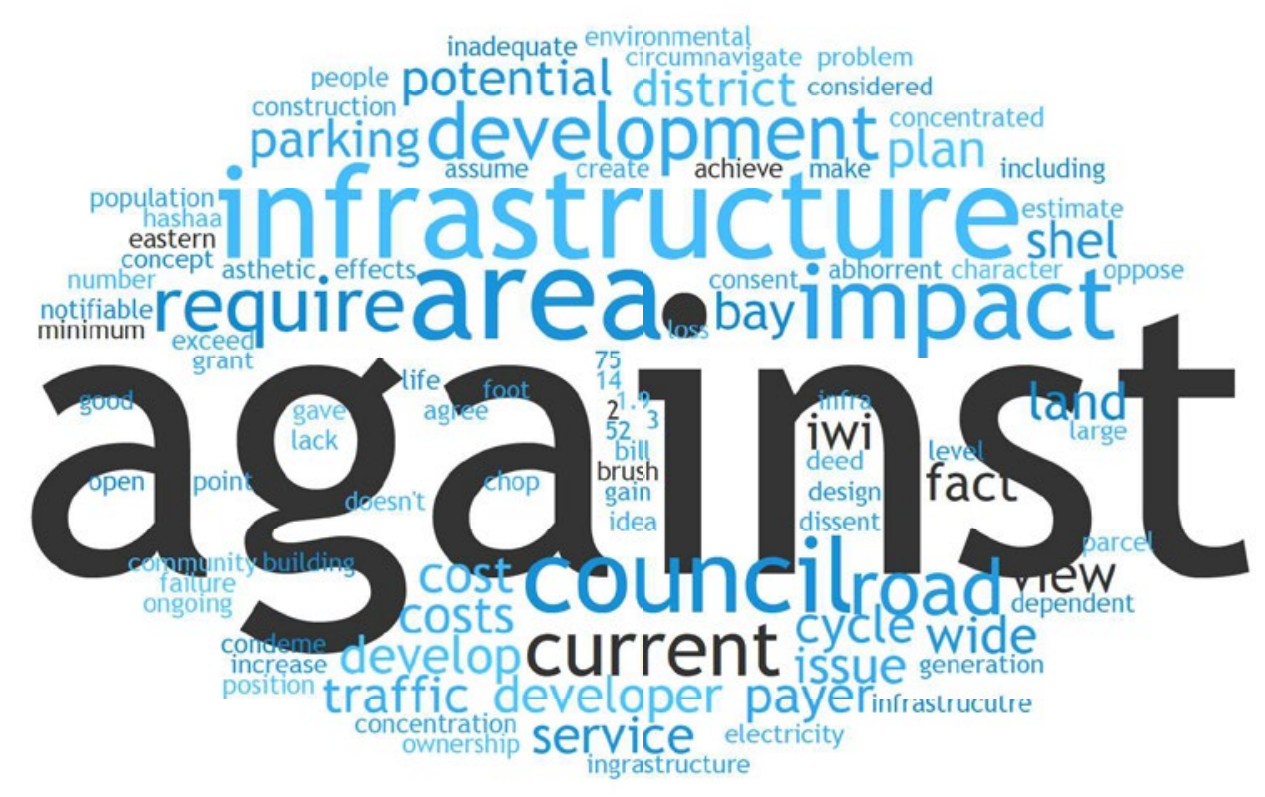

Q20 - What do you believe are the most important contextual considerations for a development at Shelly Bay? (i.e. the factors which you deem to be important in the development)

Field

Choice Count

Environment Impact

Road Infrastructure/Traffic Control

Coastline Access to Public

Recreational Spaces

Costs to Wellington Rate Payers 
Q22 - What other considerations do you believe are important in creating a successful development at Shelly Bay?

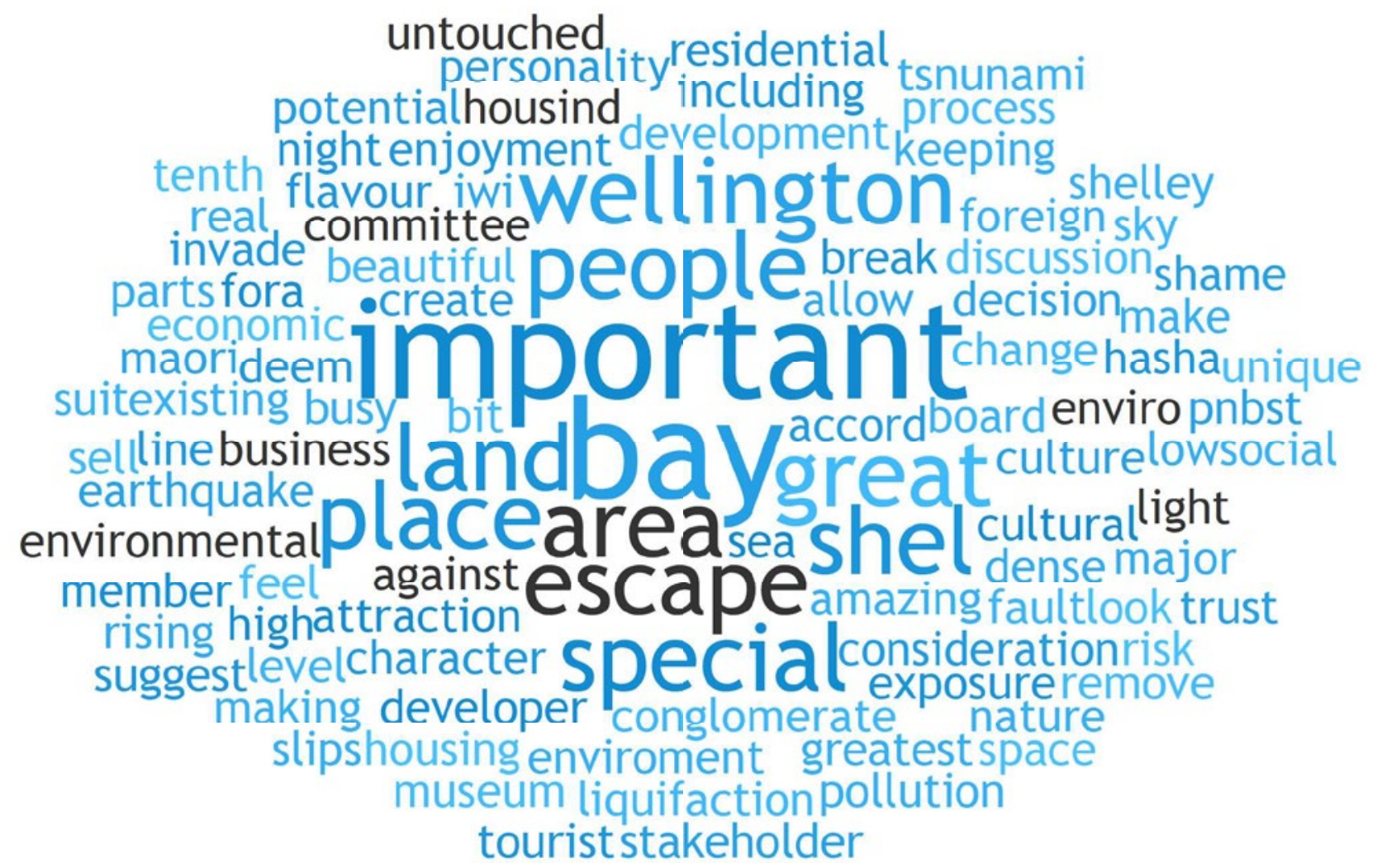


Q8.1 - What is your personal vision for Shelly Bay? Would you like to see it remain as it is or developed? If you are for its development, how would you like to see it developed? Please be as specific as possible.

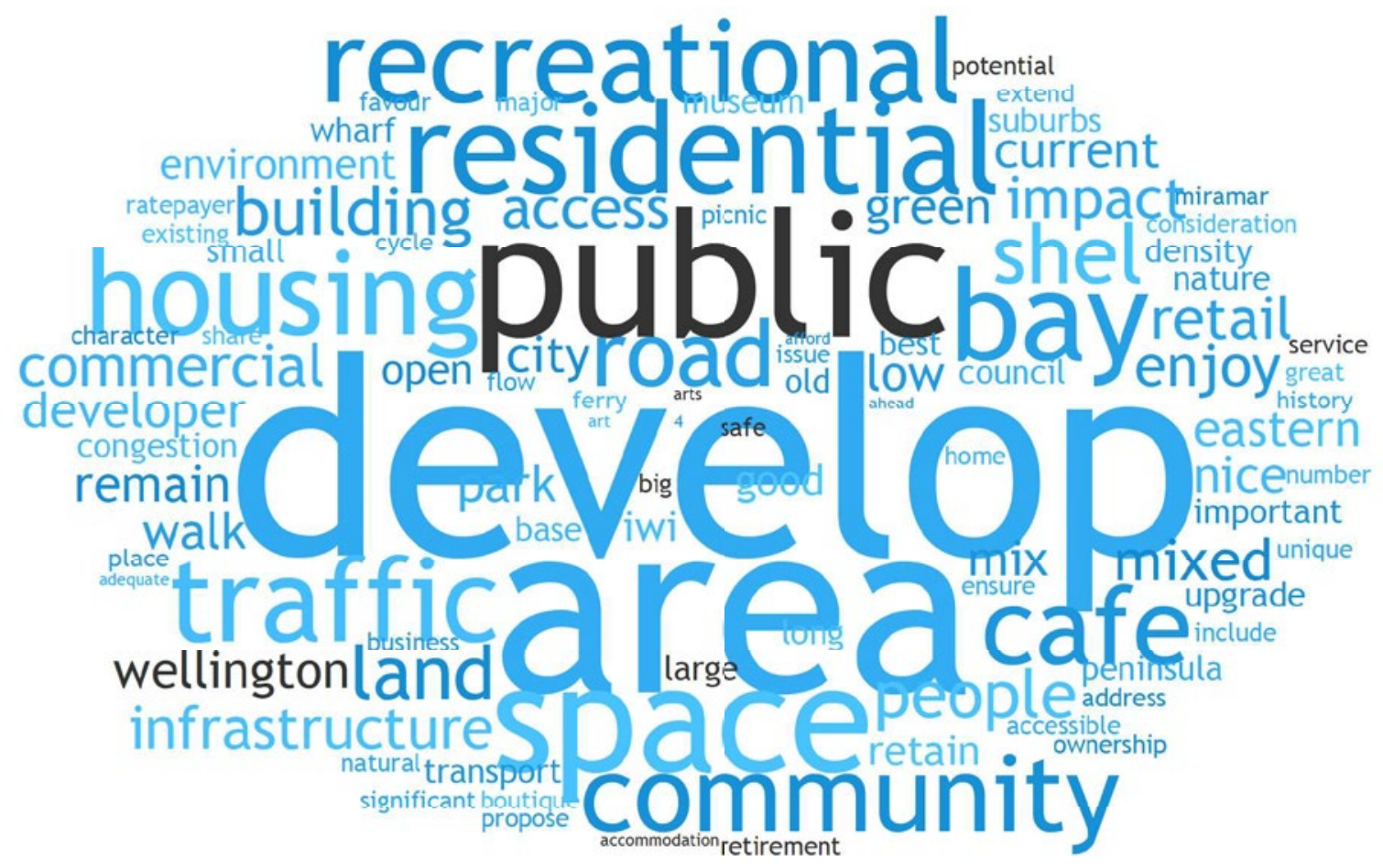




\title{
Appendix B - Interview Guide
}

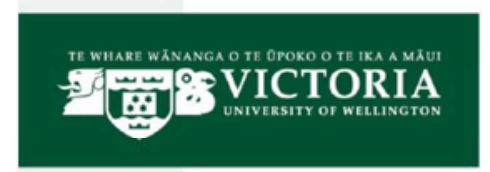

SCHOOL OF ARCHITECTURE Te Kura Waihanga

FACULTY OF ARCHITECTURE \& DESIGN Te Wāhanga Waihanga-Hoahoa

VICTORIA UNIVERSITY OF WELLINGTON, PO Box 600, Wellington 6140, New Zealand

Phone+64-4-4636200 Fax +64-4-4636204 Email architecture@vuw.ac.nz Web

www.victoria.ac.nz/architecture

\section{Community Participation in Urban Design: \\ A Masterplan for Shelly Bay}

\author{
POTENTIAL INTERVIEW QUESTIONS FOR \\ ENTERPRISE MIRAMAR
}

- Briefly describe your organisation and your role within it.

- The Wellington City Council have agreed to offer land and ratepayers money towards the Taikuru development. Do you think this offer reflects the wishes of the communities nearby to Shelly Bay? i.e. those in the Eastern Suburbs.

- What benefits do you see the Taikuru development having to the wider community?

- What negatives do you see the Taikuru development having to the wider community?

- Do you believe that the infrastructure currently in place will be able to cope with the development? i.e. traffic congestion

- From July $17^{\text {th }} 2017$ to August $14^{\text {th }} 2017$, the Wellington City Council invited Wellingtonians to "have their say" on the proposal. They received 1103 submissions. Have you had access to this information?

- What further consultation took place with community groups following the "Have Your Say" campaign?

- There has been a lot of resistance against the Taikuru development - of which you have played a major role. Why do you think it is fair that the communities who are attached to Shelly Bay should have a say on its future when they have no legal right to it?

- Do you believe that the community had any input in the Taikuru design?

- What would Enterprise Miramar like to see happen to Shelly Bay? 
SCHOOL OF ARCHITECTURE Te Kura Waihanga

FACULTY OF ARCHITECTURE \& DESIGN Te Wāhanga Waihanga-Hoahoa

VICTORIA UNIVERSITY OF WELLINGTON, PO Box 600, Wellington 6140, New Zealand

Phone +64-4-463 6200 Fax +64-4-4636204 Email architecture@vuw.ac.nz Web

www.victoria.ac.nz/architecture

\section{Community Participation in Urban Design: \\ A Masterplan for Shelly Bay \\ POTENTIAL INTERVIEW QUESTIONS FOR SURVEY PARTICIPANTS WHO WISHED TO BE INTERVIEWED}

- Which suburb do you reside in?

- Briefly describe your personal relationship to Shelly Bay.

- What is your opinion on the planned Taikuru development at Shelly Bay?

- What benefits can you see from the development?

- What draw backs can you see from the developments?

- What impact can you see the development having on the wider community?

- Were you aware of or did you attend any public consultation regarding the future of Shelly Bay?

- Were you, personally, ever asked your opinion on the development by the developer, land owner, council or designer? If yes, explain. If not, why do you think that is?

- What changes would you make to the planned development at Shelly Bay?

- If we could start from scratch, what would you like to see happen to Shelly Bay in the future? 
Appendix C - Workbook

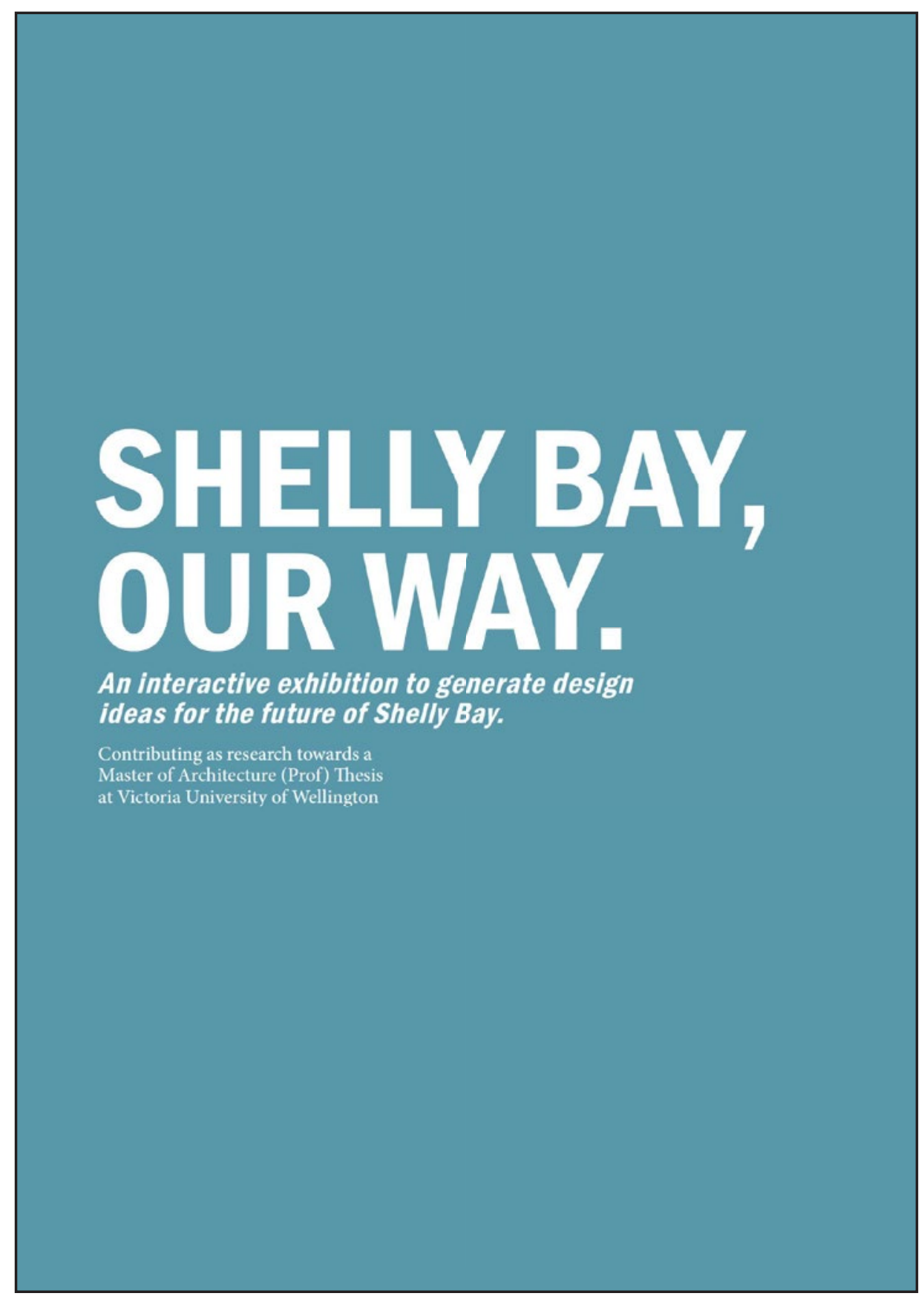



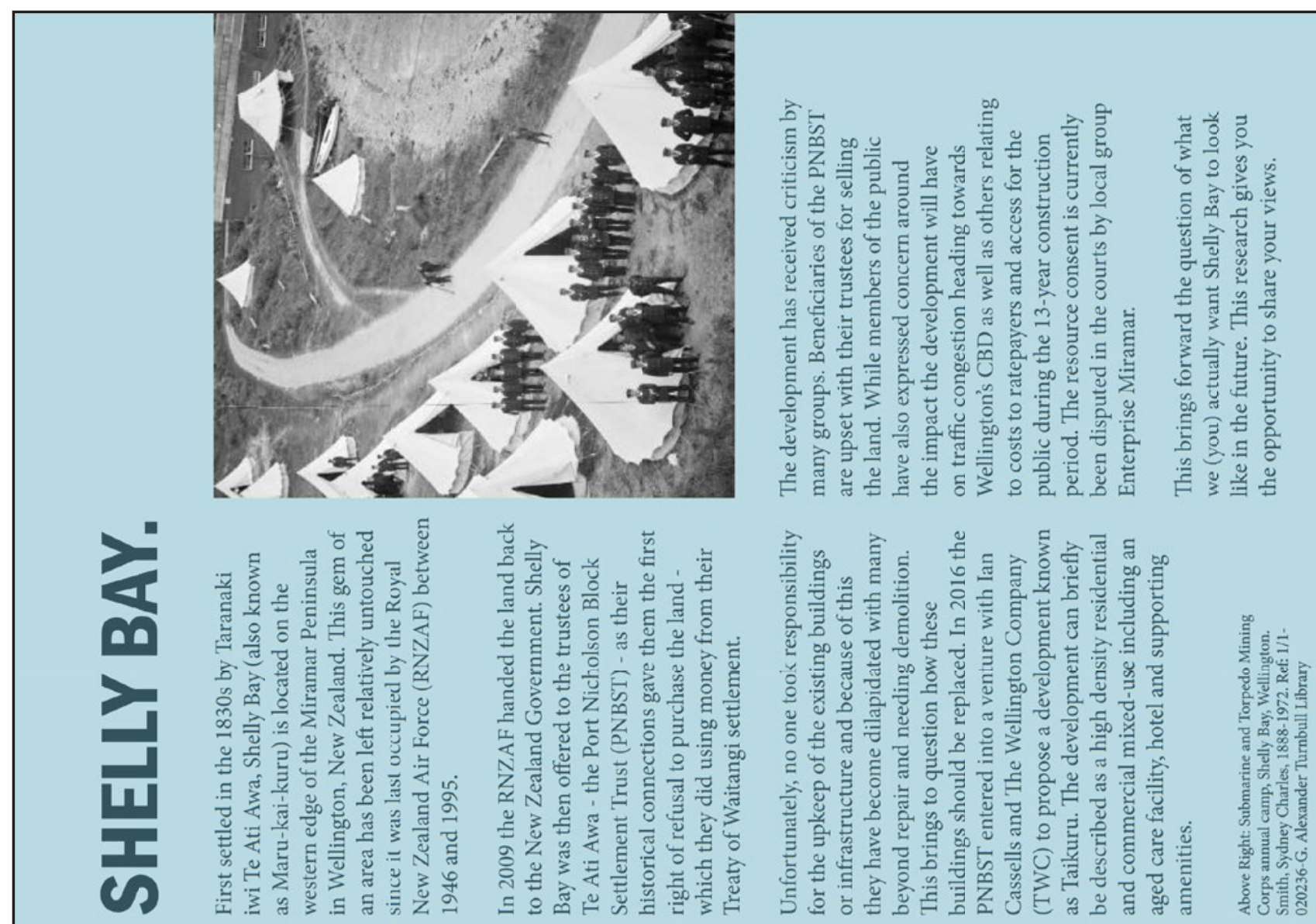

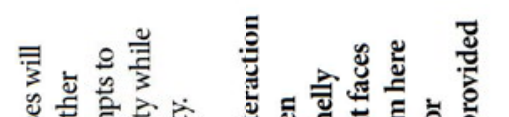

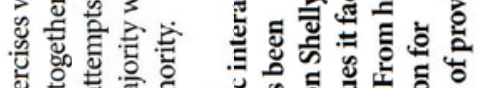

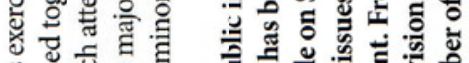

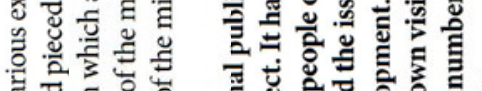 \\ 당

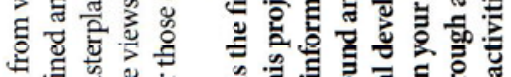

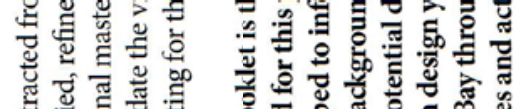

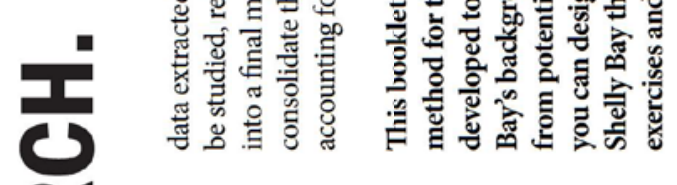

a

岕

里

迎

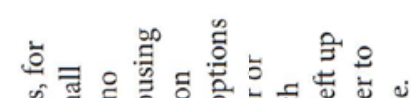

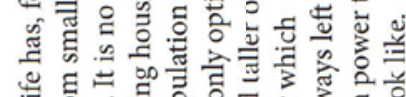

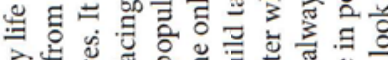

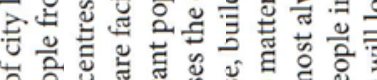

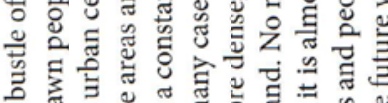

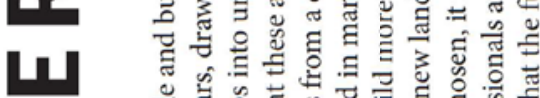
5

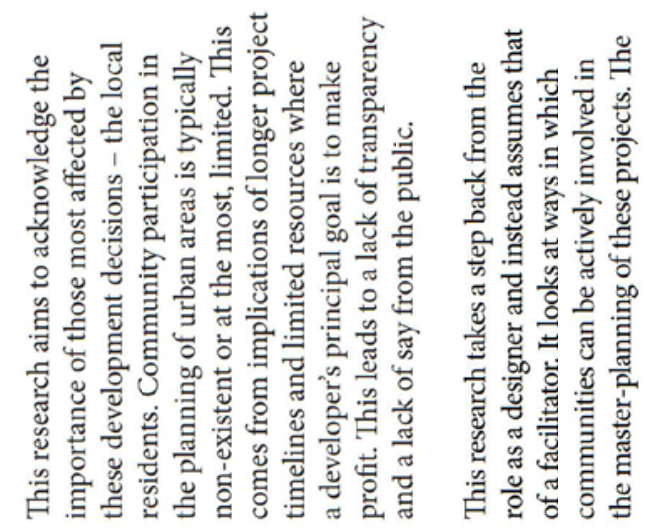

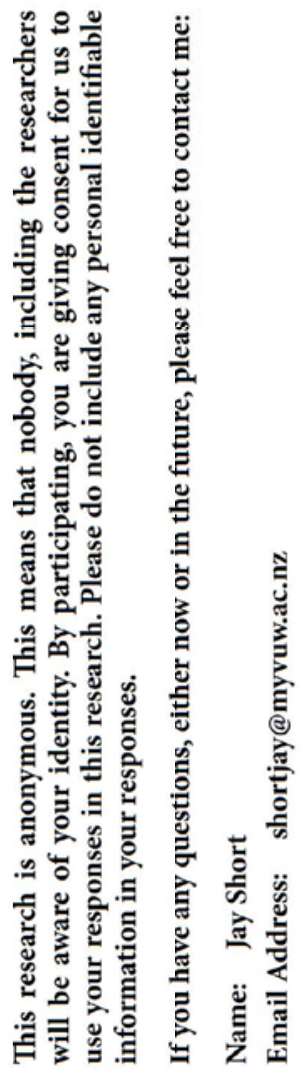




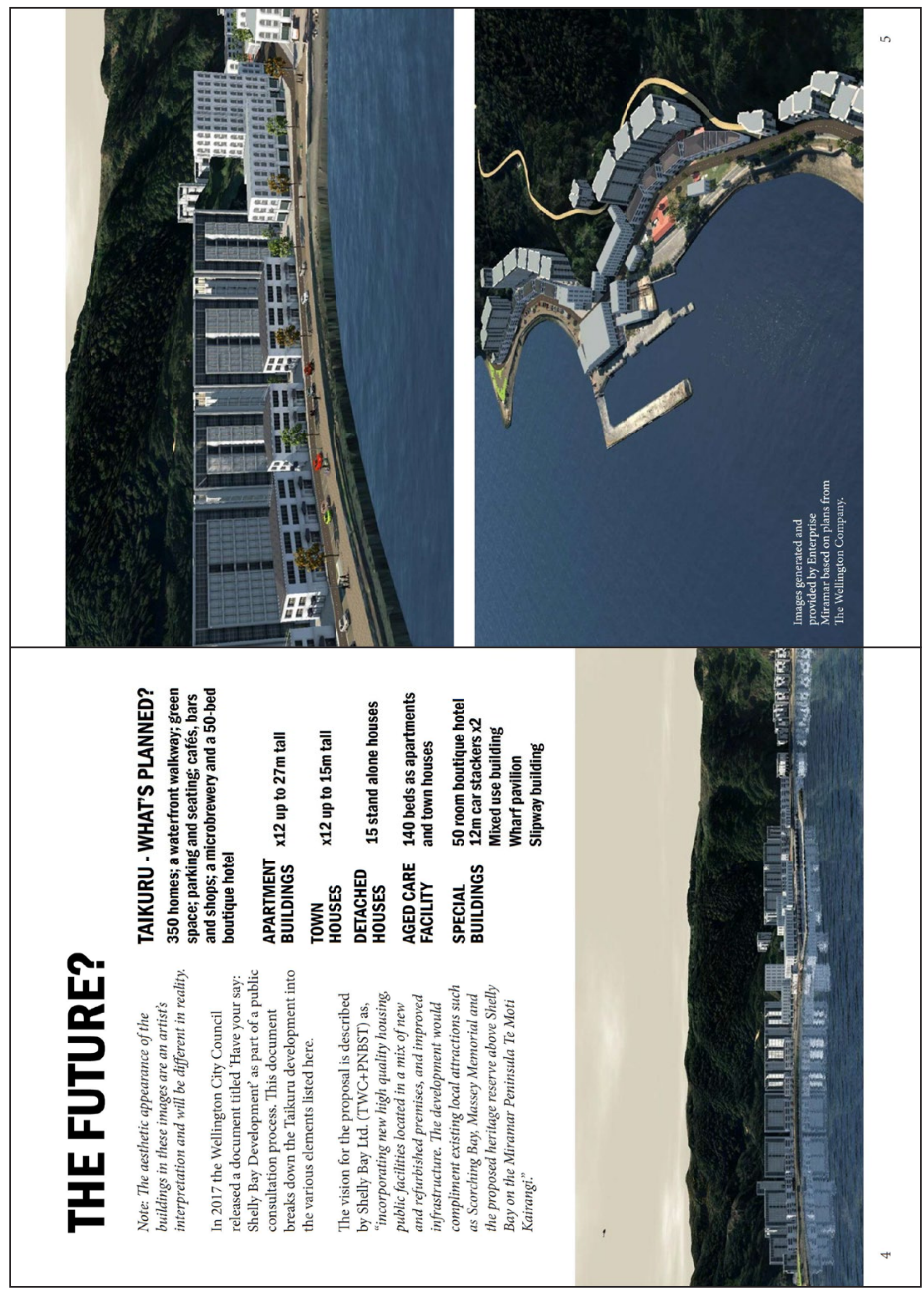


च.

ช 돈

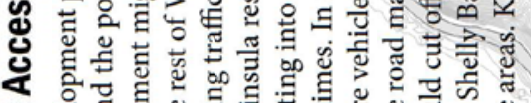
め

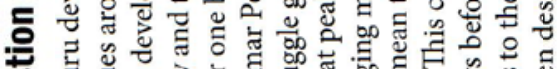

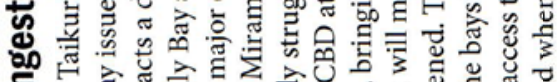

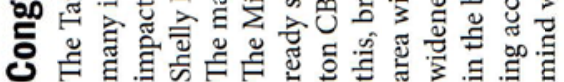

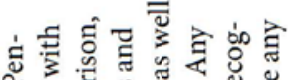

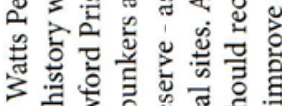

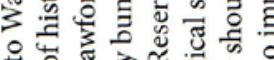

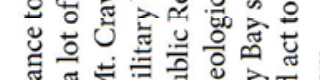

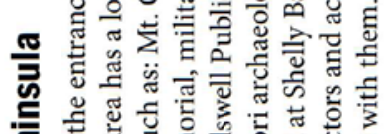

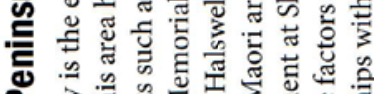
ब。

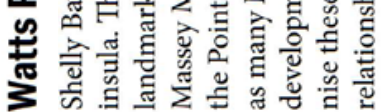

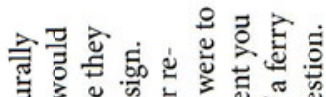

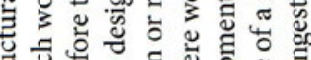

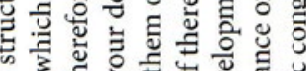
党 总言产

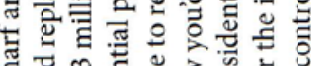

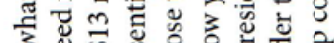
むె

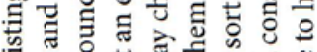

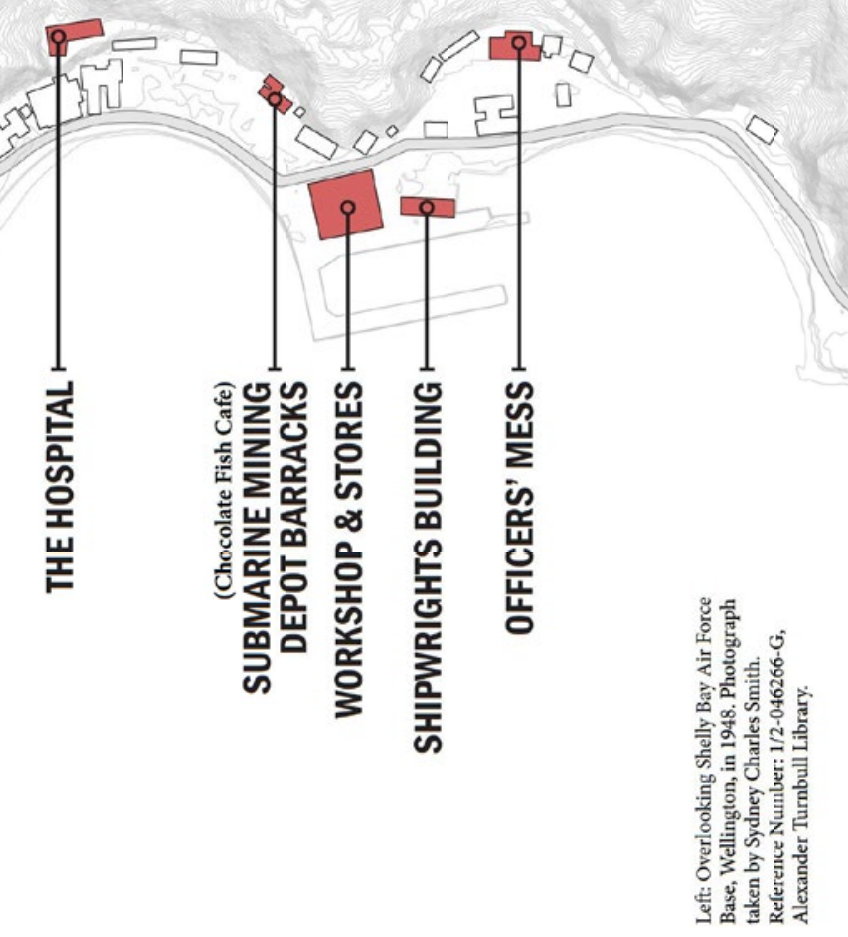

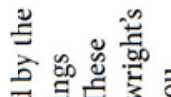

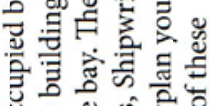

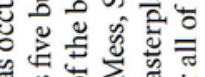 解证}

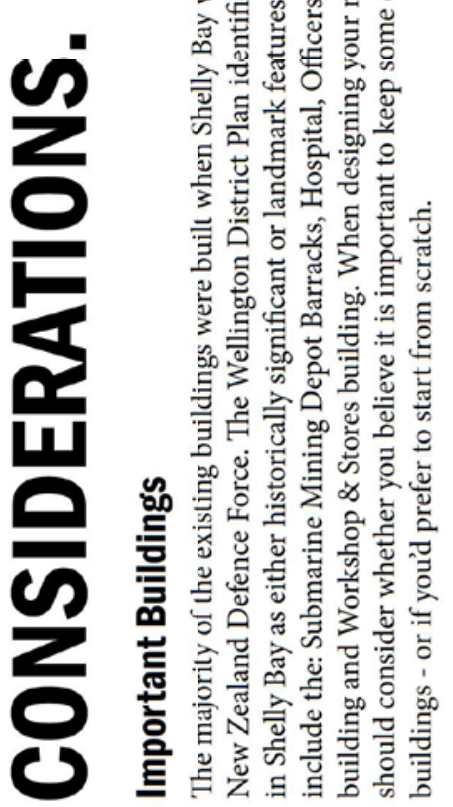

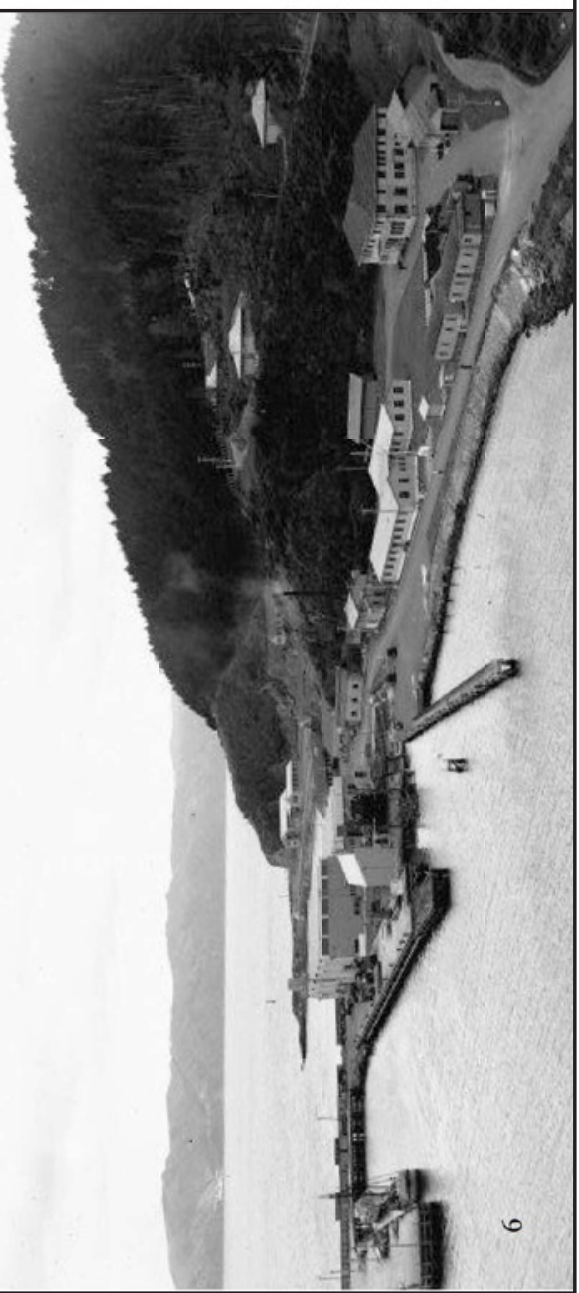



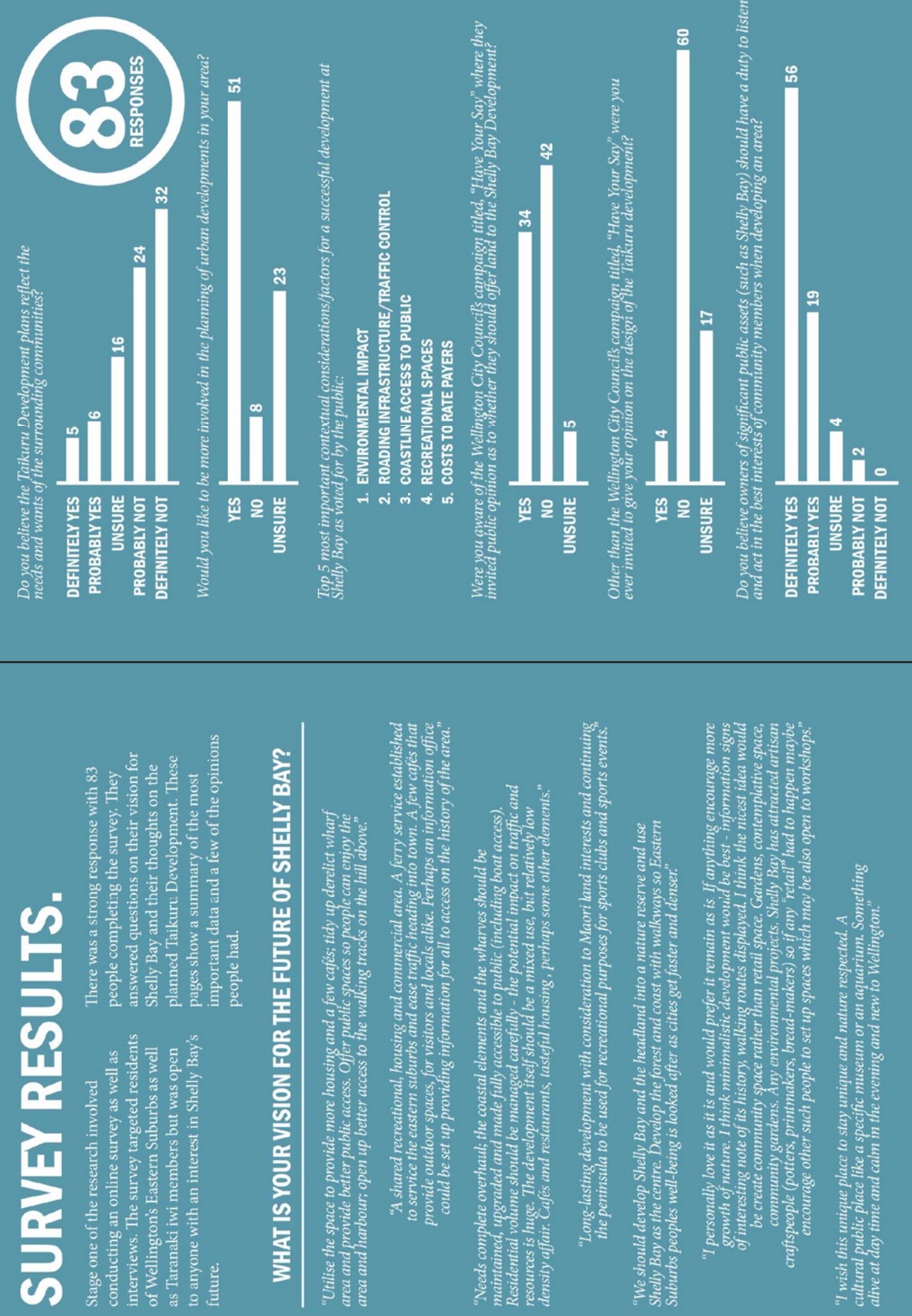

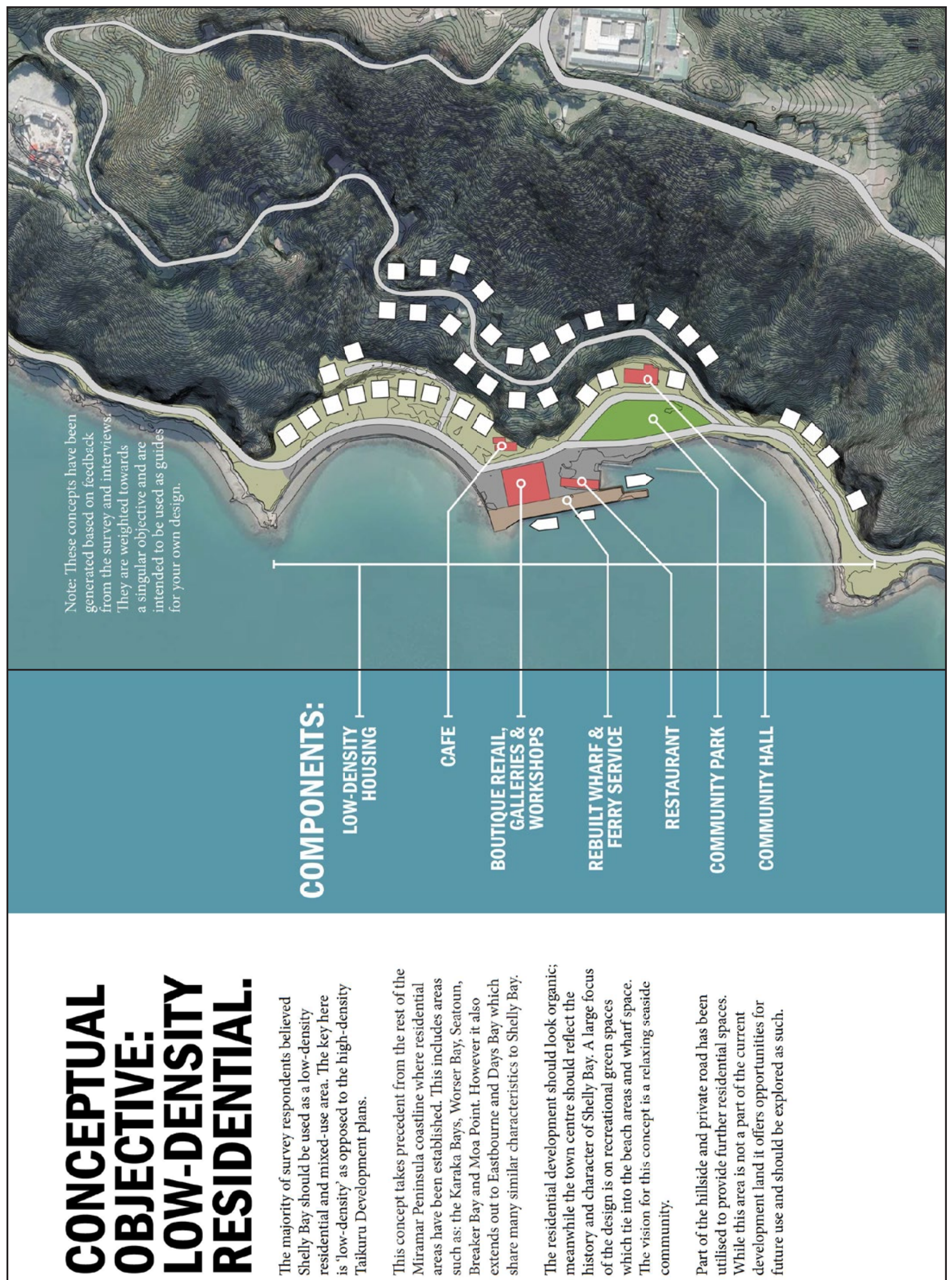

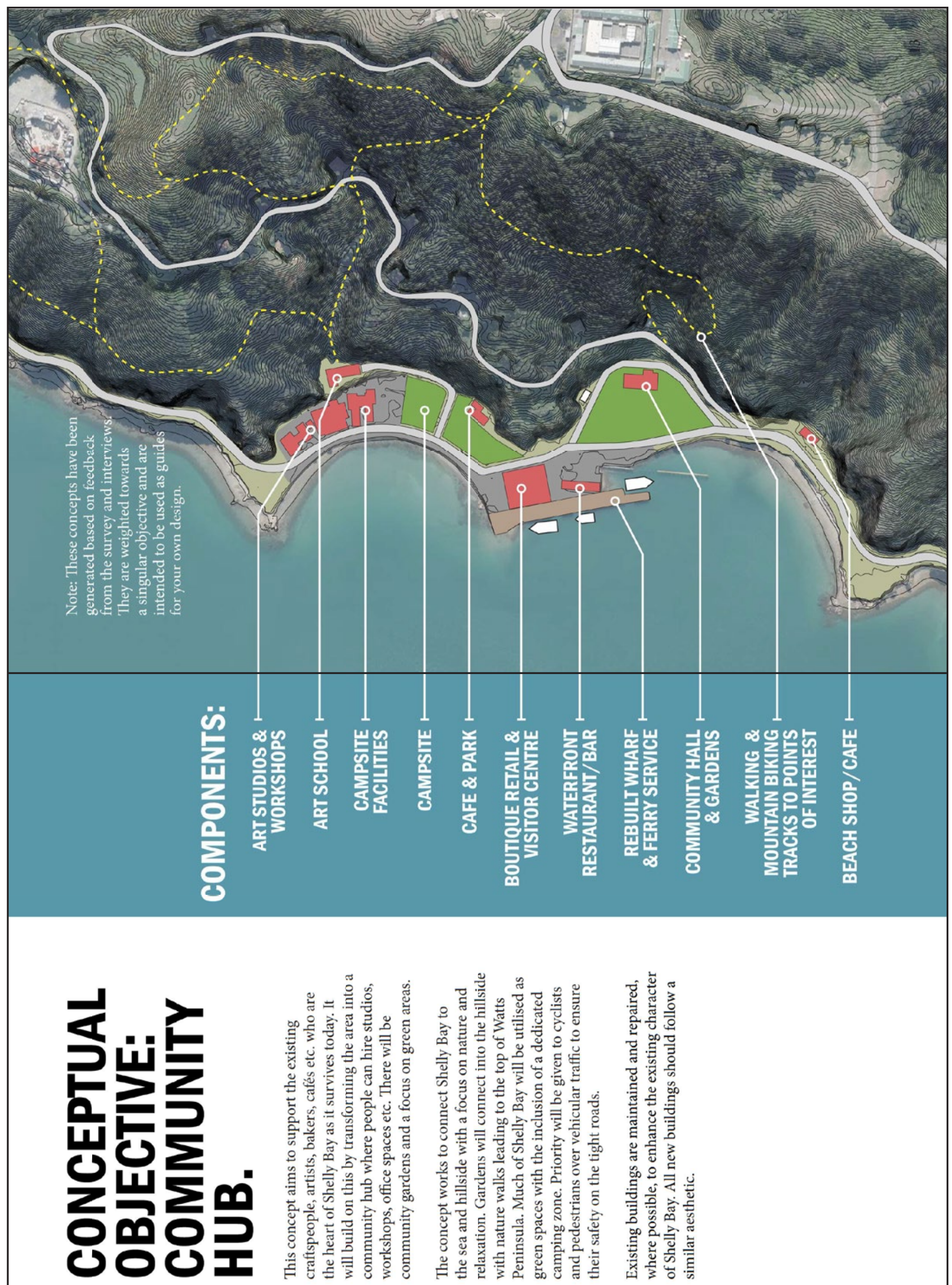

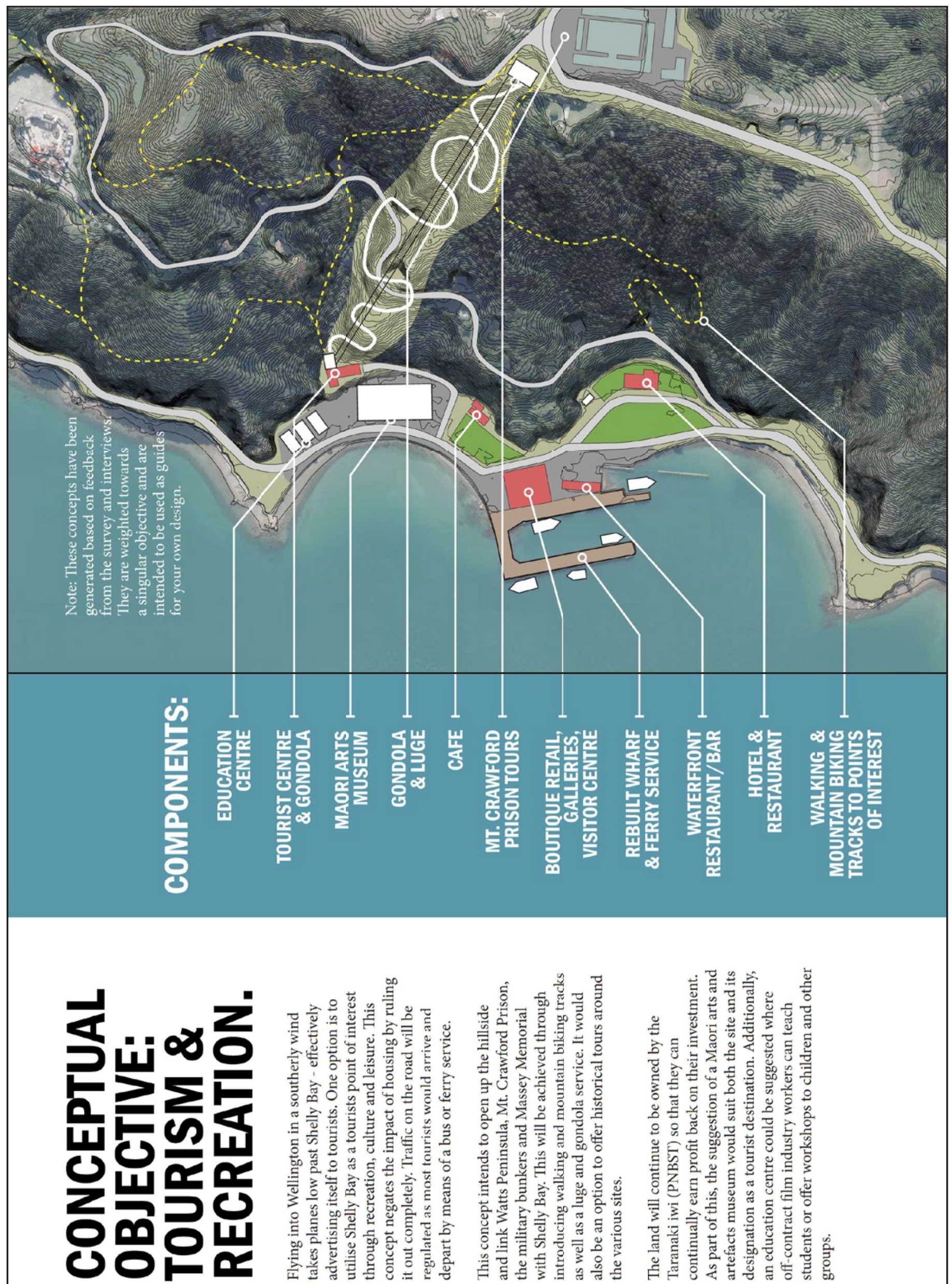

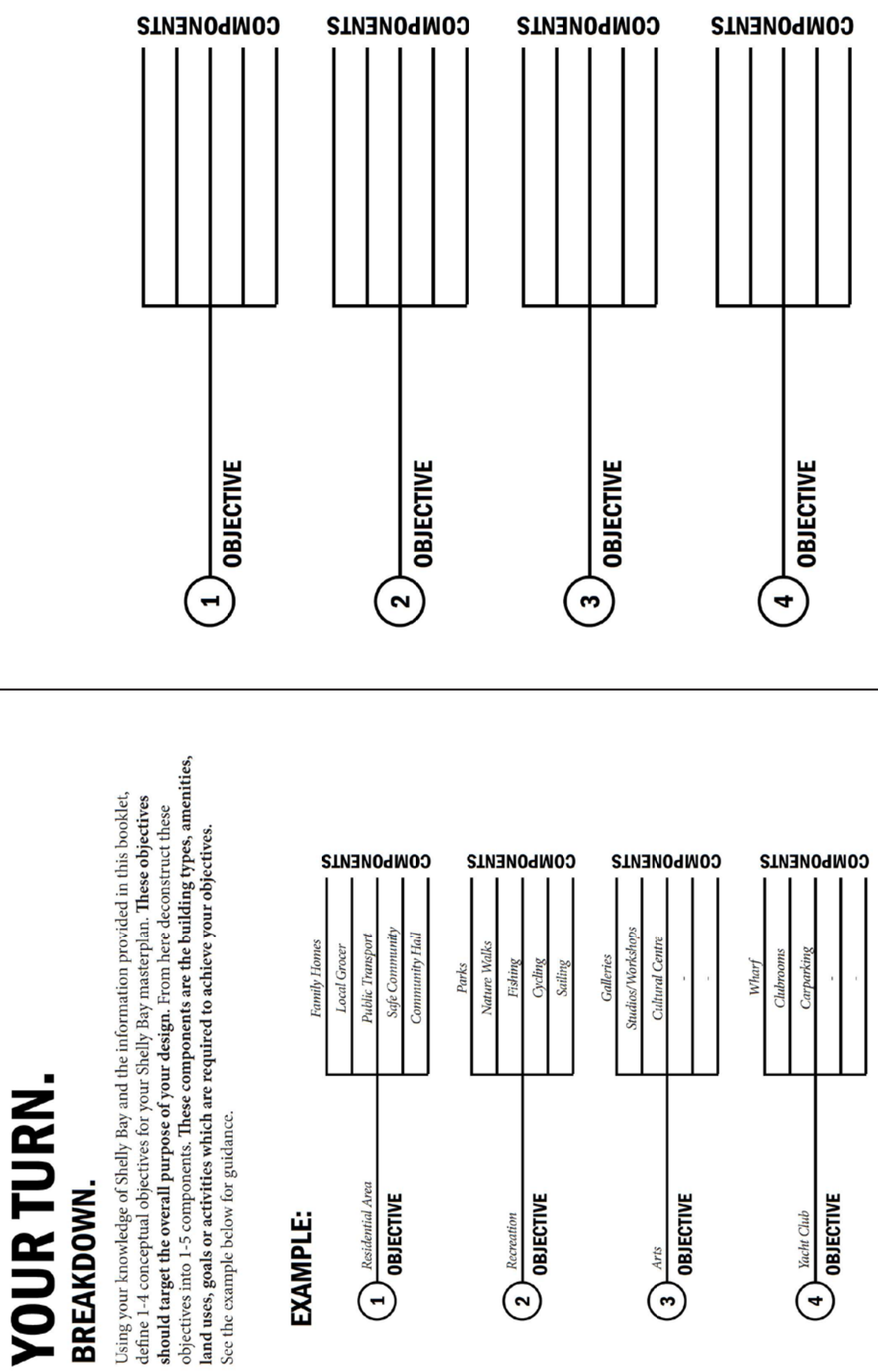


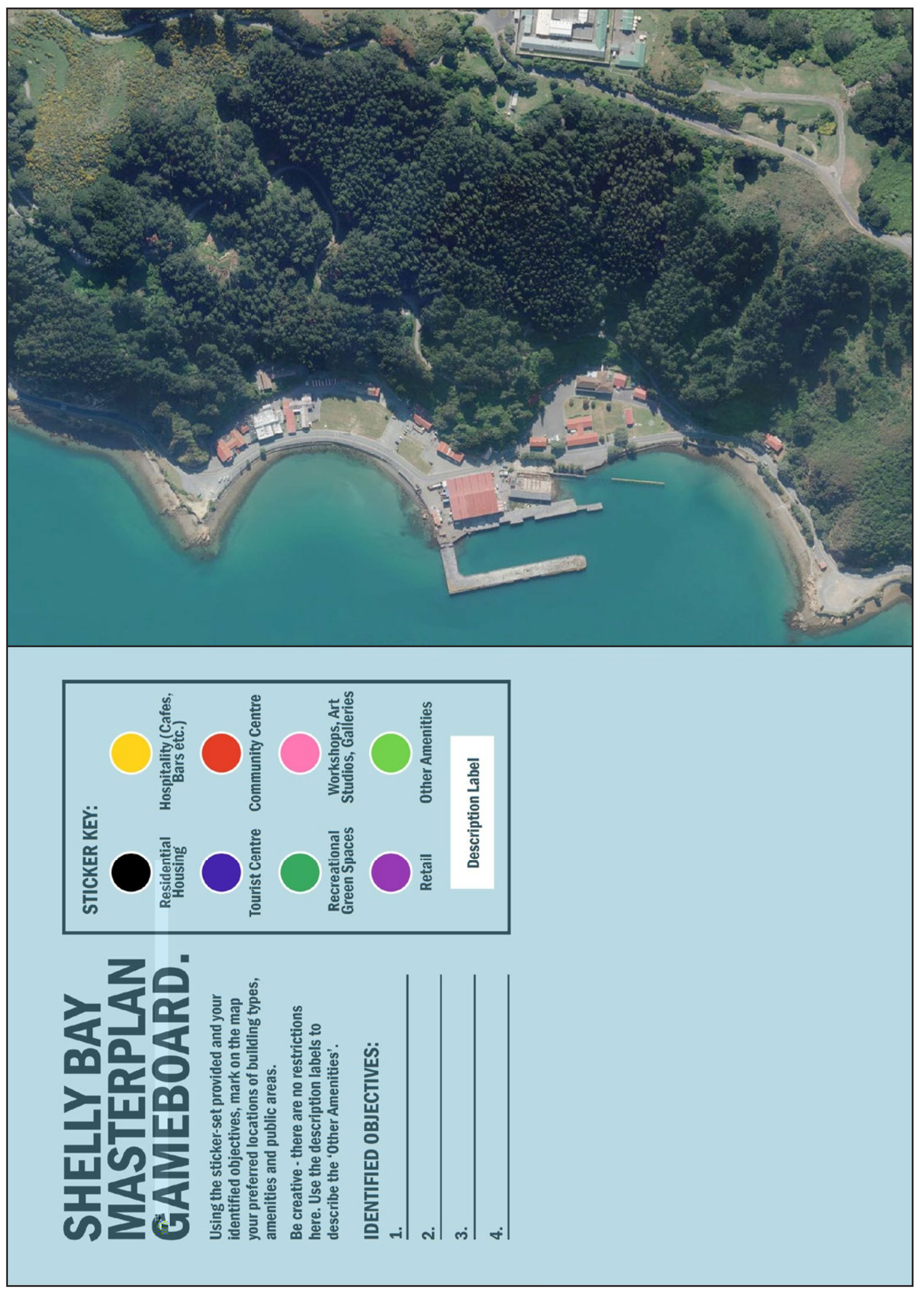



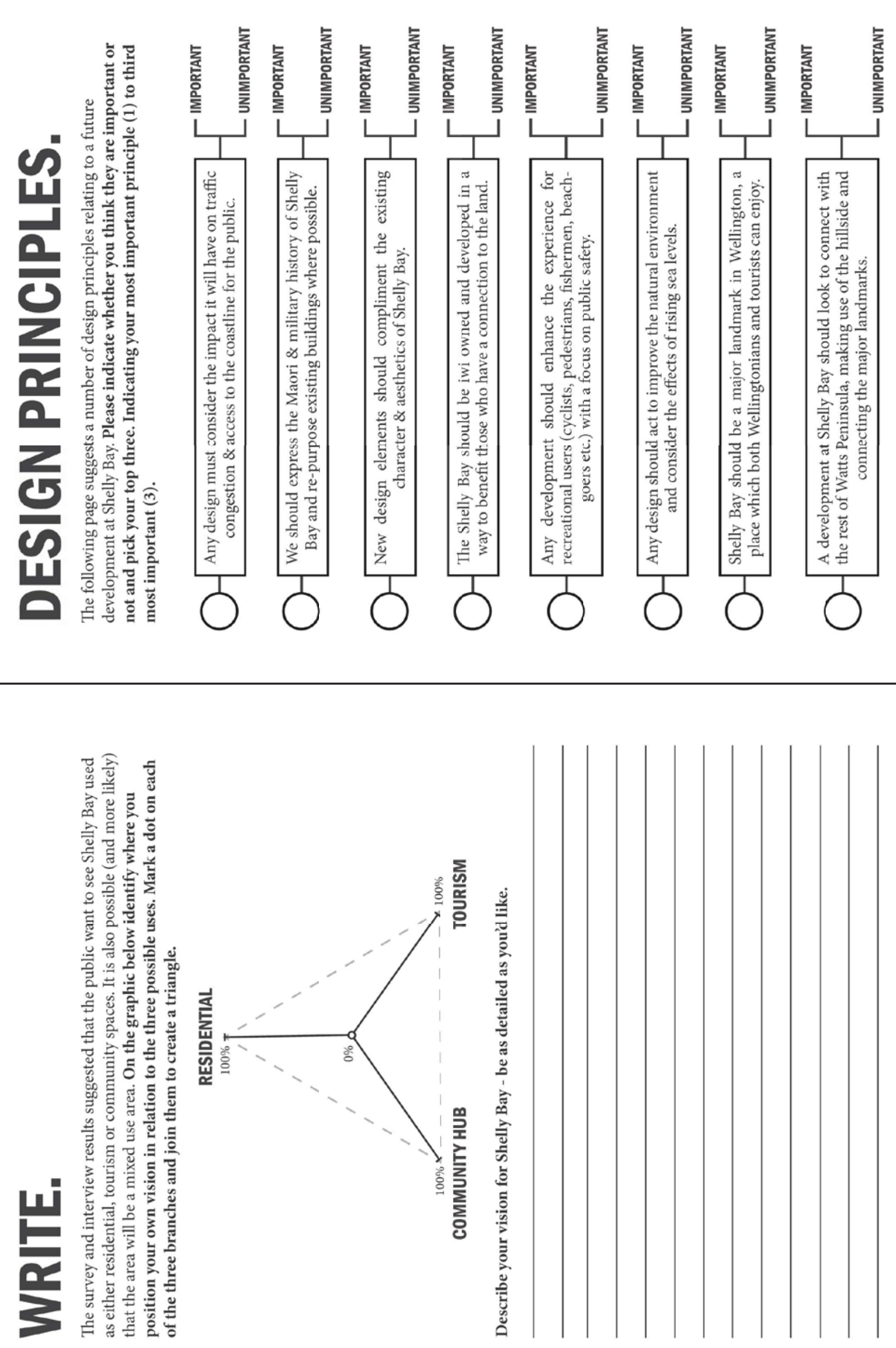


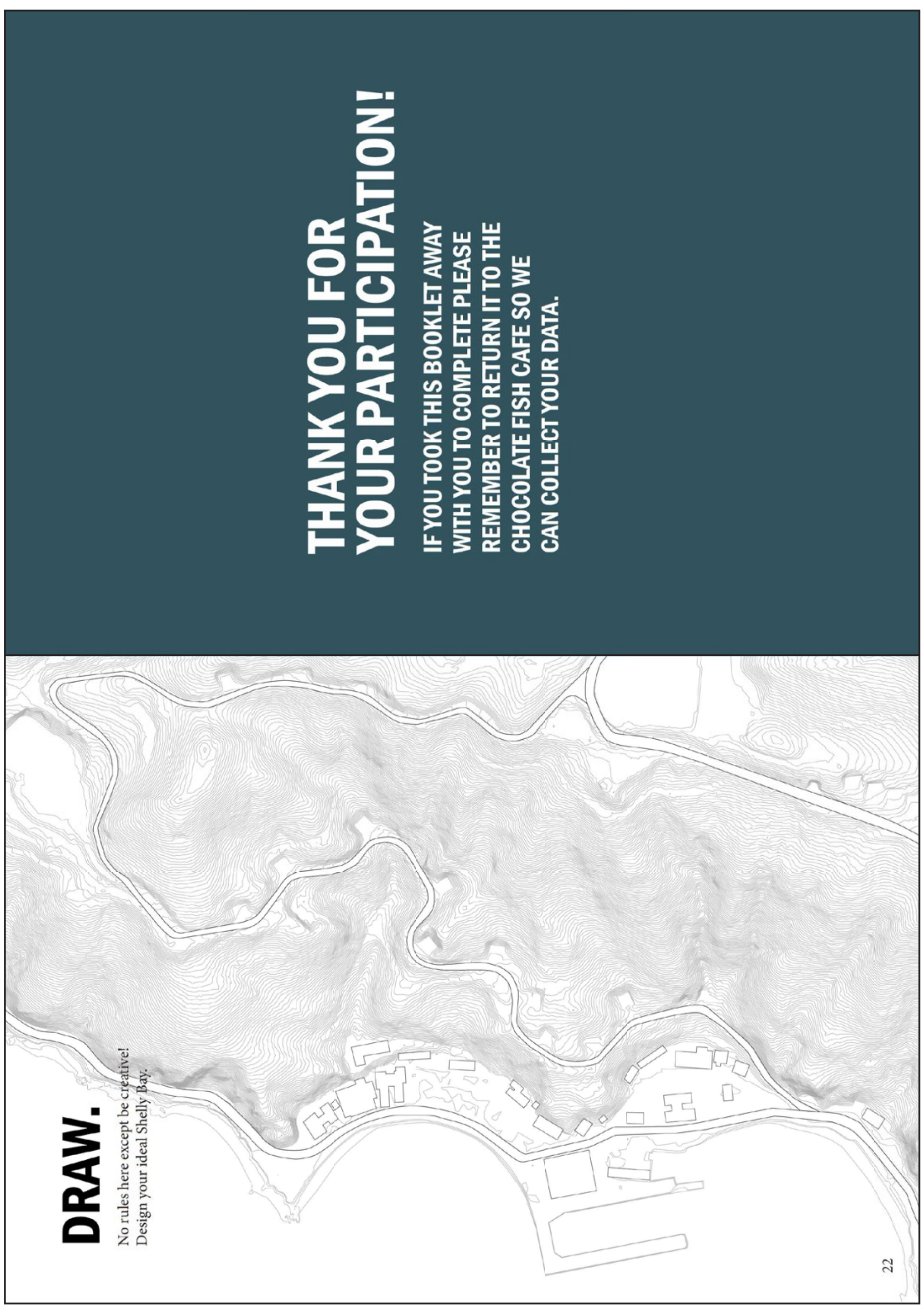


